\title{
ADVOCACY AND
}

\section{NONPROFIT CHARITIES:}

TWO CASES

ON HOME CARE

by

\section{Theresa White Lobsinger}

A thesis submitted to the School of Public Policy and Administration in conformity with the requirements for the degree of

Doctor of Philosophy

\author{
Carleton University \\ Ottawa, Ontario, Canada \\ October, 2007
}

Copyright (C) Theresa White Lobsinger, 2007 


$\begin{array}{ll}\begin{array}{l}\text { Library and } \\ \text { Archives Canada }\end{array} & \begin{array}{l}\text { Bibliothèque et } \\ \text { Archives Canada }\end{array} \\ \begin{array}{l}\text { Published Heritage } \\ \text { Branch }\end{array} & \begin{array}{l}\text { Direction du } \\ \text { Patrimoine de l'édition }\end{array} \\ \begin{array}{l}\text { 395 Wellington Street } \\ \text { Ottawa ON K1A 0N4 }\end{array} & \begin{array}{l}\text { 395, rue Wellington } \\ \text { Ottawa ON K1A ON4 }\end{array} \\ \text { Canada } & \begin{array}{l}\text { Canada } \\ \end{array}\end{array}$

Yourfile Votre référence

ISBN: 978-0-494-36800-8

Ourfile Notre référence

ISBN: 978-0-494-36800-8

NOTICE:

The author has granted a nonexclusive license allowing Library and Archives Canada to reproduce, publish, archive, preserve, conserve, communicate to the public by telecommunication or on the Internet, loan, distribute and sell theses worldwide, for commercial or noncommercial purposes, in microform, paper, electronic and/or any other formats.

The author retains copyright ownership and moral rights in this thesis. Neither the thesis nor substantial extracts from it may be printed or otherwise reproduced without the author's permission.
AVIS:

L'auteur a accordé une licence non exclusive permettant à la Bibliothèque et Archives Canada de reproduire, publier, archiver, sauvegarder, conserver, transmettre au public par télécommunication ou par l'Internet, prêter, distribuer et vendre des thèses partout dans le monde, à des fins commerciales ou autres, sur support microforme, papier, électronique et/ou autres formats.

L'auteur conserve la propriété du droit d'auteur et des droits moraux qui protège cette thèse. $\mathrm{Ni}$ la thèse ni des extraits substantiels de celle-ci ne doivent être imprimés ou autrement reproduits sans son autorisation.
In compliance with the Canadian

Privacy Act some supporting forms may have been removed from this thesis.

While these forms may be included in the document page count, their removal does not represent any loss of content from the thesis.
Conformément à la loi canadienne sur la protection de la vie privée, quelques formulaires secondaires ont été enlevés de cette thèse.

Bien que ces formulaires aient inclus dans la pagination, il n'y aura aucun contenu manquant.

\section{Canadä}




\section{ABSTRACT}

This dissertation examines the policy activities of nonprofit charities in Ottawa, Ontario and Edmonton, Alberta in home care. The research begins with a static set of roles which include providing services in partnership with government, redistributing societal resources, doing environmental scanning, promoting values in society and fostering stability and democracy to demonstrate the importance of the performance of advocacy to all roles. Nevertheless, the research also demonstrates how government's cost cutting and efficiency policies in home care both constrain the advocacy work of charities and misalign them with respect to their identity, roles and activities, and in terms of the public benefits which they may provide. Charities which choose to continue working in home care's current policy environment must improvise and innovate extensively, and in ways which risk contradicting their missions and purpose as public serving nonprofit organizations. This conceptualization of the advocacy work of charities, a subset of organizations within the nonprofit sector, and its dynamic processes enhances the ideas which emerge from nonprofit literature about the sector, as a whole, and more specifically about public serving nonprofit organizations. Empirically, the research demonstrates how home care policies which focus on narrow efficiency objectives risk producing consequences which have the potential to impact, negatively, charities, seniors and the public. Potential losses include less transparent public debate on important social-health issues and the risk that the benefits of working with charities become invisible when compared to for-profit firms. 


\section{ACKNOWLEDGMENTS}

I owe much gratitude to a number of people in relation to this research project. I thank Professor Hugh Armstrong for his guidance, supervision and mentoring, and for seeing this research through to the end, with me. I thank Professors Bruce Doern, Alan Maslove and Susan Phillips for their comments and contributions to previous drafts of this document, and I thank Professors Jane Aronson and Pat Evans for their review and helpful suggestions. I thank Carleton's School of Public Policy and Administration. As well, I thank the Vanier Institute of the Family for being trusted mentors in this project and for their technical and administrative support.

I thank my husband, John, for his unending love, support and patience, without which, this research would never have come to completion. I thank my mother for her love, support and prayers and for her enduring belief in me, particularly in relation to this research.

Finally, I thank my children, Alison, Meghan and Timothy. It was fun being a student in tandem with you all. My message, particularly for you three, is that no matter what happens in your lives, you have it within you to always fulfill your dreams. So, dream on my loves. 


\section{TABLE OF CONTENTS}

CHAPTER 1 - INTRODUCTION AND OVERVIEW $\ldots \ldots \ldots \ldots \ldots \ldots \ldots \ldots$ CHAPTER 2 - THE HISTORY OF PUBLIC HOME CARE, THE NEEDS OF SENIORS AND A ROLE FOR NONPROFIT CHARITIES $\ldots \ldots \ldots \ldots \ldots \ldots \ldots \ldots \ldots$

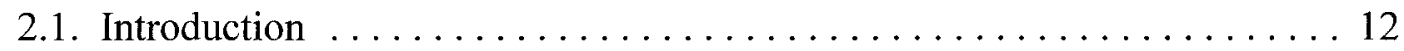

2.2. History of Public Home Care's Development $\ldots \ldots \ldots \ldots \ldots \ldots \ldots$

2.2.1. From Medicare and Social Services to Home Care? ........ 14

2.2.2. The Federal Government's Cost Cutting Agenda and Home Care

2.2.3. The Provincial Response to Funding Cuts and Their Impact on

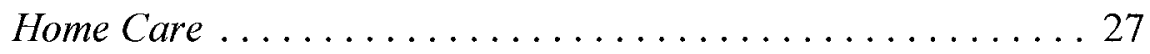

2.2.4. Other Federal Government Policies, Studies and Commissions . 35

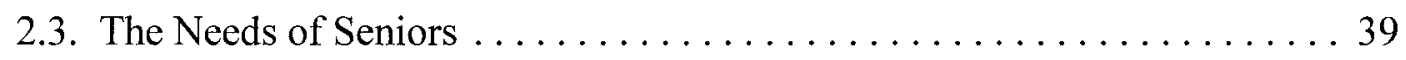

2.4. Chapter Summary and A Policy Role for Nonprofit Charities $\ldots \ldots \ldots 49$ CHAPTER 3 - THEORETICAL FRAMEWORK $\ldots \ldots \ldots \ldots \ldots \ldots \ldots \ldots \ldots$

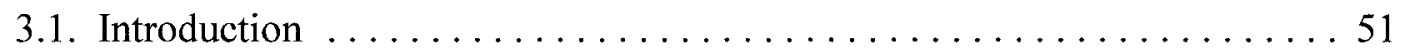

3.2. Theory Supporting the Development of the Theoretical Framework .... 54 3.2.1. The Nonprofit Sector and the Changing Welfare State ...... 54

3.2.2. Nonprofit Theory $\ldots \ldots \ldots \ldots \ldots \ldots \ldots \ldots \ldots \ldots$

3.2.2.1. The Need for Positive Nonprofit Theory ......... 58

3.2.2.2 Nonprofit Theory and the Welfare State ........ 59

3.2.2.3. Nonprofit Advocacy ................. 60 
3.2.3. State and Community Power ..................... 61

3.2.4. Why Nonprofit Charities? ..................... 64

3.3. The Research Framework $\ldots \ldots \ldots \ldots \ldots \ldots \ldots \ldots \ldots \ldots 68$

3.4. The Roles of Charitable Nonprofits in a Home Care Context ........83

3.5. Chapter Summary $\ldots \ldots \ldots \ldots \ldots \ldots \ldots \ldots \ldots \ldots \ldots \ldots$

CHAPTER 4 - RESEARCH DESIGN AND METHODOLOGY $\ldots \ldots \ldots \ldots \ldots 91$

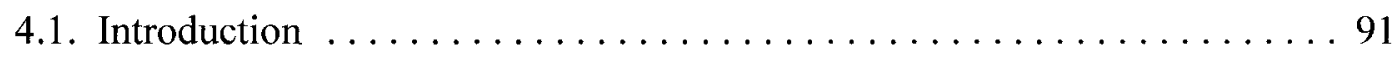

4.2 Case Study and Qualitative Method $\ldots \ldots \ldots \ldots \ldots \ldots \ldots \ldots \ldots \ldots \ldots \ldots \ldots$

4.3. Ethics and Research Participants $\ldots \ldots \ldots \ldots \ldots \ldots \ldots \ldots \ldots . \ldots 9$

4.4. Data Analysis ............................... 101

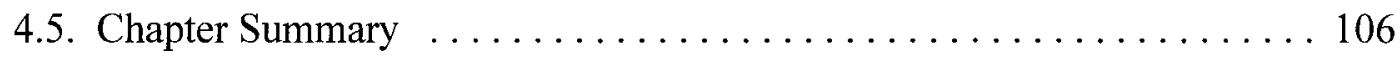

CHAPTER 5 - HOME CARE IN ONTARIO ..................... 107

5.1. Introduction: Home Care's Early History and Financing $\ldots \ldots \ldots \ldots 107$

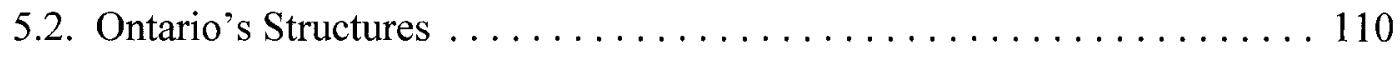

5.2.1. Legislative - Bill $173 \ldots \ldots \ldots \ldots \ldots \ldots \ldots \ldots \ldots \ldots$

5.2.2. The Promotion of Efficiency .................. 112

5.2.2.1. Under The "Common Sense Revolution" ........ 112

5.2.2.2. In Health Institutions via The Health Services

Restructuring Commission $\ldots \ldots \ldots \ldots \ldots \ldots \ldots 114$

5.2.3. Home Care Services ...................... 118

5.2.3.1. Community Supports $\ldots \ldots \ldots \ldots \ldots \ldots \ldots \ldots 118$

5.2.3.2. CCAC Competitive Arrangements ........... 120 
5.2.4. Health System Integration and a New Government . . . . . . 126

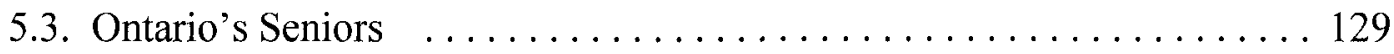

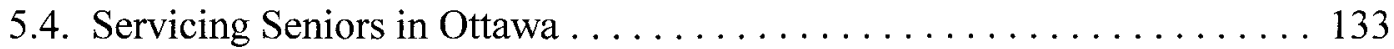

5.5. Chapter Summary . . . . . . . . . . . . . . . . . . . . 139

CHAPTER 6 - HOME CARE IN ALBERTA $\ldots \ldots \ldots \ldots \ldots \ldots \ldots \ldots \ldots \ldots$

6.1. Introduction and Home Care's Early Years $\ldots \ldots \ldots \ldots \ldots \ldots \ldots 14$

6.2. Alberta's Cost Containment Strategies ................ 145

6.2.1. Setting the Stage for Change . . . . . . . . . . . 145

6.2.2. Legislation, Regionalization and Home Care .......... 151

6.2.2.1. Legislation and Regionalization $\ldots \ldots \ldots \ldots 151$

6.2.2.2. The Seniors' Policy Initiative or Action Plan . . . . . 153

6.2.2.3. Home Care ................... 155

6.3. Alberta's Seniors . . . . . . . . . . . . . . . . . . . . 159

6.4. Assessing The Impacts of Policy Change . . . . . . . . . . . . . 162

6.5. Servicing Seniors in Edmonton $\ldots \ldots \ldots \ldots \ldots \ldots \ldots \ldots \ldots \ldots \ldots \ldots \ldots \ldots$

6.6. Chapter Summary $\ldots \ldots \ldots \ldots \ldots \ldots \ldots \ldots \ldots \ldots \ldots \ldots \ldots \ldots \ldots$

CHAPTER 7 - HOME CARE IN OTTAWA, ONTARIO $\ldots \ldots \ldots \ldots \ldots \ldots \ldots$

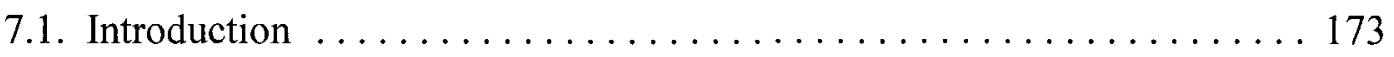

7.2. Ottawa's Charities, Their Redistribution and Societal Stability Roles . . 175

7.3. Ottawa's Charities According to A Service Providing Role . . . . . . . 178

7.3.1. Through The Ottawa CCAC ............. 178

7.3.1.1. Introducing The Ottawa CCAC ......... 178 
7.3.1.2. Managed Competition and Government's Cost Cutting Agenda $\ldots \ldots \ldots \ldots \ldots \ldots \ldots \ldots \ldots \ldots \ldots$

7.3.2. Through Community Support Agencies $\ldots \ldots \ldots \ldots \ldots \ldots 2$

7.3.3. Doing Advocacy on Public Home Care ............. 185

7.3.3.1. For Individuals as The Public ............. 185

7.3.3.2. For Community Organizations ............ 189

7.3.3.3. On Quality ......................... 194

7.3.3.4. On Preventive Home Care $\ldots . \ldots \ldots \ldots \ldots . \ldots 196$

7.3.3.5. To Protect Against Contracting ............. 199

7.4. Ottawa's Charities and Their Environmental Scanning Role ....... 206

7.4.1. Describing Environmental Scanning .............. 206

7.4.2. The Steps and Processes of Environmental Scanning _..... 207

7.4.3. The Burden of Proof and Data Collection ............. 209

7.4.4. New Programming Initiatives $\ldots \ldots \ldots \ldots \ldots \ldots \ldots \ldots \ldots$

7.4.4.1. Works-in-Progress ..................... 214

7.4.4.2. Successful Public Policy Initiatives ............ 220

7.5. Promoting Values in Society Through Advocacy-constituted Roles .... . 222

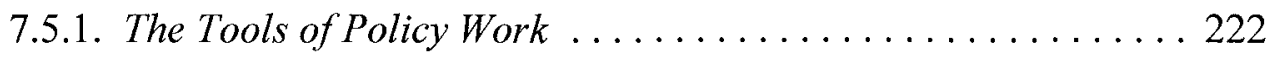

7.5.2. Through Broader Engagement and Advocacy .......... 224

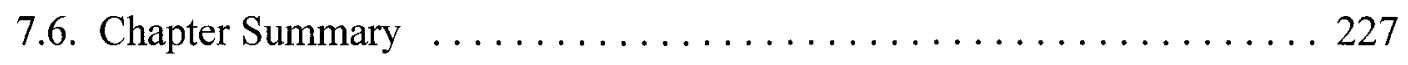

CHAPTER 8 - HOME CARE IN EDMONTON, ALBERTA $\ldots \ldots \ldots \ldots \ldots \ldots 231$

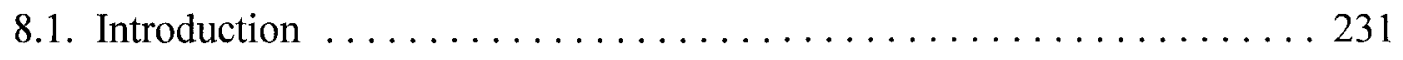


8.2. The Redistributing and Societal Stability Roles of Edmonton's Charities

8.3. Providing Services and Doing Advocacy Under Government Structures

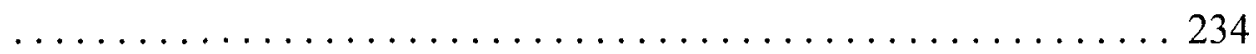

8.3.1. Working With Capital Health . . . . . . . . . . . . 234

8.3.1.1. Under the Capital Health Board Structure . . . . . . 234

8.3.1.2. Working with CHRA's Community Health Councils . . 235

8.3.2. Working with Other Government Ministries and Governments

8.3.3. Charities Struggle with Politics, Control, and Jurisdictional Complexity ......................... 239

8.3.4. Providing Home and Continuing Care Services . . . . . . . . 246

8.3.5. Edmonton's Charities Exercise Caution ............ 253

8.3.6. Providing Services While Dealing with Additional Constraints 256

8.4. Edmonton's Charities Undertake Policy Advocacy . . . . . . . . . . . 257

8.4.1. For Individuals and the Public ............ 257

8.4.2. Charities Protect The 'Contracted' Public Good .......... . 261

8.4.2.1. On Funding $\ldots \ldots \ldots \ldots \ldots \ldots \ldots \ldots \ldots \ldots \ldots \ldots \ldots \ldots \ldots \ldots \ldots$

8.4.2.2. On Quality and Long Term Care ............ 263

8.4.2.3. About Preventive Home Care ........... 266

8.4.2.4. For Employees . . . . . . . . . . . . . . . 267 
8.4.3. Edmonton's Charities Collaborate .............. 270

8.5. Edmonton's Charities and Their Environmental Scanning Work . . . . 276

8.5.1. Environmental Scanning in Alberta . . . . . . . . . . 276

8.5.2. The Burden of Proof and Data Collection ........... 278

8.5.3. New Programming Initiatives $\ldots \ldots \ldots \ldots \ldots 28 \ldots \ldots \ldots$

8.5.3.1. Successful Public Policy Initiatives ........... 282

8.5.3.2. Works-in-Progress to Address New and Unmet Needs

8.6. Promoting Values in Society Through Advocacy-constituted Roles . . . . 288

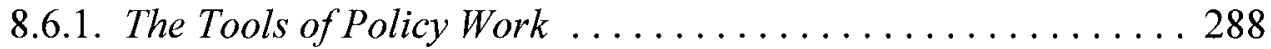

8.6.2. Through Broader Engagement and By Speaking Out . . . . . . . 294

8.7. Chapter Summary . . . . . . . . . . . . . . . . . . . . . . 295

CHAPTER 9 - DISCUSSION AND CONCLUSION . . . . . . . . . . . 298

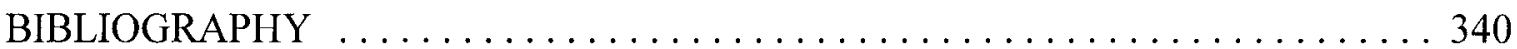

\section{LIST OF TABLES AND ILLUSTRATIONS}

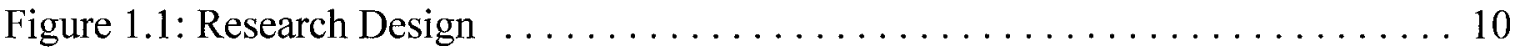

Table 3.1: The Advocacy Constituted Roles of Charitable Nonprofits . . . . . . . . 81

Table 5.1: Average Wait Times for Home Supports, Weeks . . . . . . . . . . . 138

Figure 9.1: Impact of Government Policies on the Advocacy-constituted Roles of

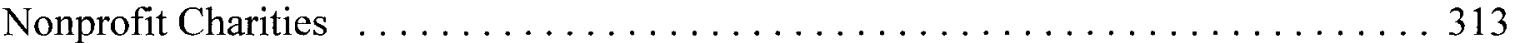




\section{LIST OF APPENDICES}

APPENDIX 'A' - ETHICS APPLICATION $\ldots \ldots \ldots \ldots \ldots \ldots \ldots \ldots \ldots \ldots \ldots$

APPENDIX 'B' - INTERVIEW TOOL USED WITH CHARITIES

AND OTHER NONPROFIT ORGANIZATIONS

APPENDIX 'C' - INTERVIEW TOOL USED WITH PROVINCIAL-FEDERAL

GOVERNMENT OFFICIALS ............... 332

APPENDIX 'D' - INTERVIEW TOOL USED WITH LOCAL GOVERNMENT

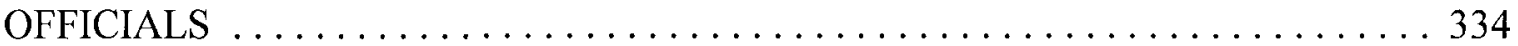

APPENDIX 'E' - INTERVIEW TOOL USED WITH PRIVATE FOR-PROFIT GROUPS 


\section{LIST OF ACRONYMS}

(ADSP) Annual District Service Plan

(AGA) Auditor General for Alberta

(AGO) Provincial Auditor General of

Ontario

(AISH) Assured Income for the Severely

Handicapped

(ALTCA) Alberta Long Term Care

Association

(CAP) Canada Assistance Plan

(CCAC) Community Care Access Centres

(CCC) Complex Continuing Care

Regulation) Coordinated Home Care

Program Regulation 296/2003

(CEO) Chief Operating Officer

(CHA) Canada Health Act

(CHCA) Canadian Healthcare Association

(CHRA) Capital Health Regional Health

Authority

(CHST) Canada Health and Social Transfer

(CLC) Canadian Labour Code
(Commission) Premier's Commission on

Future Health Care for Albertans

(CRA) Canada Revenue Agency

(EI) Employment Insurance

(EIP) Employment Insurance Program

(EPF) Established Program Financing

(ESCC) Edmonton Senior Coordinating

Council

(FFS) Fee for Service

(Framework) Health Sustainability Initiative

(GIS) Guaranteed Income Supplement

(GSS) General Social Survey

(HIDSA) Hospital Insurance and

Diagnostic Services Act

(HNSP) Homemakers and Nurses Services

Program

(HPCP) Health Plan Coordination Project

(HSRC) Health Services Restructuring

Commission

(HTF) Health Transition Fund

(HU) Hermeneutic Unit 
(ITA) Income Tax Act

(ITF) Health System Integrated Task Force

(LGIC) Lieutenant Governor in Council

(LHIN) Local Health Integration Networks

(LICOs) Low Income Cut Offs

(LPNs) Licensed Practical Nurses

(MHW) Ministry of Health and Wellness

(MLA) Member of Alberta's Legislative

Assembly

(MOHLTC) Ministry of Health and Long

Term Care

(MSAs) Multi-Service Agencies

(MSA) Medical Services Act

(MSCS) Ministry of Seniors and

Community Supports

(NCW) National Council of Welfare

(NDP) New Democratic Party

(NHPS) National Health and Population

Survey

(OAS) Old Age Security

(OHIP) Ontario Health Insurance Plan
(OSCA) Ontario Community Support

Association

(PC) Progressive Conservative Party

(RCHS) Royal Commission on Health

Services

(RFP) Requests for Proposal

(RHA) Regional Health Authority Act

(RHAs) Regional Health Authorities

(RIA-HC) Resident Assessment Instrument-

Home Care

(SAI) Survey on Aging and Independence

(Secretariat) Health Planning Secretariat

(SMO) Social Movement Organizations

(SPE) Single Point of Entry

(SPI) Seniors Policy Initiative

(The Accord) First Ministers' Health

Accord on Health Care Renewal, 2003

(UK) United Kingdom

(VON) Victorian Order of Nurses 


\section{CHAPTER 1 - INTRODUCTION AND OVERVIEW}

This research applies qualitative, double case study design to examine the public policy roles of nonprofit charities in home care in the communities of Ottawa, Ontario and Edmonton, Alberta. It represents an unconventional approach to the examination of public policy in that it isolates charities from the nonprofit sector so as to explain the policy activities of this subset of the sector's organizations, and it focuses on the policy work of these agencies in home care as its primary endeavor rather than on the policy work of government. By strengthening our conceptual understanding about the policy work of charities, as occurs through this research, we improve our understanding about this work in relation to the sector, as a whole. Government home care policies are examined, but with the purpose of providing contextual data regarding the policy activities of charities.

My interest in the nonprofit sector originates in my previous work with such organizations working in Kenya's health and education sectors. When I sought to improve my understanding of the work of such agencies in a Canadian context, my interest was piqued by the overall size of Canada's nonprofit sector which is described by Imagine Canada (2006 a.). This organization's estimates are that 160,000 nonprofit organizations employ over 2 million Canadians and engage approximately 19 million volunteers who collectively "contribute more than 2 billion hours of volunteer time per year, ... the equivalent of approximately 1 million full-time jobs" (Imagine Canada 2006 b.). Their data reflect the importance of the sector to Canada's economy and society. Nevertheless, this research focus on nonprofit home care organizations leads to an 
emphasis on charities, a subset of nonprofits which the Canada Revenue Agency (CRA) lists as working in welfare and health. For 2004 , the CRA's estimates that " $\$ 1.9$ billion in revenue is foregone through tax assistance to [all] registered charities" (Agency 2005). In 2003, "5.6 million Canadians made financial or in-kind donations worth $\$ 6.5$ billion to [all] registered charities" (Ibid.). CRA data indicate that (Ibid.) 21,506 agencies out of a total of 80,914 charities work in welfare and health, and receive both tax revenues and donations. Armed with this type of background data, a close look on home care illustrates how, for over 100 years, community-based nonprofit charities have delivered health services to Canadians in their homes in accordance with the values of compassion and justice. When medicare was established between the late $1950 \mathrm{~s}$ and mid 1970s, many new agencies emerged to supplement the at-home health care work provided by the older agencies. The locus of work of all agencies is the home where citizens secure public benefits in line with charitable status under the Income Tax Act (ITA) (Agency 2006).

This research asks, 'How are the policy functions of nonprofit charities explained and operationalized, and what constrains them?' It demonstrates how through a variety of roles, charities promote social values and democracy; they provide paid and volunteer employment; they address new and unmet needs; and they redistribute societal resources. Furthermore, supplementing all roles in home care is the advocacy work performed by charities on behalf of clients and their families, female labour, the broader public, and other community agencies.

Charities differ from other nonprofit organizations and from profit-making private sector firms or companies in the following manner. First, charities and other nonprofit 
organizations differ from profit-making organizations in that they do not earn profits and are exempt from federal and provincial income taxes. Second, charities differ from other nonprofit organizations in several related ways linked to their charitable registration, through the CRA, which requires that their purposes be directed to "the public benefit"'. Hence, charities may issue receipts for tax purposes but the law requires that they disburse eighty percent of their donations in relation to their charitable activities. While they may use some part of the remaining twenty percent of donated funds for political purposes, the funds must not constitute more than 10 percent of their total resources (McCamus 1996, p. 335); this is generally called the 10 percent rule. Finally, charities "are required to file an annual information return with the CRA, a portion of which is available to the public. They must also meet certain requirements of the Income Tax Act concerning their expenditures and activities" (Agency 2007 b.). Charities are henceforth referenced as any of - nonprofit charities, charitable nonprofits, or charities - within the dissertation. Other nonprofit organizations, e.g., member and voluntary associations, are henceforth referred to as nonprofits or nonprofit organizations.

Despite my narrow focus on charities, the starting point for the research is the literature on the nonprofit sector and a static set of five roles which are conceptualized by the literature as being performed by its' organizations. These roles are the building blocks upon which the policy work of charities is mapped out and explained here.

1

The legal, common law basis for charitable registration is the Elizabethan Poor Laws. The public benefits which are acknowledged by Canadian law include poverty alleviation, education, religion, or some other benefit (Jenkins 1987; Canada Revenue Agency 2007 b.). Nonprofit organizations, not registered as charities "because they lack a sufficient public character" (Agency 2006), are not required to register either federally or provincially to secure tax exempt status (Canada Revenue Agency 2007 a.). 
This research contributes both conceptually, in three ways, and empirically to our understanding of nonprofit organizations and of such organizations which operate in home care. First, the research demonstrates that aside from providing services, charities perform a variety of roles which conform to the conceptions explained by theory. Second, this research's examination of charities within a framework which locates their set of roles within a dynamic context suggests that a sixth role, namely advocacy, ought to be added to any conceptual role set. Furthermore, the research demonstrates that not only is advocacy being performed, it is central to all roles and activities being performed by charities on behalf of the public. This conception of the work of charities is much broader than what is explained by nonprofit literature and according to Canadian law. Third, if one adopts Jessop's (1993) conception of the Schumpeterian workfare state which distances itself from issues of redistribution in favour of issues of cost saving, flexibility and competitiveness, this research demonstrates the degree to which charities must struggle to improvise and respond to the policies arising from Jessop's hollowed-out welfare state.

Only recently, has nonprofit theory explained the nonprofit sector's organizations according to a broad set of roles, and it has said very little about the sector's advocacy work. A limited understanding of theory provides a weak guide to the policies of government designed to govern, shape and constrain the public policy work of charitics operating in sectors like home care. Both theoretical and policy conundrums are worsened by the evolving modern welfare state which has, seemingly, become nonhierarchical, interactive and negotiating. The boundaries between sectors are blurring, 
and this blurring is problematic, particularly for theoreticians and practitioners alike. Despite the blurring of boundaries or perhaps because of it, this research demonstrates how charities not only provide home care services, promote values and democracy, redistribute resources, provide stability, and innovate on issues relating to home care, but they also struggle to compete with other charities and with private sector firms in home care; they struggle to learn about business practices; and they struggle to learn how to be better policy actors and to participate fully. Charities must struggle if they are to exist and work within home care's more interactive policy regime. Improvisation and innovation are necessary for the survival of these agencies.

The empirical contributions of this research pertain to the manner in which charities in Edmonton and Ottawa have contributed to home care policy, over the years, although their contributions have responded to different aspects of their respective policy environments which, during data collection, differed. In Edmonton, for example, where health services are delivered through regional administrative structures, under centralizes control, charities have been instrumental in ensuring a continued presence and voice at the policy table. This presence arises firstly through an important agreement that was signed between the province of Alberta and the members of the Christian Health Association, the latter of which includes voluntary health facilities in Alberta. The agreement ensures the independent operation, management and control of voluntary health facilities and the ongoing voice of nonprofit organizations in the health sector. Secondly, the presence of local charities is maintained by the Edmonton Seniors Coordinating Council (ESCC), an agency which has recently been established through 
local coordinated effort. The ESCC "assume [s] a leadership role in facilitating shared planning and coordination among senior-serving organizations in the City of Edmonton... [and] support [s] senior-serving organizations in their delivery of social and recreational programs and services that are comprehensive, effective, efficient, and accessible to Edmonton's aging population" (Edmonton Seniors Coordinating Council, no date). Charities in Ottawa contributed to the 2005 review of competition in home care in the province, to the development of geriatrician programs, and adult day and respite programs which are now standard across Canada. And, they have contributed to the training and accreditation of personal support workers. Charities in both locations work to provide more and better quality services to individuals. They work on issues of ageism and elder abuse. They support other agencies within the policy community and they provide government with knowledge, ideas and information on new approaches.

Charities visibly serve the public and provide public benefits in regard to home care in a number of ways. First and often with small budgets, few staff and armies of volunteers, in accordance with low funding allocations, charities provide public services to citizens; seniors ${ }^{2}$ are their largest client group. When public home care is delivered, charities become public-policy takers implementing government policies; clients and service levels conform to government's policies and funding allocations. Through services' delivery, charities introduce government policies into the homes of clients; government's role may be expressed as developing policies related to home care and

2

Since seniors are the largest group of recipients for home care, I refer to them generically as the clients of home care. Other groups of citizens, like the disabled, also depend on home care. 
allocating funding. Charities, though, do more than simply implement public policies. Often through fundraising and donations received, charities perform additional roles which support their broader mission(s) for home care. Donated funding allows agencies to supplement government allocations, to address unmet home care service needs, to educate, to address new and emerging needs, and so forth. These roles, which occur independently of government's policies, may be interpreted, minimally, two ways. A 'positive' interpretation is that their service delivery role makes these organizations more aware than government of local needs for services; agencies more or less agree with government policies, but are simply one step ahead of a 'benevolent' government when they deliver supplementary care. A 'less benign' interpretation is that charities disagree with government's policies and funding allocations. Agencies, therefore, use donations and fundraising to bolster home care policies and government's funding allocations. Although these represent only two of perhaps many different suppositions for the use of donations and fundraising, the main point I wish to make is that the vision for home care as articulated by charities is broader than and/or different from that of government and, sometimes, even challenges government. These too reflect public benefits provided by charities.

This research argues that when charities 'partner' with government to provide services, they perform additional roles, or functions, (the terms are used interchangeably), but these roles are often less visible because government policies have a constraining effect upon them. A number of legal and regulatory constraints impact them directly and include, for example, the 10 percent rule and competition. The research demonstrates the 
challenges for charities in both Ottawa and Edmonton which struggle to provide good quality services to clients and their informal caregivers, to provide a healthy work environment for paid female labour, and to balance other requirements that arise from policies which cap budgets and use competition so as to reduce costs. While agencies partner with government through service delivery, a role dependent upon government funds, their true partnership is perhaps with community.

Urry (2000, pp. 423-424) references Newby (1976) and Savage and Warde (1993) to differentiate three types of community: a) geographic communities defined by physical boundaries; b) communities made up of social systems which imply a "degree of social interconnection of local people and institutions"; and c) human associations which suggest and/or represent "personal ties, belongingness, and warmth." Two types of community are represented in this research. One relates to the connections between people and local community charities which focus on any of home care services and/or policies, and clients and other beneficiaries, and the other represents geography in relation to the cities, Ottawa and Edmonton. With regard to Ury's third type, Rice and Prince (2000) remind us that community, including nonprofit charities, are not always benign entities. Nevertheless, rather than focusing on the 'darker side' of charities and the many ways in which they may minimize and/or detract from the provision of public benefits in home care, in the manner articulated by Rice and Prince (Ibid., Chapter 9), this research focuses on their positive contributions in relation to public policy development.

Donations, fundraising and volunteers, which arise from local communities in support of the public benefits, suggest that charities are embedded within community, 
supported by community and that, perhaps, their true partnership may be community. Community appears to become the foundation upon which the aggregate of individual advocacy builds into widespread community-based public advocacy and widespread public benefits. Charities do not work in isolation. They work collaboratively with donors, volunteers, clients and other agencies on behalf of the public. With community support, charities seek to transform individual micro-level problems and link them together so as to create a composite of macro-level problems, in search of broad-based solutions in home care (Hudson 2002, pp. 403-404). All of this is to say that charities are multi-dimensional, multi-directional, micro- and macro-level agencies which undertake advocacy work in a variety of settings which include the home. Thus, all work of charities becomes public policy work. Ideally, therefore, any examination of the public policy work of nonprofit charities juxtaposes their roles and activities in home care with government's laws and policies. In doing so, the visions of charities, both similar and dissimilar from government, become visible and the renewed actions for policy change may be examined. This is the approach taken here.

The dissertation is comprised of two distinct parts. The first part introduces the history of home care as it emerged from the federal and provincial government's high level health sector policies, and outlines both the research framework and methodology. The second part maps out the empirical analysis in terms of the provinces of Alberta and Ontario, and the cities of Edmonton and Ottawa. Figure 1.1, Research Design illustrates the connectivity between theory, methodology and data generation, analysis of empirical findings, discussion and ongoing theory building. 


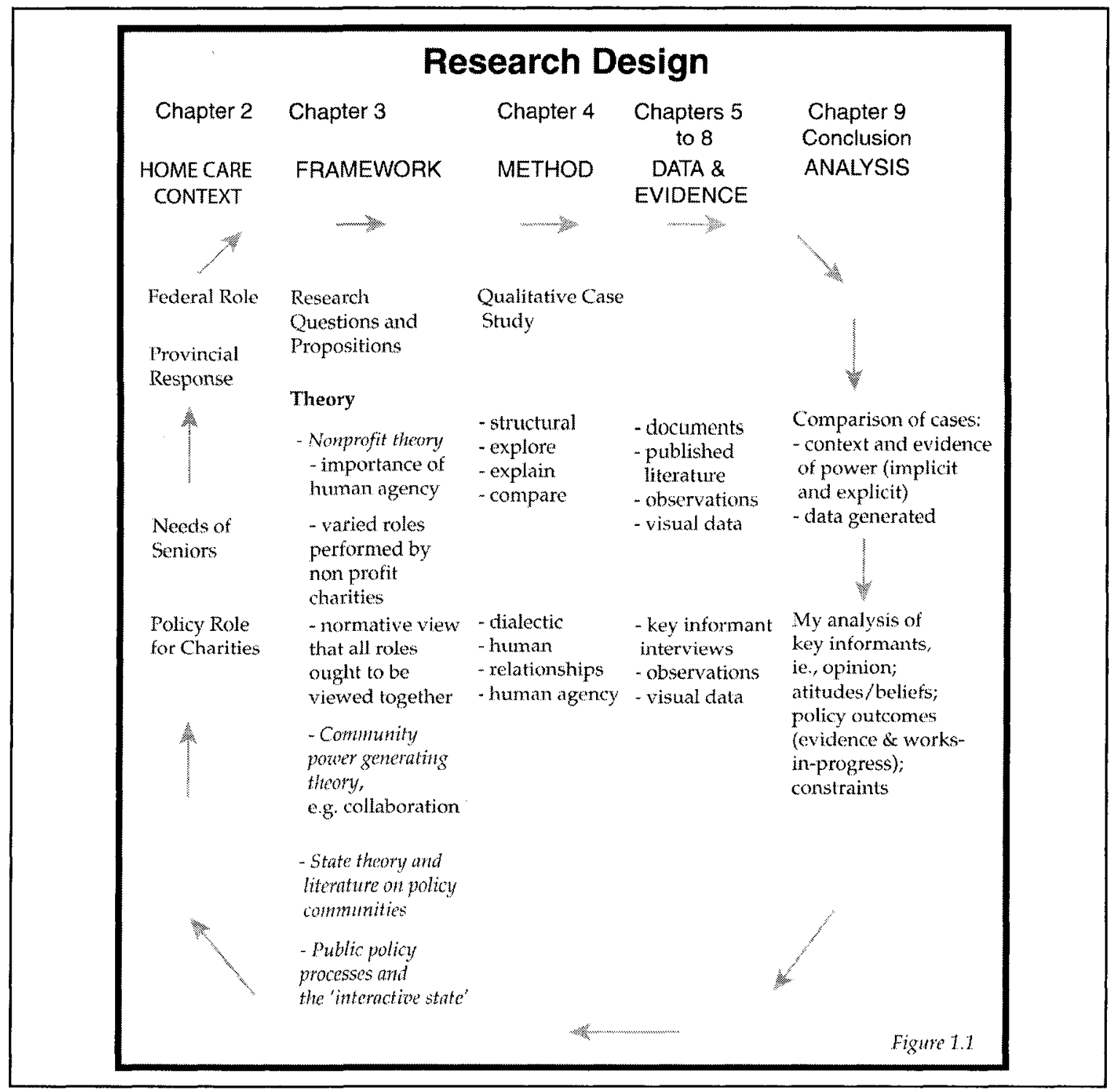

Chapter 2, which opens the first part, introduces home care as it evolved according to national and provincial policies. This history informs the examination of the work of nonprofit charities in Ottawa and Edmonton which appears in the second half of the dissertation. Chapter 3 describes the theoretical framework which guides the research in terms of four broad groupings of theory: nonprofit theory, state theory, including policy community literature, community power theory and the state's public policy processes. 
Despite its fragmented and contested state (Frumkin 2002, p. 1), nonprofit theory is the main contributor to the framework and guides the examination of the roles and interactions of nonprofit charities with their communities and the contemporary welfare state (Langton 1987, p. 135). Chapter 4 introduces the research methodology using qualitative, case study design. The methodology is grounded in the theoretical framework and allows me to highlight both the advocacy performed by nonprofit charities through their roles and their power generating activities. The methodology is both structural and discursive. This means, contextual data which describe the structures that impact the policy roles of nonprofit charities are generated mainly using documentary sources and published literature, and these data are juxtaposed with a data-generating process that uses semi-structured interviews to gather data about the policy work of charities.

Chapters 5 and 6, in the dissertation's second half, describe home care's evolution in Ontario and Alberta. Its evolution is explained according to the responses of these provinces to the federal government's health sector policies and funding cuts. They include using acute home care as a cost reduction strategy, introducing a competitive model to deliver home care, adopting processes of efficiency, privatizing long-term care services, and increasing the requirement for user fees. These chapters largely describe a home care environment which constrains and impacts the work of charities. Chapters 7 and 8 describe and explain the specific details of the policy work performed by nonprofit charities in Ottawa and Edmonton, respectively. Finally, Chapter 9 summarizes the ideas, the theory and the events which have been recorded in this research on the public policy roles of charitable nonprofits in home care. 


\section{CHAPTER 2 - THE HISTORY OF PUBLIC HOME CARE, THE NEEDS OF SENIORS AND A ROLE FOR NONPROFIT CHARITIES}

\subsection{Introduction}

This chapter examines the history of home care as it evolved within the larger framework of health care services, normally referenced as medicare, and social services mainly using published literature. I begin by recounting the federal government's initial response to the equity and efficiency needs of Canadians in regards to health services and describe this government's ongoing involvement in an area of provincial--territorial jurisdiction. Because home care arises from the history of health and social services which are characterized by political, economic and societal struggle, its own history reflects a similar set of struggles. These are reflected in the chapter. Aside from the high level political and policy factors, the chapter also explains how home care services are shaped by local issues and ideas such as the needs of clients (including informal caregivers), service developments (types, labour, quality, outcomes, etc.) and providers (nonprofit, public and for-profit). The chapter begins with a historical chronology of policy events and intersperses the other factors into this account, as appropriate. It sets the context for the empirical examination of the policy functions of charities which occur in the complex home care policy field and which are examined in later chapters.

The chapter also highlights the variety of ways in which the home care issue can be examined. Fundamental to the complex policy environment are the variety of stakeholders each of whom hold separate visions, goals and recommendations for home care. These include levels of government, charities and for-profit companies, clients and 
their families, and mainly female labour - paid and unpaid. When locating a federal government role in health services, Maslove (1995) acknowledges the potential for different visions to arise for health and economic systems according to the variety of jurisdictions, and in terms of the specific responsibilities and problems that face each of the respective authorities. In Canada, for example,

divergence most often occurs in the sense that national goals are broader than (subsume) provincial goals or because provinces, facing different demands and constraints, interpret or order national health care goals differently, rather than being in direct conflict with them (Ibid., p. 5).

Thus, when focussing on the response of charities to the day-to-day problems and demands of seniors, caregivers, female labour (paid and volunteer), it seems logical that charities would interpret provincial and national home care goals differently, and would act accordingly. Such differences could be construed as charities being in disagreement with the policies of government or they could simply be interpreted as charities doing what they do best according to their legal mandates and missions.

The first section explains how home care was shaped and defined in relation to the federal government's allocative and redistributive $\mathrm{e}^{3}$ decisions for health and social services. History explains how and why home care is about both health care and social care. In fact, the relationship between social and physical health is so strong that most home care programs are now governed by health ministries (Hollander 1994, p. 10, 1999, pp. 23-24, 33). The general response of provincial governments to the national level social welfare, fiscal welfare and occupational welfare. Social welfare relates to the provision of income support (for example, old age pensions) or the provision of services in kind (hospital care)." 
problems articulated by the federal government (Lewis et al. 1997) is briefly introduced largely from the perspective on their impact on home care's evolution. Since local nonprofit charities experience, first-hand, the needs of seniors and are compelled by their missions and law to provide public benefits to vulnerable groups, it is important to examine the needs and wants of seniors in relation to home care. The next chapter section examines these issues. The manner in which aging is framed and used by government is also introduced and examined in light of the research which challenges ideas of demographic determinism. The discussion implicitly recommends a search for better solutions to the aging issue. Questions as to the nature of the policy role of charities are then raised. A central issue for this research is the determination of the balance between constraint and action in regards to the work of charities, and the tension which exists here. Theory suggests that charitable nonprofits fulfill important policy roles in areas like home care, but it is questionable whether or not they can effectively perform them given the divergence of goals, visions and objectives in home care that arise from the two sectors. The chapter identifies a number of issues and questions against which the policy roles of charities in Edmonton, Alberta and Ottawa, Ontario are later explained and evaluated.

\subsection{History of Public Home Care's Development}

\subsubsection{From Medicare and Social Services to Home Care?}

Medicare came into being as a result of the 1961 Royal Commission on Health Services (RCHS) (Gruending 1985; Naylor 1986; Taylor, M.G. 1987) and the merging of two federal government acts, the 1957 Hospital Insurance and Diagnostic Services Act 
(HIDSA) and the 1966 Medical Services Act (MSA) (Evans and Law 1995, p. 79). The RCHS is sometimes called the Hall Commission.

These initiatives represent the response of federal and provincial governments to a number of pressures which ranged from the poor health of Canadians, financial burdens arising from poor health, disparities among the provinces in their ability to provide health services, and the "growing political pressure from the public and some provinces for a national program" (Evans and Law 1995, pp. 80, 83; see also Gruending 1985, Chapter 7; Maslove 1995; Taylor, M.G. 1987, pp. 350-352). Despite all the evidence in support of medicare's creation, reaching political consensus between levels of government and solving the twin problems of the health of citizens and market failure associated with private insurance took approximately half a century. As well, other specific challenges had to be addressed such as outlining the technical details in relation to the new public insurance scheme financed by tax dollars, and overcoming strong opposition from physician and business groups who risked income losses from medicare's introduction (Armstrong and Armstrong 1996, p. 158; Evans and Law 1995, pp. 79, 183-186; Gruending 1985; Hollander 1999, pp. 28-29; Naylor 1986; Taylor, M.G. 1987). These groups cited costs as the main reason why medicare could not work and their pessimism also extended towards other services, like home care.

The length of the decision-making period is a good indication of the complexity of the issues and the degree of opposition that governments had to overcome in gaining the much needed political support (Naylor 1986; Taylor, M.G. 1987, Chapter Six). It also represents the kinds of pressures that stand in the way of the establishment of a national 
home care program, today. Regardless of the constraints, the collective logic continues to be that public insurance was/is the best means to control costs and promote equity (Deber et al. 1999; Evans 1993; Gruending 1985, p. 101; Lewis et al. 1997; Maslove 1995; Rachlis et al. 2001). This was clear and central to Hall's recommendations and explains his recommendation to include publicly funded home care within medicare (Gruending 1985). Nonetheless, in the initial medicare decisions with respect to hospital and medical services, the federal government excluded home care services and fund [ed] approximately half the cost of all insured services. In return..., the provinces - as part of their public health care insurance plans undertook to insure hospital and physician services and to comply with certain requirements, such as universality (Madore 2004, pp. 2-5).

Thus, despite the recommendations of the Hall Commission, when medicare was born, home care remained in a 'foetal' state'.

Gruending (1985, pp. 100-101) ascribes a "lack of political will" to the implicit decision against including home care within the national health program. Taylor, M.G. (1987, pp. 356-357), on the other hand, notes how physicians and business leaders fed a mood of uncertainty in regards to the costs of medicare which then led them to challenge the idea of including home care within the new program. These interests claimed that Canada simply could not afford "to provide more comprehensive health coverage" (Gruending 1985, pp. 100-101; see also Hollander 1999, p. 40). Hence, home care in relation to medicare did not become a publicly funded service.

In 1966, the federal government initiated another joint program with the provinces which had the potential to develop into a nationally funded home care program. It was 
called the Canada Assistance Plan (CAP). Rather than producing services which catered to the physical health needs of Canadians, the CAP addressed social—health needs through income assistance and welfare services (CHCA 1999; Forbes et al. 1987, pp. 1113; Canada 1999 a.; Hollander 1999, pp. 30-31). It also fostered provincial experimentation which developed into a wider vision for home care, one which included both acute care and supportive services for the elderly and disabled. With it came the creation of homemaker and day services, long term care facilities and group homes (Hollander 1999, pp. 30-31). Pilot programs were established and plans "for a broader range of services" were phased-in (Canada 1999 a.). Quebec, for example, funded its first public home care program in 1972. Ontario introduced respite care in 1970, chronic home care in 1975, and home support and placement services in 1979 (Williams 1996, p. 942). Of relevance to this research, many of the new services which arose as a result of the CAP were delivered by charitable nonprofits (Ibid) which continue to do so today. Regardless of the possibility that the CAP, like medicare, could become a national program, this outcome never materialized. For Hollander (1999), CAP's history was one of "false starts and failed proposals" and home care, as a result, never secured public funding and protection as a national program. Because of the cost-shared aspect of medicare between levels of government, the incentive for the efficient use of federal funds by the provinces in health services was eliminated (CHCA 1999, p. 8; Evans and Law 1995, p. 100; Hollander 1999, p. 33; Maslove 1995). Hollander suggests the federal government linked the costs of the new social services programs to the costs of medicare, and then turned this into a larger problem of affordability. For him, the issue of 
'perceived' costs became the justification for doing less in relation to CAP and home care.

Angus et al. (1995, pp. 27-49) link the lack of economy in the medicalinstitutional sector with the rising health expenditures that began in the early 1970 s in both absolute terms and as a proportion of GDP, although the increase was slow. Leseman (1992 a., p. 81) and Shapiro (1991, p. 19) also link rising health sector costs with the national and provincial debts and budgetary deficits which materialized during the latter decades of the twentieth century. Hollander (1999, pp. 31-33), as well, considers the costs and debt burden of medicare to have become so untenable that the federal government enforced an 'economic brake' on all health and social programs. Mimoto and Cross $(1991$, p. 31), on the other hand, counter arguments which justify decisions against the development of other national programs like home care with rising costs in the institutional health sector. Their research explains how, "Expenditures on social programs did not contribute significantly to the growth of government spending relative to GDP" for the period between 1975 and 1991. Rather they illustrate that government's revenue shortfall was actually due to higher debt charges combined with government's decision to reduce taxes at this time (pp. 3.8-3.9, 3.12). Others suggest that Canada's health spending has not been out of line. Deber and Swan (1999, p. 1730), for example, who compare Canada's health spending with other international budgetary allocations for health expenditures using a variety of measurement approaches, conclude that Canada's health spending has been modest. They also maintain that objective measures with which expenditure and budgetary allocations can be made are not 
available. This view is reiterated by Lewis et al. (1997) who write, "there are several ways to measure health expenditures, and each has its advantages and limitations". It seems, therefore, that supplementary issues and ideas ought to be factored into decisions associated with health and home care funding. According to Lewis et al. (1997) health sector decision making requires several balancing exercises which would include balancing each of needs, resources, accountability, incentives, services, health outcomes; balancing health sector needs in relation to the rest of the economy; and balancing both health services and health funding within the health sector.

A 1998 poll indicates that 84 percent of Canadians have expressed a desire for a national home care program (CHSRF 2002). It seems logical that national opinion would be an important factor to consider in funding decisions. Also of relevance would be the needs of vulnerable Canadians for health and home care.

Other tools are available to ease a balanced approach to decision-making. Solid research, for example, helps by demonstrating that home care actually saves money. Hollander (2004, pp. ii, 2, 7) demonstrates that chronic home care is less costly than institutional care. He writes (Ibid.), "Canadian evidence... is sufficiently robust that the burden of proof... falls to those who would argue that chronic, long term, home care is not cost-effective." These data represent actual cost reductions rather than mere theoretical predictions. Average estimates are that overall health costs can be "about one half to three quarters of the costs for clients in facility care, by level of care" (Hollander 1999, p. i). Another study demonstrates that preventive nursing care is cost effective and improves social functioning by as much as 23.7 percent as compared to a control group 
whose status improved by only 5.9 percent (Markle-Reid 2003, pp. 15-17). This study also demonstrates improved functional health status and quality of life at six months, with no significant difference in total annual costs per person of service used. As well, consensus is emerging about the importance of establishing a systems approach to decisions on home and acute care: decisions made in one sector will automatically affect outcomes for another (Hébert 2003, p. 10; Hollander 1999, p. 7; Lewis et al. 1997; Shapiro 2002, p. 15). For example, discharging people to home care will yield cost efficiencies in the institutional sector only if the institutions reduce their total bed capacity (Lesemann 1992 a., p. 86; Shapiro 2002, pp. 8, 12), and only if appropriate funds are allocated to the home care sector (Shapiro 1991, pp. 27-28, 38-39, 2002, pp. 2, 20). Otherwise the impact on cost effectiveness of allocating additional funds to home care would be limited (Hébert 2003, p. 10; Shapiro 2002, p. 4). Several authors recommend, therefore, the establishment of comprehensive policies which support a systemic approach to the planning, managing and delivery of health services under a national home care program (Hollander 2004, p. 7; Lewis et al. 1997).

Governments still, however, cite costs as justification against publicly funding new national programs like home care. Fear tactics underscore claims that medicare is not working, or that it is not sustainable, or affordable. As noted above, those making such arguments are often the groups who would benefit greatly from medicare's dismantling (Rachlis et al. 2001; Evans 1993; McQuaig 1995). Alternatively, those who could suffer income loses from funding caps claim that medicare requires more infusions of money (Lewis et al. 1997). These issues demonstrate the ongoing challenges for 
governments tasked with balancing the complexity of factors that are required to maintain medicare, without even considering the introduction of new national programs.

Despite the many challenges, history demonstrates that medicare and the CAP did succeed in fostering the development of a range of home care services which extend more broadly beyond a narrow medical model rooted in physician services, to also include social models of care. This explains the prevalence of home care programs which now respond to the social-welfare needs of Canadians. These include group homes, adult day care centres, homemaker services and meals programs which are often delivered by small charitable nonprofits. Such services exist side-by-side with home care services associated with hospitals and doctors and which include patient assessment, treatment centres and day hospitals, chronic care hospitals and nursing homes. The medically related services represent government's cost reduction strategy in regards to the institutional health sector (Canada 1999 a.). Finally, a third set of home care services address public health needs and include home nursing and community rehabilitation services (Hollander 1994, pp. 610; Hollander 1999, p. 12). Generally and unfortunately, as well, a practice has emerged whereby home care services attached to the medical-institutional sector receive higher levels of secured funding. Social home care and/or public health do not receive the same levels, or security of financing (Lesemann 1992, p. 83).

Altogether, home carc's origins from two different sectors, the federal government's implicit decision not to fund home care under medicare, claims about rising health sector costs, the lack of political will and support for universal social programs, the increased experimentation fostered by the CAP, and so forth have meant that home care 
has evolved differently and according to variable funding levels across Canada (Canada 1999 b.; Hollander 1994, p. 10; 1999, p. 12). Yet, despite such contradictions, the idea of a publicly funded home care program still materializes and continues to be recommended (Lewis et al. 1997; Hébert.2003; Hollander 1999, p. 35). These ideas also suggest a policy space for charities like the Victorian Order of Nurses (VON), the Red Cross and Saint Elizabeth (in Ontario), which have been providing homemaker and nursing services to Canadians as early, if not before, the beginning of the twentieth century (Gross and Schwenger 1981, p. 49; National Health and Welfare 1977, p. 11; Ross-Kerr 1998, pp. 74-82; Williams 1996, p. 942). The policy space includes serving the public through home care's extremely complex and challenging environment.

In recent years, the work of older agencies has been supplemented by numerous new charities which have arisen to provide an expanded range of services. As well, municipalities, which historically had been providing care to poor citizens (Gruending 1985, p. 85; Montigny 1997, p. 63-72), sometimes with provincial funds and sometimes through church-based collaborative efforts (Hollander 1999, pp. 25-27), continue to shape health programs at local levels. The involvement of municipalities in this complex policy environment is mainly through public health and financing low levels of home supports.

I now focus on several federal policies for the period between 1977 and 1996 which were targeted to balancing national economic imperatives with health services and funding.

\subsubsection{The Federal Government's Cost Cutting Agenda and Home Care}

In 1977, the federal government initiated its first cost-cutting policy by 
terminating medicare's open-ended, cost-shared financing arrangement ${ }^{4}$ (Di Matteo and Di Matteo 2001, p. 322) and replacing it by the Established Program Financing (EPF). The EPF was based on block grants and tax point transfers in relation to provincial income and population (Angus et al. 1995, p. 12; CHCA 1999; Di Matteo and Di Matteo 2001; Evans and Law 1995, p. 87; Hollander 1999, pp. 32-33; Madore 2004, p. 5; Maslove 1995). It comprised a cap on federal funding but not in regards to any specific service. In this manner, it allowed for non-health expenditures. The EPF transfer was important to the provinces because it both contributed to and equalized their fiscal resources and capacities, and it enhanced their ability to allocate funds "according to their own priorities" (Maslove 1995, pp. 24, 36).

Specific to home care, the EPF opened the door wider to additional "universally admissible extended care services" (Lesemann 1992 b., p. 83; Canada 1999 a.). It led to "more comprehensive services for seniors and the disabled" (Hollander 1999, p. 34) and more investments into extended health care services and community health centres (CHCA 1999, p. 9). Hollander (1999) attributes the shift of services like long term care and social supports from social services ministries into health ministries to the EPF and its more flexible entitlements. Essentially, the EPF made possible the visible expansion of home care out of its narrow hospital-acute service base into a broader model which responds to each of the public's social, health and public health needs (Hollander 1994, pp. 6-11; 1999, pp. 12, 32, 34).

In the early $1980 \mathrm{~s}$, the federal government amended the EPF and, in doing so,

4 This also affected education (CHCA 1999, p. 8). 
came closer to satisfying its objectives to control health sector costs and extricate itself from its responsibilities for health financing (Angus et al. 1995, p. 13; Hollander 1999, p. 33). The EPF amendment, however, forced provincial governments to assume increasing responsibility for health services and their financing (Maslove 1995, p. 36). One of the responses of the provinces was to replace residential health services with home care (Hollander 1999, p. 3).

In 1984, following the EPF amendment, the federal government consolidated its two medicare Acts (HIDSA and MSA) under the Canada Health Act (CHA) (Justice 1984). This was partly to end the practice of extra billing by physicians and hospitals whereby health costs were being passed onto patients through user fees (Angus et al. 1995, p. 12; Armstrong and Armstrong 1996, p. 159; Evans and Law 1995, p. 87; Gruending 1985, Chapter Sixteen; Hollander 1999, p. 32). The CHA became an important legal safeguard for medicare in that the provinces had to adhere to five principles-public administration, universality, comprehensiveness, portability and accessibility-in return for federal cash transfers (Justice 1984, Chapter C-6, p. 5). While the CHA conferred to the federal government the image as medicare's 'protector', a somewhat useful image, this image did not transfer over to home care because the CHA safeguards did not extend to this service. The CHA may have in fact closed the door to the possibility that home care could ever become a public, national program. Home carc remained as a "patchwork of federal, provincial and municipal funding arrangements, different eligibility criteria and a range of provided services, depending on geographic location" (CHCA 1999, p. 12). Funding for social home care services like homemaker 
services continued under the CAP (Hollander 1999, p. 33).

Madore (2004, p. 8) explains that the CHA "makes a distinction between "insured health services' (i.e., those that have been deemed 'medically necessary') and 'extended health care services.' ... [The latter includes] home care... Because [extended health care] services are not subject to the two provisions relating to user charges and extra-billing, they can be charged for at either partial or full private rates." As well, the CHA stipulates that extended care services are not subject to medicare's five principles. "This is why, for example, it is possible to charge user fees in long term care facilities and why most continuing care services are not portable across provinces" (Hollander 1999, p. 33). With the CHA stipulation that user charges and extra-billing may apply to extended care services, home care is further removed from the possibility of becoming a national public health program, and becomes increasingly desirable as a cost control mechanism in regards to the institutional sector. During the final years of the $1980 \mathrm{~s}$, with provincial health expenditures outpacing economic growth, and given the funding caps imposed upon the provinces by the federal government, the provinces were searching for ways to cut costs (CIHI 2005, p. 6). Home care was a useful and available tool in this regard. Hollander (1999, p. 36-38) and others (Mhatre and Deber 1992; Hurley et al. 1994; Philippon and Wasylyshyn 1996) describe the flurry of provincial Royal Commissions and reports which followed the EPF amendment and the CHA. Six recommendations are noted in the reports regarding the financial shortfalls of the health sector: better management to contain costs, improved efficiency, flexible and responsive services, integration and coordination, improved health outcomes and greater community 
participation (Hurley et al. 1994, p. 494). Regional administration was also seen as a solution and, eventually, regional boards appeared in every province except Ontario (Lomas 1999). Ontario adopted its own regional model for health care in 2006.

The previous developments meant, however, that home care developed into a twotiered, inequitable system whereby, it is suggested, "those with money are better able to pay for care. ... [S]ome people are denied access to needed care simply because they do not meet the eligibility requirements, or are unable to pay the required user fees" (NCGHCRW 2002, p. 8). According to the Canadian Home Care Association (CHCA) (1999, p. 12), the home and continuing care patchwork system started to fray. In 1996, the federal government initiated another highly visible strategy, the Canada Health and Social Transfer (CHST). The CHST combined CAP and EPF funding into a block grant and tax point transfers for social, health and educational services. It "significantly reduced the total amount of [federal] money transferred to the provinces" (Hollander 1999, p. 38; see also Madore 2004, p. 6; Maslove 1995). The five principles of medicare remained as national standards, while the only provision that remained under the CAP was a ruling which prevented the provinces from imposing residency requirements for social welfare benefits (Hollander 1999, p. 39). In 1996-97, “CHST transfers were allocated among the provinces and territories in the same proportions as provincial entitlements under the combined EPF and CAP transfers in 1995-1996" (CIHI 2005, p. 65).

The CHST had little impact on home care: it continued to be a merit good, a social good or a private good. By this, I mean, when home care supplements hospital services, it 
exists as a public good rooted in the CHA's protection of hospital and physician services which are financed by tax transfers; it is a merit good arising from citizenship. Home care becomes a social good when it is delivered according to a social-model of health, e.g., home supports. This model of care lacks legal protections such as those provided by the CHA and, therefore, has fewer legal-regulatory protections. Although it may be financed through tax contributions, user fees are generally required. Home care is a private good when private-payments are required; standards may also be lacking. All forms of home care are evident in Canada and are being used by provinces to cut health expenditures. This is now explained briefly.

\subsubsection{The Provincial Response to Funding Cuts and Their Impact on Home Care}

As provincial governments struggled with reduced health care funding under the federal government's cost cutting policies, they increasingly embraced ideas of competition and markets in relation to their home care programs (Abelson et al., 2004; Neysmith and Macadam 1999, p. 60). Cash-strapped provinces were drawn to the popular but unproven assertions that competitive markets, i.e., managed competition, in home care will yield efficiencies that would ease the financial tensions within the health sector. Although competition might do so, research suggests its use in home care is problematic, particularly in regard to the lack of quality measures. Its emphasis on cost efficiency is not balanced by sound quality indicators simply because they are lacking. Research suggests that clients and their families, and labour are placed at risk, as a result. These issues, including other inefficiencies which arise, are now briefly examined. Williams et al. (1999 pp. 134-136) refer to Donabedian’s (1966) "classical 
approach to measuring quality" to explain how structure, process, and outcome measures interrelate to produce high quality services. Briefly, structure relates to providers, their skills and so forth; process applies to the actual delivery of care; and outcomes measure the impact of services on a client's health status. These authors explain how, in home care, traditional measures of quality do not apply, particularly in relation to established client outcome measures. Hence, quality standards as stipulated within requests for proposals (RFPs) overwhelmingly become focussed on structure and process variables, such as recruiting personal support workers who have been trained in accredited college programs and/or using full time rather than part-time, or casual workers. Williams et al. (1999 p. 135) write, with the exception of client satisfaction, outcome is basically ignored. Second, many of the standards are general 'parenthood' statements. ... Third, the standards do not attempt to micro-manage how particular standards will be met. ... [They fail to indicate] what levels [of standards] are considered appropriate or desirable.

These authors also identify other problems which include the lack of an oversight body that would test and/or validate quality, challenges associated with weeding out less scrupulous competitors, and "the potential for conflict between private profits and the public interest" (Ibid., p. 135-136). Such concerns are shared by Baranek et al. (1999 a. and b.), Nahmiash and Reis (1992, p. 28) and Shapiro (1997). Woodward et al. (2001, p. 2) succinctly summarize the issue by writing, "The measurement of quality in homecare is in its infancy."

It is the combination of the quality conundrum with the awarding of contracts through competitive processes, and capped home care budgets which is problematic for 
clients, families, and labour. Cloutier-Fisher and Joseph (2000, p. 1043) identify the risk of greater institutionalization of the elderly. Abelson et al. (2004) observe that seniors experience lower quality of service, disappointment and frustration, and they have a high risk of exiting from home care. For these authors, such poor outcomes will always occur when quality measures are lacking and, particularly, when combined with a policy focus on cost efficiency.

Aronson et al. (2004), Neysmith (1997, pp. 226-227) and Denton et al. (1999, p. 174) highlight the problems for labour which are exacerbated by competitive arrangements. The visiting employees of home care agencies are often part-time or on contract, and increasing numbers are immigrant women (ㅌid.). Approximately 80 percent of this labour group which is negatively affected are women (Armstrong 2002 a.). The conditions of their employment often include low wages, poor hours and job structure, limited training (Neysmith 1997, p. 227), and few promotions (Denton et al. 1999, p. 194). They are generally paid less than their counterparts working in hospitals or long-term care facilities; they are less likely to be protected by a union (NCGHCRW 2002, p. 9; Denton et al. 1999, p. 174); and they often find themselves taking on "additional work in order to make ends meet" (Cloutier-Fisher and Joseph (2000, p. 1043). Aronson et al. (2004) find that the conditions of employment for support workers, for example, are worsened by contractual arrangements which shift employees from unionized to non-unionized agencies. In addition to the above, the emphasis on cost reduction (Lewis et al. 1997) can also mean less time for each visit, less control over services and less control for those providing the services (NCGHCRW 2002, p. 10). 
These issues and events produce high stress jobs and lowered quality of care.

Work environment stressors [for workers] include: limited control of tasks and scheduling; job dissatisfaction; shift work; repetitive monotonous work; problem clientele; job changes; stagnancy; poor supervision or supervisors; prejudice; sexism; employment instability; restricted social interaction with and isolation from co-workers; lack of institutional and organizational support; lack of communication; transportation difficulties; and low wages (Denton et al. 1999, p. 174).

They translate into significant costs with respect to the occupational health of workers.

The managers of the visiting home care workers, on the other hand, often experience different occupational hazards which relate to job insecurity and stress over service reorganization. Denton et al. (1999, p. 173) write, "stress and the physical symptoms associated with stress are a concern for employees of home care agencies", yet according to Neysmith (1997, p.234), they are often overlooked and are considered "extraneous to a home care policy". Abelson et al. (2004, pp. 364-368) identify how competition negatively impacts several groups of relationships, specifically those between the community and organizations, between providers and case managers, and between case managers and home care workers (see also Doran et al. 2002). All negative relationships reinforce negative client outcomes. Some authors also raise concerns that financial pressures may still overrule service levels and/or performance even when quality measures are specified (Armstrong et al. 2000, pp. 4-5, 9; Neysmith and Macadam 1999, p. 17).

It is difficult to see how goal of cost efficiency in managed competition would not override other objectives like good quality. According to Shapiro (1997, p. 4), the main service input in home care is labour: case managers, nurses, social workers, physio- and 
occupational therapists, para-professionals such as licensed practical nurses, personal care workers and home helpers. Good quality would suggest, therefore, using high quality labour. On the other hand, according to Evans et al. (2000, p. 25), best price means using fewer or less costly inputs, or simply paying lower prices for the service inputs. Thus, when competition is used under the goal of reducing costs particularly when or because public funding is limited, as has been the case in Canada (Lewis et al. 1997), it is most likely that labour becomes the input which is most affected by contracting arrangements (Aronson et al. 2004; Williams et al. 1999). It is likely, therefore, that best price becomes the swaying factor in the awarding of contracts.

Other problems arise particularly when competition occurs between for profit and nonprofit providers. Shapiro (1997, p. 10) writes about the Winnipeg experience where large corporations fix home care prices and/or "underbid rivals even if it means minimum profits in order to eliminate competition". Williams et al. (1999, p 146) observe the outcome in Ontario where "large for-profit companies as Comcare (Canada) Incorporated, and Olsen have won CCAC contracts against not-for-profit companies (which, in turn, paid considerably less than did hospitals)" by hiring nurses on a casual basis (see also Aronson et al. 2004; Baranek et al. 1999 a., p. 87). The Ontario Nurses' Association, see this as "an aggressive means of eroding wages, benefits and working conditions for unionized workers, a practice that will have adverse effects on patient care" (Williams et al. 1999, p. 146). In addition to the casualization of labour, Shapiro (1997, p. 10) identifies an additional risk that "companies could try to maintain profits by reducing the training and supervision required to provide the quality of care delivered to the vulnerable 
people they serve".

Abelson et al. (2004, p. 367-370) Shapiro (1997) and Woodward (2001, p. 5) share other concerns that contracting will cost more in the longer-term due to both the higher transaction costs that are required to oversee contractual arrangements and the higher displacement costs which arise when agencies withdraw from contracts and force the transition of thousands of clients. Doran et al. (2002, p. 25) identify higher administrative costs for CCACs when managing RFPs. Hossli (2000) identifies higher transaction costs in Alberta where competition was introduced in relation to communitybased training. There are also concerns that small nonprofit organizations are not able to compete effectively against large well-funded corporations, or that mission-shift will occur for nonprofits that are made to operate like for-profit competitors (Ibid.). Such issues and concerns are identified by Boyne who examines competitive practices in the United Kingdom (UK). When reviewing the evidence on UK tendering practices, Boyne (1998, p. 710) suggests that competition may lead to "excessive expenditure and inefficiency."

Several authors also link these issues with a potentially larger problem which is associated with private financing, for-profit delivery, and NAFTA. The concern, here, is that as health care, including home care, shifts away from the protection of the CHA, the risk of increased privatization is introduced which "may be difficult and too expensive to reverse" (Baranek et al. 1999 b., p. 90; see also Appleton 1999; Armstrong et al. 2000; Puscas and Clarke 2002; Taft and Steward 2000; and Williams et al., 1999). According to Evans et al. (2000, p. 25), we must take care not to sacrifice public objectives to private 
profit in order to secure the desired efficiency gains. Several authors ask, 'Whose opportunity cost is being affected by the business model?' (Armstrong 2002 a., p. 3; Clark and Pelham 1986, pp. 177-178; Neysmith and Wells 1991, p. 103). Finally, Williams et al. (1999, pp. 143-144) explain how the evidence to demonstrate that "competition can be managed by intermediary organizations in the interests of consumers and the tax-paying public" is equivocal.

It appears that home care, as with other health services, is a complex good which suffers from market failure issues which may produce other inefficiencies particularly when delivered through competitive market-like arrangements. Authors writing about the private home care market in the United States identify the risks for vulnerable people and/or their families (Herd 2005; Keigher 1999) which arise from their inability to assess both the quality of the services and the price of services they wish to purchase. This risk is sufficiently significant that Keigher $(1999$, p. 182) suggests "marketized" services ought to come with the tag "consumer beware", purchasing them can "be precarious to one's health". Another drawback for American citizens is that the market model limits the redistributive elements of social insurance programs like medicare (Herd 2005, p. 292). Given the mixed review of the experiences to date with competitive contracting in Canada, Abelson et al. (2004, p. 359) conclude improvements are required. One way of doing so is suggested by Doran et al. (2002, p. 28) who identify, for example, "the need for empirical data to address questions about the impact of managed competition on community nursing services."

For Evans (1997, p. 428), "no 'private, competitive market' of the form described 
in the economic textbooks, [exists] anywhere in the world [for the health sector]. There never has been, and inherent characteristics of health and health care make it impossible that there ever could be." For him, the persistent interest in an "imaginary private competitive market" is sustained by three interrelated issues: the degree to which progressive or regressive distributional objectives underscore health services' financing, the relative income of providers, and the level of access to health services citizens should receive. Evans suggests the real policy issues are decisions over whether or not market mechanisms should be used within public finance or whether certain services should be financed outside the public sector (Ibid., p. 428). Williams et al. (1999, pp. 147-148) write that more debate is needed about these issues in relation to home care in Canada, particularly as it is provided to some of the "most vulnerable in society".

When Canadians respond to these policy issues regarding home and health care, they consistently support medicare and continuously favour distributional and equity goals over profit, particularly profits which are earned "off the backs of the sick and needy" (Lewis et al. 1997). Canadians have expressed the desire for a national publicly insured home care program (Armstrong 2001, p. 65; CHCA 1999, p. 15; National Forum on Health, 1997, p. 9; Shapiro 1997, p. 11). All the same, given the complexity of issues and variety of stakeholders it is questionable whether or not a national home care program can and/or ought to be established.

I now refer to other health policies, studies and commissions that were introduced by the federal government over the period during which health funding was being reduced and which impact the home care environment. 


\subsubsection{Other Federal Government Policies, Studies and Commissions}

Over the years when the federal government was reducing its responsibilities in the health sector, it was interweaving into public debate, other normative ideas and/or social-justice agendas. One of the earliest examples is the notion of the determinants of health which first appeared in the federal government's Lalonde Report, released in 1974 by the Ministry of Health. It states,

the traditional view of equating the level of health in Canada with the availability of physicians and hospitals [is] inadequate. ... [Moreover] future improvements in the level of health of Canadians lie mainly in improving the environment, moderating self-imposed risks and adding to our knowledge of human biology (Lalonde 1974, p. 18).

These ideas which have since been called the determinants of health (Evans and Stoddart 1990) have been well used within the federal government's policies. They represent forward thinking when they acknowledge other important criteria which foster good health, e.g., education, income, housing, exercise and nutrition. Their value is diminished if they are used to justify cost reductions to institutional health services without making the necessary financial re-investments into those areas which do enhance health. They are further weakened when home care, a service which may provide many of the recommended preventive and maintenance functions, is not accorded the protections and financial supports that would enable it to yield these important benefits.

In 1994, the federal government launched the National Forum on Health "to involve and inform Canadians and to advise the federal government on innovative ways to improve our health system and the health of Canada's people" (National Forum on Health 1997). In 1997, the federal government established the Health Transition Fund 
(HTF), a joint effort between federal, provincial and territorial governments, "to encourage and support evidence-based decision making in health care reform" (Shapiro 2002, p. iv). Between 1997 and 2001, 114 pilot-evaluation studies took place "in four priority areas: home care, pharmaceutical issues, primary health care, and integrated service delivery" (Ibid.) through the HTF alone. Four years after the National Forum on Health, the federal government established the Romanow Commission, a one-year Royal Commission on the Future of Health Care in Canada which released its report in 2002 (Romanow 2002).

Through each of these more recent initiatives, the federal government sought the, seemingly necessary, re-commitment of Canadians to medicare. Both national studies conclude that home care ought to receive the same protections accorded to hospital and medical services, although the Romanow Commission endorses acute and palliative home care services over preventive and maintenance home care. Canadians are committed to medicare and research suggests that they would benefit from these enhanced services. Perhaps due to the various factors which include the problems of securing consensus, weak political will or leadership, and the challenge of balancing national objectives (Hébert 2003; Shapiro 2003), the concept of a national, publicly funded home care program may never materialize.

More recently, the federal government in consultation with the provinces renewed its funding commitment to health and home care but with some limitations. Briefly, in the 1999 budget, the federal government increased its funding allocations to health care under the CHST in three targeted areas: diagnostics, primary health care, and technology 
(Canada 2002). Then, in 2000, federal, provincial and territorial First Ministers "agreed on a vision, principles and action plan for health system renewal" (Canada 2003 b.). In 2003, this commitment was strengthened by means of the First Ministers' Health Accord on Health Care Renewal (the Accord) through which, the federal government once again agreed to increase its health funding allocations. Among the purposes of the Accord is improvement in timely access to a number of services, regardless of location. These include $24 / 7$ health care, diagnostic procedures, home and community care services and drugs which are to be provided in a system which is efficient, responsible and adaptable to changing health needs. The three targeted priority areas are primary health care, home care and catastrophic drug coverage (libid.).

In 2004, through a further agreement between the federal, provincial and territorial governments which built upon the Accord, the federal government committed to transfer $\$ 41.2$ billion to the provinces and territories in order to address the issue of timely access to care in the priority areas of cancer, heart, diagnostic imaging, joint replacements and sight restoration (Canada 2004 b.; Dawson and Kennedy 2004; Laghi et al. 2004). It was promised that home care would receive, by 2006 , an infusion of money for short-term acute care, short-term acute community mental health, and end of life palliative care. Interestingly, when referencing pharmaceuticals and the Ministerial Task Force tasked with developing and implementing the pharmaceutical strategy, the 2004 agreement uses language which conveys a Canada-wide, national strategy. It does not refer to home care in a similar manner (Canada 2004 b.).

The Accord represents both redistributive and cost-cutting policies. To illustrate 
how or why they performs both functions, I refer to seniors (in the following section), the population which relies on home care, and to Health Canada's definition of home care. I

begin with the latter which defines home care as

an array of services which enables clients, incapacitated in whole or in part, to live at home, often with the effect of preventing, delaying, or substituting for long-term care or acute care alternatives (Canada 1999, p. 10 , italics in original).

As well, home care performs three purposes. Substitution services may replace services received by acute and long-term care facilities. Maintenance services may foster independence and home living. Lastly, preventive services may aid in cost reduction.

Hence, home care

may be delivered under numerous organizational structures, and similarly numerous funding and client payment mechanisms. It may address needs specifically associated with a medical diagnosis (e.g., diabetes therapy), and/or may compensate for functional deficits in the activities of daily living (e.g., bathing, cleaning, food preparation). Home care is a health program, with health broadly defined; to be effective it may have to provide services which in other contexts might be defined as social or

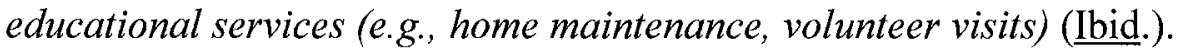

Finally, home care

may be appropriate for people with minor health problems and disabilities, and for those who are acutely ill requiring intensive and sophisticated services and equipment (Ibid.).

This definition of home care makes allowances for services to be provided to citizens who experience chronic and/or other long-term health conditions. $\Lambda$ majority of home care users, people who require home supports because of their long-term chronic conditions, are seniors and frail elderly persons (Ibid, p. 10; Forbes 1987, p. 51; Hébert 2003, p. 10; Shapiro 1991, p. 21, 2002, p. 1, 2003, p. 16). 
The Accord makes allowances for short-term acute home care and, through it, an Employment Insurance $(\mathrm{EI})^{5}$ benefit is available for family members providing palliative care for a six week end of life period (Canada 2003 b., 2004 b.). By restricting funding to short-term acute home care and by limiting the EI benefit to people in paid employment to a six-week benefit period, the Accord represents cost-cutting policies targeted to institutional health services. Hence, its redistributive aspects in relation to the EI benefits do not extend to informal caregivers and are limited for paid employees. It does not address the needs of seniors' chronic and supportive care requirements. As well, it is misaligned with the government's definition of home care. It is important, therefor, to examine more closely the needs of seniors and the types of services that would actually benefit them in light of recent policies and practices, such as the Accord.

\subsection{The Needs of Seniors}

Literature highlights the goals of seniors to remain independent for as long as possible and their desire for a variety of options which do not penalize them and/or their families with undue hardships, as their independence deteriorates (Clark and Pelham 1986, p. 169; Garber 1991, p. 109; Neysmith and Wells 1991, p. 96; Tindale 1991, p. 71). Several contested and interrelated issues arise which impede the availability of choice for aging populations. These include the pathologization of aging, medicine's dominance in home care, and the costs associated with caring for the elderly. These are now examined

5

The Accord is a step forward in that it is a "compassionate care [employment] benefit [that] has been made available [for employees] through the Employment Insurance Program (EIP), and job protection [is provided] through the Canadian Labour Code (CLC). This is available for those who need to temporarily leave their job to care for a gravely ill or dying child, parent or spouse (Canada 2003 b.). 
beginning with evidence which describes the social and health condition of seniors.

Data for 2003 which describe seniors according to their health, wellness and need for personal care help (Turcotte and Schellenberg 2007, p. 48) demonstrate little variation in terms of the overall condition for seniors as compared to data for the early $1990 \mathrm{~s}$. When writing about the early 1990s, Lesemann (1992 b., p. 82), for example, indicates that two thirds of seniors between ages 65 and 74 were able to care for themselves. Current data (2003) indicate that about one quarter of seniors between the ages of 65 and 74 reported they had helped others outside the home as compared to 11 percent of seniors over age 75 (Turcotte and Schellenberg 2007, p. 155). Only 7.8 percent of seniors over age 65 require help with meals while 15.9 percent of this age group require help with housework, 5.8 percent require help with personal care and 3.3 percent require help with movement (Ibid., p. 83). The proportion of seniors requiring help increases for seniors over age 75 and are 13.2, 24.7, 9.8 and 4.8 percent, respectively for the daily activities of meals, housework, personal care and movement (Ibid.). Earlier data (1990s) indicate 50 percent of seniors between age 65 and 74 provided moral support and 35 percent provided home help; 35 percent of seniors over age 80 provided moral support and 19 percent provided home help (Forbes 1987, p. 122; Lesemann 1992 b., p. 87). In 2003, 77.4 percent of seniors between ages 65 and 74, and 67.9 percent of seniors over age 75 reported having good to excellent health (Turcotte and Schellenberg 2007, p. 81). Other research indicates seniors seek public assistance from home care only when they are very old and frail (Hébert 2003, p. 10). Seniors over age 85 are the population sub-group which represents the largest users of home care in Ontario (Mitchell et al. 2005, pp. 60- 
63) and Shapiro (1991, p. 21) attributes this trend to the lack of family support for day-to-day needs. Neysmith and Macadam write, "THE elderly, [as a] homogeneous concept ... is so broad as to be analytically useless" (1999, p. 6, emphasis in original). What these data suggest is that contrary to fiction, not all seniors are unwell and draining the health system; a significant proportion of seniors live independent and healthy lives (Forbes 1987, p. 48; Maurier and Northcott 2000, Chapter 4; Neysmith and Wells 1991, pp. 96, 98; Turcotte and Schellenberg 2007).

A number of authors suggest the aging process is distorted by the use of descriptive rather than analytical data and analysis based upon this type of data creates problems of demographic determinism and the demonizing of aging (Denton and Spencer 1995, p. 178; Lesemann 1992 b., pp. 96-97; Montigny 1997; Ridler 1979, pp. 6-16). Many suggest it is easier to create financial crises by demonizing aging than to provide geriatric programs such as senior-friendly public transportation (Northcott 1997; Maurier and Northcott 2000; Montigny 1997; Stewart 1979, p. ii-iii). This is not to suggest that 'baby boomers', Canada's largest aging population cohort, are not a demographic anomaly (Canada 2007) which must be managed appropriately, but several authors suggest it is important to include other factors in the analysis of demographic trends such as declining crude birth rates (Marzouk 1991, pp. 490-491), fertility decisions, infant mortality, and immigration policy (Neysmith and Wells 1991, p. 98; Northcott 1997, pp. 15-22; Ridler 1979, p. 12). A number of authors claim the narrow framing of the aging process is problematic particularly because it is used to justify budget cuts for programs that are needed by seniors (Barer et al. 1995, pp. 193, 195; Maurier and Northcott 2000, 
p. 152; Montigny 1997, pp. 9-11; Neysmith and Wells 1991, pp. 102-103, 1999, p. 1).

For Clark and Pelham (1986, p. 160), Forbes (1987, p. 88) and Neysmith and Macadam (1999, pp. 10, 22; 1991, p. 98), statements which pathologize aging are problematic because they distort reality and contribute to ageism and age-phobia. For these authors, aging is a social construct based upon human decisions rather than on biological factors. Such constructs only exacerbate the problems experienced by the elderly, meaning ageism and the over servicing of seniors with medical tests and procedures that may not contribute to positive health outcomes. For them, current home care policies and funding ${ }^{6}$ reflect a lack of political will, stereotyping and ageism towards seniors. Rather than lumping all seniors together, it might be more appropriate to disaggregate them as the well elderly, the frail elderly, the functionally disabled elderly and the ill elderly (Havens 1995, pp. 247-249), and to develop programs that are appropriate to the respective age cohorts.

Another idea which inhibits the independence of seniors is the view that home care ought to address, firstly, their medical-nursing problems. The suggestion, here, is that access to home care is ideally linked to clinical, physical and cognitive functioning problems, and/or that medical referral can also adequately manage the social support needs of seniors. For Neysmith this view leads to the risk that if a choice had to be made, social outings become the services that are cut $(1999$, p. 13). While not diminishing the importance of medical and nursing care, empirical research demonstrates that more often

6

Government spending on home care was almost negligible at 0.65 percent of total public health expenditures in 1975-76 and rose to 3.45 percent of total public health expenditures in 1995-96 (Canada 1998, pp. 1, 3; see also Ballinger et al. 2001; CIHI 2005). 
than not, social services are the services required by seniors residing at home. Neysmith and Wells (1991, pp. 99) write that seniors need

assistance with instrumental activities of daily living (snow removal, cleaning, shopping, meal service), companionship, information, education and skill development, security monitoring, financial services, personal care services (bathing, dressing), equipment (wheelchairs, oxygen), transportation, opportunities for social integration, diagnosis and treatment (medical, physical and occupational, social work, nursing, lab tests).

For the early 1990s, Shapiro (1991, p. 20) notes that two-thirds of senior Manitobans required "social supports such as home help whereas only one-quarter to one-third require any medical service". Yet, despite seniors' great need for social supports, doctors and nurses become home care's gatekeepers and, as a result, hospital dischargees rather than people living in community tend to receive home care. Long-term clients tend to become under served.

The tendency to ignore chronic care needs is reinforced by policies like the Accord which support acute home care because of the cost advantages associated with caring for people with acute needs at home rather than in hospitals and in long-term care facilities (Di Matteo and Di Matteo 2001, p. 322; Lowry 2002, pp. 2-3; Hollander 1999, p. 3, 2001, p. i). Research demonstrates that the growth in post acute home care has parallelled trends to downsize the hospital sector, to discharge people earlier from hospital, to expand day surgery procedures, and to introduce new treatments and technologies into acute home care (Shapiro 2003, p. 15). Moreover, these practices are occurring within stagnant and/or declining home care budgets, and together they are pressuring home care systems. Minimally, they lead to wait lists and greater use of higher 
cost health services (Ibid.).

The formal health sector, as a result, provides only 10 to 20 percent of the required social supports to seniors (Neysmith and Wells1991, p. 96). By comparison, estimates are that up to 60 percent of public home care expenditures are devoted to hospital care (Shapiro 2002, p. 8). Compounding the situation for seniors is the risk, identified by research, that when they use acute home care, they may be over serviced with more diagnostics, intensive therapies, or more medicating than is necessary (Angus et al. 1995, pp. 31-33; Auer et al. 1995, pp. 82-84; Barer et al. 1995, p. 219; Black et al. 1995, pp. 240-241; Finlayson et al. 2005, p. 23; Havens 1995, p. 257).

These policies and budget allocations also impact informal caregivers. Forbes $(1987$, p. 48) writes, the majority of informal family caregivers of the elderly are, themselves, elderly and are outside the paid workforce. Hence, these caregivers cannot benefit from the EI programs associated with the Accord. As well, approximately 60 to 80 percent, (estimates vary), of informal caregiving work is being done by women (Fast et al. 2004, pp. 6, 17; Lowry 2002, p. 3; Shapiro 1997, p. 5), most of whom are spouses (Lesemann 1992 b., p. 82). Some estimates define the upper limits for the number of women who provide informal caregiving at 85 or 90 percent $\left(\mathrm{O}^{\prime}\right.$ Connor 1999, p. 71; Fast 2004, p. 6; Lowry 2002, p. 3). Yet according to O'Connor (1999, p. 71) spouses are the least likely group to use formal support services even though they provide significant levels of informal care. The important point is that women-old and young-are doing a fair amount of informal caregiving work and this is a huge burden for them, and they receive little public support. 
The 1996 General Social Survey (GSS) measures the burden of home care work on spouses who spend, on average, 16 hours per week on elder care (Cloutier-Fisher and Skinner 2006, p. S40). The opportunity cost of this spousal caregiving work is estimated to be " $\$ 1.88$ billion and represents a lower limit of the value of spousal care in Canada, since this figure was based on an underestimate of the spousal care actually received" (Ibid., p. S46). Publicly funded home care, by comparison, averages at 6.3 hours per week per family, with Albertans receiving only 3 hours per week. The factors which determine receipt of public home care include personal care limitations such as incontinence, the presence of a spouse and, living in a richer province (Ibid., p. S41). Having a spouse means around 4.7 hours less public home care each week. According to GSS estimates, spousal related home care reductions saves the public system around $\$ 518$ million each year (Ibid., p. S44).

Research demonstrates, as well, that the EI contributions regarding palliative care are insufficient. Henderson (2006, p. 1), for example, reports that "caring today does not last for a few weeks or months ...- it can now last up to twenty years or more, completely disrupting one's personal, work and financial life." For palliative care, "[i]nformal caregivers spen[d] roughly 79 hours per week and formal caregivers roughly 26 hours." Palliative informal caregiving saves the public system approximately $\$ 6,000$ per person requiring end of life care (Greaves 2002, p. 4). EI benefits appear to be of minimal use here when compared to the size of need. In addition, families are not only providing long-term chronic and palliative care in the home, they are also providing informal care in institutional settings because of governments' cost containment strategies (Clark 2001, 
pp. 26-26).

According to research, all of this caring work has a tremendous negative impact on the mainly female informal caregivers. Financial hardships are almost the norm (Browdie and Turwoski 1986, p. 36; Fast 2004, p. 6; Lowry 2002, p. 4). They suffer a number of health related problems ranging from stress (Lesemann 1992 b., p. 88) and burnout (Payne 2002, p. 12), to physicial and emotional strain (Hébert et al. 2001, p. 17; Payne 2002, p. 12). They experience "higher rates of depressive and anxiety disorders and use mental health services twice as much" (Lowry 2002, p. 4). Moreover, because they have insufficient time to devote to friendships, relationships or other interests (O’Connor 1999, p. 91; Fast 2004, p. 6), it is not unusual for female caregivers to gradually experience an intense sense of isolation (Armstrong 2002 a., p. 12; Williams 2002, p. 9). Over time, caregivers become increasingly exhausted which adds to their sense of isolation and leads to their own dependence on the health system ( $\mathrm{O}^{\prime}$ Connor 1999, p. 92).

The caregiver problem is worsened by home care's under funding, by governments focused on acute home care and by the lack of political will and leadership (Vogel et al. 2000). Some authors suggest that governments have "on-load[ed] to informal caregivers" and their families by its "off loading" actions (Havens 1986, p. 253), meaning reduced personal care in many jurisdictions (Cloutier-Fisher and Joseph 2006, p. 7). While governments may be saving money, research indicates the social, economic and health costs to informal caregivers and their families are high (Fast 1995, p. 6; Forbes 1987, p. 120). 
Acute home care does not provide seniors with the preventive and maintenance functions they need, and the job protections and palliative care supports of the EI benefit are of little use to many caregivers engaged in long-term caring work. Thus, for seniors and the large numbers of unpaid informal caregivers, it seems that government's policies as exemplified by the Accord represent backward steps, or very small forward baby steps. Within the current policy framework, seniors experiencing increasing functional decline seem to have three options: use the minimal social supports provided by public or formal home care; rely on informal caregivers and/or their own resources as they are available; or be institutionalized. The first two options have already been discussed. With respect to the third option, the predictors of institutionalization of the elderly speak volumes. They include being Canadian, especially from Alberta (in 1981), or Ontario (in the 1990s), being frail and/or disabled, or a member of a small family (Forbes 1987, pp. 40, 51, 89; Maurier and Northcott 2000, p. 99). Other factors which increase the risk of institutionalization for seniors include bad housing or few housing options, (Forbes, 1997, p. 112; Lesemann 1992 b., p. 88), social isolation, living alone, poverty, poor diet, gender, i.e., being female, being a visible minority, and minimal education (Forbes 1987, p. 113; Neysmith and Macadam 1999, p. 4; O’Connor 1999, p. 71; Shapiro 1991, p. 21; Turcotte and Schellenberg 2007, p. 163). Many of these reflect health determinants.

If seniors wish to avoid institutionalization when they begin experiencing functional decline, they will require a wide ranging set of formal services and their informal caregivers will also require adequate and appropriate support. Leaving institutional options aside, Turcotte and Schellenberg's (2007, p. 163) analysis of the 
2002 General Social Survey (GSS) demonstrates that at the present time, seniors with long-term health problems who are living in private households are experiencing unmet caring needs. The authors, however, do not specify whether or not these unmet needs pertain to formal, informal or both types of home supports. They identify regional differences in the care provided to seniors (Ibid., p. 164), and they observe that about three quarters of help provided to seniors with long-term health problems is largely associated with informal sources (Ibid., p. 166). Formal sources of support seem to be restricted to the most elderly seniors, meaning the 40 percent of seniors over age 85 with long-term health problems. They write (ㅎid.),

the proportion receiving care from formal sources was higher among older seniors. Some $60 \%$ of those aged 85 and over received part or all of their help from a formal source, whether government, personal paid employee, or non-governmental organizations. In contrast, this was the case for less than half of those aged between 65 and $76(47 \%)$. As they get older, the chronic conditions for which seniors need help may become more severe or numerous; consequently, more specialized home care can be required and members of social networks may no longer be sufficient for providing support.

On average for all seniors in 2002 over age 65, Turcotte and Schellenberg (2007, p. 198) note that about 45.1 percent receive informal help because of a long-term health problem as compared to 28 percent who received only formal help and 26.9 percent who received both forms of care. Seniors over age 75 receive more formal care than do seniors between the ages of 65 to 74 but, surprisingly, more seniors between ages 75 to 84 (30.6 percent) receive care than do seniors over age 85 (23.1 percent).

Altogether, the above illustrates the complex set of factors associated with decision making about the mix and type of services required for seniors and their 
caregivers. It also illustrates the challenge of balancing such needs and decisions with those associated with female labour in the formal home care sector, the wider health system and the economy. It also identifies the need for significant public debate from all sources and directions about these issues. Moreover, it raises several questions about the role of charities in this debate.

\subsection{Chapter Summary and A Policy Role for Nonprofit Charities}

This chapter presents the history of home and health services according to the complex challenges that face governments and policy makers who strive to balance various needs and goals in relation to the economy, and in relation to health and home care services and their funding. The needs of seniors as impacted by the decisions and policies of government are also examined in light of the challenges and opportunities which charities meet in their own day-to-day policy work. Altogether, the issues which muddy the home care policy waters, so to speak, in regards to balancing the needs of seniors, their informal caregivers and paid female workers with national and provincial goals and objectives have been identified. It seems that silver bullets are not readily available to those taking on the challenges associated with home care, meaning governments, policy makers, seniors and their caregivers, labour and nonprofit charities.

Charities operate at the public and private interface of home care where the struggle to meet (or not meet) the home care needs of seniors is taking place.

Government funding is central to the services delivery component of their work, and private donor funding and labour supplement services and advocacy. According to the mission statements of home care charities and according to law, these organizations exist 
to serve seniors and the public through services and advocacy. These ideas suggest charities experience first hand the needs of seniors in relation to both formal and informal sources of care. In the formal domain, they experience the tensions which arise for seniors in relation to the funding allocations for home care, for both support and acute home care, and the service gaps which arise as measured, for example, by wait times; they experience the issues associated with the quality conundrum and competition; and they experience the policy issues associated with paid female labour. In the informal domain, charities experience the needs of female caregivers, many of whom are experiencing their own health problems; and in a policy context, they experience the lack of support provided to informal female caregivers. Given the first hand experience of charities in home care, it is likely that their policy objectives and recommendations would diverge from those articulated by government.

This chapter suggests, therefore, a number of questions about the policy work of charities. 'How do charities articulate a vision for home care and what is their vision?'. 'How do they go about defining, measuring and promoting this vision?' 'What are the constraints (internal and external) on the visioning work of charities?' 'What are the opportunities for change and how are they achieved when charities operate in a policy environment where they are largely dependent upon government funding?' These are the questions which are examined in the following chapters. 


\section{CHAPTER 3 - THEORETICAL FRAMEWORK}

\subsection{Introduction}

This chapter presents the theoretical framework which guides the examination of the policy engagement of charities, a subset of nonprofit organizations, in home care. This means examining the policy actions of charities in this policy field. The framework first roots this examination within a set of functions or roles (the two words are used interchangeably) performed by charities in order to test the argument that they, like other nonprofit organizations, perform a variety of important roles on behalf of society rather than merely providing services. This more'structured' approach to the examination is then expanded and/or adjusted so as to capture the actions and more dynamic components of the policy engagement of charities which is rooted in their human agency and their missions. Hence, both human dimensions and structures shape the research endeavor. The idea which guides framework building is that the identity (and missions) of nonprofit charities is one with their human agency and their roles/functions.

The previous chapter informs about the constraints which arise from government policies and which impact and shape the home care policy context. The framework considers these, as well, but frames them as the external constraints which impact the policy actions of charities. While these contextual structures are considered, their consideration is superceded by the examination of the policy activities of charities according to the identity, missions, human agency and roles of these agencies. The framework seeks to explain how charities may generate power so that they may participate in policy-making activities and it seeks to explain how their activities and 
roles, in this regard, are constrained.

The history of Canada's home care sector, which began as early as the late $1890 \mathrm{~s}$, suggests that charities do more than simply provide services, and that they generate their own power to advocate on behalf of vulnerable people. Before public home care's formal appearance in both Ontario and Alberta, nonprofit charities had been doing visiting nursing, providing homemaker services, establishing hospitals, engaging in public health and training, and laying the foundation for provincial health and long term care systems. Aside from these positive contributions to public health and home care, their permanence and history are indicators of ongoing public support which enable(d) them to raise funds, educate the public, do social activism and solve societal problems. Otherwise, they never would have survived, particularly given the tensions within the health system.

Home care is a good testing ground for this research because the strength and durability of the state's structures and power within the health sector, as described in the previous chapter, represent powerful disincentives for charities to use their human agency under the goal of participating in, and shaping public policy. The strength of state structures may also lead to a narrow understanding of the policy roles of charities which focuses attention solely on their service role, rather than according to their broader identity and roles. Structures seem to contradict the core values, missions, identity and work of charities as well as the beliefs, values and activities of their volunteers and the wider community.

To ensure that both the human and structured aspects of the policy engagement of charities within home care are captured in this research, the framework thus uses four 
broad groupings of theory: nonprofit theory, state theory, including policy community literature, community power theory and the state's public policy processes. Nevertheless, nonprofit theory is the predominant contributor to the framework. Emergent nonprofit theory identifies a number of roles-functions that are performed by the sector's organizations (Gassler 1986, Frumkin 2002). But, Frumkin (2002, p. 1) suggests nonprofit theory remains fragmented and contested, meaning ongoing theory development is required. This need is particularly relevant in light of the engagement of the sector's organizations with the contemporary welfare state (Langton 1987, p. 135). Further theory development is required despite the work in economics, law, sociology and political science which began in the 1970s; "the study of nonprofit organizations has yet to find a home in any single discipline" (Frumkin 2002, p. v). Thus a key goal for this research is that it will instill new understanding about the nonprofit sector, particularly in regard to the policy roles of a subset of its organizations, namely charities. The other three groups of theories explain the dynamic context within which nonprofit charities operate as they shape home care policy.

This research asks 'How are the policy functions of charities explained and operationalized, and what constrains them?'. The very nature of the question challenges a narrow instrumental view of charities as partners with the state, providing services. When considering this question in home care, my propositions or arguments are that:

1. Charities actively exercise a range of policy roles and/or functions in addition to service provision because they are arise from and manifest human ingenuity and societal values. They are advocacy-constituted roles because, ultimately, their purpose is to change and/or align government's policies and funding with their own vision(s) with respect to the needs of seniors, female paid and informal 
caregivers, and the broader public. This is being tested in the policy field of home care.

2. Their varied roles are evident in their operations, their policies, their home care programs, and in the outcomes of their work which benefit both the public and government which, itself, relies on the work of charities when developing its own home care policies. Nonetheless, government's policies constrain their full performance in home care. Thus, although agencies partner with government in their service delivery role, their true partnership is perhaps with their communities.

3. Finally, all functions performed by charities - promoting values, environmental scanning, providing services, redistributing resources and promoting societal stabilization through employment and democracy - are interrelated and ought to be considered in a balanced manner, rather than being pursued in isolation or in excess.

In the following, I explain why this research endeavor is legitimate, particularly at this time and place, using five points which arise in relation to three of the four groups of theory: state, nonprofit and community power. These literature groups provide background to the framework. They are supplemented by the state policy theory by the third chapter section; the latter explains the policy making processes of the state. The framework also explains my narrow focus on charities, a subset of nonprofit organizations. The fourth chapter section explains the roles performed by nonprofit charities as delineated by the framework, according to a home care context. I now explain the need for this research and introduce background information which supports the framework.

\subsection{Theory Supporting the Development of the Theoretical Framework}

\subsubsection{The Nonprofit Sector and the Changing Welfare State}

Since the early 1970 s, we have gained knowledge about many aspects of the nonprofit sector such as its size and composition according to the varied organizations 
that constitute it. Much remains unanswered about the sector, particularly in relation to the roles assumed by types of nonprofit organizations and in regard to the interactions with the welfare state assumed by the respective types. Further complicating any research on the nonprofit sector is the idea that the modern welfare state is, itself, changing. As pieces of the nonprofit theoretical puzzle find their home, shifts in the policy environment within which these organizations operate, meaning a changing welfare state, will likely require ongoing refinement to nonprofit theory. So how is the welfare state changing in a manner that may impact the operations of nonprofit agencies?

Sullivan and Skelcher (2002, p. 3), who quote Peters and Pierre (2001), observe that the modern welfare state is increasingly characterized by multi-level governance, negotiation and non-hierarchical exchanges between actors. They observe this phenomenon at many levels: national, regional, local, and international. Taylor (2003, p. 110), who builds upon the ideas of O'Donovan (2000, pp. 226-7), also acknowledges these processes associated with a changing welfare state, but uses the terminology of the 'interactive' state. Shields and Evans (1998, pp. 36-38), on the other hand, observe the logic of restraint which is characterizing the modern welfare state. Rice and Prince (2000, Chapters 4 and 5) explain the changing welfare state in terms of a crisis which requires government to respond. They identify three government responses to the crisis of Canada's welfare state: dismantling social welfare systems through retrenchment, remixing the social economy through new partnerships and making incremental adjustments to existing systems. The above explains how, in this new era, governments' roles are being redefined in social welfare and income security, health services, and in the 
economy's regulation. One outcome of such change is that the state's public bureaucratic form and its size are under siege. Another is that workers and citizens are being stripped of their social and economic rights (Shields and Evans 1998, p. 37). Essentially, the restraint logic means that less is being made available through the welfare state. It also introduces the option for the state to privatize and/or devolve its responsibility and/or authority to its 'rightful place' which could be any or all of family, community, church and/or charity, market, or other level of government (Ibid., p. 39; see Lewis et al. 1997, for explanations of such processes in Canada's health sector). According to Hirst (1994), the use of the 'P-3' model-public private partnerships-is another indicator of the state's shifting of its responsibilities in the economic sphere; the state downloads social provision onto voluntary associations and retains public funding and political accountability. It appears that multi-level governance, negotiation, non-hierarchical exchanges, the 'interactive' state, and the restraint logic are all interconnected, and the outcome is that the boundaries between sectors, including the nonprofit sector, are changing. For the nonprofit sector, it suggests changes in identity, roles and operations.

The above does not suggest the state's abdication of power; rather the opposite seems more true. Haddow's (1999) conception of the state's interactions with policy communities and networks to develop public policy illustrates how it variously wields power within sectors. It does so through, for example, its legal authority which is legitimated by appeal to popular will, its discourse, its manipulation of the political system, the agenda and decision-making processes, its use of the media, and its use of science and technology (Atkinson and Coleman 1996; Nordlinger 1981; Pierson 1995). 
Furthermore, of interest to this research is the state's power which is displayed in Canada's health sector (Boase 1994, 1996; Tuohy and O’Reilly 1992; Tuohy 1999).

The concept that is useful to this research is the idea that the 'interactive' state which works through policy communities seems to make space for the release of human agency by groups such as nonprofit charities as they perform their individual and collective roles and functions. Hence, the 'interactive' and changing welfare state either abdicates power or makes space for other groups to generate their own power and to participate in public policy processes in policy fields such as home care. Nevertheless, Haddow's (1999, p. 508) typology and the restraint logic as identified by Shields and Evans (1998) indicate that positive outcomes may not arise from the negotiations and interactions between actors.

When examining the recent changes associated with the welfare state, Aucoin (1995, p. 3) questions whether the normative task of mapping out the visions and philosophies that guide our public affairs and society is being undertaken. Although this is a challenging endeavour, he suggests that it be undertaken because it defines who we are as Canadians. Shields and Evans (1998), who do not believe the task is being addressed, and Rice and Prince (2000, Chapter 10) challenge government to open the debate, engage in the conflicts and the risks that come with their office, and "rebuild their social role and capacity" so as to "re-energize the politics of social policy (Ibid., p. 245) .

Of concern to this research is the manner in which recent state developments impact the nonprofit sector, especially charities working in home care. Minimally, recent developments suggest a framework that acknowledges how nonprofit charities perform 
their varied functions and generate their own power so as to effect policy change through their interactions with a modern, changing and powerful welfare state. This is my first justification for researching the advocacy roles of charities. Three additional points are explained in the following separate subsections.

\subsubsection{Nonprofit Theory}

\subsubsection{The Need for Positive Nonprofit Theory}

My second point reiterates that identified by others about the fundamental need for a 'positive theory' about nonprofit organizations, one which begins with the sector and explains its organizations and their operations as the primary objective. Salamon (1987), for example, observes that much nonprofit theory begins with a phenomenon or failure within other sectors, meaning market or government, rather than with the nonprofit sector. This means nonprofit organizations are explained as state failure (Weisbrod 1977, 1988), contract failure (Hansmann 1980), or market failure (Gassler 1986). When theory building on the nonprofit sector begins with either the private or government sectors, as in these instances, the nonprofit sector assumes a secondary place and our understanding of the sector is minimized. Nonprofit organizations simply become derivative agents which solve some kind of failure, rather than existing in their own right, performing their own specific purposes according to their own value to society.

For Lohmann (2001, pp. 198, 200), derivative theories of the nonprofit sector fail to acknowledge the rational choice for voluntary action and make invisible the human urge to create common goods. When addressing this issue, Salamon (1987, p. 39) recommends the consideration of government as the derivative institution; nonprofit 
organizations then become the first line of response to societal problems with government only responding to the failures of the nonprofit sector, namely philanthropic insufficiency, philanthropic particularism, and philanthropic amateurism. Nevertheless, he also acknowledges that this idea does not explain the necessary and important cooperation that occurs, and which is required, between the nonprofit and government sectors, particularly when public goods are delivered (see also Rekart 1993; Smith and Lipsky 1993). In addition to limiting our understanding about the roles and value of nonprofits in society, a derivative view of nonprofits working with the welfare state minimizes the mutuality of benefits that accrue between the sectors (Grønbjerg 2001, p. ix; Hall and Banting 2000, p. 1; Salamon and Anheier 1996, p. 2; Smith and Lipsky 1993, pp. 1, 5). Benefits flow in both directions.

\subsubsection{Nonprofit Theory and the Welfare State}

My third point is that much nonprofit theory focusses narrowly on the public services delivery role of its organizations under the welfare state. Grønbjerg (2001, p. 224), for example, examines the partnership role between nonprofit organizations and the state where the former execute public mandates. Rekart (1993, pp. 55-56, 77, 148), who also studies this role, identifies nonprofits as public agents. Young (2000, pp. 149-150) examines them according to their 'public-private partnership...' with government. Regardless of the contribution of empirical research, in this regard, their narrow focus on a services delivery role is problematic for several reasons.

Essentially, a partnership framework hides other realities that arise when nonprofit organizations work with government, such as tension, disagreement and power 
differentials. Frumkin (2002, pp. 74-77), who writes about these issues, raises several important points about the service delivery role of nonprofit organizations when organized through, seemingly, partnership arrangements. For him, well functioning partnerships require a balance of power between participants. This would suggest a balance between charities and government where the positive contributions of both partners can be realized. He also acknowledges the differences between the missions of nonprofit organizations and the goals of government (see also Douglas 1987, p. 46; Ott 2001, p. 49; Weisbrod 1977; Young 2001 b., p. 191) which lead to tension and disagreement between the sectors. These issues are problematic for nonprofit organizations because they result in overall loss of autonomy, mission-drift arising from a single activity focus, and increased requirements for bureaucratization, professionalism or accountability (see also Smith and Lipsky 1993; Weisbrod 1977, 1988). These types of problems would arise in any unequal partnership whether with government or the private sector. Thus, when partnerships define the work of nonprofits, it cannot be assumed they are frictionless or that they are ideal for society. Other realities generally arise and ought to be acknowledged.

\subsubsection{Nonprofit Advocacy}

My fourth point is that the narrow focus on the service delivery role of nonprofit organizations also makes invisible the other important roles performed by these agents such as advocacy, policy entrepreneur, or policy advocate as identified by Frumkin (2002), Gassler (1986), Salamon and Anheier (1996, p. 123) and Young (2000, p. 150). According to Young (2000, p. 155, "the advocacy role of nonprofit organizations in 
public policy ... [has] not been explicitly addressed in economic theories of nonprofit organizations." Although some authors account for this deficiency and others simply reference them, the roles are generally not considered in their totality.

Brooks (2002, p. 140) and Eisenberg (2000, pp. 326-327), for example, consider nonprofits as exerting a self-correcting force on good government for the public sector, ensuring that government is accountable and effective. Douglas (1987, p. 46), Frumkin (2002, Chapter 4), Ott (2001, p. 49) and Smith and Lipsky (1993), on the other hand, identify the dissemination of values by nonprofits which include fairness, equality and justice in society. For Lohmann (2001), values flow back and forth, among and between sectors. Collectively, individual actions represent an advocacy role which becomes relevant particularly when the boundaries between sectors are shifting and the state engages, increasingly, in 'negotiated' processes of restraint.

\subsubsection{State and Community Power}

My fifth point is that Taylor's 'interactive' state and its negotiated policy processes allows for, or makes space for the release of human agency (Taylor 2003, p. 110). This is possible despite the views put forward by some authors (Wharf 1992, p. 16, quoted by Rice and Prince 2000, p. 214) and despite the 'darker side' of community which may be "authoritarian, discriminatory, traditional, and conservative" (Ibid., p. 219). Human agency is a resource which nonprofit organizations have in full measure and which facilitates the generation of their own power, needed for policy change. Moreover, according to Stone (2002, pp. 376-383), at every boundary change there is the potential to redefine the problems, the arguments, the reasoning and so forth. 
Thus, wherever an opportunity for negotiation arises, human agency can be harnessed by nonprofit charities as they butt against the 'interactive' state which wields power through, for example, its discourse, its manipulation of the political system, its use of the media, and its use of science technology. Nonetheless, rather than viewing the release of power as a "zero-sum" game which is perpetuated in favour of the power holder(s), as proposed by Gramsci (1973), Bachrach and Baratz (1962) and Lukes (1986), Taylor $(2003$, pp. 89, 91, 92) builds upon the ideas of Clegg (1989) and argues that power can be generated by those who do not have power; it can be reshaped by new ideas and language. Its supply is not limited and can, therefore, be shared among societal groups. This suggests that within the 'interactive' state, power can be a 'positive-sum' game. This view of power means that societal groups, including nonprofit organizations, have both the incentive and potential to act. Indeed, history demonstrates that nonprofit organizations do act and release human ingenuity. Their human agency is evident in their civic and political engagement, when they deliver services, or undertake social entrepreneurship, and it is central to their identity (Frumkin 2002). Nevertheless, this aspect of the work of nonprofit organizations has largely remained hidden because the traditional structural view of power has left little space for its acknowledgement.

While it is legitimate to examine how nonprofit organizations release human agency through their varied functions and roles, it is important that this endeavour be a realistic one. By this I mean, given the state's exercise of power, the degree of change that may be achieved by nonprofits may be small or peripheral as compared to what can be accomplished by the state. As well, according to Taylor (2003, p. 108) who quotes D. 
Marsh and Rhodes 1992,

the degree of change that is possible will depend on the salience of the issue. If the issue is peripheral (or secondary, pace Sabatier 1988), there will be more room to manoeuvre. Nonetheless, even with more central issues, they suggest that the journey from intention to implementation is far from straightforward.

We are also reminded by Taylor (2003, p. 107) who references Sabatier (1988), that change which arises from advocacy coalitions are generally limited to secondary aspects of policy which relate to problem defining, identifying causal factors, and how to address specific problems, for example; "changes in core beliefs are rare". Thus, when using the definitions ${ }^{7}$ outlined in the Accord between the Government of Canada and the Voluntary Sector (VSI 2002) to argue that nonprofit organizations assume additional public policy functions, their degree of involvement and the degree of change which follows their efforts will depend upon the particular policy issue. If the issue is small and local, their efforts and the outcomes associated with their efforts, i.e., their overall influence, will reflect the scale and scope of the issue, and its location-geographic spread. Using the terminology of Taylor (2003, p. 117), they will have a spectrum of involvement on policy issues of varying saliency.

While the above explains why this research is important given the current dynamics in the modern welfare state and according to the importance of ongoing positive

"Public Policy: a set of inter-related decisions, taken by public authorities, concerning the selection of goals and the means of achieving them. Public Policy Dialogue interaction between governments and nongovernmental organizations (in this Code, the voluntary sector) at the various stages of the policy development process to encourage the exchange of knowledge and experience in order to have the best possible public policies. Public Policy Development: the complex and comprehensive process by which policy issues are identified, the public policy agenda is shaped, issues are researched, analyzed and assessed, policies are drafted and approved and, once implemented, their impact is assessed" (p. 3). 
theory building about the nonprofit sector, it doesn't explain why I focus on charities, a subset of nonprofit organizations. This is explained in the following.

\subsubsection{Why Nonprofit Charities?}

My explanation for narrowly focusing on nonprofit charities relates to law and to nonprofit theory. First, according to a practice which dates back in history to the 1601 Statute of Charitable Uses (Douglas 1987, p. 43; Webb 2000, p. 123) and English common law (Salamon 2001 a., p. 25), Canadian law sets charities apart from other organizations in the nonprofit sector. While all nonprofit organizations are exempt from federal taxes, only charities have the right to issue charitable donation receipts for tax purposes (Agency 2006). However, in return for this entitlement, charities must disburse 80 percent of such donations to charitable purposes such as poverty relief, educational or religious advancement, or some other purpose which benefits the community and which may be regarded as charitable (Agency 2003; McCamus 1996).

Charities become, therefore, the nonprofit organizations which deliver services under Canada's welfare state through tax expenditures and income redistribution (Phillips and Graham 2000; Rekart 1993; Thayer Scott 2001). As well, according to Salamon (2001 a., p. 25), they are the organizations that first come to mind when the public thinks about the nonprofit sector. Salamon (Ibid., p. 25) links the justification for both their legal constraints and their right to issue tax receipts with the fact that charities are "serving purposes that are public in character and that government might otherwise have to support through tax revenues." Yet, according to Carson (2002, p. 25), they are misunderstood even by government when it narrowly focuses on this subset of nonprofit 
organizations whether through laws or in terms of their varied functions. Whether or not government is supporting charities through direct $\operatorname{taxes}^{8}$ or not misses the point that the legal reasoning which underscores these laws simply reinforces a narrow functionalinstrumental view of charities. Nascent theory (Frumkin 2002; Gassler 1986) and empirical research, on the other hand, suggest that charities undertake a variety of roles.

Second, when wrestling with the types of nonprofit organizations under theory building exercises (Douglas 1987, pp. 51-53; Frumkin 2001, pp. 8-10; Hansmann 1980, pp. 840-841; Salamon 2001, pp. 23-25), several fundamentally different types of nonprofit organizations arise. Three types or subsets of nonprofit organizations which are generally common to the above include: public serving, member serving and voluntary associations. The common elements for all nonprofit organizations are the nondistribution constraint (Hansmann 1980; Weisbrod 1977), the lack of coercion in regards to societal participation, and the fact that ownership and lines of accountability are unclear (Frumkin 2002; Gassler 1986; Hansmann 1980; Weisbrod 1977). The subsets generally map out according to the primary target group, meaning the primary beneficiaries, of any particular type of nonprofit organization. As well, subsets differ in terms of their financial independence and solvency and in their relations with the welfare state.

Despite the differences, Frumkin (2001, p. 94) makes the important point that the public's demand for the outputs of the nonprofit sector "is not limited to areas where from direct taxation, the support arises from foregone tax revenues for which government has a right. Foregone tax revenues constitute government support. 
social injustice may persist. In fact, the productive capacity of the nonprofit and voluntary sector is focused on a very broad range of needs or wants", which means the public requires a variety or types of nonprofits. He also claims that the individual subsets of organizations are key sources of the strength of the sector and are an important factor of the sector's popularity and support (Ibid.).

My purpose in highlighting the policy roles of charities is not to diminish the functions, products or outcomes of either member serving nonprofits or voluntary associations. Rather, my purpose is to heighten awareness of the specific manner in which nonprofit charities interact with the welfare state and to examine more carefully their own roles and interactions with it, hence their particular contributions. This means explaining the key role that nonprofit charities have with the welfare state, which is itself changing and, in the process of doing so, blurring the boundaries between sectors. It also requires consideration of the laws which set charities apart from other nonprofit organizations according to specific goals for society. Finally, improving our understanding about a subset of nonprofit organizations is legitimate, in and of itself, and moves forward the broad goal to continue developing a 'positive theory' about the nonprofit sector. All of the above explain why charities are the main focus of my work.

My specific goal is to make visible the varied roles performed by nonprofit charities: advocacy, problem solving, societal stability and democratization, and working collaboratively with donors, government, other agencies within the community, staff, and volunteers which are additional to service provision. While this set of functions is not necessarily acknowledged by all theorists, per se, Douglas (1987), Rekart (1993), 
Salamon and Anheier (1996), and Young (2000) acknowledge at least one or more additional roles, while Frumkin (2002) and Gassler (1986) acknowledge a broader set of roles. One only has to consider the missions of these organizations to understand how charitable nonprofits are compelled to do more than simply provide home care services, at the fringe of medicare.

Referring back to my second proposition, I suggest that the full set of roles are clearly evident in the interactions between charities and clients, the broader public, government and other nonprofit charities. While the proposition mainly reflects an empirical-descriptive explanation of the functions of nonprofit charities, a normative explanation and interpretation also applies. Frumkin (2002, pp. 176-178) claims that the manifestation of any of the roles/functions of nonprofit organizations has normative value because public and societal benefits accrue to service users and the broader public from them (see also Rice and Prince, pp. 208-211). As well, positive outcomes can be measured, hence their value to society can be ascertained. These points apply here. All of the above relate to my third proposition that the roles of nonprofit charities ought to be considered in a balanced manner, according to a holistic understanding of these organizations. Each function is an integral aspect of the identity and full contributions of nonprofit charities. Minimally, to ignore one or more functions is synonymous with diminishing the identity of nonprofit charities. Frumkin (2002) also acknowledges this issue. He highlights (2002, p. 178) some of the problems that arise when the roles of nonprofit organizations become unbalanced, or when only one function is highlighted. They lose legitimacy and support, over the long term. Thus, taking this 
idea to its logical conclusion I suggest that if, when developing home care policy, for example, government fails to take into account the other functions performed by nonprofit charities because, for example, it predominantly engages with these organizations under their service delivery role, government's policies risk contradicting or eliminating the other functions performed by these organizations. As a result, charitable nonprofits could close, clients could be disadvantaged, and policy makers and communities could suffer. The overall risk is that more than services are lost when the purpose and/or mission of these agencies are altered or if agencies simply close down.

Having explained my research questions and research propositions I devote the next section to the details of the various functions performed by charitable nonprofits in home care. Since human agency is the foundation upon which their functions or roles are activated, the framework is both structural-instrumental and dialectic-discursive. The former refers to my objective to build upon the development of a more positive theory about the roles of nonprofit organizations in the public policy process, while the latter refers to the importance of their agency when they do so. The dialectic-discursive aspect of this research builds upon the ideas developed by Taylor that power can be generated, hence used by nonprofit charities when they shape public policy. In this manner, I attempt to present a more holistic understanding of nonprofit charities.

\subsection{The Research Framework}

Given my objective to examine charitable nonprofits through a wider perspective, my research framework has several starting points. Gassler (1986) and Frumkin (2002) are two of my starting points to explain what nonprofits do according to the positive 
theorizing recommended by Lohmann (2001). A third starting point identifies how the Canadian state interacts with societal groups. I combine Taylor's (2003, p. 110) 'interactive' state, which makes space for other societal groups to inform and shape government policies according to their human agency and through negotiation and collaboration, with Haddow's (1999) policy communities which work with government to shape Canadian public policy. This literature allows me to incorporate the idea that the Canadian state wields its own power as it works with policy communities, e.g., charities working in home care. These ideas, when combined, enable me to ascertain the scope or reach of the policy work of nonprofit charities in home care.

Since I examine how charitable nonprofits shape public policy, a third starting point refers to the public policy making steps and/or processes. For this, I mainly reference Doern and Phidd (1992), but I limit my articulation to three steps: defining problems, promoting solutions and implementing solutions (see also footnote 7; Pal 1987). Furthermore, Taylor's point (2003, pp. 106-108) about the messiness of policy making is well taken. For her, policy making is more than a technical-managerial process which is based on objective facts, devoid of value (she references Sabatier 1988 and D. Marsh and Rhodes, 1992; see also Stone 2002). Thus, policy making is a complex process involving conflict, negotiation and exchanges. There may by several points of engagement which do not necessarily conform to the neat articulation of ordered steps. Groups may be effective change agents only when and if they own power and can determine the policy agenda (Atkinson and Coleman 1996; Haddow 1999; Stone 2002; Taylor 2003). 
While these approaches to the Canadian state and its policy-making processes are valid, they predominantly lead to structured-instrumental explanations. They do not allow me to explain why or how nonprofit charities generate power for themselves through their interactions with other interests when participating in policy-making process. Clement's (1997, p. 4, 6) identification of human agency and Pal's (1987, p. 227) multidimensional state with its flexible agencies, agents and bureaucrats suggest that groups may generate their own power and that space may be available for them to do so according to their own goals and resources (see also Melucci 1985, p. 792). Their ideas are expanded predominantly by the work of Taylor (2003, Chapter 6) who outlines not only the possibility for the generation of power within communities, but also why and how this it can be achieved. This becomes my fifth starting point in framework development. I now introduce the roles that charitable nonprofits perform.

Gassler $(1986 ; 2003)$ introduces the market and the assumptions of the economic neoclassical model to tease out five economic functions performed by 'nonprofit enterprise'; by enterprise, he refers to any non-market organization. He calls the functions environmental, systemic, allocative, redistributive and stabilization (Gassler 1986, Chapter V). For example, the environment is one of the assumptions of neoclassical model which states that individuals' tastes, technology and resource endowments are fixed, or givens. Gassler (1986, Chapter V) turns this assumption into a role for nonprofit organizations; nonprofits undertake an environmental function by socializing society's tastes for goods and services, by doing research and introducing new technology, and by changing individual endowments. This role is performed prior to any 
market involvement. Another assumption of neoclassical economics is that the issue of property rights have been addressed, meaning contracts will be honored and that information about the quality and costs of market goods are widely available. Gassler converts this assumption into a systemic function performed by nonprofits and links it to the nondistribution constraint which characterizes them. Hence, nonprofit organizations are accorded values, e.g., trustworthiness, which grant them status to protect or promote conditions needed for ownership. As well, they may reliably engage in decisions about what becomes a public or private good, or socialize society, or provide trustworthy information; they are 'trustworthy' contracting partners.

Gassler's three remaining functions arise from Musgrave's (1959) theory on public finance, which outlines how through political and economic processes the state's allocation decisions arise. Thus, nonprofits provide public goods or services according to the state's allocative decisions and they encourage the development of public goods (he refers to them as merit goods). They redistribute resources through in cash or in kind contributions, e.g., donations and volunteers, and they promote societal stability in regards to labour (Gassler 1986, pp. 13-17, Chapter V; see also 2003). Gassler's fïrst two functions establish conditions for market success while this second group corrects for market failures. Gassler's functions represent both a 'positive' approach to theory in that they articulate clear roles for the sector and a derivative approach because the roles largely map out according to the needs of the market.

Frumkin (2002, p. 24), who also explains the roles performed by nonprofit organizations, identifies four types: delivering services, encouraging civic and political 
engagement, enacting private values and religious convictions, and providing a channel for social entrepreneurship. Two dimensions underscore his model, demand and supply: nonprofits are driven by the both the demands of citizens and society, and by the resources and ideas that are supplied to or flow into the nonprofit sector, e.g., a supply of ideas. He refers to the latter as a supply-side position which acknowledges the "resource and ideas that come from social entrepreneurs, donors and volunteers" (Ibid., p. 21). He writes (Ibid.), "The idea of a demand-driven nonprofit and voluntary sector dominates much of the research that is conducted in this field. Yet a central claim of this book is that the demand-side approach captures but one aspect of this broad phenomenon." While he considers the supply-side of his model somewhat controversial, it is important because it acknowledges the role of human agency in propelling much of the work of nonprofits, which may not always be altruistic.

Three controversial elements of the ideas of Gassler and Frumkin ought to be addressed. Gassler's static model is primarily a heterodox use of economic theory which outlines the functional-economic activities of nonprofits. It is silent about the role and/or importance and occurrence of human agency to these functions; we are left to infer that human agency exists for Gassler's (1986, pp. 51-53, 62) nonprofits when they "pursue goals related to the reduction of free-rider problems" and when they produce services or output in line with their 'unselfish' motives. For him, nonprofit organizations also operate outside of a public policy context with its power games and contests, another limitation. While Frumkin's (2002, pp. 20-22) model, on the other hand, is both positivedescriptive and normative, its normative dimensions are controversial because they make 
"strong claims about how nonprofit organizations should be managed and operated". Unlike Gassler who is silent about human agency, human agency is visible in Frumkin's model, particularly in the functions which are more firmly based upon the expressive rationale of these organizations, meaning how nonprofits motivate people (2002, pp. 25 , 103). Thus, human agency is visible when nonprofits mobilize citizens with respect to the political process and it is associated with the application of values to motivational activities. Although he doesn't specifically make this point, human agency would also be the basis for the entrepreneurship function whereby nonprofits generate new activities and services for the public; possibly some nonprofits may be moving away from their traditional, altruistic approach to society. What is useful to me, in spite of the controversial aspects of the two models, is that both Gassler and Frumkin map out clear and distinct roles for nonprofits which suggest that they are more than service providing organizations. As well, the idea of human agency which arises from both models, although one does so more directly, is also useful to my framework.

While human agency is innate to the identity of nonprofits and supports their various functions, their ability to activate it also arises because of the 'interactive' state. Human agency is fundamentally important to all roles performed by nonprofits regardless of whether they supplement state decisions and actions, or whether they challenge the policies of government. Altogether, these ideas provide a basis for me to begin mapping out the framework according to a broad set of functions performed by nonprofit organizations in accordance with their human agency, or in the words of Frumkin (2002, p. 25), according to their 'expressive rationale'. 
Using the ideas of Frumkin and Gassler, I list five functions or roles performed by charitable nonprofits which include: environmental scanning (an entrepreneurial role), promoting values in society, providing services, redistributing resources and promoting societal stability. While these correspond more closely to Gassler's set of functions, they also incorporate all of the roles identified by Frumkin. The environmental scanning function corresponds to the environmental role as outlined by Gassler and to Frumkin's entrepreneurial function. The idea I borrow from both authors relates to its timing: it arises prior to the involvement of either government and/or the market. As well, I consider its performance as being separate from government and/or market; it is not linked with a failure within one or the other sector. Rather, I liken it to Salamon's notion $(1987 ; 2003)$ which simply states that nonprofits are the first responders to the needs of citizens in society.

The promoting values in society function which is delineated in my framework corresponds to Gassler's systemic function and Frumkin's function whereby nonprofits enact private values and religious convictions. I also relate it to Frumkin's idea that nonprofit organizations encourage civic and political engagement, and to his social entrepreneurship role where nonprofits provide services supplementary to those of the welfare state; such engagement requires strong values and convictions. Underscoring this role is the nondistribution constraint of nonprofit organizations which is embedded in theory and law; the constraint may provide some comfort to donors that their donations will be used for the purposes articulated by the agency. Although it may not always apply, the fact that charities do not earn profits suggests that they may be more 
trustworthy agents when providing services on behalf of the welfare state, when recommending and proposing new ideas within the public domain, and as appropriate conduits for the communication of societal values. Given the pervasiveness of nonprofit theory to focus on the service provision role of nonprofit organizations, it does not require further elaboration.

Both Gassler and Frumkin explain how nonprofits redistribute resources in society (e.g., donor funding, allocating government funds through services, and through volunteers), but Frumkin doesn't specifically identify this as a separate function. For him, it mainly arises through his social entrepreneurship role when donors work to satisfy both commercial and charitable goals in an entrepreneurial fashion. Since the contributions of donors and volunteers which are filtered through the activities of nonprofits are sufficiently important, they are acknowledged here as the function, redistributing resources. This role may also be linked to the service providing role of charities where they provide services on behalf of the welfare state and on behalf of donors in a manner that supplements government's allocations.

Finally, while Frumkin doesn't set apart a role whereby nonprofits promote societal stability, as does Gassler, it is suggested in his role where nonprofits 'encourage civic and political engagement'; nonprofits mobilize citizens to advocate for causes and build social capital within communities. It is a somewhat stabilizing effect simply because nonprofits provide a venue or opportunity for the articulation, expression and activation of individual and societal agency. I therefore acknowledge this role-function for charities as a democratizing, cum stabilizing role in regards to society. As well, it 
relates to the manner in which nonprofits stabilize society through paid and unpaid labour. Altogether the above delineates five distinct roles-environmental scanning, promoting values in society, providing services, redistributing resources and promoting societal stability and democracy.

Although the five roles are described as separate and individual, I do not think charities activate each one equally explicitly. Some would be more explicitly visible while others would latent and/or implied. Determining whether a function is explicit or latent would be decided according to the manner in which charities express their tasks, meaning how they define goals and objectives, implementation strategies, monitoring and evaluation frameworks, and so forth, in relation to each role. In this regard, providing services, and environmental scanning would be explicit roles performed by nonprofit charities because they could be operationalized using clear terminology. Promoting values, or redistributing resources and promoting societal stability and democracy, on the other hand, may be considered as latent or implied roles because although they are performed in accordance with the identity and missions of charities, it is difficult to objectively measure them as goals, objectives and outcomes. Charities may not, therefore, specifically acknowledge and or express them as roles which are distinct from providing services, or solving unmet needs in an environmental scanning role. All the same, it is important to acknowledge them as separate roles because, fundamentally, nonprofit charities provide services and do environmental scanning because these roles are rooted in societal values, because they are linked to the redistribution of societal resources, and because they provide individuals with the opportunities to enforce societal 
stability and democracy. They are therefore expressed, here, as distinct roles.

Frumkin (2003, pp. 52, 53) also makes the important point that nonprofit organizations do advocacy, but he mainly links advocacy to the functions of civic and political engagement and enacting private values and religious convictions. For him, nonprofits do advocacy when they identify problems, when they open up new positions and policy alternatives and when they influence local priorities. Gassler, on the other hand, doesn't specifically address the idea of advocacy. I consider advocacy to be central to each of the different roles performed by nonprofit charities for the following reasons. It is fundamental to the mission statements of many nonprofit charities and is a manifestation of the human agency of organizations that undertake public benefitting work. It arises from the values they promote. It is central to their identity. Nonetheless, two questions arise, 'How do they do advocacy?' and 'Under what conditions to they do advocacy?'.

Frumkin (2003, pp. 52-53) provides us with some ideas on the advocacy work of nonprofit organizations in a manner which accords with public policy processes and individual tasks. These include identifying problems which are neglected by the public and the media, developing positions or policy alternatives about issues that have been neglected, and by influencing priorities at either the local level or more broadly through a filtering up effect. According to his theory of leverage, the advocacy tasks performed by nonprofits "takes a small number of resources and tries to multiply their impact by changing public priorities" in a manner that is greater than "converting nonprofit

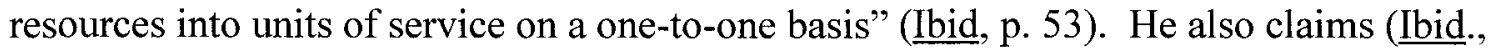


p. 54) that some nonprofits actually lobby, although according to law, charities risk losing their charitable status depending upon the amount of lobbying they undertake.

Taylor (2003) provides a comprehensive discussion of advocacy that is useful to this research. For her, advocacy takes place throughout communities and through the activities of individuals and organizations within community. It goes hand in hand with the idea that power can be generated; one advocates because one believes that successful outcomes may arise. As well, power arises from the control of uncertainty, through the ownership of assets, and it is embedded in ideas and language. Each of these can be manipulated, e.g., by charities, meaning power can be reshaped. These ideas provide a strong rationale for the expansive and expressive sense of human agency which is released through and underscores all the roles of charitable nonprofits. They suggest that policies can be changed and that individuals, communities and nonprofits can have more meaningful partnerships with the state aside from and/or in addition to services. All of the above suggest that charitable nonprofits have many opportunities to generate their own power and to participate fully in public policy processes with the state.

Taylor also identifies ways in which charitable nonprofits can generate their own power so as to do advocacy. Power generating strategies include "negotiating and learning to manipulate the 'rules of the game', packaging local knowledge in such a way that it becomes a material asset-technical advice, expertise, or information--which can be traded, creating alliances which can increase the influence of outsiders with respect to more powerful players, "learning - recognising, discovering and acquiring skills, finding out how to do things, acknowledging and sharing knowledge, developing awareness", and 
“organising - mobilising energies and knowledge, engaging people, building networks and organisations, taking action" (2003, pp. 104, 134, 140). An important additional step is to collaborate through informal and formal networks, in the manner suggested by Hannah Arendt (1958), as quoted by Taylor (2003, p. 147). Thus, charitable nonprofits can generate power by using their human agency or initiative, through any or all of the above. This means they can exercise their leadership in home care. Moreover, the 'interactive' state opens up windows of opportunity for charitable nonprofits to inform decision-making and/or to make decisions (2003, pp. 119-120). As well, they can work to reduce the imbalance of power which is embedded within state institutional structures by collaborating on

how meetings are run, how bids for funding are appraised and funding dispersed, how needs and priorities are defined, how agendas are defined and structured, and so on. These mechanisms make assumptions visible and offer ways of overcoming the tendency of government partners (in particular) both to automatically assume (or select) the chair in partnerships and participation initiatives and to privilege the views of their own constituency (Taylor 2003, pp. 201-2).

Taylor (2003, p. 208) also suggests that, ideally, such processes would work at many levels. When performed along horizontal lines, they are particularly useful to the following: stimulating knowledge exchanges between and across boundaries; securing and maintaining allies across boundaries; "build [ing] on assets rather than on focusing on needs"; and encouraging joint learning. Lastly, for Taylor (2003, p. 213), the approach must be dynamic so that the rules and practices associated with power generating arrive from negotiation and collaborative action, rather than from a reliance "on 'formal legal and procedural rules embedded in established organisations'." 
I use these ideas to suggest that charitable nonprofits do advocacy when they undertake each of their various functions, and when they do so at each stage of the public policy process. This means that the expressive rationale of nonprofits, as proposed by Frumkin, is more expansive than he suggests. It underscores all aspects of their work and their identity.

The various roles that I have mapped out for nonprofit charities are presented in Table 3.1: The Advocacy Constituted Roles of Charitable Nonprofits. The five roles are listed, vertically, on the left side of the table. I have listed only three public policy processes horizontally across the top; other stages are identified in footnote seven. Corresponding to the different functions and policy processes are suggested activities that are performed by charitable nonprofits. They represent the ways in which charitable nonprofits may generate their own power so that they can do advocacy on home care. The lines separating the functions, policy processes and activities are broken to signify the messiness of reality. While I identify each one as a separate entity, with/in its own box, I do not wish to suggest that they occur in a rational and linear manner. I subscribe more to the messy and complex view of the policy process. Finally, the roles, policy processes and corresponding activities all 'seemingly' float on a grey background which represents the release of human initiative and agency. Rather than calling it the expressive rationale of nonprofits, I simply refer to human initiative or human agency as advocacy, and I identify three types of advocacy: individual, organizational and public. Charitable nonprofits do individual advocacy on behalf of individuals who need specific services. 


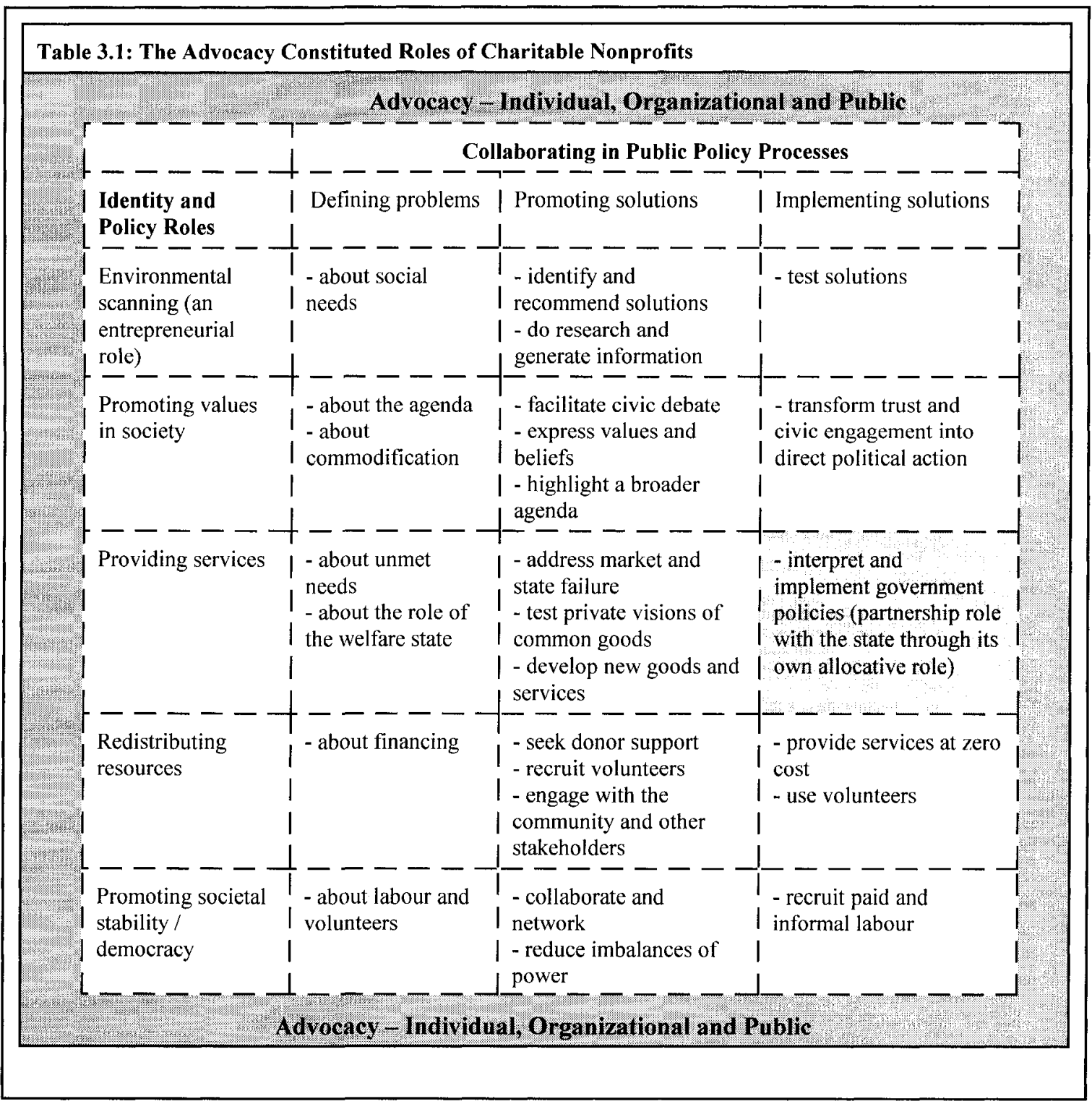

They do organizational advocacy on behalf of other agencies, meaning building

collaborative networks which support the work of individual agencies and of the network.

Finally, public advocacy arises from the sum of individual and organizational advocacy.

Public advocacy is built one 'individual and organizational advocacy' step at a time and becomes a form of broad-based societal advocacy which possibly reaches out to national audiences. 
The last point I wish to make concerning the table pertains to the highlighted rectangular grey area which is at the opposite end, but on the same line with providing services. This grey area corresponds to the 'partnership' role between nonprofits and the state. Partnership terminology is often used by government to denote the service delivery function of nonprofit organizations under the welfare state. The remaining functions and activities are left in a white background. I have done this because I wish to suggest three points in relation to Taylor's idea that a true partnership requires the equal distribution of power. My first suggestion is that charitable nonprofits partner more with their community, i.e., clients, donors, other nonprofits, and the general public in all roles than they do with government through their service delivery role. The strength of this partnering with community is suggested by the white boxes and the general idea is that this partnership between charities and community operates on a more equal basis to address societal problems. This doesn't mean that unequal power relations might not sometime arise, but rather that the starting position is one of equality. Second, when the 'interactive' state imposes policies on charitable nonprofits in regards to its 'partnership' with these agencies, automatically the partnership ceases; the very act of 'imposing a policy' establishes a zero-sum game which undermines a true partnership. My third point is that the charitable nonprofit-community-partnership becomes more valid, true and more important than (a normative view) that which 'exists' when they provide services on an unequal basis on behalf of the welfare state. The grey-white colour scheme highlights the difference in scale with respect to where the true partnership exists for charitable nonprofits, meaning with the community, or with the state, or with both. It also 
highlights what can be lost if the 'partnership' with the state fails and/or charitable nonprofits cease to exist. I now make a few suggestions on how this framework applies in the context of home care.

\subsection{The Roles of Charitable Nonprofits in a Home Care Context}

In the previous chapter, I demonstrate how Canadian federal and provincial governments have had and continue to have their own goals, motives and agendas on and about home care in the manner suggested by Bachrach and Baratz (1962) and Lukes (1986). This section is a simple outline to describe how charitable nonprofits may generate their own power so as to participate as full members of the home care policy community.

Since charitable nonprofits are close to the needs of citizens, their environmental scanning role exists as a first 'public' response to social-health needs at the local level in the manner suggested by Salamon $(1987 ; 2003)$. They define new and emerging problems. They identify and recommend solutions about home care needs. They may do research and generate new information about these problems. Furthermore, they may test solutions by collaborating with other agencies and partners, e.g., applied research with academics, or volunteers. In this manner, it is an entrepreneurial function.

Often, when charitable nonprofits collaborate they promote values in society about the importance of collective action, ethics and trust in partncrships which may pertain to caregiver-client relationships and/or in social-economic transactions. While promoting values they also introduce a diversity of views and practices into the agenda shaping process. For home care, they may express the importance of debating about privatization 
related to the commodification of health and home care services. Nonetheless, in order to generate power, they do not promote values in isolation. Rather, they relate the values promoting role, which underscore their identity, to other roles like environmental scanning. Charities promote solutions by facilitating civic debate and, in doing so, highlight an agenda which is larger than what appears at the local level. Their identity and their values facilitate the transformation of trust, civic duty and engagement into political action (Frumkin 2002). As well, because of this role, the transaction costs ${ }^{9}$ associated with the work of charitable nonprofits may also be lower (Frank and Salkever 1994; Salamon 1987, p. 39). Charitable nonprofits become trustworthy providers of choice for complex goods because, in the words of Young (2001 a, p. 196), their "essential currency ... is trust". Their trustworthiness is related to the nondistribution constraint (Hansmann 1980 pp. 844-845, 1987 p. 41) and is an important signal to purchasers, government or other third parties, about quality of care issues in regards to vulnerable populations (Frank and Salkever 1994, p. 129; Smith and Lipsky 1993; Weisbrod 1988, pp. 59-60, 84; Young 2001a., p. 194). It is important to acknowledge, however, that while they may appear trustworthy, one very possible outcome of the competition between agencies - nonprofit charities with other charities and/or with forprofit companies - is that charities may become more and more business-oriented in their day-to-day work and practices. This risk has been identified by a number of nonprofit theoreticians (Frumkin 2002; Hossli 2000; Smith and Lipsky1993). As well,

9

Home care is a complex good, characterized by information asymmetry, which makes determining quality difficult for purchasers; purchasing services from trustworthy partners becomes all the more important. 
trustworthiness does not preclude the 'darker side' (Rice and Prince 2000) of the nonprofit sector which is described by Salamon (1987) as being related to philanthropic insufficiency, philanthropic particularism, philanthropic paternalism and philanthropic amateurism.

The trustworthiness of charitable nonprofits constitutes an efficiency gain in the form of a prevented efficiency loss-citizens are prevented from accessing "second-best" home care, a form of contract failure that arises from asymmetric information (Hansmann 1980 , pp. $844-845,1987$, p. 40 ). Other potential savings arise because charitable nonprofits use volunteers and they offer lower salaries and fringe benefits to their administrators (Douglas 1987, p. 50; Weisbrod 1988, p. 31). All these factors lend credibility to their work and their products whether as information, research, policy analysis, capacity building efforts, educational campaigns, services. All facilitate the promotion of direct action (Hudson 2002, p. 407; Salamon 2001, p. 25).

When charitable nonprofits provide services according to government's allocative funding decision (Musgrave 1959, Chapter 1), in regards to home care, both sets of actors enter into a 'partnership' arrangement (Douglas 1987; Gassler 1986, pp. 26-30; Hansmann 1980, 1987; Ott 2001; Te'eni and Young 2001; Weisbrod 1977) which may benefit both parties. Grønbjerg (2001) characterizes it as a reciprocal arrangement; government contracts with charitable nonprofits to provide home care services according to the needs of the median voter; charitable nonprofits gain access to revenue. For charities, reciprocal arrangements may lead to their dependence on and being controlled by government. Nonetheless, other benefits may arise such as the exchange of legitimacy, 
knowledge and influence between the two sectors (Grønbjerg 2001, p. 224). In addition, partnership provides additional opportunities for charitable nonprofits to advocate about other aspects of home care. Charitable nonprofits may educate government about unmet needs, or about a wider agenda on home care; solutions about problems that have been identified through their environmental scanning function may be presented. Charitable nonprofits may prod government to change its policies on home care so as to become more accountable to the public (Eisenberg 2000, pp. 326-327), an issue which is compromised when contractual arrangements arise for services delivery. Minimally, government would be encouraged to be more transparent about its objectives and policies on home care.

Regardless that the opportunities for additional advocacy may arise from their service providing role, charitable nonprofits are constrained by law and the rules of Canada Revenue which restrict their advocacy role (see Chapter 1). The law and its applicable regulations are imposed upon charitable nonprofits to influence their behaviour (Smith and Lipsky 1993, pp. 146, 172; see also Frumkin 2002, p. 75; Rekart 1993; Young 2000 , p. 151). Another example of the regulatory approach used by government to constrain charitable nonprofits is the "Code of Good Practice on Policy Dialogue", signed in 2001 (VSI 2002). As a result, government has the dominant role and the 'partnership' relationship with charitable nonprofits becomes distorted and unequal.

An additional form of regulation which is imposed upon charitable nonprofits by government pertains to the competitive arrangement in home care; charitable nonprofits and for-profit firms competing together for service contracts. Not only does this 
arrangement signify unequal power between charitable nonprofits and government, but it also places the former in unequal power arrangements with for-profit firms and it may be detrimental to the collaborative relationship between charities. While Frumkin (2002, pp. 78-79) identifies five competitive disadvantages that arise for nonprofits when they are placed in competitive relationships with "profitmaking business firms", it is his fourth point which has some resonance, charities are less able to raise large sums of money as compared to for-profit firms. For Frumkin (2002), nonprofits also lack management expertise. I would characterize this as lacking the language of business; lacking a specific language is different from lacking management expertise. Finally, while he suggests nonprofits cannot lobby, while for-profit firms can (Ibid.). Smith and Lipsky (1993) and Steinberg (2003) balance Frumkin's observations with the counter point that nonprofits may provide efficiencies which for-profit companies cannot and which may reduce overhead and transaction costs. Labour donations in relation to more minimalist benefit packages is one example where overhead costs may be lowered.

While the goals of charitable nonprofits and government may appear similar (Grønbjerg 2001, p. 225), it is important to acknowledge how they may differ according to the vantage point taken by the respective sectors. This allows for the identification of different agendas and solutions to home care issues. It is logical to assume that charitable nonprofits would recommend solutions which government, constrained by the categorical constraint, for example, cannot condone (Young 2001b, p. 190). On the other hand, when unsatisfied citizens cannot access services because service allocations accord with the needs of the median voter, charitable nonprofits may do individual, organizational or 
public advocacy (Berger and Neuhaus 2001, p. 241) because of their partnership with the community, wherein their real power arises. Thus, regardless of the potential two-way flow of benefits that seemingly arise from the 'partnership' arrangement between nonprofit charities and government, any number of words may describe the relationship between charitable nonprofits and government. It may be complementary (Salamon 1987), cooperative (Grønbjerg 2001, p. 225), collaborative (Brown and Kalegaonkar 2002, p. 231; Hossli 2000, p. 37), direct or, adversarial (Young 2000). It may also represent a range of power for charities which may vary between having power and having none, meaning being nonparticipants (Arnstein 1969).

Because charitable nonprofits have a stronger partnership through their connection with community, they are able to redistribute additional societal resources. Fundamental to this role is their collaboration with donors who finance additional services and support their advocacy, and their use of volunteers. Taylor (2003, p. 118) quotes Jackson (2001) to identify the importance of collaboration to the generation of power which, then, becomes transformed into shared decision-making. This idea suggests that community is the source of power used by charitable nonprofits to redistribute societal resources, to supplement government's allocations, provide additional services whether on sliding fee scales or at zero cost. It explains why partnership with community is important.

Finally, charities promote societal and democratic stability through their home care work, but not by enforcing price stability or through some other macro-economic function (Musgrave 1959, Chapter 1). Rather, they do so by employing paid and volunteer labour and by addressing labour issues such as wages, training and working 
conditions, particularly from a gendered perspective. Societal stabilization also becomes a democratization role (Eisenberg 2000; Gassler 1986, p. 31; Rekart 1993); they promote diversity, pluralism, social values (Douglas 1987, p. 45, 2001; Ott 2001, pp. 47-48), and they provide outlets for the expression of voluntary action through all roles and activities (Frumkin 2002, p. 23).

\subsection{Chapter Summary}

This chapter uses four broad theory groups - nonprofit, state and policycommunity, community power, and public policy processes - and argues that charities, a subset of organizations of the nonprofit sector, actively perform a variety of public policy roles which are additional to service provision, but that governments' policies have a constraining effect on them. While the individual roles are introduced and presented as distinct functions which include environmental scanning (an entrepreneurial role), promoting values in society, providing services, redistributing resources and promoting societal stability, they overlap and do not operate in a linear and rational manner.

Current literature on the state highlights recent changes to the welfare state which seemingly make it a non-hierarchical and negotiating state. As a result, boundaries between sectors seem to be blurring. Taylor calls this the 'interactive' state. While this state may appear more benign, theory suggests it is perhaps as powerful as ever; its new arrangements distort services' delivery traditionally provided by the welfare state, hence its benefits to citizens (see Rice and Prince 2000). Citizens and advocates will need to generate their own power if the distortions of the welfare state are to be minimized. Organizations like charities will be required to take on more and more advocacy work. 
For this reason, alone, advocacy becomes the first and foremost role undertaken by nonprofit charities. Its importance is such that it is and/or becomes fundamental to all operations and roles. The 'distinct' roles are called advocacy-constituted policy roles because advocacy underscores each one under the goal of shaping policy. The next chapter explains the methodology used to generate data on the roles of nonprofit charities. 


\section{CHAPTER 4 - RESEARCH DESIGN AND METHODOLOGY}

\subsection{Introduction}

This chapter introduces the research methodology through which the advocacyconstituted roles of nonprofit charities in the communities of Ottawa, Ontario and Edmonton, Alberta are explored. The broad research objective is to explain more positively how these agencies release human agency, make choices and perform acts that will change public policy on home care. Nonprofit theory has been challenged by its inability to fully reflect the varied roles of nonprofit charities, particularly, in relation to the constraints imposed upon them by government. It also accords to the roles of nonprofit organizations a secondary or derivative importance with respect to state and/or market theory. Often, examinations of policy change begin with the state, its structures and power. These two issues generally mean that the advocacy-constituted work of nonprofit charities in policy change becomes invisible and/or less understood.

Rather than taking a conventional approach to policy change processes, I explore how these seemingly powerless agencies use a variety of tools such as ideas and language, knowledge about clients, networking and collaboration with other agencies to generate power and to shape home care policy. The ideas about the manner in which charities may generate their power, i.e., discursive, are mainly borrowed from Taylor (2003, p. 91) and are applied to these community agencies. Thus, by considering the varied roles and activities of nonprofit charities, in a positive-theory building sense, we can understand how they shape policy and do so in significant ways, notwithstanding the powerful structures that constrain them. 
The first part of the chapter introduces the methodology-qualitative and case study-and links it to the theoretical framework which highlights the advocacy work performed by charitable nonprofits. Data are generated about the tools which are identified by Taylor (2003) as being used by communities in generating power. These include sharing ideas and skills, being in close association with vulnerable people, developing new knowledge and discourse, recruiting committed staff, volunteers and boards, and so forth. Data explain how charities are compelled and mobilized to act on behalf of vulnerable people, other agencies and the public through, for example, trades, negotiations and building new home care agendas. The methodology, data generation and analysis mainly conform to a conversational or discursive approach. This is to reflect the predominantly discursive approach assumed by charities in their advocacy-constituted roles, when they generate their own power. Data which provide contextual information with respect to the two cases is generated from documentary sources. The latter generally informs about the structures which constrain the advocacy-constituted roles of these organizations. Hence, the research design is both discursive and structural, and mirrors the theoretical framework. Nonetheless, a heavier emphasis is placed on the discursive. The second section in this chapter introduces the research participants and the ethics approval process. This is succeeded by a section which explains data analysis, data display, and the issues of reliability and generalizability.

\subsection{Case Study and Qualitative Method}

The chosen methodology is qualitative and uses a double case study design (Burawoy 1998; Yin 1989, p. 14) to explain the policy functions of nonprofit charities in 
Ottawa, Ontario and Edmonton, Alberta. The cases are built with data generated, firstly, through key informant interviews and, secondly, through documents. The case study design facilitates a comparative analysis of the activities of nonprofit charities vis-à-vis the structures within each provincial and urban location (Mason 1996, p. 36). The time frame for this work concentrates on the period beginning in the early 1990 s.

Ottawa and Edmonton are targeted for three reasons. At the time of data collection, the two locations represented different administrative structural arrangements, one regional and one central; Ontario has just recently adopted a regional structure for its health care system. Despite Ontario's new arrangement, the timing of data generation has provided an opportunity to determine whether or not, and how, administrative structures impact the policy activities of nonprofit charities. A second reason for choosing the two communities is that Statistics Canada places both within the same peer group for analytical purposes; this lends weight to my choice of cases. Being in the same peer group means that the citizens of both communities share similar socio-economic characteristics $^{10}$, e.g., their needs for health and home care services are similar. Thus, any variation and/or difference noted between them can be explained by some factor(s) other

10

Peer groups are groupings of geographic health areas which share "similar socio-economic characteristics" (MacNabb 2002, p. 2). "The peer group methodology ... was developed by Statistics Canada to allow one to compare health status measures across the country" (Ibid., p. 8). Data used in the analysis were derived from the 1996 Census of Canada. The analysis included population change, demographic structure, social status, economic status, ethnicity, aboriginal status, housing, urbanisation/metropolitan influence, income inequality and labour market conditions (Ibid., p. 2). It showed "that [among] the ... predictors of the final peer groupings ... in descending order ... included unemployment, size, age, income inequality and growth. These ... variables derived from the stepwise discriminant analysis, appear to represent the factors that differentiate among health areas. ... [T] he groups are described based on their relative value among each of the seven variables. ... [P] eer group B (with Ottawa-Carleton [Public Health Unit and Edmonton, Capital Health Authority]) is the only peer group with high urban concentration and low unemployment" (Ibid., p. 3). 
than social or economic ones. The two locations were also selected for practical and personal reasons. I now address the relationship between theory and methodology. Chapter 2 explains the four broad groups of theory which inform the research question, the research propositions, the research design and the research instrument (Yin 1989) (see Chapter 2). Nevertheless, as Buraway (1998, p. 13) and Mason (1996 pp. 93$94,100-101$ ) suggest, while these groups of theory are my point of departure, they are not my point of conclusion. Rather, this theory

guides [my] intervention... [1]t constitutes situated knowledges into social processes, and it locates those social processes in their wider context of determination. Moreover, theory is not something stored up ... but itself becomes an intervention into the work it seeks to comprehend (Burawoy 1998, p. 21).

Thus, a circular process has been established whereby theory first informs my framework and methodology such that the research outcomes may later inform and add to the original theory under a larger theory building process. Theory informs about the kind of data needed and the data generation processes required, e.g., securing documents, establishing the interview strategy, developing questionnaires to build the two cases (see Figure 1.1, Chapter 1).

State and policy process literature, and nonprofit theory predominantly inform about the structures which constrain, shape and inform about the advocacy-constituted roles of charitable nonprofit. Nonprofit theory mainly highlights the varied roles and functions performed by nonprofit charities. State theory and policy community literature seek to explain how the Canadian state regulates and controls the activities of charities. The state is a forceful player in the home and health care systems of these two provinces 
and communities. Government documents largely inform here.

Community theory seeks to explain how individuals and groups may generate their own power which can be used throughout the policy process to release communicative action, to network and so forth under the ultimate goal of policy change. In addition to guiding the development of the questionnaires, this theory guides the interviews, and the organization, coding and analysis of the data (Mason 1996). Theory and the goals of this research highlight the need for data which explain the human agency of these agencies in policy change. Key informant interviews are the tool of choice because they mirror the way in which nonprofit charities collaborate and network when performing their advocacy-constituted roles. The interviews, which were conducted on site, in the offices of the respective research participants, provide information about the advocacy performed by nonprofit charities on behalf of clients, other agencies, the public and so forth, despite the strong constraints which exist within the home care policy environment.

Altogether, the approaches used for data generation mean that "the holistic and meaningful characteristics of [the] real-life events" associated with the advocacyconstituted roles of nonprofit charities are retained (Yin 1989, p. 14-16). Moreover, the discursive format of the data, its coding and analysis (Mason 1996, p. 142) enable me to gain new insights about the policy functions of these agencies. The research design incorporates and accommodates both the structural and dialectic elements of theory. Background and context data which are used to build the two cases are generated from documents, published literature on home care, my observations and visual data. 
These data highlight the existence of structured power which compel nonprofit charities to perform advocacy-constituted roles because, among other things, the structures minimize, reduce and/or eliminate the potential benefits of home care for the public, particularly seniors. They also impact the operations of nonprofit charities; see the next two chapters.

Once structures are acknowledged, I contain and set them aside (Burawoy 1998, p. 25) so that other issues and ideas can come to light with respect to the role of nonprofits. The traditional practice is to consider state structures as constraints on societal groups, e.g., nonprofit charities. I invert this practice by constraining the structures so that I may pursue Taylor's (2003) idea in regards to nonprofit charities that power can be generated through their relationships within their communities. Only then am I able to determine how nonprofit charities work to establish positive-sum games which enable them to contribute to policy change. Her ideas have guided my data collection strategy which accommodates both the communication and networking skills of nonprofit charities while also acknowledging and containing state structures.

The key informant interviews provide data about the new knowledge and ideas of nonprofit charities which include the importance of: sharing and networking (including donors); awareness raising; learning the 'rules' of the political game; and raising the skills of home care workers. These demonstrate how nonprofit charities establish positive-sum games for policy change on home care. While the research participants have shared with me their views on the above, and more, they didn't necessarily consider these activities as policy activities, nor did they consider themselves as being political. They simply 
recounted these activities as their day-to-day work which takes place in accordance with their missions and public mandates. Despite their political modesty, their stories recount numerous incidents of individual and collective human agency which is at work in their communities. Theory helps me to name the above as political. Moreover, the communicative format used for data generation acknowledges their efforts, in this regard.

The key informant interviews were designed as "open ended questions in an otherwise structured interview schedule" (Mason 1996, p. 39). Their format and use in the individual office contexts, in Ottawa and Edmonton, support my objective to contain the affects of the state's power (Burawoy 1998, p. 25) so that their respective policy activities in home care could be probed and understood more fully. Altogether, the discursive format ensures that the emergent theory is "produced dialectically" (Mason 1996, p. 142) through the multiple dialogues that have taken place between myself and the research participants (Burawoy 1998, p. 7). It mirrors the approach used by nonprofit charities in their home care work. The format also allows me to probe about the use of communicative action (discursive and dialectic action) throughout the set of roles performed by these organizations for policy change, i.e., through their role-structures as illustrated in Table 3.1, Chapter 3. Thus, not all structures are constraining; those owned and used by nonprofit charities may be liberating for themselves and society.

Since state structures do constrain nonprofit charities, I also consider the degree to which nonprofit charities are effective policy change agents in regards to home care. This requires considering how scale-national, provincial or local-may affect the measurement of effectiveness. What is effective locally may not be visible nationally, hence may not 
be considered effective nationally. This also suggests that effectiveness can be hidden or latent; if as stated by Lukes (1986) resistance can be latent, then effectiveness can also be latent. It takes time to secure policy change, and my conversations with the agency representatives took place at a single point in time.

My immediate solution to the effectiveness issue is to give equal weight to all policy outcomes as described by the research participants, particularly because advocacy begins with one voice at a time and, over time, may build up into a collective voice that can reach a wider geographical area. Thus, one policy outcome, even a small and local one, is important because it may be joined with other, bigger and more widespread outcomes. These ideas also highlight the importance and effectiveness of networking action: the potential for the sum of all outcomes to be heard beyond the local level. As well, I consider some actions performed by nonprofit charities as works-in-progress, in which case, their effectiveness is presumed to be latent. While being latent and possibly less forceful, they do represent important precursors to policy change. Altogether, the research design supports the analytic development of theory rather than a statistical approach to the development of theory (Mason 1996, p. 153; Yin 1989, p. 38). Since data was generated from human subjects, ethics approval was required. This is described next.

\subsection{Ethics and Research Participants}

An application was made to the Carleton University Research Ethics Committec prior to the field work; approval was granted. The application, (see Appendix 'A'), includes a basic research plan and design, a brief description of the research participants, the potential risks and benefits to the research participants, and the recruitment process. 
All requirements of the Ethics Committee were met, particularly those which protected the anonymity of the research participants, unless they specified otherwise. Data security requirements were also met. All interviews were taped and each tape was transcribed by a third party who signed a document indicating compliance with the Ethics Committee's requirements.

A pre-existing list of research participants was not available. I developed my participant list using the 2001 Directory of Ottawa Community Services (Ottawa 2001) and The Directory of Community Services 2004: Edmonton and area's most comprehensive human services directory (Network 2004). I also referred to the Health Care Employers Key Contacts and Information For Human Resource Practitioners (Alberta 2000 a.) for the Edmonton case. Several of the Ottawa-based research participants were identified with the help of a small undated pamphlet produced by the Ottawa Community Support Coalition entitled Help for Seniors Living at Home (Coalition). A preliminary list of potential interviewees was drawn up and each person was sent a 'Letter of Invitation', including a copy of the 'Informed Consent' (see Appendix 'A'). Each letter was followed up with a telephone call to schedule the respective interviews. Once the interview process began, additional potential research participants were recruited through a referral process. Thirty people provided information in relation to the Ottawa case, and 29 people with respect to the Edmonton case. The interviews began in Ottawa in October 2004 and were completed in April 2005. The Edmonton interviews took place between November 15 and December 2, 2004.

The research participants represented the following types of agencies and sectors: 
41 nonprofit charities involved in home and continuing care work, (of which Ottawa's CCAC and Edmonton's Capital Health function more as provincial government departments because their lines of accountability flow upwards to government); four nonprofit organizations, based on membership, which were working in the broader health sector; one informal, i.e., non-registered, organization advocating on behalf of seniors; three private sector home care providers; two provincial and two municipal governments. The figures do not add up because some organizations are represented more than once. For example, Ottawa's CCAC is represented by two people, each providing a different perspective; Edmonton's Capital Health is represented by three people who provide different perspectives. Two people, one a program staff member, the other a senior operational manager, represent Ontario's Ministry of Health and Long Term Care. Two individuals represent the government of Alberta, a paid staff of the Ministry of Health and Wellness, and a member of Alberta's Legislative Assembly (MLA). Two people, one paid staff and a City Councillor, represent the city of Ottawa. All, but one of the 41 nonprofit charities were represented by executive directors, (some using the titles President and/or Chief Operating Officer (CEO); one agency was represented by a staff member. Three of the four membership nonprofits were represented by their most senior staff; the remaining organization was represented by a senior researcher. Private sector participants were either owners or senior vice presidents. Unfortunately, physician groups declined to participate in this research.

Data generated by the research participants who do not represent charities give a fuller understanding of, and alternative perspective about home care and its policy 
development processes in relation to the issues, problems, needs, and strategies adopted in relation to the two cases. Hence, their views help to verify the accuracy of data provided by the representatives of charities. This strengthens the reliability of all data.

All of the people who were contacted with respect to the Ottawa case agreed to participate in the research. Unlike my experience for Ottawa, the early phase of recruitment for the Edmonton case was challenging; people were reluctant to participate; I had 5 refusals. At the time of my departure for Edmonton, I had managed to schedule only 13 interviews. The 16 additional people who eventually agreed to share their stories with me in regards to the Edmonton case were contacted on site, by referral. Aside from these recruitment challenges, all research participants from both locations were extremely generous with their time, and many talked to me longer than the planned hour-long interview. After each interview, particularly those which took place in Edmonton, I noted my own views and perspectives about the agencies, the people and so forth; this was to eliminate problems with memory and for verification purposes. As well, some people gave me concrete examples of their public policy activities. Data analysis is now explained.

\subsection{Data Analysis}

Miles and Huberman (1994, p. 10) suggest that data reduction actually begins with the development of the conceptual framework, the choice of cases, the development of the research questions and the approach for data collection (see also Yin 1989). Broadly speaking, therefore, my data analysis begins with the ideas as outlined in Chapters 1,2 and 3 and continues with the data generation processes. More specifically, analysis of the 
two cases incorporates the reduction of documentary data so that the context of the two cases can be explained, and the reduction of data generated through interviews, including taping and transcription. The latter explain about the policy activities of nonprofit charities. Documentary data are displayed separately from the interview data, for each case and are presented in the successive chapters. Data coding and memo writing comprised intervening steps of data reduction and analysis of the interview data. The discussion and conclusions are presented in the final chapter. They arise from a comparison and verification of the facts of the two cases with one another and with theory (Miles and Huberman 1994, p. 10).

All interviews were transcribed and transferred to the program Atlas.ti 4.2, a data base or data storage program. The program conveniently stores interview data for each case as a separate Hermeneutic Unit (HU). Thus, Ottawa and Edmonton each represent separate HUs and each interview has its own number under the respective HUs. Atlas.ti also provides a feature which enables the researcher to input codes and to attach them to the respective interviews. As well, it allows the researcher to write and attach memos about the data-new ideas, emerging patterns, nascent theory, and so forth-and these can be attached to the respective interviews and to individual codes, as well. Thus, armed with this useful data-management tool and armed with theory, I began coding and analyzing the data.

Theory informed the development of my preliminary set of codes. Soon, this small set of codes was supplemented by a whole new and larger set of codes which were informed by the interview data. I introduced into each HU a new and expanded set of 
codes according to the ideas that arose from the data; Atlas.ti's open coding tool facilitated this step. Each interview within the respective HUs was coded separately and each one was given a separate identifier number. As well, each unit of data within each interview, meaning each code unit attached to a paragraph, (paragraphs could have one or more codes attached to them), was allocated a number. The individual and numbered code units are also attached to the numbered interviews within each HU. Altogether, all data units can be located, rechecked and verified as per the features available in Atlas.ti.

Data relating to the Edmonton case were coded first using both the preliminary codes and an open-coding process. I captured and recorded in memos new ideas, patterns and themes, as they arose from my reading and analysis of the data. When I completed the data-coding process, I cleaned the data, meaning I merged codes which captured similar elements, but according to different code names, into single codes, as appropriately. Throughout the coding exercise, I wrote memos about the patterns, differences, regularities, new ideas, possible explanations, and so forth, and attached these to individual paragraphs and codes. Through this process, I developed preliminary conclusions with respect to the analyzed data (see Miles and Huberman 1994, p. 11). The list of codes from the Edmonton HU or case were imported into the Ottawa HU/case to facilitate its coding. However, the differences in the data between the two cases soon became apparent and required the introduction and application of new codes to the Ottawa case.

Once the coding process was complete, analysis continued whereby related codes were grouped into networks. For each code, Atlas.ti displays two numbers which indicate 
the degree of groundedness of the data and the degree of theoretical density (both according to identifier numbers). The first number indicates the number of quotations which have been allocated a particular code by the researcher. A larger number indicates that the researcher has identified more evidence in regards to that particular data code. The second number indicates the number of codes which have been linked together by the researcher in a network. Here, as well, a higher number indicates stronger theory which is emerging from the data. All of the above was applied to analysis of the cases.

Analysis continued with the production of code tables for each case/HU. These are frequency tables which list and count the frequency of use of the codes in the individual interviews. The codes were ranked and percentiles calculated in terms of the code ranking. This allowed me to view the codes in terms of their frequency of use for each case. It also facilitated pattern mapping of the codes and to identify the themes that emerged from the data according to existing and new theory.

Altogether, I spent a significant amount of time, (many months), listening to the tapes, talking to my research assistant about the data, reading the transcripts, puzzling through, examining individual data paragraphs and so forth, in the analysis phase of this research. When this major piece of analysis was completed, I moved onto the next phases of writing and data display, comparing the two cases and writing the conclusions. The interview data are displayed as extended text and appears in later chapters. The memos are displayed in the concluding chapter as new ideas and theory.

The issues of reliability, accuracy and validity have been addressed through a number of procedures which encompass the development of the interview tool, ethics 
approval, and the manner in which data were generated, interpreted and analyzed. The following briefly introduces the interview tools which were used to ensure reliability.

Four interview tools were used, see Appendices ' $B$ ', ' $C$ ', ' $D$ ' and ' $E$ ', depending on the sector within which the respective research participants worked, e.g., nonprofit charities and other nonprofits, local and provincial government officials, and private sector operators. The tool designed for nonprofit charities was applied to individuals from member-based nonprofit organizations. Each interview tool contained samples of potential responses, i.e., preliminary codes, which were informed by theory and the interviews varied from one to one and a half hours. Each interview was taped to facilitate a conversational style which enabled me to probe statements, more deeply, as appropriate.

The five sections of the interview tool targeted to nonprofit charities (see Appendix ' $\mathrm{B}$ ') allowed me to solicit the following data: basic information about the organization; its knowledge, involvement, and capacity to shape home care public policy, including its views on policy; and the organization's collaborations with other interests (peers) within an associational or other system(s); their views on/about other interests which develop home care policy. The interview tool targeted to provincial and federal government officials (see Appendix ' $C$ ') enabled me to solicit data on: government's role in home care; how government generates information on home care; how government assesses the public's need for home carc; and how government makes decisions on home care. Using the interview tool targeted to local government officials (see Appendix 'D'), I gathered the data on: how local government frames the issue home care and consults with the public; how local government assesses the public's needs for home care; where 
the locus of decision-making on home care resides; and how autonomous is local government decision-making on home care. Using the interview tool targeted to private sector operators (see Appendix 'E') I gathered the following data: basic information about the organization; its knowledge, involvement, and capacity to shape home care public policy, including its views on policy; how it collaborates with other interests (peers) sharing a home care associational system; and their assessment of the policy operations of others within the home care policy community.

\subsection{Chapter Summary}

This chapter maps out the research design through which data about the public policy functions of nonprofit charities in Edmonton, Alberta and Ottawa, Ontario have been collected. Key informant interviews provide data about the communicative action released by nonprofit charities in shaping home care policy. The chapter also describes the use of case study to contain both structured-contextual data gained from government documents and to identify the advocacy-constituted roles of nonprofit charities as told by the research participants. This chapter also describes how the issues of reliability of both method and interpretation have been addressed. The research does not make the empirical, generalizable claim that the charities in this research represent all similar agencies, in Canada. Nor do the two cases represent all home care policy communities in Canada. Rather, this research contributes to theoretical generalization with respect to the advocacy-constituted roles of nonprofit charities as operating in policy communities like home care (Mason 1996, p. 154) which are constrained by government policies. Hence, it contributes to the ongoing work of theory development on the nonprofit sector. 


\section{CHAPTER 5 - HOME CARE IN ONTARIO}

\subsection{Introduction: Home Care's Early History and Financing}

The Ontario provincial government's involvement in home care began in 1958 with the Homemakers and Nurses Services Program (HNSP), a nursing demonstration project. The province engaged three existing nonprofit charities to provide nursing and homemaking services under the project: visiting nursing was supplied by both the Victorian Order of Nurses (VON), established in 1898, and the St. Elizabeth Visiting Nurses Association, established in 1908, and homemaker services were provided by the Red Cross Society, established in 1920. Soon, other pilot projects appeared to test respite and acute care services in home care (National Health and Welfare 1977; Williams 1996). All nascent home care services were financed under a cost-shared arrangement between provincial and municipal governments with the latter responsible for half of all costs. When the federal government 's cost-shared financing arrangements were introduced, in 1957 and 1966, municipal subsidies increased to approximately eighty percent of costs. By 1970 , home care had become a publicly funded home care program in Ontario (Health Canada 1999 b., p. 39; Williams 1996, pp. 941-942). In 1974, home care became an insured service under the Ontario Health Insurance Plan (OHIP) (Williams 1996) with approximately 90 percent of home care financed under the Ontario Health Insurance Act (Baranek et al. 2004, pp. 10-11, 17).

Over time, additional new pilot projects emerged and led to the establishment of a chronic home care program, in 1975, and a community program, meaning home support services, in 1979. Nonetheless, acute home care dominated in the provincial home care 
program despite the aproximately 200 nonprofit agencies which provided home supports under the chronic and support programs ${ }^{11}$.

In 1986, the Integrated Homemaker Program (IHP) was introduced and, one year later, the Hospital in the Home Program (HHP) was introduced (Williams 1996, p. 943). For Hollander (1994), these two programs represent the kind of experimentation that was facilitated by the federal government's EPF program, introduced in 1977, and the amendment to the program that was introduced in the early 1980s. Ontario responded to the funding cuts with its own cost reduction exercise. Since the EPF eased the restrictions over the provinces' use of federal funds, it facilitated experimentation and, in this regard, it improved access to services like homemaking, shopping, meal preparation, cleaning, laundry, ironing, essential mending and personal care. In this regard, home care was being transformed out of its narrow medical-institutional form (Hollander 1994).

All the same, in spite of easier access to support services, Williams (1996, p. 943) observes that increasing numbers of families were providing care to their frail elderly and disabled adult family members. Hollander (1994) interprets this outcome as families supplementing and/or subsidizing provincially funded health services.

By 1994, the core services of the provincial home care program included acute home care and chronic-maintenance care services, with the latter targeted to individuals with functional disabilities and/or requiring limited rehabilitation. Both nonprofit

11

The services included "meals on wheels; wheels to meals (congregate dining); friendly visitors; security checks for the home bound; minor and seasonal home help; telephone reassurance; counselling and referral as they relate to home support; day care for seniors; transportation; and other personal services" (Williams 1996, p. 942). 
charities and for-profit companies provided services, but the major providers were nonprofit agencies (Baranek et al. 2004, p. 151). As well, home care's public finance under OHIP ended at this time (Ibid., pp. 11,17, 148), and this was a key event which facilitated trends towards its privatization in Ontario in the form of an increased role of for profit providers, less public money, and the introduction of competition.

In 1975 , when home care was first introduced, $\$ 1.62$ per capita was allocated to this service (Ballinger et al. 2001). Since 1982, Ontario's home care expenditures levels have steadily increased and, by 1998 , Ontario's home care spending was $\$ 124.88$ per capita (Ibid.). For comparative purposes, Ontario spent $\$ 1,777.20$ per capital overall on health, in 1998 (CIHI 2005, Table D.4.6.3).

The growth in home care expenditures reflects the province's use of home care as a cost-reduction strategy in relation to the hospital sector. It is a strategy that eases the financial burden for the province, impacted by the federal government funding restrictions. Hence, Ontario's strategy for home care partly originates in the decisions and structures of the federal government, but as Maslove (1995) explains, the provinces may interpret the goals of the federal government in a manner which accords with their own priorities for the health sector and the provincial economy. This chapter explains how the provincial government has responded to national health policies by reforming both health and home care, meaning greater use of home care as an acute care substitution service. The recent 2003 First Ministers' Health Accord on Health Care Renewal (the Accord; Canada 2003 b.) reinforces this type of strategy to transform home care into a predominantly acute care service. Ultimately, as well, government's structures, strategies, 
and transformations impact upon the home care work of nonprofit charities at the local level.

The first section of the chapter maps out in greater detail the outcomes of the federal government's decisions on Ontario's health and home care sectors. The outcomes appear as a series of Ontario government strategies which have been used by all provincial governments to cut costs. Home care has been a convenient vehicle in support of this strategy and has, itself, been affected by them. The structures which are introduced and explained according to their impact on home care are embedded within the ideas efficiency. They include Acts, spending and service caps, competition, health system integration, a bias in favour of acute home care, and an implicit gender bias. These are explained according to the needs of seniors, particularly for those in Ottawa, in the succeeding two sections of the chapter. The chapter ends with a brief summary of how the various policies shape the home care context and impact the policy work of nonprofit charities. The state's structures are now examined in greater detail beginning with legislation introduced by the New Democratic Party (NDP) government and modified by the Progressive Conservatives (PC).

\subsection{Ontario's Structures}

\subsubsection{Legislative - Bill 173}

The fourtecn-year reign of the Progressive Conservative (PC) party under Premier Davis' government ended in 1985 and was replaced by a Liberal government under Premier Peterson. Mr. Peterson's five-year term was succeeded in 1990 by the NDP government under Mr. Rae. The five-year NDP government was replaced by another PC 
government led, firstly, by Premier Harris and, later by his successor, Mr. Eves. Since 2003, Ontario has been governed by the Liberal party under Premier McGuinty. Over the past 35 years, four different governments have had the opportunity make their mark on home care and the broader health care system (Ontario $2006 \mathrm{c}$.). Numbered among the goals of all governments, regardless of their ideological perspective, have been funding reductions in the hospital sector and better acute care services, caps on home care expenditures and home care's removal from the Health Insurance Act. In 1989, a Liberal government imposed the first spending cuts to home care through a 70 percent cap on public contributions. In 1994, through Bill 173-An Act Respecting Long-Term Care-the NDP government enforced a complete cap on home care by removing it from OHIP because they believed costs could be controlled simply by moving the home care budget out of this open-ended universal entitlement (Baranek et al. 2004, pp. 17, 144, 148).

Bill 173 was the NDP government's cost-containment strategy which, for Baranek et al. (2004, pp. 143-144), meant more and more

prioritization, waiting lists, and denial of services... Additionally, government would restrict hospital capacity (through hospital restructuring and budget cuts, which in turn dramatically reduced bed availability) and move people more rapidly into the community through reducing length of stay and emphasizing day procedures.

These authors explain how through the Bill's 80-20 rule, the NDP shunned for-profit home care operators in favour of community participation and services delivered through large numbers of nonprofit multi-service agencies (MSA). The rule was to limit the purchase of external services by MSAs to only 20 percent of an agency's budget (Ibid., 
pp. 149-150). They describe, as well, how the NDP planned to incorporate home supports into mainstream home care services, but not necessarily with the guarantees that government would pay for them. Rather, an income means-test would determine access to meals, transportation, home maintenance, and some homemaking; income-tests were preferred by the NDP because they considered them to be more equitable than asset tests.

In 1995, an election was called, the PC-Harris government won a majority of seats and Bill 173 was never implemented (Ibid., pp. 93, 148). Despite the fact that Bill 173 arose from a government having a perspective that was diametrically opposite to that of the new government, aspects of it accorded well with the new government's agenda. Baranek et al. $(2004$, pp. 149-150, 177) explain that the Harris government chose to retain the Bill, but modified those parts which contradicted its own plans, particularly eliminating the MSAs and the 80-20 rule. Home care's removal from OHIP was retained. Essentially, the Harris government took the building blocks laid out by the NDP government and built upon their foundation a PC vision for the health sector as described by the 'Common Sense Revolution' (Progressive Conservative Party 1994). This is now explained.

\subsubsection{The Promotion of Efficiency}

\subsubsection{Under The "Common Sense Revolution"}

The government's overall target, under the 'Common Sense Revolution,' was to "give Ontario a balanced budget within four years, and create more than 725,000 new jobs" (Ibid.). It incorporated income tax rate cuts (30 percent) and cuts to non-priority spending. For the health sector, the 'Common Sense Revolution' meant cutting overhead 
and/or introducing new management techniques and thinking which would allow for reinvestments to health care that would improve patient services. A common sense approach would guide patient-based budgeting which meant making the people, who 'need' health care, the priority. The government's focus was to "put more health care dollars into direct care for those in need, and more into the preventive care which can help people avoid becoming ill in the first place" (Ibid.). A mere sixteen days after taking office, the new health Minister announced the government's changes to Bill 173 .

The government also introduced omnibus legislation-Bill 1996, the "Government Process Simplification Act"- -and established the Health Services Restructuring Commission (HSRC). The general purpose of Bill 1996 (Ontario 1996) was "to simplify government processes and improve efficiency". It became the means through which broader economic objectives of the PC government would be achieved. The new government maintained the following aspects of the NDP plan: hospital restructuring, cost containment and budget cuts, wait lists and service cuts. As well, the PC government added a few new twists. For example, rather than delivering home care through approximately one hundred nonprofit MSAs, Baranek et al. (2004, p. 235) describe the government's plan to deliver home care through 43 Community Care Access Centres (CCAC). They also describe the controlled consultations which were undertaken by the PC government prior to creating the CCACs. For these authors, the degree of control demonstrated less concern for transparency and community participation. Another significant difference between the NDP and PC governments was that the PC government clearly preferred, and increased the private sector's role (see Armstrong 2001 
for an account of how health care was being privatized by the Harris government). According to Baranek et al. (2004) the elimination of the 80-20 rule meant more external purchase of services by for-profit contractors.

For home care, government's mantra became 'highest quality of services at the best price.' Efficiency was being promoted by streamlined access to services through CCACs and by the introduction of competition between nonprofit and for-profit providers. 'Red tape' and duplication were eliminated and more funding was injected into front-line services. New and improved provider accountability requirements were also introduced to highlight how money was to be spent on services. As well, in line with the NDP plan, community support services were to be accessed directly. For Baranek et al. (2004, p. 228), these changes signaled an "ideological shift in focus towards private business ... and against public government”. Armstrong (2001) is more upfront about these practices and calls them "privatization by stealth". Throughout these changes, the chameleon good—home care—was simply undergoing another transformation from its merit, public good affect to a more private one.

In tandem with the home care reforms, the Harris government was reforming the hospital-institutional sector so that it would become more efficient, so that a reformed home care sector could then align with, and support a reformed institutional sector. The institutional sector reforms which also shaped home care were introduced and managed by the HSRC. These are now explored.

\subsubsection{In Health Institutions via The Health Services Restructuring Commission}

The Health Services Restructuring Commission was established in April 1996 
(Commission 2000, p. 179). Its twelve volunteer members were appointed by the government and represented business interests, physicians, nursing, and academics. Clearly absent from this membership list is representation of the large numbers of charitable nonprofits which work in home care. The membership ${ }^{12}$ reflects government's narrow objectives for the home and health care sectors, meaning less government, probusiness and greater efficiency, and is indicative of the recommendations that would eventually emerge from the HSRC.

The first and main task of the HSRC under its four-year mandate was "restructuring Ontario's public hospitals"13. The HSRC claimed it was not charged with cutting costs, rather it simply issued formal directives to communities and institutions across the province, requesting that reforms-amalgamating and closing hospitals, including chronic care facilities-be introduced. Despite such claims, it indirectly cut costs through the closure and/or amalgamations of hospitals, program transfers, and volume reductions. Accompanying the directives relating to institutions were recommendations that communities and institutions reinvest in other areas like home care and other community-based services (Commission 2000). The latter were designed to support the efficiency objectives with respect to health institutions. Acute home care, for

12

The membership include eight people who represented private interests through law, financing and banking, and one private sector home care operator; 3 physicians, one of whom had previous experience in government; 1 nurse; and three ex-officio members who represented academic/health administration, the hospital sector and medicine (Commission 2000, pp. 1, 173-177).

13

Two other inter-related tasks included reinvesting in the health system and recommending how other areas in the health system could be restructured so as to "improve quality of care, outcomes and efficiency and help create a genuine, integrated health services system" (Commission 2000, p. iii). 
example, would pick up the slack of a downsized institutional sector.

The mandate, and each decision and recommendation of the HRSC echoed the mantra of the Harris government in regards to "quality, accessibility and affordability", stability of the "financial... system", reasonable but limited spending on health, and a private sector role. The latter is visible in a HSRC document which states (Commission July 1999, p. 10),

There does not appear to be any real clash in preserving/enhancing the role of the private sector in the provision of health services within an IHS [Integrated Health Service] structure. ... Accountability to the legislature can be achieved through enactment or regulations that set-out criteria to be followed and monitored/policing of criteria (i.e., Health Care Accountability Act). There are numerous ways to achieve public accountability including public election of members to new structures etc.

Since the HSRC's approach to home care considered how it would support the objectives for the institutional sector, its vision for home care was restricted to its acute care form. It seems that the social supports which facilitate independence for seniors were not part of the mandate of the HSRC. Seniors are not mentioned, nor do the recommendations developed by the HSRC even consider how to meet the long term needs of the elderly, the disabled or, the frail elderly. These other objectives for home care seemingly became secondary to institutional-efficiency goals. This is reflected in statements relating to how home care would be evaluated, e.g., in regards to "post same day surgery or in-patient discharge" (Commission 2000, p. 58), and according to the efficiencies it created with respect to institutional settings. Re-investments, whether in acute home care or long-term care, were mapped out according to the requirement of supporting acutely ill patients. Another less visible reform was introduced by the HSRC 
in the non-acute institutional sector: complex continuing care $(\mathrm{CCC})$ beds were also being reduced.

At the end of its mandate, the HRSC (Commission 2000, p. 7) claimed it had secured its objectives for "A more appropriate balance of institutional and communitybased care". Home care appeared to be 'captured' by the institutional sector and the health system remained hospital-centred, but was less visibly so because home care picked up some of the slack for hospitals.

Given the nature of its recommendations, the HSRC was rightly concerned that the public would embrace the above noted reforms with scepticism and would perceive the whole process simply as a money saving exercise (Ibid., p. 57, 59, 61). The PC government sought to soften the blow to the public with the announcement, given in April 1998, by the health Minister that 20,000 new beds for nursing homes and homes for the aged would be created (Hansard 1998). Unfortunately, the health Minister omitted some other interesting facts when making this announcement. First, Ontario's long-term sector, the sector receiving the additional 20,000 beds, "is dominated by large, proprietary for-profit facilities" (Berta et al. 2005, p. 71). Unlike the CCC beds that were being reduced, Deber and Williams (1995, p. 301) make the point that homes for the aged and nursing homes are not protected by the terms of the CHA. Thus, the 20,000 new beds were being introduced by private sector operators which earn income from any of: private payment, provincial subsidy and/or a municipal contribution (see also Maurier and Northcott 2000 , pp. 100,101). So, in actuality, the government was converting a public good, CCC, into a private good: homes for the aged and nursing homes. By doing so, the 
HSRC was engaged in a cost cutting, privatization, and pro-business/efficiency agenda. Having established its reforms in the institutional sector, the government could then introduce its specific reforms to home care, particularly acute home care. Before these last set of reforms are explored, I briefly introduce Ontario's home care support services.

\subsubsection{Home Care Services}

\subsubsection{Community Supports}

Community supports are home care services which arise in relation to the CAP, see Chapter 2, and demonstrate a "generous attention to social needs" (Council 2003, p. viii). Approximately 850 community support service agencies receive transfer payments from the province to provide services such as supportive housing, meals, transportation, home maintenance and repair, friendly visits and security checks. Other services may include homemaking services—housekeeping, laundry, shopping—and personal support services such as bathing and dressing. Generally, support services assist patients who would otherwise be institutionalized and/or who require long-term assistance to remain living independently at home for as long as possible. Most clients are seniors or adults over 65 with physical disabilities (Auditor General of Ontario 2004, p. 190; Council 2003, p. 10). The province's community support agencies are represented by the Ontario Community Support Association (OSCA). According to the OSCA, they employ approximately 10,000 staff and 45,000 volunteers.

Community support agencies are volunteer-based charitable nonprofits and many have historical roots in faith groups and in community sponsorship (Council 2003, p. 10; Tanner 1999). They are small with an average number of staff varying between two and 
four full-time equivalents. Volunteers are a major driving force behind these agencies which often provide both direct service hours and indirect support for other functions, like fundraising; volunteers are large in number. A former District Health Council used the word 'profound' to describe their impact on the availability of services within communities (Council 2003, p. viii, 10).

In 1994/95, the Ministry of Health and Long Term Care (MOHLTC) introduced a funding envelope system to fund community-based long-term care services through community agencies. The allocation to this funding envelope, however, was based upon funding levels which had been frozen in 1992 (Council 2003, p. 244). The funding freeze was partially alleviated in 1998 when the Ministry introduced its plan to expand longterm supportive care over an eight year period, in geographic locations which had been under funded when measured against the per capita average for the province (Council 2003 , p. 3). So areas which fell below the provincial average received funding increases to bring them in line with other locations (Council 2003, p. 12). In effect, historical funding averages, which were already low due to local deficiencies, determined the funding increases for home support services, rather than any objective measures of need, service standards, or local-wider program objectives for the whole care system.

Traditionally, both the MOHLTC and municipalities have contributed towards the budgets of individual agencies although, generally, the Ministry provides the major amount. As well, both funding sources and funding levels vary from agency to agency, and within agencies according to individual programs. Overall, government's financing of home supports is uncertain and because of this, agencies must rely, more and more, on 
outside funding sources if they wish to continue providing care. Agencies fund their services, increasingly, from a variety of other sources like the United Way, private donations and fundraising. As well, most agencies "have at least one program that requires a client fee. This is the one funding source over which an agency can exercise some control" (Council 2003, p. 244). The services generally covered by user fees are: "adult day service, meals on wheels, diners clubs, transportation, home maintenance, respite services, home help and foot care. Fees [are] set according to individual agency policy" (Council 2003, p. 244). Overall, fees vary from agency to agency, but they represent only a small portion of an agency's budget. I now introduce Ontario's reforms for home care which parallel the reforms in the institutional sector.

\subsubsection{CCAC Competitive Arrangements}

On January 1996, having established home care as a vehicle to reduce costs arising from health institutions, the PC government introduced its model through which home care would be delivered. The model simply mirrored the NDP plans to introduce competition between providers; however, as indicated above, the providers were both nonprofit and for-profit. The procurement model uses requests for proposals (RFP) which solicit "proposals to supply complex products and services ... [according to evaluation criteria which include] the quality of the service delivery approach as well as price" (Caplan 2005, p. 8).

In 1997, 43 Community Care Access Centres (CCACs) started operations across 
the province ${ }^{14}$ (Auditor General of Ontario 1998, p. 103; Baranek et al. 2004, p. 235).

CCACs were established as nonprofit

corporations under contract with the Ministry of Health to arrange long term and home care services to the community. The operation of CCACs focuses on purchasing services via Requests for Proposals ("RFP"). That is, CCACs enter into contracts with multiple providers. In the CCAC framework, providers of services are restricted to provide services and can not also purchase services while purchasers of services cannot also provide services (Commission 1999, p. 18).

The speed with which the CCAC model was introduced meant that the regulatory and legal supports which governed their operations were not in place when the centres began operating (Commission 1999, p. 18; O’Brien 2002). While such shortsightedness may have impeded day-to-day CCAC operations from the point of view of government, it did support the introduction of a community perspective on home care through the CCAC operations, at least for a short period of time.

During this early period, CCAC operations were overseen by board members who were appointed by government, but who resided in the communities of the respective CCACs. Gradually, these initial appointees were replaced by community-appointed boards who were favoured by the public because they introduced a stronger and much desired community perspective.

In 2001, with the introduction of Bill 130, The Community Care Access Corporations Act (O'Brien 2002), the government set in place its structure through which increased efficiency would be achieved with respect to CCAC operations (O'Brien 2002).

14

In their first operating year, CCACs received approximately $\$ 1.2$ billion of transfers and increases were expected for the next eight years (Auditor General of Ontario 1998, p. 104). 
The $\mathrm{Act}^{15}$ enhanced government control over CCAC management and day-to-day operations and transformed them from nonprofit agencies governed by community boards to statutory corporations with boards appointed by the Lieutenant Governor in Council (LGIC) (Auditor General of Ontario 2004, p. 191). The LGIC now appoints CCAC executive directors, sets their salary and outlines other benefits. CCAC executive directors now report to government through both the MOHLTC and their board. Their key focus has become appeasing government rather than pleasing and addressing the needs of their communities.

With a provincial deficit of $\$ 11.3$ billion, in 1995 , and health sector costs representing approximately 35 percent of annual budgets, in 1999, the government was determined to reduce costs ( Finance 1999). The closure of publicly funded chronic care hospitals, the increased reliance on nursing homes, or homes for the aged (Maurier and Northcott 2000, p. 100; Hansard, 2002) and the establishment of CCAC statutory corporations were key to the government's ultimate objective to balance the 2000-01 budget (Finance 1999; see also Maurier and Northcott 2000, pp. 146-147). Interestingly, as well, the government froze its CCAC funding allocations for the 2001-2003 period at 2000-01 levels (Auditor General of Ontario 2004, p. 193).

It is not surprising, therefore, that communities expressed displeasure with the

15

The Act maps out mandates of CCACs which are: 1. To provide, directly or indirectly, health and related social services and supplies and equipment for the care of persons. 2. To provide, directly or indirectly, goods and services to assist relatives, friends and others in the provision of care for such persons. 3 . To manage the placement of persons into long-term care facilities. 4. To provide information to the public about community-based services, long-term care facilities and related health and social services. 5. To cooperate with other organizations that have similar objects (Ontario 2001). 
new CCAC board structure and felt the loss of community involvement. Discontent has also been expressed over the competitive model, in part, because a number of community agencies have lost contracts. Several sources have written about the strained relations between communities, labour, nonprofit charities and government that have resulted from the government's policies (Carnwath 2004, p. 11; Employees 2004, 2005; Coalition 2004; OPSEU 2004 a., b., c). Such discontent is fed by the new reality for seniors, identified by Maurier and Northcott (2000, p. 103), who are experiencing increasing problems with access to long term care facilities because of more stringent eligibility requirements and wait times. This component of the new long term care system is also being managed by CCACs which function as gatekeeper. Seniors are denied admission if they are well enough to function in their homes with home care or other supports. Altogether, these issues when combined with the new home care policies mean lower access to services for seniors. One alternative for seniors is to pay privately for care within facilities which are now largely owned and operated by private sector firms.

Maurier and Northcott (2000, p. 99), who write about the institutionalization of seniors, observe that in the mid-1990s, the period during which the PC government was introducing its reforms, Ontario had the highest institutionalization rate for seniors in Canada. While the HSRC's 'delisting' or transformation of publicly funded chronic care into nursing homes and/or homes for the aged may have lowered this rate, there is less scope for optimism, here, when considering the alternatives for seniors. Maurier and Northcott (2000, p. 99) explain how the rates of seniors' institutionalization vary according to the unavailability of home support services and informal caregivers; both 
may postpone institutionalization "for a short time or even indefinitely" (Ibid.). Thus while a variety of factors may impact upon the quality of life for seniors, it appears that, when faced with the tensions arising from competing objectives and cost control, efficiency won over other objectives which may have been more senior-friendly. Overall, the public health good available to seniors has been reduced, privatized and made less accessible. According to the Auditor General Of Ontario (AGO), service quality has also been affected; perhaps by the speed with which the Harris government proceeded with its home and health sector reforms.

These types of problems have been highlighted by the AGO. Its 1998 audit identified the need for a funding formula that allocates funds according to assessed need for community-based services. Its 2004 annual report highlights the need to improve both the measurement of quality and the indication that clients are actually receiving quality care (Auditor General of Ontario 2004, p. 192). It recommends that an information system be establish to collect client-level service and costing data ${ }^{16}$. In addition to these concerns over the ability of the MOHLTC to assess quality of care, the AGO also expresses concern with the Ministry's compliance with legislation. Compounding these problems is the tendency for CCACs to overlook "whether the quality-of-service

16

The 2004 annual report states (Auditor General of Ontario 2004, p. 193), "The formula used by the Ministry to determine the level of funding to be provided to CCACs and CCS agencies still does not assess the need for services or ensure equitable province-wide access to services... From 2001/02 to 2002/03, during a period when funding provided to CCACs was frozen at 2000/01 levels, the number of nursing visits decreased by $22 \%$ and the number of homemaking hours decreased by $30 \%$. The Ministry had not formally assessed the impact of such a significant decrease either directly on recipients... The Ministry had not yet developed service standards to determine whether community-based services are being provided at expected levels and in a consistent, equitable, and cost-effective manner across the province." 
commitments made by successful bidders were actually being met" (Ibid., p. 199). As well, quality is negatively impacted by the absence of common intake assessment processes and the inconsistent application of the Resident Assessment Instrument-Home Care (RIA-HC).

In addition to the above, the AGO cites concerns with funding, i.e., the funding split between CCACs and community support services, which results in large inequities related to access to services (Ibid., p. 195) and slow budget review processes with respect to CCAC budget allocations. For example, "the CCACs and the CSS agencies received approvals for their 2002/03 budgets only in January 2003, nine months into the fiscal year" (Ibid., p. 201). This is particularly problematic for the large numbers of seniors who require support services. Compounding such access problems, according to the AGO are information deficits related to wait lists and wait times for home care, and analytical deficits which would ascertain what is deemed appropriate (Ibid., p. 197).

Accountability measures are also deficient. Performance measures and reporting, for example, lack clear goals and objectives, relevant performance measures, appropriate standards and targets for measuring results, reliable systems for gathering information, and a reporting mechanism to communicate accomplishments and areas needing corrective action (Ibid., p. 212). Additional concerns of AGO relate to the bidding process and the impact of contracting on the availability of future suppliers needed for effective competition. The above represent the kinds of problems which faced the new Liberal government which took office in October 2003. The following introduces some of the changes put forward by the Liberals to address issues within the health sector. 


\subsubsection{Health System Integration and a New Government}

In 2003, while agreeing with "Roy Romanow that home care is the "next essential service'", the health Minister announced that home care funding would 'grow' to $\$ 1.3$ billion in that year. Of that amount, $\$ 73.2$ million represented new investments in CCACs for acute home care, palliative care and chronic care (Ontario 2003, July 5). One year later, the Health System Integrated Task Force (ITF) was established to support this government's reform agenda for the health sector, namely to create Local Health Integration Networks (LHIN) (Force 2004). The new government had concerns, as well, with aspects of the CCAC model and with individual CCACs. Problems with Ottawa's CCAC, for example, led to the Ministry's announcing ${ }^{17}$, on September 3, 2004, that a new interim chair would govern its operations. Nevertheless, while these issues bore no relation to the government's commitment to the CCAC model, the government did establish, one month later, a broader province-wide review to examine the managed competition, or procurement process across Ontario.

The mandate of the Procurement Review under Elinor Caplan was to examine all aspects of procurement from quality of care, to value for money, to impacts of the current procurement model, to delivery services, to resources of the CCAC, to the selection of service providers and so forth (Caplan 2005, p. 1).

The goal of this Review [was] to cnsure that Ontario select the best competitive model, and that this model be well managed. Effective management includes responsible oversight to mitigate the adverse effects

17

The announcement coincided with the release of a report on the operational review of the Ottawa CCAC (Ontario 2004). 
of unfettered competition that inevitably arise from imperfect market conditions (Ibid., p. 7).

Between October 2004 and January 2005, extensive (and intensive) consultations with "service providers, [home] health care workers..., clients..., health care researchers, unions and interested citizens" were undertaken ( $\underline{\text { Ibid. }}$.). Round tables were held, submissions were received, a survey was conducted, and conclusions were drawn up. The report Realizing the Potential of Home Care, which was released to government in May 2005 , made "70 recommendations which will allow home care to realize its potential in the best interests and their families" (Ibid., p. v.).

The government's response to the recommendations was firstly to narrow them according to three subsections - defining and monitoring quality, workforce, and procurement practices - and then to address each set accordingly (Ontario $2006 \mathrm{~b}$.). Essentially, the government "has accepted the ... recommendations with the exception of all but two...: Allow CCACs to reallocate up to five per cent of their budget annually; [and to] consider cross-appointments between CCAC and ... (LHIN) boards" (ㅎid., p. 4). LHINs were recently established with the passing of the Local Health System Integration Act, 2006.

The purpose of the LHINs is to plan, integrate and fund the following local services: hospitals, CCACs, Community Health Centres, home and long term care, mental health and addictions, and community support services (Ontario 2006 a.). The Ministry did not accept the recommendation to cross-appoint people to CCAC and LHIN Boards because it wished to avoid the conflict of interest between CCACs and LHINs, who fund 
the former. In its response, the government also indicated that it had already begun acting on many of the recommendations, e.g., "establishing working groups to revise current Request for Proposal (RFP) documents and tools" (ㅎid.).

The timing of the data generation period in relation to this research, using key informant interviews, was prior to the events associated with the Review and the LHINs. Thus, their impact on the advocacy-constituted roles of charitable nonprofits cannot be ascertained, at this time. Of import to this research, however, is the government's commitment to maintain the competitive arrangements for home care using RFP processes even though, as the Review ${ }^{18}$ notes, "the information needed to measure quality is not readily available" (Caplan 2005, p. 6). Another point of interest relates to two factors, one of which is identified by the Review. The first is that seniors are the largest users of home care (Ontario 2006 b., p. 3). The second pertains to the manner in which the allocation of different kinds of home care services contradict the needs of seniors, the largest users of home care. For example, acute care clients account for the largest proportion of home care (at 35 percent), rehabilitation clients second (at 22.4 percent), long term care placement clients third (at 12.7 percent) and, then, maintenance or support service clients (at 12.1 percent). The Review links these outcomes to the Accord and the federal government's specific targeting of acute home care which creates a "trend towards

18

Further to this point, the Review states (Caplan 2005, p. 6), "There is an obvious need for consistent, accessible information that can provide a basis to measure client outcomes. There is currently no single authority to locate or collect this information, commission research, promote innovation, monitor client outcomes, or undertake the work needed to develop quality indicators. Work currently being done in this area is fragmented and generally conducted by individual CCACs and service providers without provincewide coordination.". 
serving more acute clients ... at the expense of maintenance clients" (Caplan 2005, p. 3).

The Report quotes a study in the Journal of Aging which states,

people in need of long term personal care and practical support are given lower priority and are gradually being rationed out of the system for all but the most minimal bodily maintenance. This medicalisation of home care generates particular jeopardies for the frail older people who dominate this category of need, most of whom are women (Caplan 2005).

These trends are also noted by Ballinger et al. (July 2001) who suggest that over half of Ontario's home care dollars are targeted to acute home care rather than to home supports. Hébert (2002, p. 345) echoes these issues and suggests that the real issue ought to be whether government is adequately financing home care according to the needs of seniors, meaning 'are support services provided, as appropriate?'. It is difficult to determine, at this time, the full impact of the Liberal government's policies on the needs of seniors. The next two sections examine more carefully why it is important that government addresses such challenges.

\subsection{Ontario's Seniors}

In 2005, 12.9 percent of Ontario's population was classified as senior, over age 65. By comparison, when medicare was introduced in the early $1970 \mathrm{~s}, 9.6$ percent of Ontario's population was a senior (Canada 1976, 2001). Women predominate among the older-old seniors' group for both time periods. According to Maurier and Northcott (2000), population projections for 2016 suggest that between 14.7 and 15.8 percent of Ontario's population will be classified as senior and, of these, 2 percent will be mainly female in the older-old group. They also observe that as seniors age, they require increasing levels of support (Ibid., pp. 26-33). Using several data bases-the 1991 
Survey on Aging and Independence (SAI), Canada's General Social Servey (GSS), and the 1996-97 National Health and Population Survey (NHPS)-Maurier and Northcott (2000) provide us with some interesting facts about Ontario's seniors.

First, Maurier and Northcott (2000) tell us that seniors are not all frail, or sick and/or dependent. Rather, the opposite is true; most are healthy and active. Seniors contribute to both the economy and to society and, in 1996, almost 9 percent were actively employed or were looking for work in the labour force (Ibid., p. 35). When referencing the 1991 SAI, aging survey, Maurier and Northcott write,

Over $50 \%$ of Ontario seniors reported helping a neighbor or friend, $44 \%$ helped a spouse, $32 \%$ helped a daughter, $30 \%$ helped at a voluntary organization, $27 \%$ helped their grandchildren, $25 \%$ helped someone in their extended family, and $24 \%$ helped a son. On average, seniors provided help to two different types of people. For example, the same senior may have helped a spouse as well as a daughter (Ibid., p. 82).

While some seniors may be well and active, these authors also suggest that older seniors will need more and more support. This conclusion may be related to the compression of morbidity hypothesis ${ }^{19}$ (Finlayson et al. 2005, p. 15; Forbes et al. 1987, p. 117; Hébert 2002, p. 344; Northcott 1997, p. 42-44). Nevertheless, given the difficulty in predicting morbidity and the onset of death (Northcott 1997, pp. 42-44), it is perhaps safer to examine actual data on the patterns of health and morbidity of seniors when establishing their needs for services, including types of services.

19

The compression of morbidity hypothesis mean that the impact of the aging population on the health care system will be gradual due to the improving health status of older people. Finlayson et al. $(2005$, p. 15) cite the following authors-Barer, Evans, \& Hertzman, 1995; Chen \& Millar, 2000; Doblhammer \& Kytir, 2001; Hubert, Bloch, Oehlert, \& Fries, 2002-to suggest that "the impact of ... aging ... will be gradual..." For a succinct description of the social epidemiology of aging, see Maurier and Northcott (1997, p. 41-44). 
To explain these issues, Maurier and Northcott $(2000$, p. 89$)$ refer to the GSS and observe that " $80 \%$ of seniors aged 80 and older received assistance with meal preparation, housework, or yard work, whereas $58 \%$ of seniors aged $65-69$ reported receiving help with these activities." The authors also consider the opinions of seniors about their own health as indicated in the 1996-97 NHPS. GSS data note that about half of seniors in Ontario, between age 65 and 69, reported their health as excellent or very good, while only 39 percent of those over age 80 reported having good health. Interestingly, the data also indicate that only 12 percent of seniors had used home care in the year prior to 1996 , while 15 percent had been hospitalized (Ibid., pp. 45-47, 78). As well, female seniors tend to have higher rates of illness, disability days, physician visits, prescription and nonprescription drug use, and their health status declines with increasing age. According to Turcotte and Schellenberg $(2007$, p. 46), the most recent data on seniors' self reports of health and well being, "one of the most useful and reliable indicators available in population health surveys", do not suggest significant changes from earlier data, specifically data arising since 1994 .

Maurier and Northcott (Ibid., p. 51) also observe that the income effect on health is significant in explaining the health and morbidity status of seniors; those with higher incomes have more control over their health, in part, because they purchase better and more suitable housing, food and other staples. Turcotte and Schellenberg (2007, p. 46) note that higher education is a good predictor if excellent or good health. These ideas suggest a closer look into the predictors of good health for Ontario's seniors and, when the health of seniors fails, their accessibility to home care. 
I answer these questions by referring, again, to Maurier and Northcott (2000), but in combination with the recommendations of the National Council of Welfare (NCW) which draws upon Statistics Canada data. Maurier and Northcott (2000, p. 50) provide some information on the income (1996-97) of seniors: 85 percent of Ontario seniors relied on seniors" benefits as their "main source of household income"; the household incomes of slightly less than one quarter of seniors was under $\$ 15,000$; the household incomes for approximately 60 percent of seniors varied between $\$ 15,000$ and $\$ 39,000$; the household income for the last and small set of seniors was over $\$ 40,000$. NCW uses Statistics Canada pre- and post-tax Low Income Cut Offs (LICOs) to describe poverty (Welfare 2006); LICOs vary according to family and community size. Data for 1997 indicate the before-tax LICO, for 2-person families is $\$ 18,182$ (Paquet 2002, p. 49). Comparing LICOs with the Maurier and Northcott (2000) data, I observe that slightly more than one quarter of all senior households in Ontario, in 1997, were at or below the poverty line. Recent analysis of the NCW (2006, p. 121) suggest that poverty rates for seniors are improving (see also Turcotte and Schellenberg 2007, pp. 63-71). NCW lists Ontario's 2002 seniors' poverty rate at 12.3 percent (Ibid., p. 122) with 71 percent of poor seniors being female. Poor seniors, particularly, female and lone seniors would need some form of publicly funded home care supports. Thirty four percent of Canadian seniors over age 85 and 22 percent between ages 65 and 74 lived alone in 2001 (Turcotte and Schellenberg 2007, p. 138).

I also use census data to compare the rates of growth of Ontario's senior population to the growth of several public health services: with government funding for 
hospitals and other institutions, respectively, for the period between 1975 and $2003^{20}$, and to home care for the period between 1975 and 1998. The comparison of senior population growth with: a) the growth rate of home care funding demonstrates that the senior population is growing at a rate that is about 2.6 times faster than the former; $b$ ) the funding growth rate for other institutions, e.g., long-term care, demonstrates that seniors are growing at a rate that is 2.3 times faster; and c) hospitals demonstrates that seniors are growing growth at a rate which is about half the rate of growth of hospital funding.

Minimally, these comparisons suggest that Ontario's seniors are not being well served by public health services, particularly home care. The relative decline in home care is worse than these data suggest because, as Caplan $(2005$, p. 3) writes, minimal levels of home supports are funded and home care largely represents acute services. If these trends continue, seniors in Ontario will be even worse off in the future, particularly female seniors. With the above as background, I now refer to the servicing of seniors in regards to home care in the city of Ottawa.

\subsection{Servicing Seniors in Ottawa}

The integration of Ottawa's CCAC into the community, during the period of the Harris reforms, was complex and contested. The first CCAC community Board struggled with the budgetary restrictions imposed upon the community by the Ministry (interview with former Board member). Ultimately, they were replaced by a Board appointed by the LGIC, but this did not ease the problems for Ottawa's CCAC. It increasingly became

Source: Population data from Statistics Canada, Annual Demographic Statistics 2005, catalogue 91-213XPB CD-Rom. Home care funding data from Ballinger et al. July 2001. I refer to CIHI for all other health expenditures. 
characterized by a state of crisis-internal and external, stress and overall anxiety. The internal crisis can be linked to government's cost cutting agenda, and centralized ministerial control over governance, management, and human resources. The situation became so severe that, in 2002, the CCAC commissioned its own operational review (Consulting 2002).

The CCAC review highlighted budgetary issues as being among its key challenges even though its budget was $\$ 0.89$ per capita above the provincial average in 2002 (lbid., p. 8). Two years later, due to the ongoing problems with the CCAC, the new Liberal government established its own review process. The Ministry's report describes a CCAC which was plagued by “'change weariness,' with staff at all levels showing signs of stress" (Carnwath 2004, p. 4). Compounding the staffing problems were financial issues, particularly as costs significantly exceeded funding (Ibid., p. 96). All of these problems were catalogued during a period when Ottawa's seniors population was growing 7 percent faster than the rate of growth of the city's population.

The population of the amalgamated city of Ottawa ${ }^{21}$ was 806,096 in 2001 . Of this population, 11.5 percent were seniors (the provincial average was 12.9 percent). In some areas of the city, seniors comprised as much as 18 percent of the population with as many as 9 percent being over age 75 (Canada 2001; Council 2003, p. 215). Using 2001 data,

21

2001 Census of Canada for Census Metropolitan Areas (Statistics Canada). The 2001 census indicates a multicultural population among Ottawa's seniors with 19.6 percent reporting French as their mother tongue and another 17.9 percent reporting mother tongues other than French or English. The latter could be an indication of in-migration so as to offset the projected rise in numbers of seniors over the next couple of decades. As with elsewhere across the country, estimates for 2016 and 2021, suggested the senior population levels could rise to 16 and 19 percent of the city's population (Council 2003, pp. 215-219). 
the Council on Aging (2004, p. 44) notes that 42 percent of senior households in Ottawa represent seniors living alone; the median income for these seniors was $\$ 26,340$. The median income for the remaining seniors not living alone was $\$ 44,830$. Similar to their counterparts elsewhere in the province, Ottawa's seniors are active, with approximately 17.3 percent of them reporting they provide care or support to another senior. The Council on Aging (2004, p. 40) also differentiate individual seniors' income from household income and observe that for 2000, the median income for individual seniors in Ottawa was $\$ 25,000$; this figure "tends to hide the fact that many have very low incomes, especially women. ... [Some] (41\%) had incomes below $\$ 20,000$ and of these $73 \% \ldots$ were women." When comparing such data with the NCW LICO's, it appears that a significant number of Ottawa's seniors exist at or below the poverty line. Regardless of the complexity associated with the measurement of poverty, it appears that approximately one third of Ottawa's seniors would require some degree of public home care/supports.

Supplementing the work of the Ottawa CCAC to coordinate home care services in the city (Caplan 2005, p. 5) are 23 charitable nonprofits which provide support services (Council 2003, pp. 10, 405). Although small in size and number, these agencies represent significant numbers of volunteers; volunteer hours are indicative of the concern of the community for its senior citizens. A total of 3,608 volunteers were reported to have donated 254,759 hours to service, in 2001-02. These hours are valued at $\$ 3,159,012$, and "actually underestimate... the contribution made by volunteers to this sector" (Ibid., pp. $10,11,248)$. Since $1996-97$, the number of volunteers had increased by only 9 percent, while the number of volunteer hours had increased by 25 percent (Ibid., p. 238). The 
numbers illustrate a serious management problem for agencies which deliver support services and rely on volunteers who are likely to suffer from volunteer burnout.

Ottawa's home care funding allocation for 2002-03 fiscal year was $\$ 106,974,847$ as compared to $\$ 93,918,575$ in the previous year (Ibid., p. 221). They were allocated as follows: CCAC services received 79.75 percent of funding for nursing and therapy, placement coordination, attendant care and homemaking; community support services received 6.2 percent; supportive housing received 4.72 percent; elderly persons centres received 0.35 percent; and palliative care received 0.29 percent (Ibid., 2003, p. 221; see also Consulting 2002). These data represent a service bias against the needs of Ottawa's seniors. Other data substantiate this observation.

The report of the Ministry's operational review of the Ottawa CCAC (Carnwath 2004, pp. 96-97) acknowledges that the CCAC had decreased personal support service hours "in order to match available funding and meet the pressures of increased service rates." It also identifies wait lists for homemaking, personal support and therapy. There were no waits identified for services associated with acute home care, i.e., nursing services, other than the occasional shift nursing. Of all wait times, homemaking services had three wait lists, one of which listed approximately 4,500 clients. Compounding such service deficiencies were issues concerning quality of care. The Ministry's report notes that since the CCAC had stopped offering homemaking, quality of care had fallen so low to the point where "Case Managers [were] not assessing for homemaking unless there [was] an infestation or a threat of eviction" (Ibid., pp. 82-83). External interviews undertaken by the review identified 
concerns that the OCCAC did not seem to understand the value of support services in keeping people in their homes. ... Case Managers [on the other hand] expressed frustration that they could not indicate to clients how long they might have to wait for Personal Support Services. The very term 'waiting list' conveys an expectation that eventually one will get to the top and receive service (Ibid., p. 83).

Another problem which compounded the above was the lack of proper client assessments, particularly full client assessments ${ }^{22}$ (Ibid.).

Six years prior to 2002, a trend had been observed where seniors over age 75 tended to have more complex needs and required "multiple services and more intensive service coordination. ... [A]gencies report that they are serving an increasing frail population" (Council 2003, p. 240). Not only were they more frail but, there was less service available to them. The proportion of seniors who were able to access home support services decreased by 23 percent over the period when Ottawa's senior population had been increasing. The rate of growth in the number of clients served by community support agencies was not keeping pace with the needs of seniors (Ibid., p. 237). Not only is this a problem for seniors and their families, but it represents a substantial struggle for the agencies providing the services.

Average wait lists for various home support services, measured in weeks, are displayed in Table 5.1: Average Wait Times for Home Supports, Weeks. In regard to transportation services, which are not listed in the table, the District Health Council report states, "[t]here has been an increase in the number of unmet requests for service between

22

Without minimizing their importance to the seniors of Ottawa, these problems were common across the province during 2001-04 and were not restricted to Ottawa's CCAC (Auditor General of Ontario 2004; Carnwath 2004, p. 85). 
98/99 and 01/02. Reasons for unmet requests in 01/02: volunteer shortages, staff/worker shortage, insufficient notice given, [and] complex client needs" (Ibid., p. 284). This situation suggests that an increasing numbers of seniors would be unable to access the community supports.

Adult day programs are also problematic. Due to increases in the number of clients and decreases in the number of units of service available, each Altzheimer client receives fewer and fewer units of service (Ibid., p. 229); a similar pattern appears for the

\begin{tabular}{|c|c|c|c|c|}
\hline Service & 1998-99 & 1999-00 & $2000-01$ & 2001-02 \\
\hline $\begin{array}{l}\text { 1. Adult Day for: } \\
\text { - Altzheimer }\end{array}$ & - & $5-16$ & $12-26$ & $4-52$ \\
\hline - Frail elderly & - & 6 & 6 & $2-6$ \\
\hline - Integrated & - & $4-25$ & $2-12$ & $4-12$ \\
\hline 2. Meals on Wheels & 0 & 0 & 0 & 0 \\
\hline 3. Congregate Dining & - & 8 & $6-8$ & 24 \\
\hline 4. Home Maintenance & - & - & $1-5$ & $2-3$ \\
\hline 5. Friendly Visits & $2-12$ & $4-30$ & $4-30$ & $4-16$ \\
\hline $\begin{array}{l}\text { 6. Caregiver Supports: } \\
\text { - Counselling }\end{array}$ & - & $4-6$ & $4-6$ & $4-6$ \\
\hline $\begin{array}{l}\text { - Volunteer hospice } \\
\text { visits }\end{array}$ & - & - & - & 4 \\
\hline - Respite services & - & - & 0.53 & $3-5$ \\
\hline 7. Foot Care & - & - & $2-4$ & $0-4$ \\
\hline 8. Home Help & - & - & $1-3$ & $1-6$ \\
\hline
\end{tabular}


frail elderly who need adult day services and integrated adult day services (Ibid., p. 233). One may infer from these data that Ottawa's caregivers are also suffering as they, themselves, are not being adequately supported. Compounding this lack of support for caregivers, who are increasing in numbers, has been the decreasing numbers of service units available for respite (Ibid., p. 226).

Compounding the wait list and transportation problems is the issue of user fees. The Champlain District Health Council (2002) states, "[o]f concern is the cumulative impact to seniors of user fees. As clients age, they tend to require more services, thus placing an increasing financial burden on the client." User fees vary by agency and the availability of fee subsidies to clients varies from agency to agency. Not all agencies are able to provide subsidies and this is often dependent upon fundraising and outside funding. Thus, for the many seniors in Ottawa who are existing below the poverty line, ability to pay and access to home care are significant problems.

\subsection{Chapter Summary}

This chapter describes the home care context within which Ottawa's charitable nonprofits undertake and perform their advocacy-constituted roles. It identifies five key structures which affect services and access to home care for seniors across Ontario, and for those in Ottawa. They include legislative, budgetary, service types and competition. All are related.

This chapter also demonstrates that, like other seniors across the province, significant numbers of Ottawa's seniors would be negatively impacted by these structures because they exist below the poverty line and would be increasingly dependent, therefore, 
upon public home care, especially as they age. Poverty would also preclude the purchase of private home care services.

The promotion of efficiency reinforces the emergent trend which leads to both the rationing and privatizing of services. It seems, therefore, for significant numbers of seniors in Ottawa and throughout Ontario, efficiency has become their public good rather than equity. As well, solving home care's procurement problems seems to have become the current government's first priority. Finally, all of the above reinforces a focus on acute care services which leaves out huge numbers of seniors who depend on home supports. Compounding this narrow vision for home care are the long wait lists for home supports. Other secondary, but important issues that have been identified in the chapter pertain to the problems associated with the measurement of quality of home care services, which in the competitive environment can affect services and client outcomes, and the issues of labour, paid, volunteer and informal caregivers.

Thus, for Ontario's seniors, and particularly those in Ottawa, a significant number of whom are below the poverty line, there appear to be fewer publicly funded careoptions. This suggests more private payments through user fees, more care by family members, and/or being institutionalized in mainly private for-profit facilities. Finally, the combined issues of population aging and the policies of restraint would suggest an increased reliance on private solutions in regards to the future home care needs of seniors. 


\section{CHAPTER 6 - HOME CARE IN ALBERTA}

\subsection{Introduction and Home Care's Early Years}

Nonprofit charities are a cornerstone of Alberta's modern health and home care systems. Agencies like the Victorian Order of Nurses (VON), the Red Cross Society, and the Grey Nuns had been providing home care services and laying the foundation for the province's health and long term care system for up to three quarters of a century prior to home care's formal establishment in 1978. They established hospitals, did home visits, initiated public health movements through women's associations, developed courses in public health nursing, and set standards for high quality services (Ross-Kerr 1998, pp. 612, 74-82). Their contributions were so significant that Ross-Kerr writes (Ibid., p. 8), "the foundations laid by the Grey Nuns provided a standard of service that other hospitals and health agencies have had to work diligently to meet."

Formal or publicly funded home care, called the Coordinated Home Care Program, appeared following two years of pilot projects in the period between 1976 and 1978 (Health 1992). Although home care's purpose was to maintain independent living for the elderly (Health, 1992, p. 1), Forbes (1987, Table 3.2) notes that Alberta's institutionalization rate of the elderly was the highest in the country, at this time. However, Northcott (1990, p. 3) observes that the institutionalization rate declined between 1976 and 1986 from 13.4 percent and 10.2 percent, respectively.

In 1984 , home care was expanded to provide support services to seniors on a universal (regardless of need) basis (Health 1992; Northcott 1997, p. 94). Palliative care services were added to the newly expanding services (Health Canada 1999 b., p. 38). In 
1991, a Single Point of Entry (SPE) was established for "persons requiring long-term care to ensure that all possible community options are explored 'before admission to a long term care facility is considered"' (Northcott 1997, p. 94). Finally, in 1991, seniors gained access to home supports regardless of their need for professional health services (Health 1992, p. 1).

When formal home care was introduced in Alberta, its funding represented $\$ 0.14$ per capita as compared to the province's health expenditure ${ }^{23}$ which amounted to $\$ 504.73$ per capita (both in current dollars). This funding level placed Alberta in $6^{\text {th }}$ place among the provinces. By 1998, its rank in relation to home care funding in the amount of $\$ 65.01$ per capita fell to $7^{\text {th }}$ place (in current dollars; the average of all provinces was $\$ 90.22$ per capita); its overall health spending was $\$ 1,688.58$ per capita (Ballinger et al. 2001; CIHI 2005). Despite its lower ranking between 1978 and the early 1990s, Alberta Health (Ibid.) writes, "Home Care [had] grown to become the largest program in health units and the largest community care program in the health and social service system." Home care would have a key role in the future, but its purpose would shift in support of government's cost reduction strategy in relation to acute care services.

As with the other provinces and territories, the introduction of the federal government's funding cuts to medicare which were first introduced in 1977, through the EPF, meant that, sooner or later, Alberta would need to respond accordingly. Initially, the EPF and the elimination of the 'fifty cent dollar' wasn't particularly problematic because Alberta's economy was comparatively strong during the late 1970s and early $1980 \mathrm{~s}$. The

\footnotetext{
${ }^{23}$ Ballinger et al. (July 2001) report and CIHI (2005), Table D.4.9.3.
} 
EPF tax point allowances actually produced increasing tax revenues which simply offset the federal government's new funding restrictions. Eventually, the province's total EPF "transfer ... became more than twice the value of... [its] cash payment", and this surplus became its "fiscal dividend" (Hyndman 1989 c., p. 68). For a few years, the fiscal dividend actually buffered the province against the economic realities associated with the federal government's policies.

Nonetheless, when the federal government unilaterally decided to both terminate its revenue guarantees to the provinces and introduce technical changes to the EPF funding formula, Alberta's transfers were reduced so significantly that its surplus actually started to evaporate. For the first time, the province experienced the full effects of the federal government's policy changes. When the federal government decided in 1986-87 to "reduce the growth rate of the total EPF entitlement to nominal GNP - 2\%", Hyndman (1998 c., p. 69) indicates that Alberta's fiscal reality required some major adjustments.

Philippon and Wasylyshyn (1996, pp. 73-75) describe six broad initiatives used by government to kick-start the adjustment period. They include: the introduction of the concept of efficiency, the reallocation of financial resources among hospitals based on performance, and the introduction of a severity-based funding system; greater use of community resources; closing the "open-endedness of many high-cost health-care programs" while also conveying the idea that "health providers [including physicians] had to work within a defined budget"; and the initiation of a major health sector review to secure funding reductions to the health sector. The 1987 review was called the Premier's Commission on Future Health Care for Albertans (Commission). Its report is commonly 
referred to as The Rainbow Report (Hyndman 1989 c., p. 69).

Two of the Commission's specific tasks included curtailing rising institutional health sector costs (Hyndman 1989 c., p. 69), and managing the growing number of aging Albertans who, increasingly, would be dependent upon the health system (Hyndman 1989 a., p. 61). It responded by articulating a new vision for health services for Albertans which, among other things, included significant reductions in the financing of institutional health services (Philippon and Wasylyshyn 1996, p. 71; Northcott 1997, pp. 96-101).

With the above as background on home care's formative years amidst other realities and pressures, the chapter uses a chronological approach to present the ongoing developments in home care and these are presented in light of the fiscal restraint theme and a restructured health system. The first section begins by explaining Alberta's cost containment strategies in terms of messages which prepared the population for change. These are followed by a brief examination of new legislation, the implementation of regionalization and a recent policy targeted to seniors care needs. Home care is then, briefly, outlined in terms of these issues. The next section takes a closer look at seniors in Alberta, particularly with the intent of presenting another dimension of the needs of seniors while also examining their ability to respond to government's policies in relation to home care. The next section presents a few preliminary ideas from researchers and the Auditor General for Alberta on the impacts of government's high level policies on regional decision-making, on accountability, and on continuing care services. Following this is a closer examination of the services which are available to seniors in the Capital Health region, i.e., in Edmonton. The chapter ends with a brief summary of the context 
within which Edmonton's charitable nonprofits perform their advocacy-constituted roles.

\subsection{Alberta's Cost Containment Strategies}

\subsubsection{Setting the Stage for Change}

The Commission's report, entitled the 1989 Rainbow Report: Our Vision for

Health, was the first of several years of studies, task forces and policy changes ${ }^{24}$ which set out the government's agenda to control costs and to reduce provincial government spending on health care (Philippon and Wasylyshyn 1996, p. 75; Northcott 1997). A key strategy endorsed by the Commission to promote this goal was the introduction of a new regional model for the local administration of health services (Hyndman 1989 a., pp. 40, 41; see also Hicks et al. 2000, p. 1). As well, a new message was being conveyed to the citizens of Alberta and that was a call for their increased individual responsibility and self reliance in regards to their own health needs (Health 1992, p. 5). Northcott (1997, pp. 89, 92) cites Neysmith (1987) to explain how among the government's responses to the mid1980s downturn of the economy were messages which emphasized individual selfreliance and messages which meant a shift from universal entitlements to entitlement restricted to need with respect to seniors programs.

These messages were reiterated in Alberta Health's report "New Directions for Community Support", released in 1992, which identified a greater role for home care.

24

These include the following. Home Care in Alberta, New Directions in Community Support, August 1992. Starting Points 1993 and Healthy Aging: New Directions for Care 1999 are two government studies. The altzheimer and dementia task force released its report Altzheimer Disease \& Other Dementias in 2002. Three policy directive reports include the Partners in Health released in 1991, A Framework for Reform released in 2001, and Alberta's Healthy Aging and Seniors Wellness Strategic Framework 2002-2012. Philippon and Wasylyshyn (1996) provide a good summary of the reform process and its antecedents. 
The Alberta Health (Health 1992, p. 1) report states,

The decade of the nineties will see program adjustments based on the recognition that good health is dependent on factors beyond traditional health care services. The new environment of fiscal pressures has created the momentum for re-examination and change throughout the health system. Many of these changes will involve Home Care, presenting new opportunities for achieving the program's mission.

The purpose of this report was to generate discussion about health system reform, but in relation to home care's greater role in a health system which was experiencing pressures

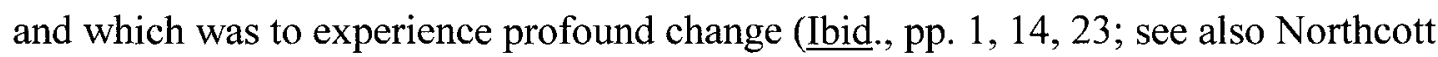
1997, p. 94). It identified the need for new partnerships and collaboration between home care and other sectors of the health system, the existence of a 'consumer rights movement' which demanded a range of home care service options while also representing an opportunity for their increased participation in the community, an aging trend, the introduction of new technologies, and fiscal constraints because resources were 'finite'. All of these required fiscal policies which make better use of existing resources and which develop further community care (Health 1992, pp. 2-4). Following on the heels of this report was the arrival of a new provincial leader determined to make his mark.

Taft and Steward (2000, Chapter 4) describe not a change in government, because the Progressive Conservatives have been in power since 1971 (Nodice 2005), but rather how Mr Klein who took office in 1993, as the new Premier, chose to compete with his predecessor, Mr. Getty, so as to make his own mark on the policy environment. They write,

when he became Premier, Ralph Klein went into communications overdrive to convince Albertans that spending had been soaring in the 
Getty years. It is an astonishing and disturbing example of the power of a skilled and determined communicator to reshape information. Over and over, Premier Klein told Albertans that spending had been 'out of control' before he came to power $(2000$, p. 35$)$.

Later they explain that the basis upon which Mr. Klein secured support for the cuts to health budgets and other public services was inaccurate and misleading (Ibid., p. 37). They claimed, "there was no real change in per capita spending on health care for almost ten years before any of his cuts began in 1992" (Ibid., p. 111). On the other hand, Alberta's health care spending had surpassed the health spending of all provinces for 1976, 1981 and 1986, and was second highest in 1991 (Ibid., p. 114). By 1996, however, Alberta's health spending was

lower than the Canadian average, and third lowest among all provinces, just below the levels of Newfoundland. [sic], Prince Edward Island, Manitoba, and Saskatchewan. Alberta actually reached its highest level of

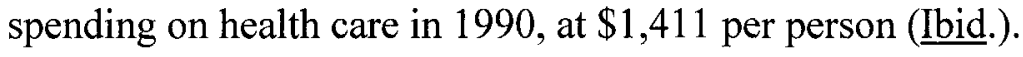

CIHI (2005, Table B.4.2) data place Alberta in $6^{\text {th }}$ place among the provinces and territories, in 2003, with respect to its health spending. Given its high spending on health services during the period when the federal government initiated its spending controls, Alberta began prepare the population for reform using messages which appear timeless in relation to their use by government.

The following are short excerpts taken from government documents which both prepared citizens for the changes that were about to take place and which, because of their use throughout the decade, appear to be a foundational aspect of the government's approach. Central to all excerpts which address seniors' needs are the themes of self care, family care and community care. The earliest document cited frames home care as a 
service whereby "individuals and groups manage their own care" (Getty 1991, pp. 2, 39, 35; see also Health 1992, p. 5). Another document links individuals "to health and welfare services, family friends and volunteers. Such... network $[s]$... keep the elderly or the chronically ill out of hospitals or nursing homes and might relieve the taxpayer of the burden of institutional costs" (Hyndman 1989 a., p. 61). A more recent document claims that, "While many seniors want to remain independent as long as possible" it also maintains that "independence' has to be balanced with 'interdependence"” (Broda 1999 c., p. 16). Altogether, the messages appear to be that autonomy for seniors means selfcare, then family care, then possibly friend-care, and when all else fails, the health system will provide. The study undertaken by Saunders et al. (2001, p. 508) on the trends in the utilization of health services by seniors in Alberta, for the period between 1992 and 1998 , reinforces this observation; it acknowledges that the policy shifts probably meant more self-, family- and privately-funded care for seniors. In addition to messages which communicated that citizens, particularly seniors, would need to change their expectations in regards to health and home care services, government also changed the way in which it referenced its citizens and services.

Noteworthy in government documents is the general use of market terminology. Citizens are referenced as consumers and home and health services are framed as commodities. It is not unusual, for example, to read 'consumer-first', or messages which promise a more 'service-oriented' and 'consumer driven' health sector. Albertans are told they come "first", as consumer-Albertans. As a result, they would be at the centre of all decision-making... [H] ealth services [would] be delivered 
more cost-effectively and with the flexibility Albertans deserve. ... '[O]nestop shopping' [would be available in each region] for the consumer. ... However, consumers... [were also told that] they [would] need to pay for services considered non-essential under a newly created definition of basic health services (Mirosh and Oberg 1993, p. 13).

Being consumers, on the other hand, also meant that, as with any commodity, Albertans would get to choose from the continuing care market place what goods they and their families might purchase (Health 1992, p. 2; Hyndman 1989 a., pp. 6-8). Albertans know best what their health needs are - not government... [Hence, Albertans will] learn how to stay well. ... [But, c]onsumers need to be taught more about keeping themselves well through diet, exercise, stress reduction, and proper use of medication - among other practices. ... [and] wellness promotion must become a regional responsibility (Mirosh and Oberg 1993, p. 19).

Thus, consumer Albertans would also be taught how "to stay well -... [rather than] just

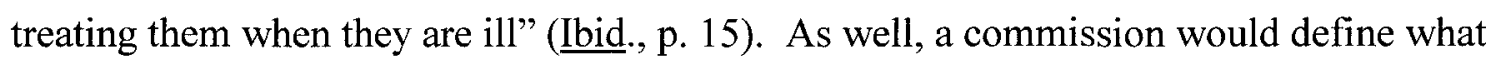
would be included as the basic set of services in the health market (Ibid., p. 16). Nevertheless, the Health Planning Secretariat (Secretariat) did not indicate what criteria would determine how basic services were to be defined and/or who would participate in the planning / defining exercise.

Altogether, the plan meant eliminating "waste, inefficiency, duplication and over expenditure" in the health system (Ibid., p. 5). Moreover, according to government documents (Mirosh and Oberg 1993, pp. 24, 26), seniors would need to pay "for services outside the definition of basic health services". The role for consumers, on the other hand, was to become more accountable when using health care services. Government documents suggest that consumer accountability would be facilitated by providing people 
with the costs related to their use of services (Hyndman 1989 a., p. 25; Mirosh and Oberg 1993, p. 10).

Northcott (1997, p. 89) explains that the policy changes introduced by the Alberta government shift programs for seniors away from age-based universal entitlement to programs based on 'need'; age becomes less "salient as a criterion for social entitlement." He identifies how the new policies reflect "equality of opportunity" which rewards initiative and success, but may also lead to "inequality of outcome." He also maintains that while such messages were targeted to all health users, seniors have been unfairly targeted (Northcott 1997, pp. 98, 105, 107-108). For him, the targeting of seniors, in this manner, is useful because it creates a health expenditure 'crisis' which he claims is not supported by evidence. In this manner, he suggests that government reduces not only current expenditures to seniors' services, but also the rate of growth for future expenditures except for the most needy seniors (Northcott 1997, p. 98). His claim (Ibid., p. 101) is that the Alberta government has(is) offset(ing) its responsibilities to citizens, particularly the elderly and their families. Taft and Steward (2000, p. 99) share this view and make the point that seniors and their aging are not responsible for the fiscal situation in relation to health; rather it is that our "health-care responses to aging that are often poorly managed."

Nevertheless, having prepared the population, government proceeded with its plan and established the Health Plan Coordination Project (HPCP) which was tasked with recommending the specific strategies for change (Philippon and Wasylyshyn 1996, p. 75). The HPCP was given fifteen months to achieve their outcomes because 1994 was targeted 
as the year for action.

\subsubsection{Legislation, Regionalization and Home Care}

\subsubsection{Legislation and Regionalization}

In May, 1993, government passed the Deficit Elimination Act which set out the goal of eliminating the deficit in four years using expenditure cuts rather than through tax increases; the strategy was reaffirmed in the 1994 budget and in the Alberta Health Business Plan (Philippon and Wasylyshyn 1996, pp. 74-75; Northcott 1997, p. 95). According to Philippon and Wasylyshyn (1996, p. 75), the purpose of the Alberta Health Business Plan was to reduce "total provincial government spending on health care from \$4.2 billion in 1992-1993 down to \$3.4 billion in 1996-1997" (see also Northcott 1997, pp. 96-101; Saunders et al. 2001, p. 495). Its four goals included: appropriate high quality care in appropriate settings; enabling Albertans to lead healthy and independent lives; requiring increased personal financial contributions towards health costs through health premiums; and requiring increased individual accountability and responsibility for health (Philippon and Wasylyshyn 1996, p. 76). According to Saunders et al. (2001, p. 495), establishing the health regions was a key aspect of the overall plan to reduce health expenditures and restructure the health system. Age based entitlements for seniors were also eliminated and replaced by a Seniors Benefit targeted to less financially well-off seniors (Northcott 1997, p. 95). Northcott (1997, p. 95) suggests that "equity among the generations" is the principle underscoring the government's age related policy changes.

While population aging in Alberta tends to exacerbate fiscal difficulties, nevertheless, the primary causes of the fiscal crisis lie elsewhere. The population aging crisis scenario, however, justifies cuts in expenditures for 
seniors while at the same time placing blame for these cuts on the growing number of seniors themselves. (Emphasis in original.)

He also (1997, p. 108) explains that government framed Alberta's fiscal situation in terms of spending problems as opposed to revenue problems so as to justify the respective policy changes. Hence, through all of the above, the future costs of supporting the aging population would be reduced (Ibid., pp. 96, 98)

In 1994, five years after the Commission released its report, The Regional Health Authority Act (RHA) was proclaimed (Alberta 1994; see also Lomas $1999^{25}$ ). One year later, the Public Health Act was amended through Alberta Regulation 164, Application in Respect of Regional Health Authorities Regulation (Alberta 2001). This amendment transferred the responsibilities and functions of local health boards to Regional Health Authorities (RHAs) (Alberta 2001, p. 2). With these legislative changes in place, the regions became the sites for the rationing of health services under the direction of the Ministry of Health and Wellness (MHW).

More recent changes have been introduced to the Public Health Act (Association 2003, p. 1/14) as per the Coordinated Home Care Program Regulation 296/2003 (Regulation) (Alberta 2003). The Regulation has changed home care's availability to citizens by making it an 'optional' service (Ibid., pp. 3, 4, 6). Exceptions are made, though, for people on social assistance, widow's pension, old age income supplement or AISH. Although the Regulation 'de-lists' home support services, professional nursing services are ensured (Ibid.).

25 Physician services and drugs were exempt from the Act (Lomas 1999). 
Within this regional framework, the responsibilities of the MHW currently include: establishing the direction, policy, and standards for the health care system; setting priorities based on the health needs of citizens; overseeing financial, capital, and human resources requirements; measuring and reporting on the health system's performance; promoting wellness and preventing disease and injury; facilitating informed decisions about the health of Albertans; and engaging in cross-ministry initiatives to address challenges to the population's health and wellness (Wellness 2006). All of the above accord with the Commission's recommendations and the foundational policies of Alberta Health (Health1992) to restructure the health system, in part, by using home care as an acute care substitute.

\subsubsection{The Seniors' Policy Initiative or Action Plan}

More recently, in 2001/2002, eighteen departments and government entities came together to "develop a strategic framework and 10-year action plan" for seniors (Healthy Aging 2002, p. 11). Its various names include the Seniors Policy Initiative (SPI), the "cross ministry Health Sustainability Initiative" (Ibid., p. 8) and the senior's action plan. This plan builds upon previous studies (e.g., Broda 1999; Wellness 2000 a., b.), but combines their messages - consumer choice and individual responsibility and accountability - with the messages associated with the health determinants. Government defines the health determinants as:

income and social status, social support networks, education, employment and working conditions, social environment, physical environment, biology and genetic endowment, personal health practices and coping skills, healthy child development, health services, gender, and culture (Healthy Aging 2002, pp. 8, 3). 
The plan recognizes health services as only one of several requirements for being healthy and well and, in this regard, it separates medical-functional needs from social-health needs. It states, "The medical-functional dimension focuses primarily on physical health and functional capabilities. The social-health dimension focuses primarily on emotional health and social and mental functioning" (Ibid., p. 15). The action plan also outlines four components of successful aging: "promoting health and preventing disease and injury", "optimizing mental and physical function", "managing chronic conditions" and "engaging with life" (Ibid., pp. 16, 30).

Although the action plan does not address the specifics about how these goals are to be achieved, it does acknowledge the primary role for the regions, but in partnership with other stakeholders such as individuals, families, communities, voluntary and community organizations, municipalities and corporate communities, among others (Ibid., p. 31). "Stakeholders are invited to use this framework to identify their healthy aging and seniors' wellness needs and to develop programs and services to meet those needs" (ㅁid., p. 7). However, the first or most important direction of the strategy is "healthy aging" (Ibid., p. 7). Under this new philosophy, Albertans will "have a sense of pride in [their] healthy aging and [will be] provided opportunities to live independently in a safe and supportive environment" (Ibid., p. 8).

Under the action plan, home care is framed as one of eight opportunities available to seniors seeking to experience healthy aging. Interestingly, the government had previously identified supportive housing, one of the opportunities listed (Ibid., p. 10), as a sector which promised an increased role for the "private sector ... in providing the new 
housing alternatives so people can 'age in place"" (Broda 1999 a., p. 9; see also Anderson et al. 2000). For Anderson et al. (2000) increased private sector involvement puts in question the future direction of continuing care services.

The ideas of the seniors' action plan are similar to those which previously been communicated to the public through the 1999 Broda report. In that report, seniors had been told, they could expect to access to 'home care' independently and privately. Moreover, they were told this service trend would only increase because long-term care costs were rising and were expected to continue doing so (Ibid., p. 14, 1999 c. p. 65).

While the seniors' action plan guides the planning and service delivery work of regions with respect to health promotion, disease prevention and continuing care programs (Healthy Aging, p. 31), it is silent about the responsibilities for the respective stakeholders. It doesn't articulate how the health needs of seniors will be addressed through either, or both, the medical-functional and/or social-health dimensions of their health needs. Nor does it outline how home care and home supports could represent an opportunity for seniors to 'age in place' and remain independent.

\subsubsection{Home Care}

During the late $1990 \mathrm{~s}$, the period immediately following the introduction of the regional model, DiMatteo and DiMatteo (2001, p. 320) write that Alberta shared with Prince Edward Island the status of being the lowest public home care spender in the country. This low expenditure rate coincides with the period during which the institutional sector was also being reformed: acute care beds were reduced, hospitals were closed, day surgery was increased, admissions and hospital stays were reduced and, 
palliative and post-operative care was shifted into the community (see also Saunders et al. 2001, p. 495). Saunders et al. (2001, p. 504) also observe the decline in the rate of longterm residents for the period between 1990 and 1996 and the increase in average care intensity for residents, particularly those under age 65. They also identify the "lack of an abrupt increase in out-of-hospital services to parallel the sharp declines in hospital utilization rates"(Ibid., p. 508). Their observations align with government's strategy to eliminate the province's deficit through service cuts.

Home care services, managed by the regional authorities, are available as one of three streams of service under a continuing-care umbrella. The two other streams of service include a supportive living stream and a facility living stream (Broda 1999 a., p. 16). A population-based funding formula which considers a region's total population including age, gender and socio-economic traits governs the planning and delivery of these services. The formula also considers how services are planned and provided in other regions. Although government finances home care and the other two continuing care streams, a significant degree of continuing care is now self pay.

Among the responsibilities of the regional authorities is oversight of service contracts in relation to continuing care services. Anderson et al. (2000, p. 26) explain that the regions contract for services in residential settings (care centres, supportive housing and assisted living) to both for-profit companies and charitable agencies which provide home care. "Within the facility and supportive housing streams there is a mix of public and private ownership, and within 'private' there are FP [for profit] organizations and NFP [not-for-profit] organizations" (ㅎid.). Professional services, e.g., assessment and 
discharge planning, are generally provided by the regional authorities, while home supports are provided by a mix of agencies (Broda 1999). Specific home care services include "professional services such as assessment and case coordination, nursing, physiotherapy, occupational therapy and nutritional therapy, and support services such as homemaking and personal care services" (Broda 1999 b., p. 5). Nevertheless, funding is capped and services are rationed. For example, professional home and support services are capped at $\$ 3,000$ per month, and homemaking services require co-payments of $\$ 5$ per hour, to a maximum of $\$ 300$ per month. Home supports are provided "on a sliding fee schedule for individual and family income" (Broda 1999b., p. 11).

For Anderson et al. (2000, p. 28-34), it is not the public-private split which is problematic for stakeholders, rather it is that "type of ownership in the continuing care sector may change, and this will have a significant bearing on the nature of 'the industry' in the future." They consider how budget caps, which were introduced in the early 1990s, in combination with competitive processes determine which organizations will provide care and create opportunities for increased private market involvement. They also note differences with respect to how the various providers-public, nonprofit and private- use funds and are efficient in responding to the tendering process. They also note that private sector companies use non-unionized workers and this work-force leads to depressed wages [which makes] making community-based care less attractive, when compared to the institutional settings. Irrespective of the unions, however, there is an ongoing struggle to retain staff as the institutional settings provide better wages and more stable working conditions than do the community-based jobs. A general concern regarding the Broda report is that more attention should have been given to the human resource issue, and in particular, to increasing salaries (pp. 33-34). 
They also note that, although three key drivers of change in regards to the continuing care system seem to be caused by private capital investments and labour, population aging, and changing values, the predominant one appears to be the role for capital. In addition to the above, they identify the transition in the broader health system, namely the shift towards post acute-care, which is taking place at the expense of home support services.

In addition to the above, Anderson et al. (Ibid, pp. 26, 30-31, 35) identify several issues in regards to tendering which may be problematic, particularly for the continuing care sector. First, for profit agencies generally have "a greater understanding of the tendering process." Nonprofits, on the other hand, may do fundraising which can subsidize a region's service allocations. Nonprofits "can also undertake a strong advocacy role (e.g., for seniors issues), and can do so quite often through their fund raising capacity". This may be supplemented by grants and public funds. Charitable nonprofits may also reinvest additional funds back into their operations. On the other hand, they often lack the appropriate skills that are required to participate effectively in RFP processes. For-profit companies, on the other hand, are better skilled at participating in, and succeed with these processes, but they do not advocate for, nor do they provide additional and/or supplementary services. These authors claim such issues make for an uneven playing field, particularly for charitable nonprofits. For seniors, on the other hand, Anderson et al. (2000, p. 34) note the lack of defined client outcomes and ask whether or not quality ought to include increased quality of life and of services, and improved quality of care. Quality of outcomes would pertain to all providers, regardless of ownership. So how do Alberta's seniors respond to the above listed policy changes? 


\subsection{Alberta's Seniors}

During the early 1990s when government introduced its reform initiatives, 230,550 Albertans, or 9.1 percent of the population was classified as a senior over age 65 and, of these, 3.7 percent were over age 75 (Northcott 1997, pp. 23-24). Alberta's senior population was the lowest in the country. Projections for 2016 suggest that seniors will represent between 13.4 and 14.5 percent of Alberta's total population; of these, between 1.81 and 1.84 percent will be older-old. Half of Alberta's seniors reside in Calgary and Edmonton (Ibid., pp. 25-27).

As with their counterparts in Ontario, senior Albertans are well and active. For example, in 1991, up to 20 percent of seniors reported they were active in the labour force. As well, most seniors reported they live independently and their health was either good or excellent. They were "cash poor, but assets rich", according to Northcott (lbid., p. 36), but for many, their homes and key assets are in great need of repair.

Also similar to their Ontario counterparts, senior Albertans experience an income effect on health with health status increasing with income. Moreover, while only a few seniors are hospitalized, when they are hospitalized, their length of stay is generally longer than the hospital stays of non-seniors by a magnitude of three (Ibid., pp. 44-45). While most seniors use medical services infrequently, and support services rarely, as they age, senior Albertans use more physician services than the average Albertan (Ibid., pp. 66, 44; Saunders et al. 2001, p. 504). This is an indication of declining health with increased age. The average cost of home care and the number of care hours increase with increasing age, particularly for those over age 85 (Saunders et al. 2001, p. 501). 
During the 1991-92 period which was prior to the introduction of government's cost controls, 86 percent of home care clients were seniors. What is at issue, in light of government's recent policies to rationalize the health sector, is the degree to which public home care is currently available and accessible to seniors and/or whether or not seniors can afford private payments for home care and supports.

With the goal of partly addressing this concern, I refer to the Broda report (1999) which reveals median income for seniors, and the policy recommendations of the NCW (Welfare 2005, p. x) which refers to Statistics Canada data on low income cut-offs (LICOs). According to the Broda report, the 1995 average before tax income of a lone senior in Alberta was $\$ 23,467$, and the median income was $\$ 16,000$ (Broda 1999 b., p. 19). The report states, "Senior families have a much higher income, about twice as much on average" (Ibid.). Paquet (2002, p. 48) lists the 1995 before-tax low income cutoff (1992 base), for a one person family at $\$ 12,532^{26}$. These data suggest that significant numbers of lone seniors in Alberta could be living at or below the poverty line. Northcott (1997, p. 37) provides more details in relation to this assertion. He writes, in $1992 \ldots, 5.6 \%$ of seniors received the maximum [guaranteed income supplement] GIS, meaning that they had little or no other income than the [federal Old Age Security] OAS. Another $33.9 \%$ of seniors received partial GIS meaning that they had modest incomes from other sources than the OAS. Over half of seniors ... (60.5\%) had sufficient income that they did not require any supplementation ... Of these, some were "near poor" while others were more well-to-do. Second, the risk of being (income) poor increases with increasing age, and this is higher for women and for persons without a spouse.

26

Before-tax LICOs for families of one and two, as averaged against all sizes of communities, are calculated as $\$ 14,151$ and $\$ 17,688$, respectively (Paquet 2002, p. 34). 
For 2002, NCW reflects a downward, but levelling trend for seniors' poverty in Canada; Alberta's rate is the lowest at 9.3 percent (Welfare 2006, p. 121); of these poor, 75 percent are women. When public home care is rationed, access to private home care services for poor seniors, particularly lone and female seniors, would be problematic.

I also use census data to compare the rates of growth of Alberta's senior population to the rates of growth of several public health services, specifically, government funding in relation to hospitals and other institutions, separately, for the period between 1975 and 2003 27 , and to home care for the period between 1975 and 1998 . The comparison of senior population growth to the growth of home care funding demonstrates that Alberta's senior population is growing at a rate that is about 3.1 times faster than home care funding. Seniors are growing at a rate which is 2.8 times faster than funding for other institutions. Lastly, seniors are growing at a rate which is 0.378 faster than that for hospital funding.

As well, the trend in regards to seniors and home care may be worse than these data suggest because of acute care substitution in home care ${ }^{28}$. Compounding these issues is the policy and practice which reduced the availability of chronic care services that were traditionally provided in institutional settings and which were formerly protected by the CHA (see Saunders et al. 2001). Such services have been replaced by the three streams of

27 Canada 2005; Home care funding data from Ballinger et al. July 2001. I refer to CIHI (2005) for all other health expenditures.

28

Data on the distribution of home care expenditures in terms of acute care versus home supports is not available for Alberta (Ballinger et al. July 2001). 
continuing care, all of which require client fees. The above raises the concern of whether or not Alberta's seniors, particularly female and lone seniors, are well served by public continuing care services. In light of this concern, Northcott $(1997$, p. 65) identifies the requirement to study the needs of seniors, especially those who are most at risk and who are not easily identified: females, older and frail seniors, the dying, the socially isolated, the most poor, those who are recent immigrants, and those suffering from chronic conditions such as diabetes, foot problems, arthritis, dementia and so forth. The following presents a few preliminary opinions about the impacts of change from a variety of perspectives.

\subsection{Assessing The Impacts of Policy Change}

While some see regionalization as an opportunity for improved decision-making and more efficient allocations of care at the local level, Frankish et al. (2002, pp. 14711472) and Lomas (1999) question the validity of these expectations. For Lomas (1999, p. 180-181), the regional model seems to represent a "convenient way to shift blame and place a buffer between [government] and community discontent with the consequences of fiscal retrenchment." Frankish et al. (2002, p. 1477) write, "there is as yet little empirical evidence to indicate that they [, regions,] make better decisions (and thus produce better health outcomes), allocate resources more appropriately, or use resources more efficiently than did the authorities that existed before their creation." It is not clear, therefore, to what effect has been government's devolving of responsibility to the regions.

Another factor which makes empirical analysis difficult, particularly in regards to outcomes for seniors, pertains to the number of oversight bodies which are responsible for 
seniors' care. The Auditor General for Alberta (AGA) identifies how oversight for home care services, for example, is fragmented among the regions, the MHW, local municipalities, quasi-governmental bodies as well as private and nonprofit agencies (Dunn 2005, p. 1). Seniors' needs are also overseen by the Ministry of Seniors and Community Supports (MSCS) in relation to the Alberta Seniors Benefit Program (Dunn 2005, p. 53). The specific services available to seniors under this Benefit Program include: providing financial support and information services to seniors; managing and providing seniors, family, and special purpose housing; undertaking planning and policy development for seniors, senior's housing and Alberta's aging population; overseeing the program Assured Income for the Severely Handicapped (AISH); and promoting the inclusion and participation of Albertans with disabilities (Supports 2002). The 2001/2002 Seniors Policy Initiative (SPI), mentioned above, is another example of fragmented authority in relation to services for seniors' services.

A couple of potential risks exist in relation to this degree of fragmented responsibility for seniors' care. One is that the health needs of Alberta's elderly citizens are poorly defined, managed and met, and that quality of services available to them is compromised. Another may be that accountability to the public is being obfuscated.

These types of concerns are documented in the AGA's May 2005 report (Dunn 2005). This report summarizes an audit of senior care programs which are the responsibility of MHW, the regions and MSCS. Although the report mainly considers long-term care facilities, the Seniors Lodge Program and the Alberta Seniors Benefit Program, the findings are indicative of the kinds of problems that may also arise in 
regards to home care. Because of the problems which exist in the health system, some of which have been highlighted above, the AGA recommendations included tasks to: develop and maintain standards, and undertake regular reviews so that compliance with standards can be enforced (Ibid., pp. 7, 29, 31); collect information on costs and charges so that the appropriateness of fees can be determined; monitor compliance with legislation (Ibid., pp. 9, 37); "establish standards for care and housing services provided in assisted living and other supportive living settings" (Ibid., p. 11,45); and require MSCS to obtain further information which would facilitate improved decision-making with respect to cash and accommodation benefits to help seniors with the necessities of life (Ibid., pp. 13, 55, 56).

Of particular interest to this research is the AGA's finding that the costs of some assisted living settings, through which home care may be accessed, are impediments to access for many seniors. The report states,

In many cases, the costs of living in an assisted living setting are similar to the cost of long-term care facilities but residents in the assisted living settings do not qualify for the supplementary benefit. This is an issue because the government's objective is to shift seniors from long-term care facilities to supportive living settings. However, without adequate support, seniors may not be able to afford to live in supportive settings (Ibid., $p$. $57)$.

On this particular problem, the AGA considers future funding plans as being inadequate.

Other problem areas include: outdated cost estimates used to fund the regions; lack of information on both the determination of quality of services and the standardization of quality between regions (Ibid., p. 2); and lack of minimum standards for services provided in assisted living and other supportive living settings (Ibid., p. 4). 
Another issue identified by the AGA relates to quality of care in relation to personal care attendants, an unregulated health group of workers who are often trained on the job. While certification programs are available, the curriculum's completion is not required prior to employment as an attendant (Ibid., pp. 23-24). As well, nurses and licensed practical nurses (LPNs) are aging and the existing problems associated with their recruitment are worsening (ํid., 2005, p. 25).

One issue not specifically addressed by the AGA was wait lists. Rather, the AGA report examines how residents are admitted in long-term care facilities and it examines the conditions of these facilities. The report states that people are placed in long term care on the basis of 'first available bed', and facilities have the right to refuse prospective residents if they cannot provide the appropriate care. Moreover, at the end of 2003, "over $75 \%$ of long-term care residents were in the highest three categories of functional need." As well, the functional needs of residents are about 35 percent higher than they were in 1990. The net result is that seniors are living at home longer and when, and if, they enter long-term care, their needs are greater (Ibid., pp. 20-22). The issue which is relevant here relates to the availability and accessibility of home care to seniors prior to their admission into long-term care.

When writing about home care, Anderson et al. (2000, pp. 35, 39, 40) make the point that because of the connectivity between services, wait lists in one area will affect wait lists in other areas. They also identify a higher acuity level of clients within home care which arises from wait lists for long term care, from hospital closures and the increased use of acute home care. Their conclusion is that funding for home care is not 
keeping pace with demand. As a result, clients are relying on families because of service cuts to home care and/or they are going without services. I now examine how these issues relate to seniors in Edmonton.

\subsection{Servicing Seniors in Edmonton}

The Capital Health Regional Health Authority (CHRA) is responsible for the health needs of Edmonton's population ${ }^{29}$. In 2001, approximately one third of senior Albertans resided in this metropolitan area and represented 10.6 percent of Edmonton's population. This percentage was marginally higher than the average proportion of seniors, i.e., 10.4 percent, who resided in other locations in the province (Census of Canada, 2001). For 2005, Statistics Canada (2007) estimates median family household income for seniors, in Edmonton, between the ages of 65 and 74 years as $\$ 58,300$, and for seniors over age 75 as $\$ 45,600$; median income for lone-family seniors for similar age distributions are $\$ 24,200$ and $\$ 21,000$, respectively. One and 2-person LICOs for 2005 are $\$ 20,778$ and $\$ 25,867$ (Welfare 2006 , p. 146). These data suggest that poverty would be a problem for seniors in Edmonton, particularly lone seniors and female seniors (Ibid.).

The 2005-06 annual budget of the CHRA was $\$ 2.4$ billion of which approximately 4.03 percent was allocated to the community and home-based services (Health 2007). This is down from the levels recorded for 2003-04 at 6.5 percent (Health 2004, pp. 6, 156). Community and home-based services include supportive living beds/spaces,

29

Since April 1, 2003, the geographic boundaries of Capital Health includes the "cities of Edmonton, Fort Saskatchewan, St. Albert, Spruce Grove and Leduc, along with the communities of Devon, Stony Plain, Evansburg, Redwater, Morinville and Parkland, Sturgeon, Srathcona, Leduc and East Yellowhead Counties" (Health 2004, p. 6). 
Capital Health Link (a call service which provides information and advice), central assessment and placement services, children's home care, the CHOICE program, community care access and home adult services.

According to the CHRA 2003-04 report, the broad goal of the region, as reported in its 2003-04 report, to reduce hospital admissions and lengths of hospital stays, was achieved. For comparative purposes, 66.9 percent of the annual budget was targeted to institutional services, including facility-based continuing care, diagnostics and therapeutic services (Ibid., p. 156). Approximately 13.6 percent of that year's budget was targeted to supportive care, meaning mental health, continuing care beds and assisted living spaces, home care clinic visits for ambulatory patients, and client assessments to support

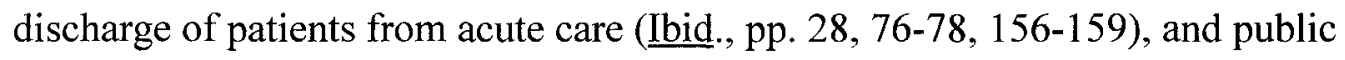
consultations $^{30}$. Home supports designed to help seniors remain independent in their homes is absent from this list. The remaining funds were allocated to research and education, administration, health promotion and facilities.

The 2003-04 annual report is stronger on description and weaker on analysis, and this impedes assessment of its operations in relation to needs, priorities, outcomes and effectiveness. Performance measures and targets are described, including a quality improvement framework (Ibid., pp. 104-137), but explanations on how the respective measures and targets contribute to improved health outcomes for Senior Edmontonians

30

The CHRA report states (Health 2004, p. 15), "In October 2003, Community Health Councils presented to the Board their ideas and advice on "How to enable individuals and communities in our region to take greater responsibility for their own health," which was the consultation topic that the Board asked for Council feedback on in 2002 . Council reports built on previous community views presented to the Board on the topics of ... "Healthy Aging." 
are almost always lacking. Its quality measures represent the concerns highlighted by Williams et al. (1999) as described in Chapter 2 in relation to the quality conundrum. Most of the measures presented in the report are process variables with the exception of two structural considerations in relation to staff retention. The quality standards are largely parenthood statements and they reflect little analysis on what might be considered appropriate. As well, aside from patient satisfaction, patient outcomes are virtually absent. Although the report specifies a goal to lower wait times under the quality improvement framework, wait times for specific services, such as home care, are not listed (Ibid.). In my access to information request, (Health 2007), I was informed that average wait times are only available for the 2005 CHOICE (ambulatory home care) program. Its wait time, as measured by the time entered on the waitlist to admission date, was 82 days, or approximately 3 months.

In addition, the CHRA report does not compare sub-groups of populations, like seniors, with epidemiological data and/or disease patterns. It is essentially difficult to ascertain both the needs of seniors and how they are being served. Yet, against this lack of information, the CHRA stigmatizes seniors as being both a growing population subgroup and a special need group, i.e., being high service users (ㅁid., pp. 35, 37, 144, 146). The 2003-04 report (p. 37) states,

Nearly $11 \%$ of people in the Capital Health region are seniors, and our population is continuing to age. Because older people typically need a wider range of health services, the aging of our population will put added pressure on our hospitals, primary health care services, promotion and prevention programs, and continuing care and assisted living.

The report also cites a 'cost gap' and describes aging seniors among the cost drivers 
which include labour, drugs, population growth and new technology (Ibid., pp. 145-146). This representation of seniors as a key problem accords with the concerns expressed by Northcott (1997, p. 104) that the age "crisis' "has more to do with fiscal difficulties than with population aging, per se." He observes (Ibid., p. 105) that per capital health care utilization has been increasing for both seniors and non-seniors alike and in recent years, per capital usage has often increased more for non-seniors than for seniors. In other words, there is an upward trend in health care utilization/costs that is separate from the population aging trend.

His view is that blaming seniors is easier than looking elsewhere for the cost escalators and addressing those factors (e.g., health providers).

In line with the government's policies to promote increased individual responsibility, information dissemination services such as Health LINK, the Critical Care Line, and diabetic patient education are framed by the CHRA as important services which help to build a better, more affordable system (Health 2004, p. 149). When considering that such services are being introduced at the same time that cost cutting policies are being introduced one questions whether or not a new trend is emerging whereby services are being replaced by information. The observation provided by Anderson et al. (2000, p. 42) that increasing numbers of people are buying private services because they are not available in the public system supports this concern.

With respect to the needs of Edmonton's seniors for home supports, Anderson et al. $(2000$, pp. 39,41$)$ observe that seniors are "paying privately for services, paying their home support worker 'under the table' (which for workers actually resulted in more 'takehome' pay), increasing their level of family support, or simply doing without the 
services." They also note a significant increase in volunteer hours. Capital Health (2007), indicates that "in the 6 month period from June to November 2006, an average of 144 clients received visits from [its own] home care volunteers." Their monthly average of volunteers is 210 .

Anderson et al. (2000, p. 39) note the use of the competitive model by regional health authorities to "reduce costs and enhance the quality of care". They also observe the increased use of private insurance because of the gap between the demand for services and the limited resources available in the public system. Budget pressures also mean fewer and fewer home supports, huge wait lists for services and institutional beds, and the early discharge of people who are sicker and who put additional pressures on home care (Ibid., p. 39). They link all service trends and pressures with budget reduction pressures. Anderson et al. (2000, pp. 35-37) observe other phenomenon which relate to the quality conundrum, as identified by Williams et al. (1999). For example, quality it seems is "determined by elements such as client satisfaction, the demonstrated ability of the agency to provide services in a timely and reliable manner, and the number of complaints that the RHA may have received concerning the agency" (Anderson et al. 2000, p. 36). This suggests, outcome measures are also lacking. Home support workers, who are one of three factors which contribute to quality, receive low wages and are not reimbursed for travel time (Ibid., p. 37). Furthermore, many of them must "work on a casual basis with more than one employer in order to get enough hours to make a living. Agencies would like ... to pay more in order to keep staff' (Ibid., p. 37), but they cannot because of the flat billing rate. For profit companies which "are seen as more cost efficient", provide 
training only as required (Ibid., p. 36). Anderson et al. (2000, p. 38) also identify the challenges for seniors seeking home support services in relation to personal insurance when services are less and less available in the public system; private insurance often supports nursing services, but not home supports. Thus, for these authors, the problem of access to appropriate care is worsened.

The combined factors-flat billing rate, structural issues associated with labour, limited access to needed services in the public system, and an increasing need for privately financed services-leads one to conclude that cost efficiency assumes a greater priority for policy makers and administrators, over patient outcomes. It is no surprise therefore, that Anderson et al. (Ibid., p. 38) write, "after years of entitlement, there were some clients who did not actually need services. And now with a shift to eligibility rather than entitlement it has become apparent, when assessed, that many individuals no longer need services." In other words, services, e.g., baths, which were previously considered as entitlements or requirements to good quality care, are not longer considered necessary.

\subsection{Chapter Summary}

The above describes the Alberta context within which nonprofit charities perform their advocacy-constituted roles in home care. Although this environment is shaped and constrained by several structures, the central and overriding one which impacts home care and the broader health sector is Alberta's cost containment / reduction agenda. This agenda underscores recent government Acts, administrative arrangements, and continuing care services and it is explicitly expressed in reports and documents. Specifically in relation to home care and continuing care services, government's role appears to be 
shifting away from its traditional responsibilities in regards to services' provision, and although home care levels were never high, towards an increased role as broker, coordinator and educator-information provider. For seniors and other clients, it means more self- and family-care, and self-payment. As well, within this context, the complex home care system is characterized by fragmented authority which, in turn, may weaken accountability to the public. Other issues include a funding formula which governs continuing care services that is not up-to-date, home care services that would support seniors' autonomy are not considered mandatory, and/or they require co-payments, and the lack of outcome measures for clients. This research also raises the issue of seniors' poverty, specifically for female seniors and half of lone seniors. It raises the question of affordability in relation to private payments for home care and/or other services under the continuing care stream, hence the quality of life for poor seniors and informal caregivers. It is not surprising that one government document indicates that informal caregivers, the majority of whom are women, become stressed and "prefer direct service programs to either cash payments or tax allowances" (Broda 1999 c., p. 101; see also Northcott 1977, p. 65). Another document maintains that caregiving is a significant risk to the health of those who provide care, and many who provide care are also dealing with their own preexisting health conditions (Healthy Aging 2002, p. 35). Finally, the chapter identifies problems for paid labour in the home and continuing care streams in relation to their benefits and their own quality of life. 


\section{CHAPTER 7 - HOME CARE IN OTTAWA, ONTARIO}

\subsection{Introduction}

We are [a] nonprofit [charitable] agency and that carries with it a certain amount of rigidity in this environment. We are so bloody darned focused on serving people. Our board of directors ... and our volunteers, all 600 or 700 of them... want to make a difference. I think that brings a certain clout, certain grass root clout to any discussion (12:45).

I chose this profession, this field for the very fact that I don't think it's a business. ... I think it can be run as a business. ... I think that health is not an industry ... It's a human service. And, that's what ... makes us different from animals or other living creatures (27:18).

Those who are on really fixed incomes, they know that it's a much better option to come... here ... because it's more likely that they're going to get the equipment $(17: 15)$.

We are involved in ... advocacy on behalf of our clients to inform healthier public policy rather than lobbying per se. And, it's a fine line that has never really been successfully defined (20:23).

These quotes are the voices of 22 representatives of charitable nonprofits who tell the stories about their agencies' public policy work with respect to home care. Their stories are not only their own because they arise from the stories of Ottawa's seniors, the frail elderly and other vulnerable people. They tell about Canada's invisible citizens.

All too often the policy role of charities is restricted to policy implementation related to the delivery of home care services. The stories being told in this chapter, however, recount other aspects of the policy work of these agencies which includes identifying new and emerging needs, advocating about unmet needs, testing new ideas, doing research, and so forth, on behalf of vulnerable people. Much of this additional work is done with money provided by foundations and other donors, meaning collaboratively with communities. Altogether, this work epitomizes a network of charities working together on home care on behalf of vulnerable people. 
Previous chapters have described the state structures which impact home care in a manner that controls types of service, local budgets and, ultimately, rations services. As a result of this rationing, vulnerable citizens rely on charitable nonprofits for both supplementary care and advocacy; they and their caregivers are often too vulnerable due to illness and/or disability to speak for themselves. As one executive director said,

The clients are the ones that have the say. The challenge there is that people do not receive home care services because they are feeling terribly empowered and vocal. They are receiving home care services because they are vulnerable. They are ill. They are frail. They are sick and they want someone else to stand up for them and tell them what they need (24:24).

The policy work which is undertaken by charitable nonprofits to maintain the dignity, independence and choice for vulnerable people who are, more often than not, at their end of life period is explained in this chapter. The explanation adheres to the roles which are delineated in Chapter 3.

The first section provides a few facts about the agencies such as date of establishment, budgetary details, and so forth. These facts are linked with the redistribution and societal stability roles of nonprofit charities. The next section then introduces the policy work of charities which is linked to their service delivery function to provide public home care through both the Ottawa CCAC and community support agencies. The environmental scanning work of charities is examined and explained, next. Environmental scanning is defined and explained and the outcomes of this work are introduced. Following this is a section which describes and explains both the tools of policy work and the broader engagement of charitable nonprofits through which they 
promote values in society while also improving the situation for many people. The summary section of the chapter begins by introducing the assets of charitable nonprofits which support their advocacy-constituted work in regards to the Ottawa community. I begin by introducing charities in Ottawa and their roles to redistribute societal resources and to promote societal stability and democracy.

\subsection{Ottawa's Charities, Their Redistribution and Societal Stability Roles}

This section describes the organizations of the research participants in relation to their redistributive, societal-stability and democracy roles. Budgets which come from both government allocations and donors are synonymous with redistribution. So are volunteer boards and other volunteers. Societal stability, on the other hand, is enhanced when volunteers and paid staff are provided the space within which they can use their skills, knowledge, networking capacity and so forth on behalf of their communities.

Of the 22 Ottawa-based charities represented by this research, half were created between $1845^{31}$ and 1968 by religious and community groups. They existed prior to home care's formal establishment in 1970 (Health Canada 1999 b., p. 39). According to one research participant, these historic organizations developed home care in Ontario.

Organizations like VON and, to a certain extent, the Red Cross and, Visiting Home Making Association that were in Ottawa, and were in Hamilton, and currently only in Toronto, they have a long history too. ... Some of them have 75 years [history]. ... They were very instrumental... in developing [the] first service[s] which is ... a policy initiative (15:3).

They paved the way for other charitable nonprofits which emerged in response to the

31

Of these, four were established between 1845 and 1898 and five were established between 1908 and 1933. 
creation of home care and which are also represented by this research.

The participating charities are equally split between those which provide a complex set of long term and home care services and those which provide what are considered 'soft services', meaning home supports. The budgets of individual agencies reflect the complexity of the services they provide; agencies which provide more complex services are allocated higher budgets. Thus, charities providing less complex social and home supportive care generally have budgets as low as $\$ 215-300,000$. The budgets of the much larger agencies which provide more complex care vary between $\$ 1$ and $\$ 10$ million, and a few have budgets that are even much higher.

The budgets of all participating charities arise from a mix of funding sources. At the time of data collection, approximately half of the participating charities were considered as transfer agencies, meaning they received direct funding from the Ministry of Health and Long Term Care (MOHLTC) to provide services. Another large set of charities that participated in this research receive funding mainly from contracts financed with tax dollars, and these funds are supplemented by donations and the community campaigns of the United Way. Only one charity, a provincial association, receives funding from the membership fees of the agencies it represents, across the province. Other funding sources, which vary across agencies, include grants from foundations, project funding, individual donations and fees for service (FFS). Sliding FFS are received by nine charities. Only four charities solicit funds from fundraising, and only one charity raises income through sub-contracts and/or product sales. As well, only one charity earns income on a FFS basis by providing private home care nursing services on behalf of 
insurance and as a sub-contractor for other private firms under contract with government.

All, but one of the participating charities are governed by volunteer boards which are appointed by the community. Incumbent boards recruit new members using public notices like newspaper adds, posters and so forth. As indicated in Chapter 4, the CCAC board is appointed by the LGIC on behalf of the MOHLTC. All charities are lean, having flat or minimal organizational structures. One agency describes the challenge of performing their policy work with minimal human and financial resources in the following.

Community support agencies, community support programs, ... generally speaking, are very small agencies. Their service delivery infrastructure is as much volunteer as anything else, and ... [we don't have] very much resources to put into this. When the community support agencies try and lobby, locally, for improved services or policy shift of one kind or another, we are talking about agencies that actually employ 2 or 3 people... (20:17).

Later on, he said,

We are funded to deliver services... We don't have the resources, the staff time, whatever, to spend, the kind of energy we would like to spend in terms of policy development. We don't have the policy analyst on staff... Funders ... are [generally] reluctant to fund administration, never mind this kind of activity and work. So that's one of the challenges (20:23).

Another executive director said, "We have six staff here and over 500 volunteers...

Volunteers, come for free. ... I think [this] gets said. But, I don't think it gets heard".

This comment was made in regards to the lack of financial support for infrastructure. The individual continued, "One of the biggest ... changes that ... we have seen and feel, ... is the disappearance of infrastructure money from the government for charitable organizations" (17:30). Thus, because of budgetary and organizational constraints, both 
of which are linked, much of the policy work done by charities is done on a voluntary and collaborative basis. Nineteen of the research participants said their volunteer community boards and/or they themselves, as executive directors, undertake a policy analyst function in addition to their governance and administrative duties. Only three charities employ policy analysts and of these, one agency's operations are large enough to extend across the province. This agency can easily justify employing a policy analyst on staff. Another charity is a provincial association which exists to conduct policy analysis on behalf of similar agencies across the province, and a third is a foundation that provides grants to community agencies. By definition, the latter two would be required to employ policy analysts on staff. Aside from the input from volunteers, policy work is dependent upon sponsorship funding, as well.

Having examined the resource redistribution and societal stability roles of charities, I now explain the service delivery role of Ottawa's charities in relation to community supports and services provided through the Ottawa CCAC.

\subsection{Ottawa's Charities According to A Service Providing Role}

\subsubsection{Through The Ottawa CCAC}

\subsubsection{Introducing The Ottawa CCAC}

In Ottawa, as with the rest of Ontario, the major portion of home care is accessed through CCACs which are described in Chapter 5 as statutory corporations overseen by boards appointed by the MOHLTC. Although the Ottawa CCAC is a registered charity, it mainly functions as a department of government, operationalizing the government's mandate for home care. It oversees the request for proposal (RFP) contracting process 
through which agencies are authorized to provide home care services under three-year contracts. Prospective providers are pre-screened for their eligibility and suitable agencies are invited to submit service proposals. Proposals are reviewed, providers are selected, contracts are signed, and home care services are delivered. The Ottawa CCAC describes its home care mandate as providing

directly or indirectly, access to information and services to assist people staying in their own communities as long as possible. That would normally include the typical things for home care like access to information and services related to nursing, to therapies to personal support, to equipment and supplies, to drugs. It provides ... access to information and services in the long term care areas [, including] all placements into long term care ... [and] adult day (3:20).

For the CCAC, this means being "well positioned from a systems perspective around the notion of helping the right person be in the right place at the right time. You know, getting the right level of service from the right provider, acting in kind of what's the best clinical interest of the person" (3:35). CCACs are the "access center and ... system's navigator" mainly for acute and clinical care. The majority of home care users are seniors. $^{32}$

Regardless of their broad mission which includes supporting the needs of seniors, the CCAC's budget and policies are such that most of the services it coordinates are targeted to acute care needs for people

who no longer require acute levels of care in the acute care hospitals but, they are not quite ready to either go home. They don't need to or, they are not ready to go to a long-term care facility. Or, they are not quite ready to the needs of seniors. 
go to a complex care situation. Or, maybe even to a rehab situation. So, they need some alternate level of care, and until now they have been staying in the acute care hospitals at a greater expense to our system and taking up that bed space that then backlogs surgery, elective surgery (3:3). [Later this individual said,] Our budget, this year, we got a very tiny increase that did not even meet the cost of living but, it came with targets for the first time. And, the targets are [that] one hundred percent of that money has to go to acute care clients. And, we have a target of 643 new acute care clients that we have to see with the money we got. We have to account for that at the end of the year (3:49).

Although seniors may require acute home care services, acute home care does not support their longer-term goals with respect to independence and forestalled institutionalization. A wider set of CCAC priorities are described in reports and include removing 'bed blockers' and reducing acute health care costs through the provision of acute home care (Caplan 2005). This suggests a key priority of the Ottawa CCAC has been to keep costs down rather than to meet the long-term needs of seniors through home supports. Home supports were notably absent in the CCAC's account of its home care operations.

\subsubsection{Managed Competition and Government's Cost Cutting Agenda}

Other research participants are more explicit when describing the CCAC's management of the contracting regime to provide home care in accordance with government's cost cutting agenda. They claim that cost control and efficiency have been government's first priority and suggest such goals ought to be balanced against the health needs of the community. One representative said, "I can understand why the government wants to control their costs of home care, and I see CCACs as being a structure for cost control, but it doesn't allow sufficient community control of resources and opportunities for the community to respond in different kinds of ways to the needs that they are 
identifying" (20:33). Later, this individual describes how

There needs to be a shift of resources into the community. There has been a devolution of responsibility over the last decade or more from the federal government, in the early nineties, to the provinces. The provinces felt the squeeze and downloaded it to the municipalities and the municipalities can't manage either. And, they've got no place to devolve to, except to the charitable and community sector. And, hospitals facing budget squeezes, as well, somewhat arbitrarily and unilaterally decided to get out of certain businesses. So, there are hospitals that do not have social work, except for minimalist discharge functions. They no longer provide physiotherapy, psychology, a lot of those soft services, speech therapy, are no longer available through the hospital sector, with the assumption that they will become available in the community. That, somehow there's going to be some level of community response to fill this gap... I mean, if there's going to be this devolution by default to the community, there needs to be the infrastructure in the community to be able to respond. And right now any way, there isn't (20:48).

The reforms which have been introduced by 4 previous governments over the past years to reduce health sector costs, in part, by using home care as an acute care substitute and, secondly, by delivering home care using a competitive model have meant that communities, and community agencies have had to become policy-takers and budgettakers. But, according to the research participants, this is only part of the story.

Charitable nonprofits are the first line of contact with vulnerable people living in the community. Agencies claim that individuals with long-term, chronic conditions are not receiving adequate care and support. One individual describes the impacts of government policy on chronic care recipients as follows.

We were concerned that there were a lot of cutbacks and the people who were getting the focus of the attention were those immediately discharged from hospital who needed help immediately, while recuperating or recovering at home... It's not that they don't need it. But, what was happening is, people who were at home and needed help day-by-day, byday because of chronic conditions, whether they are families with kids or, 
people with disabilities, elderly folks, they were suffering dramatically from the cutback of services... (4:42).

Agencies question government's policy assumptions in relation to home care and the managed competition process through which services are delivered. Because agencies deal with the day-to-day challenges associated with unmet needs caused by budget cuts and policies to rationalize services, charities claim that the policies and practices of government also negatively affect them as organizations. This means, negative impacts extend to their work. They express frustration with lack of leadership, government indifference, and short-term visioning. It is not uncommon, therefore, that charities do advocacy work, and rank it as among their most important role even though they do not receive public funding to do it.

\subsubsection{Through Community Support Agencies}

This sub-set of transfer agency charities provide public home care but, on a costshared basis with the community (see also Caplan 2005, p. iv). The home care provided by transfer agencies include transportation, recreation, social supports such as friendly visits and telephone assurance services, home help supports such as housekeeping, maintenance, snow removal, grocery purchases, and so forth. Health promotion, foot care, luncheon programs and meals are also provided. Legal services, information and referrals may be provided at no cost to clients (see also Coalition undated). One executive director said, such services have "always been [considered] a friendly, fuzzy, warm service that... [are] provided by volunteers and really $\mathrm{d}[\mathrm{o}]$ not require any... legislation or public policy piece" (10:13). While these services are now provided by the 
MOHLTC, originally, they originated with social services under the CAP. Ottawa's Coalition ${ }^{33}$ of support agencies claims that support services

help people stay fit and healthy longer, enabling them to continue to be active in the workforce and the community, and decreas [e] dependence on social assistance. The services also lessen the burden on the health-care system by reducing admissions to hospitals and long-term nursing homes, and by decreasing the length of hospital stays. Yet, funding for these services is woefully inadequate, accounting for only four percent of public spending on health in Canada (Coalition undated).

Two aspects related to the financing of these services are problematic. Firstly, home support services have never been deemed sufficiently important to health so as to secure protections and guaranteed funding from the federal, hence provincial governments. Yet, they are the services that facilitate independent living in a cost effective manner. A second and related issue is that increasingly, because of inadequate funding, home support services are being privatized and/or being devolved to individuals, their families and to their communities. Given that a significant number of seniors cannot afford private payments, local charities and municipalities have had to finance services. According to the research participants, raising funds is no easy task. One executive director describes the challenges which arise from cost-shared programs.

The Ministry will pay to a maximum of seventy percent of the costs of the program with the expectation that the community [will] come up with the balance. So, as a cost shared thing, if the community fails to come up with its share then, the Ministry will back off on its share. It will not pay more

33

The Coalition represents approximately twenty community support agencies which provide community support services and which have come together to provide individual and public advocacy and to facilitate access to support services. They believe in the right for "people with chronic illnesses and disabilities... to live an independent life" (Coalition, undated). "The Coalition of Community Health and Resource Centres advocates at many levels and on many issues to help people gain access to the basic supports - including shelter and food - they need to reach their full potential" (Ibid.). 
than seventy percent of the total revenues that are applied to the program, at any one year. So it means that there's pressures for local fundraising and other partnerships to make [up] the balance. Therefore, [for the] relatively small agencies, as most communities' agencies are, that's a significant challenge (20:17-28).

When community agencies are challenged, financially, the independence and quality of life of their clients are ultimately affected. Unlike the clients of acute home care, clients of supportive home care services tend to be elderly, frail, or disabled, and may include informal caregivers. Clients may also be poor or people with low incomes, and many are at risk of being homeless, or may be homeless. They suffer from mental and physical impairment. Furthermore, the problems facing these people are increasing in intensity and severity, over time. One director describes her agency's clients.

What we [are] seeing ... is that the ... people that we're dealing with, in their homes, initially [they needed you to] ... help them vacuum, or take off their storm windows, or shovel the snow. ... What we're finding now, ... [people's needs are] much more complex ... Respite for caregivers, ... we send workers in because people ... are caring for others who can't be left alone, meal preparation, heavy housework. People have just lost the ability to look after themselves completely and their houses are in ruin... So, we're ... finding a lot more frail people $(1: 33)$.

The quality of life and independence of these clients are at risk. Despite the prevalence of constraints, charitable nonprofits collaborate with the city of Ottawa and the local community to provide stop-gap measures that will partially satisfy the health and social needs of these frail clients. But, agencies must be strategic, resourceful and stringent. In addition to their stop-gap measures, many charitable nonprofits undertake an advocacy role. 


\subsubsection{Doing Advocacy on Public Home Care}

Representatives of charities were unanimous that doing advocacy was their most important public policy work. They equated advocacy with providing a public good. The targets for their advocacy can be described as a continuum which begins with individual citizens, and gradually expands to embrace the home and health needs of all citizens. One agency representative said,

Our caregivers provide advocacy on a daily basis for individuals. So, we have a crisis intake worker and social services... that happens every afternoon five days a week. So, people can come in, so they can be elderly folks. They can be people with disabilities, people who are on the disabilities support program... Other people who are having problems and need somebody run interference, whether it's with housing, with municipal ... or provincial government... We have a specific focus on seniors outreach... We ... [do] home visits for people who can't get out for various reasons, sometimes it's seasonal, sometimes it's all the time. So, they see them in their home and provide support to them and their families. They provide palliative care... in the home. And, they are on the street. That's what they do. Our outreach nurse goes into all the seniors' buildings that are downtown and, she... [provides] individual... help and support... [She] goes out to the Well which is a woman's drop in for people who are unstably housed. ... She drops in and keeps in touch with senior women. ... [An important] part of our philosophy is their wellness (4:25).

The targets for advocacy also include other systemic issues such as quality of care and protecting home care under the Canada Health Act, issues which represent past, present and future home and health care needs. Highlights of this work are now introduced.

\subsubsection{For Individuals as The Public}

Charitable nonprofits often do individual advocacy for seniors because, as indicated above, the services prescribed by the CCAC are inadequate. One executive director said that, 
[Although the CCAC] has a lot of resources for a system... They are also under very tight requirements to use [their resources] in only certain ways. So, we've seen, over the last decade, the development of care plans that are focused on 2-3 things. When they send a home maker, they call it a personal care support worker, that worker can only do a few things: give a bath, help with personal care; that's it and, very little else (12:7).

Thus, when charities do individual advocacy, their goal appears to be securing more home support services for their elderly clients. One executive director said, "I know our providers would come in sometimes and, our outreach physician would just be beside herself. She would spend $1 \frac{1}{2}$ to 2 hours fighting to get somebody where they needed to be, with the care they needed to have" (4:42). Another agency representative said,

A lot of [what we do] is advocacy for an individual client; having them access services that they are really entitled to... Because of the back log in everything..., the... CCAC doesn't ... [provide services]. My perception is that they spend ... a lot of money changing the infrastructure and, they keep changing it... I have been here for nine years... They created CCAC as I was coming in and, they had one central office and, now they are decentralizing. A lot of energy is spent on the structure and less amount of energy is spent on direct service delivery (11:11).

Later on, this person said, "Lack of resources. I think we barely can offer the direct service that we are supposed to, and we have to do tremendous triage, which is an issue in itself" (11:30).

Charities are not alone in the struggle to make ends meet. Unfortunately, when service-levels are small and/or reduced, clients must sometimes pay privately for services, if they can afford to. According to one executive director, "More and more of the direct cost [of home care is being downloaded to seniors].... When I look at the home care program... if you want more than that one hour a week, ok, you can pay for it" (17:21). However, many clients cannot afford the fees for private services. According to one 
director, when this happens, "the Ministry's expectation is that you, as an organization, will fundraise to subsidize [the clients]. But, you're already fundraising... [often] 50 percent of your operating budget... It's quite... demanding (1:1).

Doing individual advocacy generally means being innovative, using fundraising and grants to subsidize services, providing services on sliding fee scales, and using volunteers. One agency representative said, "We have 144 volunteers who help us provide 10 different services. Our staffing complement is less than 2 FTP [, full time persons,] an hour, and last year, we served 550 clients. So, you can understand that volunteers are crucial to our organization" (16:2). Services are sometimes provided at no cost to individuals. Another agency representative, "We make no money on the program but, it allows us to run the program and to replenish equipment. ... If you [, an individual client,] truly can't pay, we won't turn you away. You can't do that with any for profit" $(17: 16,53)$.

Charitable nonprofits also inform and educate clients and their families about government policies and their impacts upon clients in order to encourage individuals to become involved as self-advocates. However, as recounted by one director, this approach must be done carefully.

It's tricky when you're dealing with the frail elderly... We have this discussion all the time at the Coalition. Do you go to those people and say, 'You know, they are cutting our funding or, they're not increasing it?' 'We're going to have to cut services. You gotta call your MP.'... Because, what does that do to them...? ... We do, but it's always, its always tricky. Because you... don't want to go to those people and alarm them or overwhelm them (1:53).

Sometimes, the advocacy work done by charitable nonprofits secures positive 
outcomes, even if the scale is small or short-term basis. They have successfully altered the municipal budget process at the local level to ensure that, at least for another year, services are available to citizens. One agency representative said, "The community has put good use to [their] time. For example, I am sure you may be aware of this, in Ottawa we [have] had a lot of community interventions in city decisions to cut back on social programs. So, we are very happy about that" $(21: 22)$. Success motivates agencies to continue doing advocacy.

Charitable nonprofits also advocate on the quality of care issue which, according to the research participants, means providing consistent and appropriate care, and care levels, using consistent staff, to frail elderly people with chronic conditions. According to one research participant using consistent staff is important to

someone's dignity ... If you are continually changing the worker, and continually may not be every week but, if for every year or so on suddenly you have got a new worker and a new case manager and so on... [The clients] have to go through it all over again... They are a year older and, maybe even more frail physically. Or, perhaps cognitively and, so on... To have the whole thing change... [Contracting] has some pretty dramatic and pretty negative impacts on our clients (16:39).

While raising the same issue, another research participant includes the needs of workers who are impacted by contracting as a quality issue. This individual describes personal support workers as becoming ping pongs in this system... What kind of impact does that have on the client? You're elderly. You're used to Joan coming to give you your bath, for ten years. And, finally you got over having her see you naked. And, you got a new person coming next week. You know you try to put yourself in the minds of the mainly seniors... Those are the types of things we try to advocate about (17:11). 
Insufficient and/or inappropriate supportive care originates from the lack of legislative protections and low budgets which often translate into private payments, or doing without care. For many seniors who cannot afford private care, these issues mean lower quality of care, greater dependence on informal caregivers, or an increased risk of being institutionalized. While institutionalization might not be appropriate to the care needs of an individual, it could be appropriate according to a financial need because it is free. One executive director said,

We know on the other end of the [income] scale, it's extremely difficult to get the kind of service that keeps people short of going to a nursing home. ... Residential care facilities are not subsidized unless it's... a welfare situation... Because of that..., sometimes [you] try to get somebody in a nursing home who doesn't really quite fit the nursing home, yet. But, at least there, government will pay $(7: 24)$.

In the short term, individual advocacy tries to ensure that seniors receive good quality and appropriate levels of care. Agencies also collaborate and network about the issues that affect individual clients, and collaboration has the potential to develop into a wider public issue. When this occurs, individual advocacy illuminates how localindividual issues and problems associated with home care can affect a wider set of Canadians. Collaboration also means providing support to other agencies.

\subsubsection{For Community Organizations}

In addition to individual and broad-based advocacy, charitable nonprofits provide support to one another within the home care network and advocate, accordingly. One agency representative claimed that, while contracting had not specifically affected the individual's own agency, it had affected the agency's "partnerships with other service 
providers."

I think that we try to be supportive from a coalition perspective, and come from it from a different perspective and say, 'OK, how can we ensure that the client gets what they need?'... So, in that sense it has not affected us. Where it has affected us is when there ha [ve] been cuts in services and we have had to provide home help [services]. When they did the first round of cuts, all of a sudden the previous support service [agencies were] getting calls... [People were] saying, 'I need a home maker to come in provide serviceY.' ... [We find that] we're filling in the slack. But, the problem is they, [seniors, now] have to pay for the service, whereas under CCAC they did not have to pay for the service $(10: 32)$.

Thus, because of the competitive home care environment, charitable nonprofits are

finding they need to support one another by working collaboratively to ensure the existence of a service network of care. In addition to ensuring a network of care, charitable nonprofits support one another because their day-to-day work is very difficult.

According to one executive director,

You can't work in isolation in this sector. You have to have a network because there is incredible value in refining your position with the knowledge and experience of others. So we do an awful lot of networking in this sector, certainly in the not for profit sector. We spend a lot of time talking to each other and supporting one another and, helping each other with expertise, information, data, evidence that sort of thing (24:30).

Charities provide mutual support and engage in advocacy through a number of

coalitions, some of which are local, while others are province-wide. For example,

We are a member of the Ontario Community Support Association and a member of the Coalition of Ottawa Community Support Agencies... Oh, and a member of the Coalition of Ottawa Community Health and Resource Centres. Those would be the kind of associations that probably consume about 80 or $90 \%$ of our energies. We are members of a number of other organizations and alliances as well. The Ontario Health Coalition being one of them; associations that respond to the needs of immigrants. There [are] a whole pile of memberships. But, in terms of active participation, OCSA, AOHC and those local Coalitions for Community Support 
Agencies and Community Health and Resource centres would be our primary efforts (20:14).

The benefits of providing support and working collaboratively are significant.

Collaboration facilitates problem-solving on issues that affect all agencies such as rising insurance costs. It is cost effective particularly when information is shared among agencies, which also facilitates shared learning. Charities become more aware about emerging trends and issues which means that they can be more strategic in their analysis and advocacy work. Training opportunities are shared which, minimally, improve all aspects of quality. Alternatively, resources are shared among agencies so that tasks like improving service standards and quality of care can be tackled more easily. Bestpractices are shared. Altogether, a strong, common voice for all charitable nonprofits is built, evidence is strengthened, advocacy becomes more potent, and each of these represent cost efficiencies. As one executive director said,

They [, other organizations,] provide me with information... None of us believe that we should have to recreate the wheel when the wheel has been invented. So, in terms of looking at policies, procedures, best practices, sometimes those organizations are incredible resources. So, from a resource perspective they are very helpful. From an evidence-based, data gathering kind of perspective, they can be very helpful even if it's just to poll the members of the association, "What are you doing about this? What are you paying your volunteers for your mileage, kind of thing? What are you doing about lifts and transfers for disabled clients?' You know, there is a richness of information within the membership itself. From an advocacy or positioning perspective, they take on the hard fights, the fights that as an individual, I can't. And, as an individual association, I would be marginalized... [because] if I took that position... Whereas, in representing a sector-wide sort of perspective, they can take those issues to the table and represent them (24:54).

Collaborating means sharing skills which may vary from agency to agency. For example, 
We all have different interests and skills so, we're able to kind of help each other. Some of us are more policy types. Some of us are more service types. Some of us are good at politicking... So..., we kind of spread the work around and we take it on. So, two or three will take on one thing or, somebody else will be watching, brief one another and, we work together... We let everybody know what's go [ing] on and have some influence, but everybody acknowledges that certain people have the lead... Sometimes we have to go back and get our boards on side... Each board decides individually... (4:45).

When individual agency strengths are merged, there is a greater likelihood that networking and broad-based public advocacy could lead to increased budgets, more widespread use of information technology, or enhanced services to both rural areas and ethnic groups. One board member recounts the support of other community agencies to the agency's own budgetary request.

We had some very interesting people like the CEO of the Sisters of Charity [who] spoke at that [news conference], and a person that ran a community support agency and chaired their coalition spoke at that news conference... We brought in our partners. They said, 'These people are doing a wonderful job and we support this request because we care about this.'... We had community support (8:42).

Although all research participants indicated that they relied on the support and collaboration from their peers, small agencies and rural agencies particularly felt the need to be part of a larger process. The executive director of a small agency said, "We work on a multilateral basis because we're such a small agency, as most other agencies are small and don't have that many levels of management. We work very closely with the Ottawa Community Support Coalition" (12:2). Another executive director said,

The networking opportunity at the Coalition is incredible... I have gone there ever since I started with this organization. I am the first employee... I started in $1990 \ldots$ as a single staff agency, for nine years... I needed to network with people to find out how to do things and how to access people 
and we've certainly, over the years, talked to our Township Council... [on] public policy as well as [to] the different service clubs (16:10).

Later on, this individual added, "We have board members who sit on some of the committees for some of the Coalition committees because we just don't have that many staff that could send that many people... Yet, we feel it extremely important that the rural issues be made known to people" (16:59). Thus, numbered among the key benefits of collaboration for individual agencies is the knowledge that they are not alone when doing the difficult work of home care.

Notwithstanding the importance of giving and receiving support, collaborative work is not always easy. One agency representative describes the challenges and frustrations inherent in getting different agencies to work together. This individual said,

Sometimes, I become totally disenchanted with the whole process. The Coalition ..., we've had some successes but, we are such a motley group that it is very difficult to reach [consensus]. In fact, when ... this group [had] to achieve consensus, I said 'God bless them'... But..., you can't function ... on your own. You've got to belong to something and you cant just always sit there and say it's not working... I get frustrated..., but you have to be a part of it and... try to make ... changes, if you can. Or, even... to try and encourage your colleagues... (14:59).

Since collaboration is not always easy and automatic, it is sometimes facilitated by government. One director explains how the MOHLTC tried to improve collaboration among agencies.

The community support coalition... [is] working on a three-year business plan to develop shared services for seniors in the community. ... This ... started about ... 7-8 years ago, with the Ministry saying to us ... 'You really need to... work together because there's not anymore money. [Yet,] there's a huge ... and ever growing need. ... There are 18 agencies, some of [which] are this close to financial break down. There's a lot of inconsistency in what's available to people, ... in how it's delivered, what 
it costs,... and so forth. We are not going to fund any new transfer payment agencies, and you people need to come together and develop a new service delivery model.' ... So we started out on that process and we were working on that... And, it was very threatening to a lot of people... [We have to] demonstrate... how... [we] are working collaboratively $(1: 72)$.

Regardless of the challenges associated with collaborating, because individual voices are strengthened so that politicians may hear better, all charities engage in some form of collaborative network. As one research participant said,

In the last three years, ... through the Coalition ... and individual efforts like mine, with City staff ..., we are on the radar now. They pay attention not as well as we would like because we are not up there with the O-Train obviously... [But because] there is a large grouping of agencies who work with the elderly who tend to come down and make noise every so often... If we are lucky, we can even bring groups of seniors down. We hesitate to do that because... most of them are not really able to do that" (14:52).

Thus, when combined with individual and public advocacy, organizational advocacy may contribute to the broad goal to improve both the quality of services and the lives of home care clients. Although not always acknowledged, collaborative advocacy also promotes the efficient use of scarce resources.

\subsubsection{On Quality}

As indicated above, charitable nonprofits do advocacy to improve the quality of home care services. A fundamental problem, particularly for supportive home care services, is that quality indicators-input and outcome measures-are almost nonexistent (Baranek et al. 2004, pp. 12-13; Caplan 2005, p. 6). Thus, a risk arises that contracts are awarded according to best price. One executive director describes the challenges associated with the measurement of quality. 
[Although] there has been a great attempt to try to truly figure out how to get the best quality..., we have trouble defining that and, we have very little data about that... We have also a lack of understanding of cause and effect meaning, 'If you do this, does it give you better quality?'... We don't have phenomenal outcome measures... And, we don't even have phenomenal input measures in home care compared to... the hospital sector... It's so ... hard to measure... Then, ... on the other end of the equation, 'What's the best price for that quality?' ... No matter what formula you use, people are very suspect of the fact that ... quality [is] really driving [the contracting process]... Because ... we don't have enough data and measures, ... at the end of the day, the best price wins (18:12).

While supporting this opinion, another research participant voiced the concern that some aspects of quality are not reflected in CCAC's RFPs. This individual said, Quality is an ... issue ... [which relates] primarily to the RFP or, the competitive tendering process.... What quality you will get for that price?... We are involved in research, social policy development and advocacy... To us, [these quality-defining processes] ... are all part of the package [and ought to be in the RFP process]... Others won't [agree they ought to be reflected] inside the RFP.... [Thus, the RFP] doesn't measure [or] consider it and, it certainly leaves some large questions out in terms of your ability to provide... There's a lot more intangibles that we believe are not... [being acknowledged within] those (25:25).

One agency's board member summed up the general views of the research participants on this issue with the statement, "There should be no contracting at all... I don't, I'm not at that school. I find the RFP process, if it's well developed it's useful. The documents have been so watered down that the standards aren't there anymore" (8:59). Charitable nonprofits were unanimous in voicing the opinion that since quality is hard to measure, and since standards are almost nonexistent, pricing ultimately drives the process. Another executive director said, "Managed-competition drives the mantra, the mantra is best quality at best price. Best price means lowest price" (24:20). For them, when price drives competition, cost efficiency becomes government's goal, rather than providing the 
right services, in the right amount to vulnerable people. Moreover, the research participants claim that when quality indicators related to outcome measures are minimal or absent, it is easier for government to reduce or cut funding to longer-term support care needs. For the research participants, appropriate funding is a baseline requirement to ensuring that quality of home care is provided to vulnerable people.

Charitable nonprofits maintain that quality begins with consistent care and ends with identifying the benchmarks and indicators, e.g., patient outcomes, that facilitate the measurement of quality. Although some work has begun in this area for home nursing care (Doran et al. 2004), the research participants suggest more is needed.

\subsubsection{On Preventive Home Care}

Charities generally conflate preventive health programs with wellness programs, and with supportive home care services. Preventive care means healthy meals, socialization, recreation, public education on healthy living and disease prevention, safe and affordable housing, poverty alleviation, transportation assists, caregiver supports and so forth: the determinants of health. The determinants of health are considered to be the factors which improve and/or contribute to healthier outcomes because they prevent and/or delay the onset of ill-health. Doing prevention is a significant part of the advocacy work of charities. It is often included in their mission statements. One agency's representative described the agency's mission as being

founded on the social determinants of health and we see health as being much, much broader than just health care. Our mission and vision is to help people lead healthy active lives, to help them to do that, to build their own capacity and also to help them build the capacity to keep their communities healthy. So, we try to look at the whole individual, their 
families and the community around them and support them in a number of different ways (4:9).

Overall, providing home supports is a key goal expressed by charities and agencies work

to secure firmer funding for these services. One research participant said,

We are looking [to make] ... preventative health care [as the] first line health service delivery ... in the home. And, the secondary should then be... the need... [for] an active treatment hospital [service]. The system really is evolved the other way around. When in crisis, you go off to your active treatment and, then we look at how we can get you home ... earlier, and support you in the home... So, we're really advocating for an entire system [to be] developed the other way around: wellness first and wellbeing (25:32).

For seniors, home support services are important for all of the reasons cited above

and because they impede institutionalization. One agency representative said,

We're maintaining and we're showing that, in fact, if you don't provide... some housekeeping service..., that may be the tip of the ice berg for that [vulnerable] person. And, if they don't get that, that may trigger ... the [their] move into institutional care sooner... Our whole pitch is... [that] as long as the person can safely function in their own home, ... give them those supports because it's at worst, very few cases, where it will be more expensive... Usually, it is considerably less expensive to maintain them ... than ... to put them into an institution (7:9).

The research participants claim that home support services are inadequately funded;

government speaks the language of prevention and wellness, but doesn't finance it.

I think... [wellness is] the cheap fix because... let's take elderly people. If somebody is isolated and depressed, they get sick. If they don't have adequate resources, they are forced to be hospitalized or institutionalized. Whereas, if you help them enhance the quality of their life, reduce their isolation, allow them to have physical activity, social activity, they are going to be healthier longer and need less resources. And, they [, government,] do the reverse. So, it ends up costing ... much more to help take care of the person than [if they] had [received] preventive and supportive [care]. And, they end [being] institutionalize [d. Government] ... spend [s] a lot more money on that network ... [and] use the right words. 
They talk about reducing beds and improving quality of life ... and sustaining [it] but, they don't resource it. They just talk about it (11:10).

Home supports are still considered optional and/or expendable home care

services, as compared to acute care services. According to one research participant, when

hospital services were recently restructured, home supports were not ever considered.

If you look at the hospital restructuring that is going on right now with the balanced budget and you look at the people that were invited to that group. Community care services... [were not] even on the list. Even though, when the budgets come down and you have to reorganize your program and you need to refer [people] to CCAC... So, we weren't even on the list. We're not even on the radar" (10:57).

Another individual said,

Our idea is to promote wellness. And, part of the concern is that with the health restructuring, there is this focus on illness. So, if we can promote some wellness, whether it's through... socialization, ... [or] a hot meal... Can I measure that and say well they are better because of it? No. We're what I call soft services. And, it's very, very hard to say we make a difference (16:19).

Many charities expressed the concern that home supports are slowly being

eliminated from public home care programs; less preventive work is being done. One person said,

in our model, we have the home health program where the worker will go in and do a whole host of things for the client [like,] meal preparation, cleaning their home, which makes it... a healthy environment for them to remain in. And, maybe even some banking. ... A lot of the stuff that we are not able to do anymore by government regulations. Our programs have also been told to really focus and become far less responsive to the actual needs of that person..., a focus only on what some outside party determines is required (12:7).

Since government doesn't finance preventive care, charitable nonprofits undertake advocacy so that, in the short term, individuals receive services. They also do broad- 
based advocacy on this issue, but take a longer-term perspective. Advocating to operationalizing the theory about prevention is challenging work. As one agency representative asked, "How do we engage in health promoting relationships, to... using health promoting theory... directly with client $[\mathrm{s}]$ and... in relationship with the providers?... In Ottawa, we are not there yet. We are not doing a good enough job yet in implementing the theories of health promotion..." (3:45). Later on, this individual said,

We have to treat other people the way we want to be treated. So, I think it is perhaps a long longer term thing. But, we just have to keep, day by day, issue by issue, opportunity by opportunity, keep trying to improve things and seizing opportunities where we can invite more people in and around the table to discuss these very difficult issues. ... Demand does not go away. And, need has not been defined... I think, we just have to keep hiving away at it (3:52).

Thus, agencies keep chipping away at individual needs by providing services while also working on a longer-term and broader-based agenda. They do their bit individually and collectively to move forward the public agenda. Charitable nonprofits hope that a policy shift in support of preventive home supports will soon appear. Although one executive director said,

The community support sector... [is] like the small little mouse against the great big elephant of the CCAC system. ... The community support sector is... gaining profile at this point. ... Is it based on this [being] a cheaper way to do something, or is it a better way of doing something? I don't really know. But, I would say that definitely we are becoming more part of the formal system $(30: 30,33)$.

\subsubsection{To Protect Against Contracting}

The research participants suggest that while the underlying basis for contracting is to create cost efficiencies which will reduce home care expenditures, the model falls short 
when considering other goals such as caring for people with chronic needs. The lack of adequate quality indicators, particularly in relation to outcome measures of support services, is problematic for both clients and workers. A related issue, is that competition between charitable nonprofits and/or for-profit firms ignores the capacities, working assumptions, motives and contributions of the respective sectors. Charities provide public goods which build community and create efficiencies through collaboration, for example. For-profit firms provide returns on investment for owners and individual shareholders and are cost efficient, particularly in their use of business models. According to the research participants, when the two sectors compete for contracts through RFPs, the private sector has the advantage because it is steeped in the language and processes which produce cost efficiency according to government's mandate. One board member describes the philosophy behind contracting as follows.

If you read the CCAC Act, the for profit agencies... there was real ennunciation of the thinking that the for profits can do it leaner and meaner and that the non-profits are soft... That was their [, the Conservative government,] whole philosophy throughout... And, that any community processes are soft $(8: 24)$.

Another agency's executive director said, "The Health Ministry is very pro-commercial. That's been the issue and has always been. Internally that they are very open to the... commercial influence" (15:33). The research participants describe the government's narrow view of the public good which arises from the commodification of home care. For them, society loses the potential of the public-social good which is associated with the work of charities. According to one executive director, the efficiency model makes invisible the contributions of charitable nonprofits. 
I think government have not been good enough at recognizing [the contributions of charities,] for whatever reason. That delegation of people who are grass roots from not for profit agencies bring... a message should have at least the equivalent weight of a business that is bringing a message of public policy to the government and you sometimes feel that, that's not the case, which is outrageous really (12:20).

Charitable nonprofits are disadvantaged simply because they promote a social view of health rather than a commodified view of health. As a result, their missions, language and working assumptions and day-to-day contributions are minimized, and/or not acknowledged. Moreover, when a commodified belief system prevails, charities become the organizations which are required to conform and to adapt. One agency representative describes how for new charities

it would be extremely complicated to understand how to advance things. I think some of our... success is that a lot of our team... [who are] involved in advancing policy, they've been with... [us] for a long... time so, they really have understood the dynamics. But, these models, these business models, and the procurement laws and you know equal playing field, I believe it's challenged... [us] and any not for profits commitment to advancing healthy public policy for the system versus what's good for... business (18:47).

Policy makers sought to even out the playing field for charitable nonprofits by giving them a grace period within which they could adapt and learn skills such as proposal writing, required for successful contracting. Nonetheless, according to the research participants, the benefits of the new model are not transparent. One individual said, During the IIarris and Eaves governments, we became painfully aware of the need to develop and respond with business models even though we are not businesses, and we don't function according to business principals. And, we may chose to act in business like fashion. But to develop and present a business plan was really alien in the non-profit sector. So we have had a pretty steep learning curve in that regard. And, I am not convinced that it's necessarily been... helpful. I do welcome the shift [to] 
being more results-oriented. There's a shift I have seen towards increased emphasis on best practices and developing and delivering programs that are more evidence-based. If you don't know why you are doing what you are doing then you shouldn't be doing it in the first place... (20:17).

Charities maintain they have had to be quick learners; for many, their survival depends upon learning quickly.

Despite the knowledge gained, charities consider efficiency to be a minimum basic requirement when caring for vulnerable citizens through home and health care. One person said,

Yes, [we] can run a very good home care business with managed competition. That's a challenging process but, that is in my mind the absolute minimum of what we need to be doing as a non profit charitable organization... What we need to be doing is to build on that strength in all of these other venues [, meaning their advocacy work,] and in an effective way (18:38).

Charitable nonprofits said contracting and efficiency ideology places them at risk of mission shift, meaning shifting the charitable mission and focus away from their original mandates. Thus, instead of doing advocacy, they embark upon the contract treadmill of business plans, meeting cost efficiency obligations, and so forth, rather than satisfying the broader public good. Signs of mission shift are noted in the respondents' use of terminology. Some executive directors are referred to as CEOs, clients may be called consumers, or they may reference their agencies as businesses or companies. Funding arrangements, whether through contracts or project funding, also contribute to mission shift because agencies become more project oriented so as to satisfy their sponsors' interests rather than the needs of their clients and communities. As one agency's executive director said, 
You become more and more project-oriented and the project may barely fit with your mandate but you're so desperate for dollars to keep the doors open to do your original mandate that you chase these and everything becomes diminished. ... And ..., the infrastructure, nobody wants to pay for bricks and mortar and what that ugly world called overhead. ... In order to store the health care equipment that you think is such a good program, you need a building, you can't keep it in a field. You need to clean it, and that's electricity... it's units of service... [But,] show me ... how many meals you delivered and ... [they will] pay for the meals $(17: 30)$.

When the focus of charities shifts in this manner, the social-public good is jeopardized.

Charitable nonprofits recounted how contracting puts all such organizations at risk

of dissolution, particularly locally-based and smaller agencies. They describe the potential losses associated with this risk to society, clients and communities.

Communities risk losing social memory and history which inform about current social initiatives, and they risk losing the social capacity of agencies. One person recounts how, many ... agencies like VHA-Hamilton, who had been doing home making... and personal support, some nursing, [for] I think... well over 75 years in Hamilton. [They] just simply lost their contract and were out of business. ... In Ottawa, we have seen VHA-Ottawa having to survive by using other programs... We have seen branches of VON closing ... [across] the province. Red Cross ... lost some programs. ... These ... people ... built the community support sector..., that built communities (12:23).

Another executive director told how,

This year, ... for the first time in four years, [we are] no longer contracted with the Community Care Access Center. We lost an RFP ... bid. So we are in a bit of a turnaround situation... But since 1990, or going back 14-15-20 years..., we provided home care ... to the former city of Ottawa home care program which then evolved into the CCAC. ... Organizations that have had contracts for 40-50-85 years are losing $(24: 8,40)$.

A lack of capacity was the reason why this organization failed with their contract bid. 
[We] didn't have 3-4-5 people who just wrote documents. And, [we] are locally-based... We were told that it [, our bid,] was not as sophisticated as [that of] our pan-provincial colleague and that's what lost us the contract. We were told, off the record, that it's not what you write. It's how... It's not what you do, it's how you write. It's what you write about how, what you do (24:40).

Another cause for concern, recounted by the research participants, is that competing agencies low-ball their cost estimates; they underbid to produce the "best priced' proposal.

What we see, in our view, is evidence of some under bidding... Or, some serious competitive bidding... We are seeing [competitors] clearly identifying what they can't possibly deliver-the quality that they are professing to deliver, at that price... There just isn't enough margin, ... or it's undermining other policies (25:75).

They describe how cost estimates are often lowered at the expense of staff who provide services through reduced salaries and/or minimal benefit packages. One individual said,

Let's be blunt... Certainly, here in Ottawa, I have made no bones about being extremely vocal saying that, best price ... [means employees moving] to other organizations in order to maintain gainful employment... [Employees] lost their wages and benefits in terms of seniority levels, and ... reductions in hourly pay. There is no guarantee of hours. Their travel time has been reduced to the most intricate and phenomenally interesting ways of calculation (24:20).

Ultimately, when 'best price' is secured at the expense of labour, quality is compromised. Home care is a labour-intensive service and when labour is mobile or stressed and/or unhappy, clients may not necessarily receive the best quality care. Sometimes, as well, poor costing means that the winning agent cannot meet its contract obligations because it becomes insolvent. According to one executive director, whose agency failed in a RFP bid, the winning firm dissolved. 
Initially, we put in a submission to provide ... rehabilitation services, physio, OT, speech and language pathology and, all that stuff. Our proposal was not accepted. So, they went into a deal with a company that went belly up... I don't think there was a lot of appetite to go back submitting a proposal again $(27: 38)$.

What ultimately happens is that because the CCAC is concerned that bidders can meet their obligations, smaller agencies often do not qualify for the RFP process. One board member said,

We... [were] omitted from being able to have a contract... about 3 years ago, in 2001 or 2002 , when the last contract came up for renewal... We just didn't qualify... Most of us ... were really just getting our feet wet when this contract came up for renewal... It was ... a fight for survival... We were told..., we did not have the financial background... We don't have thousands ... of dollars in a bank account... because we are non-profit. We function... very close to the edge.

The irony is that this same individual was one of "four members of the community who [was honoured by the CCAC, that year, because they had] provided exemplary nursing services in the community." For another agency representative, contracting destabilizes agencies.

[Contracting is] making agencies unstable, because the agencies don't know from one year to the next if they are going to be an agency or not. VON experienced it... Nursing agencies that have been around for a long time that everybody has got a lot of trust in. Just when you hear their name and then all of a sudden they are not here. Visiting Homemakers. [It's] stupid. And it's crazy. It's bad for the client. It's bad for the people providing the services. It's bad for the agencies. And, it's totally unstable $(4: 43)$.

Altogether, it appears that contracting is producing significant negative impacts upon clients which impact communities poorly. 


\subsection{Ottawa's Charities and Their Environmental Scanning Role}

\subsubsection{Describing Environmental Scanning}

Yes, I think ... [charities,] have an incredibly important role because ... regardless of who we are serving, [we] are really grass roots. We see the needs ... [and do so] a lot quicker and ... sooner than policy-makers... We have a role to play as well as being non profits in terms of suggesting direction, ... critical roles. ... We often underestimate how far ahead we are because we are direct service providers (11:28).

When I say [we are] ahead... slightly ahead, I think the ... advantage that we have is, we are a non-profit organization. ... [and] we have a greater ability to be nimble. ... We have a board that can come together and say what's best for the community (23:10).

We often work in partnership with other funders. ... We work very, very closely with the provincial government representatives ... to ensure that funds were invested in strong programs that would help meet the needs... As we move forward, we will identify different actions as they relate to different issues, but there won't be a one size fits all... There will always be a careful thoughtful research-based focus. Here's the irrefutable evidence and... if you do this or, if you do not do this, this is what will happen. Or, if you invest here, these are the returns on your investment. ... We ... make compelling cases that way (23:3).

The environmental scanning policy work done by community charities is

exemplified by the above three quotes for the following reasons. First, environmental scanning work is about identifying the past, present and future health and social needs of vulnerable people. It emerges from individual, public and organizational advocacy which takes place in line with the missions of agencies. It arises because, being service providers, charities are the first to see, hear, measure and respond to needs. Second, because vulnerable people often have no voice, charities become the loudspeaker to solve both old and new problems. Third, environmental scanning precedes public policy meaning, charities become policy shapers in addition to being policy takers which provide services according to government's mandate. Charitable nonprofits do most of their 
environmental scanning work collaboratively with clients, client representatives, other charities, and with financial sponsors, like the United Way. All of the above suggests, environmental scanning is important solution-focused advocacy work, grounded in community networks and partnerships.

The clients for whom charitable nonprofits do environmental scanning are the elderly and frail, and many are female. They include the disabled, immigrants, refugees, the housebound and the dying. They may suffer from AIDS or from mental health problems. According to the research participants, charities are almost always the first to work with these population subsets on new problems. One agency representative said,

[We] were the first to care for the AIDS population, and that [was] way back [when] everyone was paranoid... Mental health programming..., again, we were one of the first to take on... very psychotic individuals in the community $(18: 20)$.

Social justice and human rights are central principles supporting the environmental scanning work of charities. They underscore the missions of charitable nonprofits. One agency representative describes the agency's mission as "mobiliz [ing] humanity, the power in humanity to assist vulnerable peoples... It is trying to improve the capacity of people to care for themselves through the voluntary sector..." (17:38). Thus, the scope of charitable nonprofits expands to include the broader needs of society for public goods.

\subsubsection{The Steps and Processes of Environmental Scanning}

Environment scanning begins, therefore, with problem identification. If problems are sufficiently significant or widespread, individual agencies inform others within the 
network, and collectively they advocate making a wider and stronger community response. Thus, individual awareness of problems leads to a collective awareness which promotes a wider collective response. A number of steps and processes which are generally complex and time consuming are involved. Often, as well, the time period over which individual agencies work on a particular problem may be quite long. One agency representative describes how a successful policy outcome was secured over a particularly long period of time.

So we had these two programs... And, the Ministry... finally, after analysis and review and pressure, has decided to go forward with the client intervention and assistance model and fund it more broadly... [along with] different parts of the program and, [expand it into] other parts of the province. So, in that sense, our sector was ahead of the curve. And, it took a 10-year battle to, for that to be recognized (12:4).

While individual charities may not necessarily view their individual response to social problems as political, because their individual work builds into a collective response to societal problems, environmental scanning work is political.

Because environmental scanning precedes formal public policy, the burden of proof rests upon those who identify and try to solve societal problems. The requirement is met through the collective endeavor between charitable nonprofits, clients, families, volunteers, and sponsors. Satisfying the burden of proof incorporates several steps and processes. Agencies begin by doing research on the scope and severity of problems. Solutions are tested in pilot projects which are, more often than not, financed with grants from sponsors. As well, the grant and funding process means doing public education, even if only to a potential sponsor in a grant proposal. Ultimately, environmental 
scanning means broad-based public education about problems, needs and solutions.

Satisfying the burden of proof, therefore, takes significant time, money, energy and

collaboration. As one executive director said,

A lot of money, time and energy and, several years, [has been] spent just getting to the root of validating. This is really what the consumer needs. But we are doing it and, in partnership... We are using some of our charitable dollars collectively to fund that. So, we are not just diving off into grey areas [where] we [can't] guestimate a need. It's very solid $(25: 79)$.

Evidence is also needed, particularly when the goal is to develop new public policies and programs. Producing strong evidence requires good data and data generation strategies. Thus, generating data is among the first steps in doing environmental scanning.

\subsubsection{The Burden of Proof and Data Collection}

The majority of research participants said they generated data using a variety of formats and sources, e.g., needs assessments. They use Statistics Canada census data for the province and municipality. Previously, they accessed data from the former District Health Council (DHC). They do literature reviews on demographic and epidemiological issues, searching out health status indicators, and so forth. They hold focus groups, and talk with community advocacy groups and other agencies in the community network.

One agency representative said,

We have annual consultations every year where we invite the civic society in Ottawa to kind of discuss issues that are important to them. ... Last year ['s theme] was [answering] ... 'What might be the issues in the voluntary sector?' (21:15).

Charities also undertake their own surveys with clients, volunteers, and staff to 
learn about the problems and needs of citizens. Some also track emails, client calls and web-site hits. One executive director said,

We track every phone call, e-mail, every hit on the web site that comes through... [We track] why did you call us? What are you looking for? And, we collate those things... We meet with our field staff... on a regular basis... We are looking at a trend. So, we do try to go on evidence based clinical practice guidelines (24:48).

They also collect data collaboratively and, in doing so, promote wider understanding about the scope of problems, thereby shedding light on possible solutions. One agency representative said,

We don't do all our own research. We do work with others. We're working with the Canadian Council on Social Development, for example,... to replicate something that was done in Toronto called 'Poverty by Postal Code'... We ... look, on a neighbourhood level, [for] trends in poverty, ... identify the variables that are inherent and, see if there's a role for us to play. ... [Perhaps] working in partnership ... to provide services, or ... leverage some resources (23:22).

Ultimately, the goal is to build health and social programs. One agency representative describes the agency's data generating efforts to secure funding for home support programs in the late $1980 \mathrm{~s}$.

What we had to do at that time [was] to start a home support program. You had to do a survey. And so, I was lucky enough to get a chap, on the board of directors who... was willing to give it a shot. [He] brought in about 10 people, mostly seniors and, we drafted a survey on our own without knowing what we were doing. But, we knew what we heard was needed. So, ... we went door to door and ... found not only seniors who needed the service, but younger people who knew their mum or dad needed the service, in other parts of the city. ... So, we probably helped everybody. And, that's how we had to get funding. They gave me one staff person and that's how we started (14:36-37).

Hence, data build both programs and agencies. This person also describes how the 
agency's initial steps to address local unmet needs have grown to the point where it now provides a variety of services within a larger agency setting.

One in five out here is over the age of 65 . We [were] getting calls back in... the early eighties for health for seniors... By 1987, we knew we needed to seek funding which we got from the Ministry of Community and Social Services [which] funded home care, at that time... It's just gradually evolved from one staff person, at that time, to... [four staff] fully devoted to the services to seniors... We provide that full basket of services that the Ministry of Health refers to..., from drives to medical appointments, to ... home help, home maintenance, luncheon programs, foot care, [and] friendly visiting ... (14:2).

Data also support public education and advocacy on behalf of seniors. One agency embarked upon a fairly large and collaborative data generating exercise to produce 'The Fact Book on Aging', a document which uses Statistics Canada census data to delineate the needs of Ottawa's seniors. It became one of their key public education and advocacy resources.

We did a survey this year, with an agency that we actually formed an alliance, a partnership called Successful Aging Ottawa.... It's really a partnership of a whole lot of agencies. ... We wanted to repeat the [survey done by the former Health Department, in 1988-89] and we didn't have the funding to do it. ... The Sisters of Charity coughed up twenty grand, and the United Way popped in thirty grand for a partnership grant which is one of their new categories. Regional Geriatric actually came through with $\$ 40,000$ and then smaller amounts from here and there... We've now run a survey, $\$ 120,000$ worth and, [originally,] we didn't have any money to do it. ... We have over 1,000 people surveyed..., which is a nice significant sample... We over-sampled slightly on the over 85 's... Interesting enough..., the survey [indicates that] about the same number of people are making over $\$ 50,000$ a year as those making under that. That's one of the dilemmas we have in Ottawa, for making our point with government. ... There is ... a significant number even under the $\$ 10,000$ a year income level which couldn't, by any stretch of the imagination, be considered well off... in this day and age $(7: 46)$.

Sometimes data simply allow agencies to respond better to the service needs of 
seniors so as to improve their quality of life. They may direct people to self-help groups and community services.

Community information was what we needed... So, we gradually formed that and we got the kind of data base we needed. It started out with Rolodex, and ... [is] now a totally automated database... [The data base is used] to publish a couple of directories of self-help groups in Ottawa-Carleton, plus the directory of community services that we publish every two years and distribute to ... 25,000 households... (14:2).

Data have also been used to improve the quality of food prepared for home-bound people.

So, we are very challenged with our quality management programs, to stay on top of this, and be very receptive to client feedback. We do analysis of menus on an annual basis [for] each of our ... regulated kitchens. The [food generally] comes ... from hospitals, homes for the aged, other institutional settings. ... They all have dieticians and nutritionists on staff. And, we do an independent analysis of their menus to make sure that it's meeting the standards (12:32).

In general, therefore, data collection feed into the development of strategic plans for services and programs, and for organizational administrative purposes. Charitable nonprofits now do strategic planning on a regular basis, which for some is every two to three years. Small agencies with small budgets and few staff often use their volunteer boards for strategic planning and often solicit outside funding for their planning work. One of the smaller agencies in Ottawa secured funding from the Trillium Foundation for their strategic plan. Another agency undertook a community-wide assessment through a collaboration of local charities. Agencies have had to be resourceful in collecting data and doing strategic planning because these activities are now the normal requirements of working with government and sponsors.

Data also support accountability requirements. Descriptive and financial data are 
used to write monitoring, progress and financial reports which account for funding received from local and provincial governments, and other sponsors. Data substantiate funding requests submitted to governments and sponsors for pilot programs on new and ongoing programs. They may demonstrate a program's effectiveness and support an agency's request for additional and/or ongoing funding. The ultimate goal for agencies is to secure more permanent program funding. Because this goal is so important, significant time and energy is invested in satisfying accountability requirements. One agency representative describes the agency's challenges to satisfy accountability.

The demands for reports and accountability measures of various kinds, are high... Over the next 12 months, we will be developing and delivering 120 different reports to different funding sources... It's all with a view to demonstrate our continuing value. ... None of [these are] specifically funded. So increasing amounts of our resources ... go... into data collection and analysis and report preparation... It does improve our own planning capacity, but ... the formats for different funders don't... [follow] a common report[ing format]... We don't have the administrative infrastructure to be able to do this in ways that we would like to $(20: 38)$.

Governments use the data generated by charitable nonprofits to strengthen their own information and programming initiatives. As a local government representative said,

Now what happens with all of that information that is gathered individually is that it is put into a database. We developed that last year and right now the information that's in the database is mostly used for quantitative information, ... [e.g.,] budget pressures, ... the operating budget, the total of this or that.... The database has the capacity to produce other reports. ... So, that's probably the most ... consistent method, apart from ... individual organizations coming to us making requests or organizations $(5: 1)$.

Politicians may also use the data provided by charities to introduce issues into the public domain and when making arguments and recommendations. One agency representative 
said, "Councillors use us also to help them introduce issues that is, if it's important to us and our community and we all agree" (4:46).

While data may be used by government, the end goal for charitable nonprofits is to improve the lives of vulnerable people. Thus, for seniors, environmental scanning work is not a luxury, but a requirement.

We have assessed, based on demand from the community, be that phone calls, or requests for service, or just calls to say, 'I don't know what to do. Where do I go?'. This identifies a need or gap in the sector and, we will then advocate to fill that gap and [figure out] how to do that. We feel that the [first consideration of the] not-for-profit [sector is]... best quality... before any other interest... We are not stakeholders... We are not shareholder-driven. We are not driven by how big an office we are or, how fancy it is or..., what our shareholders have to think of us because, our shareholders are our stakeholders. They are our community (24:47).

The next section describes how the environmental scanning work of charitable nonprofits improves the lives of clients. Some of the following are described as worksin-progress, while others have become part of mainstream programming for the elderly.

\subsubsection{New Programming Initiatives}

\subsubsection{Works-in-Progress}

Elder abuse is one issue which, charities say, is so widespread that it requires a wider public response. As well, because elder abuse sometimes involves an elder's closest family or friends, it is a difficult issue which must be talked about more openly. Agencies say seniors and the broader public must be made aware of the problem. One executive director said,

One of the areas we deal in most is elder abuse. ... It's a bit like an iceberg. We think that a very small percentage of it actually gets reported. We're not talking you know, always physical abuse. In fact, the biggest 
single one is financial abuse. You get to a certain stage and your niece decides she can help you with some of these things and after a while she says, 'well why don't you just sign the rest of the cheques in this cheque book because then I can just look after this for you.' Temptation sometimes means that money starts to disappear... We want the community to be more aware of it [and] ... stop it from being so hidden. The province ... is on our [target] list because [abuse also arises in] ... long-term care institutions. ... The province is now coming up with some additional rules and ... [will be] inspect [ing] the homes on a more regular basis, [and] in long-term care institutions (7:6).

This agency repeatedly asked "government [, over several years,] to license residential care homes, not just long-term care nursing home type of thing." It has also used television media to communicate to the public the severity of the problem. Through its advocacy targeted to government, it identified licensing as an important preventive mechanism that would protect vulnerable seniors from such abuse. Another agency promotes public awareness on elder abuse to high school students by developing a public education video through a project that was funded by a foundation grant.

When we did the elder abuse project, we got some funds so that we could take the video to high schools... To me that's a type of policy... We wanted young people to understand the issue of elder abuse as well as the multitudes of groups we have shown the video to... [We have] sold over 300 copies throughout the province (16:13).

Many years ago, another agency identified seniors' substance abuse as an emerging problem which required both an individual and wider public response. This agency's initial success with targeting the needs of its own clients has expanded into a city-wide service that now helps citizens in the broader community.

One agency works to resolve the problem of type-two diabetes, identified by the MOHLTC. Logically, the agency began by working with its own clients. Their 
pioneering work has paid off and they now manage a diabetes program on behalf of other agencies around the city.

Seniors' housing is another issue that is being addressed by local charities. One agency, first, tackled the issue through a pilot project funded with grants. Their successful pilot has developed into a housing model which is now funded by the municipality, on an ongoing basis. They have recently adding a French language component to the housing project.

Charities are also concerned with meeting the needs of dying people. Their pioneering work have developed into training programs for palliative care givers and volunteers, and more recently, to finding ways to provide palliative care to homeless people. One person said,

Well we started a palliative care course... maybe six years ago... That's a real need, as you know, both for our residents and also for people who need to be trained to work in palliative care. So, we started doing a course that originally had started because of a need of our own staff... Then, we opened it up to well anyone who wanted to come. And, we certainly advertised it to all the long-term care facilities in our zone... (22:27).

Another agency works with a local university to develop a palliative care program for homeless people who live outside of the purview of public policy simply because they do not satisfy technical and administrative criteria like having a permanent address. This requirement means homeless have become invisible. The agency found a way to circumvent the system and provide care for these people.

[Our agency collaborates] with University of Ottawa in terms of developing new services for the homeless, for palliative care, respite care... We actually provide the 25 staff and front line staff and the nursing care staff for the intercity mission hospice... We are the flow through funding 
agency for the hospice at Maycourt... Both [of these] are not for profit charitable bases which are testing public health models of palliative care for those in the end of life cycle $(25: 12)$.

This individual also describes how both policies and lack of funding constrain this type of piloted program.

Their own policies are limiting them... [The demonstration project for palliative care originally] started as a federal two-year pilot project. [Now the challenge is to determine] how they can convert that into existing policy because, there is no funding stream for palliative care in the semi-institutional setting[, meaning,] not the client's home (25:54).

Palliative care for children is another challenge being addressed by local agencies.

Our palliative care team ... partnered with the paediatric end of life care team at the CHEO to advocate for funding and [to] establish [a] service that also caters, to a certain extent..., [to] home bound children. ... We ... were then able to get funding for this initiative... We're here to make sure that we provide the care in the best circumstances at all times (27:7).

This charity also collaborates with a local university to develop home care technology to help seniors live safely in their homes. Although, at this time, the solution is still research-based, the expectation is that technology will ultimately become a mainstream response to support seniors' independence.

On the research side, we're involved in different initiatives... For instance, borrowing on the health line idea, we currently have a what's called TAFETA [Technology Assisted Friendly Environments for the Third Age] project is adapting the home environment to cater to the needs of the frail and mildly demented patients... We're partnered with the Carleton University Engineering Department ... [to] adapt... appliances, [and to] ... trigger ... alarm [s] if ... you fall from your bed [and so forth].... So we have different means of providing distance monitoring service $[\mathrm{s}]$ to the frail, mildly demented community (27:9).

Another collaborative initiative is a bridging program for seniors which is both an adult day program and institutionalization. The executive director of a local agency 
describes it as follows.

One of our new services that we're looking at is a 3-way partnership between ourselves... [the] Alzheimer Society and [the] Perley Rideau Veteran's Center. [It's] for a bridge from day program to what would be... long term care... We are going to build a 24 hour, 7 day a week, respite bungalow... Currently..., the only other respite alternative [is] overnight stay... into a larger ward in a nursing home or long term care institution... So we are hoping to enhance the service by presenting to the Ministry a new model of service that bridges the two. But, is really centered around the client's normal rhythm of life... [regardless of whether or not the need is] two weeks, three weeks, overnight, [or] weekend respite service (25:9).

Charities are also providing home care services to people suffering from different

illnesses like cancer or post-partum depression in a less disruptive manner.

Home chemotherapy, is another area where we really, I think we are one of the pioneers pushing... It wasn't so much.. [to] get this technology in the home but, to [minimize] the huge disruption to their lifestyle... It [c]ould be mothers that had children... [and] our mental health ... with our post-partum ... Rather than disrupt the whole family dynamic, could they not be managed in a home environment in a whole different way? So, we've really pushed on those fronts (18:21).

Another area in which charities are actively involved pertains to employees-paid and/or volunteer. The lack of a province-wide volunteer policy is problematic for many charities. One agency representative expresses this lack as follows.

One of the biggest policy vacuums in Ontario [is] the lack of any position on volunteerism and the voluntary sector... I've had a couple meetings with Marie Bountrogianni who is the Minister responsible. You know, she's very receptive (15:22).

Prior to managed competition, agencies had advocated on behalf of their staff, seeking government's approval for improved salaries, benefit packages and working conditions. One agency representative said, I recall back in $1994, \ldots$ we lobbied very hard and long with both the local 
area office and the provincial government about travel time" (24:13). However, since the advent of managed competition, she said, "These are people who have given 25-30 years of their life to work in this sector... Now, they are marginalized and unable to keep their pensions. We offer a pension plan and, not very many others do. So, it's been primarily a woman's workforce... It's about keeping people gainfully employed and able to put food on the table and most of them are not that much above the poverty line (24:20).

Charities claim that human resources are a gender-women's issue, an immigrant issue and a poverty issue. Most home support workers are female, working at the low-income end of the employment spectrum and a significant number of them are immigrants. One agency published a report on the plight of female-immigrant home care workers.

We have published a report on immigrants in Ottawa and found that the majority of home care workers are immigrant women. Actually, we... looked at immigrants in Ottawa and what they work at. And, we found that almost all recent immigrants, workers in the home care sector, are women. So, it's a gender issue (21:12).

Unfortunately, as well, charities claim society is only too willing to exploit these people while not acknowledging their contributions. One agency representative said, "If those [immigrant women] disappeared, talk about a health care crisis" (17:25). It certainly would be a care crisis because their contribution is significant.

The above are but a few examples of the works-in-progress being introduced by charitable nonprofits. Many of these agencies rely on project and/or grant funding to do this work. The next section provides examples of the policy work of charities which have developed into mainstream provincial and/or national programs. They are referred to as successful public policy initiatives. 


\subsubsection{Successful Public Policy Initiatives}

The introduction of geriatrician programs into public home care is one clear example of a policy outcome which emerged in 1982 from the environmental scanning work of one local charity. A board member from this charity said,

Out of all that work and, all the studies that went on, $\ldots$ and... academic research. There also... was community fact finding research, and this... was absolutely instrumental ... [to] documenting and chronicling the needs for people. I worked here... from 1982 to $1989 \ldots$... [on] home support and education. So, Dr. D. spent a year here... and... [facilitated the set up of Ottawa's] geriatric assessment program... I think there were perhaps three or four geriatricians in the whole of Canada[, at that time]. There aren't a whole lot now, I mean. I'm not sure what the number is, 40 maybe $(8: 6)$.

Fostering independent living for seniors through the provision of home care supports is another idea that was first piloted by local charities. Although funding is minimal, the research participants claim the wisdom of home supports is commonly accepted. As a result of the collaborative work of one agency with the with a former Board of Health Committee, Ottawa's first homemakers' program was established in 1983. At that time, the program was overseen by the former Regional Municipality of

Ottawa-Carleton. This individual said,

All those pressures were happening... from 1983 to 1990 and, in $87 \ldots$, it was acknowledged that you would never keep people in their own homes if you didn't have somebody coming in to do a little bit of homemaking for them, meal preparation, laundry. Very often people had to go into homes for the aged or nursing homes quite early, particularly, people without money, who couldn't afford to pay. ... The chronic care [home makers' program] and, particularly [for] the frail elderly... [was established] in 1987 ... And, I think there were only perhaps four in the province but, it could have been six... I can't tell you where the others were (8:5).

This program eventually became one of the first home care services which was offered by 
the CCAC, in 1997. It first appeared "as a pilot... We now call [these] personal support services or, sometimes... homemaking services... Government['s] who are hostile to them [refer to them as] housekeeping services, which is really a derogatory term and not fully descriptive" (8:5).

Senior's day and respite care is another commonly funded public program which was initiated by a local charity over twenty five years ago. Adult day programs are now mainstream programs in Ontario and in other provinces.

We saw a need in... Ottawa-Carleton for a day care. We were the first one to start it... At that time, we were doing our admission and, we saw through our admission that there [were] people who could benefit from being on a program during the day. But, [we] had kind of no formalized program in the city that they could go to... People had begun, at that time, to kind of talk about day care for the elderly... We started [it] with five [clients], and it just started to blossom from there. ... The first year, we had no funding so, we had... to pick up the tab.. It just seemed to take off and, we have never gone backwards with it. There's just more need all the time (22:2).

This same agency also pioneered a telephone assurance program which, at one time, was called 'Lifeline' and, in the 1980s, they also pioneered a 'Meals on Wheels' program.

The above are a few examples of public programs which originated in the environmental scanning work of individual charities. Eventually, with time, energy, perseverance and a vision, their small and local successes developed into larger, mainstream public home care programs. They represent the collaborative work between individuals, small agencies, boards, international and local academics, and sponsors like the United Way. Supplementing the above which have strengthened home care services and programs for the elderly are quality improvements which arise from the standardized 
educational and training programs charitable nonprofits have spearheaded. Geriatric assessment is one example of a small program that has been expanded into a standardized educational and training program for future geriatricians across the country. Standardizing training for personal support workers is another area of training that has been spearheaded by charities.

While charities work in areas that already secure some level of public financing and support, they also take on new needs. The following section describes some of the tools they use in their policy work which help them to address new and unmet needs.

\subsection{Promoting Values in Society Through Advocacy-constituted Roles}

\subsubsection{The Tools of Policy Work}

Nonprofit charities use a number of tools to promote values in society under the ultimate goal of improving the quality of life for as many people as possible through public home care programs. In this regard, public education becomes both a key tool used by charities and an umbrella under which other tools fall. Altogether tools make possible the advocacy-constituted roles performed by charities. Public education and awareness raising are targeted to citizens, users, sponsors such as foundations, politicians and policy makers and it begins by talking to individual clients, caregivers and families. It addresses old, ongoing and/or new issues. Sometimes it simply means making people aware of current programs and services. One charity representative told how the agency does public education on an existing government-funded pension program which is not well advertised or well known.

[People may be] eligible in some cases for the supplementary pension, but 
they never apply for it. ... Nobody ever told them... that you could get this... We're very fortunate in Ottawa because we have as a resource, a lot of retired civil servants, ... [who] work on financial things for us..., anything to do with pensions... We had a major program on that a few years ago and it's being followed through now with these clinics that are done... You can get your taxes done, if you are a low income senior, for example... They are all free... Run by volunteers who are trained accountants, they donate some time (7:7).

This same agency also does public education to simplify the transitions for seniors who are going in and out of acute care settings. The agency calls the project 'Senior Accessible Health Care'.

We make the entry to the health care system a lot smoother for people who are of senior age. [We've] done... a booklet called "In and Out of Hospital" which we actually have in three languages now.... [One] project, which has just finished the pilot stage now, ... is basically an offshoot of the hospital program of "Senior Friendly Hospital"... [It] has been pushed here by the Regional Geriatric Assessment Unit... We have a couple of their folks who work with us on this. And now we're trying to extend that into clinics, individual doctors offices, laboratories, any place that a senior is likely to have to go... But, if somebody doesn't bring it to their attention, it may not get done (7:26).

Public education also helps people learn how to advocate on their own behalf.

We've also [supported], because our whole theory is that we should be helping people speak on their own behalf, ... a group that... call themselves the 'No Name Seniors'... They... [got] a lot of help from one of our health promoters who's still working with them. Now, they've become the 'Ottawa Seniors Action Network' and, they are supported by [the] Sandy Hill and Somerset West Health [Community] Centers. And, these folks now go... to the city... on behalf of seniors... So they organize themselves, now. They will have meetings with the Mayor (4:5).

Volunteers often do public education and awareness raising, and may do it during annual general meetings (AGMs), for example.

From the policy perspective a few years ago we had... speakers... at our AGM... This particular year, we focused on support for seniors in the 
home and, we had three speakers...: our outreach nurse for seniors, ... the head of the Ottawa Seniors Action Network, ... and the ... head of the Good Companions. ... The three of them spoke about ... problems and issues, and what was needed... We were trying to use that as an education opportunity but, also as an opportunity to try and move the issue forward $(4: 5)$.

Hence, volunteers are a fundamental asset with respect to public education. The ultimate goal is that public education, targeted to government, will promote better quality services for seniors through better policies that address, more appropriately, their needs. As one research participant said, "We meet, I mean the Ministry, ... the local Ministry program consultant $\ldots$ attends our meeting on a monthly basis" (1:37). Another agency representative said,

We routinely schedule regular meetings with our elected representatives at all levels, municipal, federal and provincial and meet with each of those representatives around issues of concern for us, at least two or three times a year. ... We are involved in advocacy on behalf of our clients to inform healthier public policy rather than lobbying per se. And it's a fine line that has never really been successfully defined (20:23).

Other related tools of public education include letter writing and media campaigns. Data generation and information dissemination are additional, important tools. Collaboration and partnerships are also central to doing public education because they build a broader constituency. Pilot projects, projects and research are central to public education. Public presentations and the internet are also used. Participating in local, provincial and national consultation exercises also foster public education.

\subsubsection{Through Broader Engagement and Advocacy}

Representatives of charitable nonprofits were unanimous about the importance of responding to government-led consultation exercises when promoting values and 
improving the conditions of vulnerable people. Nevertheless, not all governments make space for charitable nonprofits to do so. In the early 1990s, the NDP government held extensive consultations with the public, including significant numbers of charities, over its plans to establish Multi Service Agencies (MSAs) across the province. One board member said,

The MSAs, I spent four years of my life and, there was a big planning group of about 30 people... We worked with that group to... develop principles... because they[, government,] were going to, the MSAs was going to amalgamate and absorb all the community support agencies as well as home care... That multi-service agency planning, [at] the end of four years, it just went poof because the NDP government was defeated. It was 1990-1994" (8:16).

The executive director of another agency said,

We [were]... involved both with multi-service agency discussion... I would say we were much more vocal with multi-service agencies... We actually work[ed] very closely with the Catholic Health Association of Ontario with Catholic charities, with the hospitals, certainly with our other not for profit counter parts... I would say we were extremely successful in changing that mind set (18:37).

The overriding opinion of the research participants is that the PC government which replaced the NDP government, did not work collaboratively with the community. The public consultations of the PC government were minimal and very controlled. Some people expressed the view that community engagement regressed rather than progressed under the PC government. One executive director said, "Under the Conservatives was the complete ignore, not ignoring, but the taking away of any policy capacity within governments" (15:9). Another said,

Well, oh yes, over the years, its interesting because you know each successive government has had... [its own consultation exercise]... There 
was the multi-service agencies and... before that... the service coordinating agencies... They did some consultation. Now interestingly enough, the CCAC development, [which came under the Conservative government, ] there were no consultations for that $(1: 58)$.

Another said,

We went through a very difficult period with the Conservative government. I don't think that we were very large players as far as they were concerned. I'm talking about the community supports sector, and even on a more broad scale of the home care sector. I think we were, seemed to be very minor players and not a lot of attention was paid to us. We have had better relationships, as [a] sector, with other governments $(12: 11)$.

Unlike the practices endorsed by the previous government, the current Liberal government set in motion two broad-based consultation exercises with the community.

The first related to the establishment of the LHINs across Ontario. The second related to the procurement review conducted by Elinor Caplan. A number of agencies expressed the opinion that the Caplan review came about because of the advocacy undertaken by charitable nonprofits.

The reason Elinor Caplan review is on is strictly because of [the] media stuff we did last fall. ... We can show you a stack of media stuff that we generated. ... Over there. And, you'd never know we did it. ... We don't have any face on it at all. ... But we had stories you know, developed (15).

Charitable nonprofits indicate they have participated in both Liberal government-led consultations.

As well, charitable nonprofits said they have participated in relatively recent national consultations such as the Royal Commission on Health, i.e., Romanow Commission, and the Kirby Commission. When charities engage in province and/or nation wide consultation exercises they generally do so through their associations and 
other networks.

In addition to these larger initiatives, charities target their advocacy work on local issues and needs related to home care to local government mainly through budget consultations. Sometimes they make individual-agency representation and sometimes they come together with a unified voice through the Coalition, for example.

Although charities do not consider themselves to be very knowledgeable about the political process, by and large, they have learned quickly how to participate in the political process. They never refuse to engage in any consultation, open meeting, closed meeting, and so forth. They take every opportunity to meet with local, provincial and federal politicians. Since the early 1990 s, charities have become more aware of the need to be political and have taken the steps to learn how. The next section is a brief summary which highlights the assets that charities bring to the policy table.

\subsection{Chapter Summary}

This summary section begins by recounting the ideas of the research participants in regards to their assets which relate to their identity and motives, and which facilitate their public policy roles rooted in advocacy. They explain why nonprofit charities do more than provide services. The advocacy work of charities is inseparable from their identity and individual roles, and explain my referencing the roles as roles advocacyconstituted roles. It also explains why the narrow, competitive arrangements through which many home care services are allocated put at risk both charitable organizations and the benefits they offer to seniors, caregivers, labour, other agencies, government and the public. When narrow definitions of services, roles and care are used to compare charities 
with for-profit companies and their business models, charities may appear to be deficient. When considering the ability of charities to promote a broader public good for individuals and society through their varied roles in regards to for-profit operators, charities excel.

Charities claim that their most important asset, in regards to policy change, is their identity as nonprofit organizations. Minimally, this identity facilitates their work to move forward a public good agenda on home care. Charities consider their missions, their committed staff and volunteers, including community boards, as synonymous with being nonprofit. They diligently do the work that the private sector ${ }^{34}$ is unable and/or unwilling to do because of their profit-making mandate. As one agency representative said,

We feel... that ... for profits may not be as keenly interested in those supplemental things. ... We wonder, what ... intrinsically gets lost if you are not active in the volunteer, the charitable ... and, ... advocacy and, policy development roles, because there is an awful lot there... If you don't have a critical mass and, if you are not developing the expertise and the quality and, if you are not committed to the continuous quality improvement processes of best practices, how can you share that wealth... $(25: 25) ?$

As well, their embeddedness within community means their timely and first-hand knowledge of past, present, and future issues are additional assets which enable them to invest in the future. As one executive director said, "Part of what, in particular in home care and managed competition, part of what the not for profit charitable sector brings ... is investing in the future" (18:64). They consider their commitment to good quality work,

34

It was noteworthy that representatives of two private sector firms, who participated in this research, never spoke specifically about the needs of the frail elderly, the mentally ill, people with chronic needs and so forth. The absence of these clients in the conversation was notable. However, their concerns related to promoting quality through contracts were similar to those expressed by charities. The difference seems to be that firms do not advocate in the manner of nonprofit charities, regardless of the issue or the target. 
in accordance with sound evidence and best practice on behalf of society's vulnerable as

assets. Similarly, their trustworthiness, ethical and nonpartisan approach with which they perform their advocacy-constituted roles are assets.

Another asset they acknowledge is associated with the specific efficiencies that arise from their work. Unfortunately, they are often not recognized. One agency's representative said,

A lot of our services are cost-effective and cost-efficient, are volunteer driven. The dollar allocated for the service itself is reinvested in training and partnering in and, providing a service to a client that is affordable. If it's a volunteer that is going in, it's great. But, we are also looking ... [to ensure that volunteers have the needed] skill set... Also, trying to provide the service from a brokerage perspective that has all the rights, responsibilities, and guidelines available both to the client and the worker so that the relationship between the two is harmonized. ... I would say we [are] ... one of the better service providers... I think that's what my funders are also saying... I think we do extremely well with what we do have $(10: 30)$.

These assets have enabled charitable nonprofits to advocate on behalf of individuals, other agencies and the broader public in regards to the tax-funded component of home care which is managed by the Ottawa CCAC. Charitable nonprofits have communicated to government officials and policy makers their concerns with both the processes of managed competition and the outcomes it produces with respect to individual clients, other charitable agencies and the broader public. They consistently promote the view that vulnerable citizens are entitled to both a social and medical form of home care, and that this entitlement ought to be based on citizenship. Furthermore, they consider the social form of home care as being so important to independence and choice for seniors, and to health sector efficiency, it should be government's first priority. 
Through environmental scanning, Ottawa's nonprofit charities have also been key players in the development of training programs for both personal support workers and 'professional geriatricians', and of new and enhanced services which are provided to clients and their caregivers. Supplementing these are many works-in-progress which they hope will become mainstream programs. A variety of tools are used by these agencies under the twin goals of promoting values in society and improving the situation for vulnerable people. Yet, despite all of the above, it is interesting that almost half of the research participants believed they had not positively influenced policy. Many considered the constantly changing policies, associated with the many changes of government, each imposing their own policy agenda, as impediments which restrict their ability to influence policy. Many agency representatives also expressed frustration with governments' overall lack of understanding about the needs of seniors and of the importance of home care to them. The above represent external constraints which negatively affect the advocacyconstituted roles of Ottawa's charities. Agencies also claim that, ultimately, external constraints become internal constraints which impede their ability to do individual, organizational and public advocacy. Albeit the challenges facing them, the representatives of charitable nonprofits believe their policy influence will be ongoing through each of the ways described in this chapter. 


\section{CHAPTER 8 - HOME CARE IN EDMONTON, ALBERTA}

\subsection{Introduction}

We are a charitable nonprofit. ... We all didn't want to be subsumed by ... regionalization. So, ... as the province started regionalizing, ... a number of us were very vocal and influential in sustaining our own existence $(10: 8)$.

We are registered as a non-profit, charitable organization. ... We are ... held accountable to many different levels of ... government, and also to the community as a whole. But, ... we have more flexibility in trying new things $(11: 4,39)$.

Our history is in ... care. We're a not for profit organization that has its sources in the ... Church. ... We're happy to tell our clients that they deserve better $(17: 2,43)$.

There is a reason why there [are] more voluntary not for profits in Edmonton ... than there are in Calgary. ... That's simply [because] Edmonton is more blue collar. ... So, you'll find more ... supportive housing ... in Edmonton (19:44-45).

The charitable sector in this province has no credibility. We are the whiners, and we're just there with our hands out. So, we just have to be ignored. Whereas the business sector is there to generate wealth (23:94).

These five quotes represent the voices of individuals representing nineteen community charities working in home and continuing care in Edmonton and the surrounding area. Their voices provide a snapshot of the policies, challenges and issues associated with doing home and continuing care in Alberta. They describe a health system which is characterized by fragmented authority, top down control, stagnating programs, practices of intimidation, and hidden locus of decision-making. Albeit such constraints, their stories also describe human initiative which is invested in the care of seniors. This chapter tells the story of the policy work of Edmonton's charities to shape home care. The first section introduces Edmonton's charities and explains their redistribution and societal stability roles according to the following characteristics: their 
dates of establishment, budgetary information, and volunteers. The following section introduces and explains the policy work of these agencies in terms of their service delivery role in home and continuing care. It juxtaposes the service role with the structures of government which shape Alberta's home and continuing care system. This demonstrates how government structures obfuscate the home and continuing care environment ${ }^{35}$, making it almost impenetrable to both insiders and outsiders. Against this background, the following section describes the policy and advocacy work of charities in regards to public home care services. The next section introduces what I call the environmental scanning policy work of charitable nonprofits on home care. This is followed by the examination of the tools of policy work which are used to promote values in society. The concluding section summarizes the chapter according to the assets of Edmonton's charities which enable them to be trustworthy policy shapers of home care.

\subsection{The Redistributing and Societal Stability Roles of Edmonton's Charities}

Fourteen of the nineteen charities within Edmonton which participated in this research were established prior to home care's formal appearance in the province in 1978. Of these, four are at least 100 years old and four of the youngest agencies were established between 1980 and 2002. The services provided by these agencies promote independence for seniors and include: adult day, clinical, social-recreational and home support services, long term and home care, individual and public advocacy, as well as supports for people with developmental disabilities.

35

Home care is a sub-service of the continuing care sector. My use of the term home care sector refers broadly to the continuing care system, but with a stronger emphasis on home care services. 
The annual budgets of participating agencies vary between $\$ 225,000$ to $\$ 80$ million. The budgets of half of the agencies are less than $\$ 500,000$ and reflect the degree of complexity of the services they provide. The offices of these agencies are small and often cramped, and many are located in low-income neighbourhoods. They employ few paid staff. The budgets of the four medium to large agencies range from $\$ 1$ to $\$ 10$ million, while the annual budgets of the four largest agencies range from $\$ 15$ to $\$ 80$ million. The budgets of all but the smallest agencies are associated with a more complex set of services. Despite their large budgets, only two of the largest institutions employ policy-oriented staff. None of the other participating agencies employ policy analysts. Rather the volunteer boards of these agencies and/or their executive directors perform the policy analyst function. As well, none of the above applies to Capital Health, a registered charity. With a total health budget of $\$ 2.2$ billion (Capital Health 2004, p. 6), recorded in 2004, for example, Capital Health is able to employ policy analysts. While the province, via Capital Health, is the main funder of home care, additional services are financed by municipal government, foundation grants, donations and other fundraising, and these are leveraged by local charities.

Approximately half of the participating agencies were willing to be quoted in this research. There appears to be an association between the source of any agency's funding and their willingness to be quoted. In general, agencies which are independent of government, were willing ${ }^{36}$ to be quoted.

36

Despite the permission given from some research participants to use their names, I have maintained anonymity for all people so that all are protected. 
The numbers of volunteers represented by these organizations range from a low of 15 to a high of 1,200 , within one organization. With the exception of Capital Health, all board members are appointed by the local community. Generally, board members are identified by nominating committees or, are recruited through public advertisements in agency and/or community newsletters. Alternatively, if an agency requires a particular set of skills in support of its operations, people with those skills are often invited. In general, all board members are expected to demonstrate their commitment to the work of their respective agencies. This is one way in which agencies promote and satisfy accountability requirements to their funders, members and clients.

\subsection{Providing Services and Doing Advocacy Under Government Structures}

\subsubsection{Working With Capital Health}

\subsubsection{Under the Capital Health Board Structure}

According to the research participants, government funds services and liaises with citizens and their communities mainly through Capital Health. A representative of Capital Health describes its core business as "providing health information, promoting health, treating illness and injury, providing supportive care,... and advancing education and research" (13:13). The Capital Health board is appointed by the Ministry of Health and Welfare (MHW). Thus, as one research participant said, "Each health authority has a separate board that is accountable to the Minister of Health" (9:5). Accordingly, a former representative of Capital Health said that being accountable means, "if a Minister makes a decision, as the board, we have to support what the Minister says" (8:37). Since citizens are mainly absent from the appointment process, the line of accountability for Capital 
Health differs from that of the other research participants in that it flows up to government rather than down to citizens and community ${ }^{37}$. A former representative of Capital Health said, "Don't forget that the board is appointed by the government. So in some ways, the board is the one who decides what [and] how... [Capital Health] do[es, but] if the minister says something, the board has to listen" (8:41). Also, at variance with the practice of the other agencies, Capital Health board members are remunerated for their time.

Through the Regional Health Authority Act, government requires that each health region establish at least one Community Health Council (CHC). Their key role is communication liaison between the regional authorities and local communities. Each regional authority decides on the number of $\mathrm{CHCs}$ it requires for this mainly communicative function. Capital Health governs all aspects of the operations of its CHC including establishing bylaws which govern their work.

\subsubsection{Working with CHRA's Community Health Councils}

Capital Health oversees 10 volunteer CHCs which serve the Edmonton metropolitan and adjacent rural areas. The councils report to the Capital Health board and each one is given a budget which, according to a Capital Health representative, is used

to support all the activities related to their advisory role to the board. So,

37

The board may recommend prospective members to the Minister. Sometimes, as well, individuals lobby for a position on the Capital Health board. One individual said, "you get appointed by the government and then you get the support from your MLA [, Member of the Legislative Assembly], and also from your background" (8:6). For a brief time, board members of the regional health authorities, including, Capital Health, were elected. 
it's fairly broad; most of it goes to their meetings ... People, in their busy lives, ... come, ... have a little bite to eat and then they have their meeting, and then they go home. And, that's been I think their secret to success $(13: 18)$.

The $\mathrm{CHC}$ recruitment process occurs annually; Capital Health advertises to solicit new council members who will represent their particular sub-regional area for a three-year term. According to a staff member of Capital Health,

They [, Capital Health], ... meet everybody. ... The board actually sees it as a good way to meet people from the community and learn about ... their perceptions ... [regarding] Capital Health (13:7).

Although the minutes of $\mathrm{CHC}$ meetings are maintained, at the time of data collection they were not posted on a web site. Neither were the dates of future meetings. A staff of Capital Health said,

Meetings are monthly and ... are open to the public ... Some of the councils, in the past, advertised their meetings. The experience has been ... [mixed.] Unless people have an interest, and there is some tie to the council, then you just don't get people (13:15).

Both practices seemingly contradict the purpose of the $\mathrm{CHCs}$ as communication liaison within their community. On the other hand, they could explain the comment expressed by one research participant in regards to the short-lived electoral process to recruit $\mathrm{CHC}$ members because citizens failed to respond (13:8).

CHCs are sometimes the locus for consultations between Capital Health and the community. A Capital Health representative said, consultation sessions ..., issues ... are brought forward ... [to the Capital Health] board [which] will often ask administration to look at these issues in context in relation to the business plan (13:28).

The CHCs are also assigned additional tasks by Capital Health. For example, in 1999, the 
CHCs undertook an organizational review of all their internal processes on behalf of

Capital Health. One outcome of the review was the recommendation that

the Councils ... take on ... a topic, an important health topic, an issue that the [Capital Health] board has [an] interest in and falls under their priorities. ... So, health Councils will work on that. ... [This process has been] very, very successful and it gives them [, $\mathrm{CHCs}$,] a chance to work on things that are current and meaningful and important ... [, and which are] the Board's priorities (13:11).

The issues identified by Capital Health "usually stem from somewhere in one of the ...

[region's core business] areas" (13:13). While CHCs may refer issues to the Capital

Health board, this would only be on an advisory basis. Examples of new programs which arose from $\mathrm{CHC}$-led consultations include:

- Capital Health Link which provides information to the public;

- a public education campaign on the proper use of emergency services;

- The Health Care Protection Act to govern access to private health information;

- a public education program to reduce tobacco use; and

- an educational program promoting individual responsibility for health, under a healthy aging initiative.

Interestingly, none of these new initiatives represent direct client health services.

Although CHCs exist to facilitate flows of communication and information, the

flows appear to be one-sided. A Capital Health representative describes how its board discourages the practice of allowing citizens' groups to make public statements, or presentations on any matter, problem or issue during $\mathrm{CHC}$ meetings.

Coming to the mectings, it's not to say that people don't hear about people's experience with the system and bringing forward issues and suggestions and ideas. So, those things do find their way but, in fact, ... we don't encourage, I guess in some respects, we don't encourage those groups, necessarily, to bring their issues to the council (13:21).

This individual also describes the practice whereby the concerns and questions of citizens 
are diverted, away from $\mathrm{CHC}$ meeting processes, to patient relations spokespersons or to the Capital Health link lines. On the other hand, if Capital Health seeks information from citizens on a topic that has been pre-selected by its board, the CHCs may invite citizens to scheduled focus group meetings for discussions on the various issues. Alternatively, citizens may be invited to complete informal surveys that have been developed by the CHCs on behalf of the Capital Health board.

Communicat [ing] with people... That probably is one of the greatest challenges. ... How to actually get out and learn from people what's important to them $(13: 26)$.

It was the view of the Capital Health representative that the advisory role of the CHCs works well and

is important in the [Capital Health] board. ... We talk about working together constructively and collaboratively, and I mean we try. People will come to these advisory councils usually with some experience with some part of their lives something will tweak their interest. But, ... we have to be careful because it's not a forum for you know special ... targeted ... interests. You know it's difficult because ... what's important to one person ... may not be as important to the group as a whole (13:23).

The executive director of a community agency provides an alternative point of view on the effectiveness of the CHCs as communication's liaison between citizens and Capital Health. This individual became a CHC member in order to gain access to local bureaucrats.

I was a Community [Health Council] ... member and became president ... That's the only way I even got the meeting [scheduled, between Capital Health]. ... But, that all was for nothing. I mean it was [a] useless exercise (27:22).

The views of the research participants identify the question as to whether or not Capital 
Health really wishes to communicate with the citizens it serves.

\subsubsection{Working with Other Government Ministries and Governments}

The responsibility for seniors' care in regards to home and continuing care is shared by the MHW, Ministry of Seniors and Community Supports (MSCS), Capital Health and the municipality. The research participants describe how the MSCS sometimes delegates responsibility for some of its budget to municipalities. Municipalities, in turn, channel these funds to community agencies as grants, in accordance with municipal policies. As well, some policy decisions and the associated funding which affect the clientele of local agencies may be channelled to the county level. According to the research participants, this makes for a complex policy environment which represents a major constraint that impacts their own policy work. Many agencies expressed frustration with both jurisdictional complexity and the unresponsiveness of bureaucrats and policy makers. One agency representative said, "a lot of those public efforts tend to be terribly ineffective and simply done for show.... About 2 years ago, ... [the bureaucracy] ... shuffled [the transportation issue] under the rug, because... the $[y] \ldots$ didn't want that agenda pursued (21:31). Given this complexity, it is useful to explore in greater depth the opinions of the research participants about the impacts of the jurisdictional and administrative arrangements on clients and their families, services and charities.

\subsubsection{Charities Struggle with Politics, Control, and Jurisdictional Complexity}

The research participants described continuing care in Alberta as a complex and confusing sector which is governed and managed by multiple institutions and actors. The 
net result appears to be that home and continuing care services are managed and controlled in a piecemeal manner with decisions being made on a piecemeal basis, or not at all. There appear to be inconsistencies in terms of the response of various authorities to respective issues. According to the research participants, some government ministries are more responsive and/or flexible to local home and continuing care needs than others.

One agency representative said,

I find we have a far better relationship dealing with seniors' issues with Alberta Seniors than we do with Alberta Health and Wellness. ... In the last year, long-term care was in crisis... Our numbers were showing ... [that unless] the funding or the accommodation fee increased, places were going to close. ... [Health and Wellness decided to] ... make... the residents pay more. ... Alberta Seniors [, on the other hand, increased the senior's] benefit. They provided a top up... [under] the promise ... [that] this was ... [government caring for] families" (19:55).

Sometimes, as well, ministries abstain from cooperating with others in the policy environment. Or, it appears that some parts of the system may become scapegoats for other parts of the system. It is not surprising, therefore, to. find many actors using extreme caution in their day to day policy work. This environment appears to be problematic for continuing care providers with some operators absenting their agencies from policy work by terminating their home care programs. The stories recounted by the research participants provide a glimpse inside a sector which appears to be stagnating; responding to the needs of vulnerable citizens and their families no longer seems to be a priority. As a result, agencies express concern that citizens, clients and their families are becoming invisible, or lost in the system.

Several research participants describe how the control exercised by government 
via the MHW, for example, produces a culture of subservience and fear which trickles down to Capital Health and local charities. According to one research participant,

In Alberta, we seem to change government about every 35 years. ... And so you have a very kind of subservient political culture. ... You see it in the media. ... I am not opposed to government being ... praised as long as [at] ... times, ... they ... [are] held [to] account, [even though it is done in a polite and ] ... very positive way. ... For me, it's a climate, it's a kind of cultural political subservient $(16: 45)$.

According to the research participants, this requires Capital Health to exercise caution and control in its relations and dealings with providers. In practical terms, it means community organizations can no longer raise health issues and concerns during Capital Health board meetings. One individual said, "They [the board meetings] used to be probably more of ... of the free for all" (17:32). The format of both board meetings and administrative processes have changed.

Sheila Weatherall is the CEO.... Nothing in this region goes unmanaged, including board meetings. ... Her staff ... live in fear that any of the agencies they work with would end up complaining to the board about anything. So, the staff ... will certainly, keep a dialogue going with the agency they feel is upset about an issue (17:31).

The top down control structure makes Capital Health vulnerable to the vicissitude of government. When describing a recent media-reported incident that involved both MHW and Capital Health, one agency representative said,

Capital Health ... [was] put in a bad position because on one hand Alberta Health funds these health innovations projects and then when they are over, it's the region who are looked at as the bad guys if they don't pick it up[, meaning the projects]. But, they[, Capital Health,] are not consulted in what's going to be funded. ... It's a really flawed system ... [and when] the media ... was trying to say that [the system is flawed, Capital Health was placed in a difficult situation]. ... Capital Health can't be seen to be criticizing ... Alberta Health (6:52). 
This same person also said, "In the Alberta that we live in now, ... Capital Health would be ... the guy [who] had a bad day at work comes home and hits the wife, who hits the kid, who kicks the dog. I mean Capital Health would feel the heat from Alberta Health, so we [, the contractors,] would feel it" (6:38).

Top down control also requires that Capital Health embrace the goals and objectives of government which, in Chapter 6, include reduced costs and efficient services. According to a former representative of Capital Health, they

try to provide the best services to the community and stay on budget. Also, to try to be flexible and what ['s] the word we use-the sustainability of the system. And, also looking into the second centuries. It ... is one of the goals of the board right now. Having a future perspective ... to eliminate the concerns ... in the hospital [sector] (8:2).

This statement expresses three related constraints which, implicitly, have been imposed upon Capital Health by government: budgetary policy is dictated from above, the region must remain on budget, and acute care is privileged. One agency representative said, "I think for the most part, that a lot of government folks are aware of what needs to be done, but are sometimes powerless to be able to do it because of the bureaucracy, their funding restraints, restrictions, and so forth" (24:20).

Similar to Capital Health having its priorities dictated from a higher jurisdiction, Capital Health passes on higher-order dictates further down onto service providers of home and continuing care. Although care providers are answerable to Capital Health, they too are ultimately controlled by government's agenda to reduce costs and provide efficient services. According to the research participants, one issue which is passed down 
and constrains them is cost containment.

You're asked to be the 'Bank of Capital Health' for... [the] year. You are to keep that money in the bank and make sure you don't spend it because you have to cut them a cheque at the end of the year. So if you are not on top of your staff, if five residents move out on home care you better be able to adjust your staff level downward because as soon as you start paying the staff, guess what you don't have the money in the bank to pay back Capital Health. So it's a good system for them..., [but] this whole idea of cost containment... (19:17).

This individual claimed that due to the emphasis on cost containment, some charitable organizations threaten to, and others actually do reduce their home care operations under contract with Capital Health. Others cease to provide them altogether.

The regional system seems to confer upon Capital Health a gate-keeping function on behalf of government. According to the research participants, in addition to controlling costs, the gate-keeping role also limits their access to government representatives. On the other hand, agencies express the opinion that they must cooperate with the arrangement. One person said,

Something that we haven't done since regionalization..., [is to directly contact politicians] ... and ... the ministerial offices. The region has tried, and done a very good job of having us not intervene in that avenue. The region has negotiated with us, and I guess we have cooperated because we thought maybe it was the best thing to do ..., [to] let them deal directly with the politicians, with the ministers. ... They will represent us and do everything they can for us and keep us away from that direct link (10:11).

The research participants also describe how the downward spiral of control, whether by MHW, Capital Health, or some other body, also seems to extend to who makes decisions and who sits at the decision-making table. One individual said,

I think that when you have people who have power, they like to have their people [with them who] are going to support what they want. And, I think 
that, as always, there's lots of hidden agendas. ... I think that [the agendasetting process] needs to be opened up. ... I think that there has to be a structure where more people [are] involved and invited to the table so that it is more open. ... Until we do that, we are still going to have the power builders (25:61)

The research participants identified a risk that the combined effects of control, multiple jurisdictions, divided authority and huge bureaucracy produce a stagnating home and continuing care system rather than a vibrant and flexible system which encourages the development of high standards, best practices, quality improvements and/or increased access to services. This risk is evidenced by the number of care hours that are available to clients for home or continuing care. One home care provider said,

That's great, [government through MSCS is] paying more, but what about health care at the bed. Like, when are [MHW] ... going to get the care hours up. The promise was always there that when the resident paid more, Alberta Health and Wellness, through the region, would come to the table and increase the funding in long-term care and get the care up.... Today, we are getting inflationary increases (19:56).

The suggestion here was that, although the MHW agreed that new care standards were warranted, the Ministry was not providing the appropriate funding that could address this quality issue.

The research participants describe a piecemeal approach to providing services rather than an efficient system which governs and manages home and continuing care services. Intuitively, the research participants are aware that these issues contribute to some of the problems they experience when delivering home care to seniors. In addition, they view these issues as impediments to their policy and advocacy work which seek to improve care quality and access. One research participant identified regionalization as 
the culprit with the comment,

We've approached the government for $\$ 85$ million as an industry to improve the care in nursing homes by about one hour a day and our biggest stumbling block, to be honest with you is regionalization. ... It comes back to that. It can be a problem when, instead of two funders, or one funder, you've got two. ... Well, [the] Ministry of Health or Alberta Health and Wellness gives the funding for all health care to the health regions. ... Right, so when you go to Alberta Health and Wellness they say, 'Look, we gave a 10 percent increase in health care funding over ... to the regions. So, go talk to them.' So, then you go to the regions and then they say, 'Well, Alberta Health and Wellness didn't give us enough to cover our needs in home care...' So, you're just going back and forth (19:57).

Another research participant said,

We're talking about how we can get systemic issues addressed at a higher level. I think a big part of it, is that [government] ministries tend to be terribly isolated in terms of what they want to be responsible for, and there is no end to talk about cross-ministry initiatives. But, as soon as it comes to actually doing something or sharing resources, things tighten up. ... Then you play that [back-and-forth game] between different levels of government, as well. ... [While] there's plenty talk about government departments working together, ... it often doesn't seem to translate into very much $(21: 58)$.

While government seems to use jurisdictional bickering as a mechanism to do

less, some agencies acknowledge that it is government's role to solve the problems within in the continuing care system. Agency representatives express the view that political will doesn't seem to exist.

What I think has to happen, ... it's the same thing with long-term care, either the province or the Feds have to figure it out and make it happen. I think the region is the issue. If the region wanted to fund home carc more, they could. .... [Everything is second to] the acute [care] ... monster. ... When you look at the dollars that come into the Edmonton region that go into acute versus what goes into long-term care. Like, what do they think $\$ 85$ million for 16,000 nursing home beds? That's interest. But, there is no [political] will (19:69). 
Access to government representatives is another problem which arises from trying to service a large region. One agency representative said, "The region is so large... So, you have ... one senior advocate ... [who is] a government employee for that entire region... And, that region is huge... [It's the] same ... with... monitoring the facilities... There's not enough... They can't do it all" (3:81).

The value, control, seems to take precedence for government over other values such as accountability, transparency and openness; the latter are less visible in the conversations with the research participants. If this is true, the ability of charities, citizens' groups, clients and/or their providers to shape policies with respect to home and continuing care would be weakened. As well, influencing government becomes problematic because, according to the research participants, it is difficult to identify, the locus of decision-making for home and continuing care at the regional level; Capital Health does not seem to engage in meaningful conversation with agencies, or with the MHW.

Before considering the public policy work of community agencies in home and continuing care, I now briefly describe the views of the research participants on home and continuing care services, and how they are impacted by the political-jurisdictional environment.

\subsubsection{Providing Home and Continuing Care Services}

According to the research participants, the jurisdictional and administrative complexity which characterizes the home and continuing care system is mirrored in the services that are provided and the client classification system. For example, 
Designated assisted living... is ... the entry level of long-term care. For ... people [who are classified as] ... C's and D's, in the [nursing home] classification system ..., they, [meaning Capital Health], feel that they, [the clients], could be better served in a supportive housing environment. So, let the E's, F's and G's go to a nursing home, but house these people [who require lower levels of care] in supportive housing (19:66).

Thus, clients receive home and continuing care in a variety of settings which include the homes of clients, or any of the new 'institutional settings' which are operated by both nonprofit and for-profit companies and which are commonly referred to as assisted living and supportive housing. The importance of the client classification system is logical and understandable. However, it was difficult to ascertain the rationale for the mix and/or choice of sites through which home care is accessed by seniors. Several interviewees suggested that the varied programs and settings are determined by economics, meaning profit. As one agency representative said, "To some extent, the boom in supportive housing is spread by [the belief] that, it's more cost effective to get meals and housekeeping done if you are living in an apartment in congregate living than in your own home" (17:52). This quote is representative of the opinions of the research participants.

Supplementing these access points for home care is the CHOICE (Comprehensive Home of Option of Integrated Care for the Elderly) program. CHOICE is less of a home care program, in that it is not provided in a client's home. Rather it is a day home care service which is provided on an out-patient basis. The Capital Care Group describe CHOICE as

an alternative to living in a continuing care facility. ... All participants come to one of the CAPITAL CARE CHOICE day centres from one to five days a week where a full range of medical, psychological, social and supportive services are available from our dedicated interdisciplinary care 
team (Health 2007 b.).

The CHOICE program is provided from "four sites. ... Capital Care Group [is one of the] non-profit organization[s] that has two [home care] sites on the north side of the river" (17:10). Another charitable nonprofit partners with The Capital Care Group to provide this program under contract with Capital Health.

Supplementing these services which facilitate independent living for seniors are social supports, recreational and transportation programs. Despite the varied services, according to the research participants, access to them is difficult. One agency representative said,

I'm not exactly sure how long people ... have to, or how hard they have to advocate in order to get home care. ... And [the service levels are minimal]. ... You might get someone to come and help ... once a week ... or, maybe for medications, or something really important. ... But, you aren't going to get them for any length of time, during the day. ... If you're lucky enough to get home care, it's just for a specific sort of need, whether it's a bath once a week, or it's you know, some sort of health issue, whether changing dressing (7:29).

Another individual describes how bureaucrats and politicians "talk about support [for seniors]" (11:33). Politicians may talk about it, but they don't ensure that services are available for the people who need them. The research participants suggest that government is more responsive to economic issues which have the potential to increase income for private partners, rather than being responsive to the needs of seniors. The previous individual continued,

If you look at assisted living, everywhere the developers are talking about assisted living. Health care are talking about assisted living. Social services are talking. Everyone is jumping on the band wagon. But, if you looked into it, there's a very different interpretation. ... If you just drive 
around the city, you will see signs like, 'This is an assisted living facility'... [They] will provide you with food ... and with whatever you need for $X$ amount of dollars. In fact, it's not cheap. It's very expensive for the private ones. ... [Assisted living is] driven by what I call the economics (11:33).

The research participants claim that significant numbers of seniors cannot afford to live in assisted living facilities.

But how many people could afford that kind of money, as I say, to live in a seniors apartment receiving that kind of services [, i.e., assisted living]? Now, that's why there's a need to go into what they call supportive housing... for seniors. ... It is much cheaper, but ... what are the services offered there? ... It [satisfies] ... the need for what they call a low-income assisted living (11:33).

According to the agency representatives, the purpose of supportive housing is to meet the home care needs of low-income and poor seniors by institutionalizing them in the new user-pay facilities rather than providing care to them within their own traditional home environment. They also maintain that despite the existence of a regulatory system which governs fee structures related to these facilities, fees are problematic for many people. As one individual said, "All [problems] seem ... to stem back to the funding issue ... We don't really have a formal mechanism to present all the issues. ... So, ... you [could] write a letter [because] ... there isn't really a group of block funded operators in home care that meet regularly(19:31) and which could advocate on the issue. As well, fees seem to vary, disproportionately, according to the type of accommodation which service seniors.

How can the region tell you that you can only charge the resident ... $\$ 1,100$ a month in rent when we charge a similar resident in long-term care $\$ 1,425$ ? And, how is it that the operators have shown that it costs around $\$ 1,400-\$ 1,500$ a month, true costs, to accommodate someone in either a lodge or a long-term care centre? Yet, [Capital Health only allows] you ... [to] do it for $\$ 1000$ or $\$ 1200$. The answer is you can't (19:41-43). 
Another supportive living operator, whose agency is experiencing difficulties with regulatory constraints associated with budgets and fees, said

We ... have a home care project offered by ... Center which is a senior ... citizen complex. ... It's a big complex. You are talking about ... five hundred residents. .... In the past ..., it was basically a senior's apartment but, as people get older, they require certain levels of health. ... So, we have a contract with home care ... [to provide] what they call the site-based home care services. ... Late [ly], we are running into a lot of difficulties with this program because of the level of funding. ... [People] get so frustrated ... because of stipulations and demise ... [and because the program] cannot be maintain [ed] ... the way we would really like to maintain it. ... [Operators are] serv [ing] them notice that [they] don't want to provide the services anymore (11:19).

In addition to the problems caused by the variable fee structure, the research participants raised other related issues, e.g., contract funding and care differentials, which varied according to whether or not an agency was nonprofit or for-profit. When talking about Para Med, a for-profit company, one charitable nonprofit home care operator said,

They [, the for-profit providers,] get a 15-minute minimum and they get a higher funded rate per hour to deliver the care. ... It's not [justified]. It's not. So, you know, we're hearing now that there is a committee about to be struck and things will be improved, but the last six months have been extremely difficult. ... [The for-profit companies] tend to [do] most of the community stuff, not the buildings, like the seniors apartment building ... [which are provided through] block funded contract [s]. ParaMed or one of those agencies [are] not coming $(19: 19,21)$.

This person meant private companies do not provide supportive housing to poor seniors.

This individual also claimed that Capital Health was selecting the members of this committee; community agencies were not invited to participate in this selection.

The fee differential issue appears to be related to unions and wage rates set by unions. Research participants indicate that the private sector is not unionized, hence is 
not constrained by unionized wage rates. So low funding levels are less of a constraint for private sector companies. On this issue, one agency representative said, "the for profits ... get the same dollars we do, [but] they can deliver care less costly, because they don't have union issues" (18:16).

According to the research participants, Capital Health is responsible for and ought to be managing the home care program, including resolving some of the above noted issues; it does not seem to have much scope, or will to resolve, improve and/or change the current arrangements. One individual said,

You know, I once heard someone, one bureaucrat ... said to me [when] ... I had asked, I had wanted to start a new program, [to provide] more spaces [for seniors]. And they said, 'Well, what are you going to do with more spaces?' And I said, 'I'll fill them.' [Then the bureaucrat said,] 'Yeah, but you know what, if you fill them then there will be that many more [needs to address].' And, I said, 'Well yeah. Is that not what we are here for, to help people' $(5: 38)$ ?

Another agency representative said, “they don't have necessarily a forum within Capital Health to discuss home care issues. ... There are some things that they[, Capital Health,] would feel probably powerless to do much about" (17:29; lines 452-53). Yet, another agency representative said,

The region would prefer to deal with each operator individually and never as a group. So we [, the block funded partners], don't meet regularly; we don't discuss funding at all. ... No, and we've probably had three meetings with the region as a group in the last four years. Meanwhile, long-term care operators ... usually meet with the region four times a year to discuss issues, education, all sorts of things (19:28).

According to the research participants, prior to the establishment of the current system, local jurisdictions had greater authority to resolve local health system issues. One 
agency representative said,

At the home care board of health, we used to have an assistant director whose responsibility was to monitor the, maintain the relationship with the agencies, affect change when it was required. That position no longer exists and, the other mechanisms. ... It's all about keeping the costs down" $(23: 115)$.

This research participant continued, "Welcome to the world of regionalization. ... Home care just doesn't seem to be, of all the issues, it's probably not the major, major, major issue. ... [Rather,] funding and long-term care" are the main issues for the region " $(19: 27 ; 34)$

Another agency describes the poor response from Capital Health to a presentation made by a group of community agencies seeking additional funding. This agency's executive director said,

We, for example, Capital Health, we definitely did try to do a presentation. And, all of us got together, the seniors organizations because, for example, we host their flu clinic and we inoculated six thousand people. ... It's all our volunteers doing it, and we don't get a dime for that. ... And, the government is willing and ready to use our facilities and our volunteers, but not to ... to [provide financial support]. So, we all got together and met with them. ... Zero [was its impact]. It was stopped right then and there $(27: 21)$.

When speaking about unmet needs within the region, a Capital Health representative said,

The nurses bring forward those issues, and we try to find ways to meet people's needs. And, there's also a fairly extensive concern and appeal process is available to the client. There's a client representative in every division. ... It's a paid position, really just to help deal with some of those concerns. And, so that clients know that there's some person that is sort of outside of the program area that they can talk to $(9: 38)$.

Altogether, the research participants describe a home care system which is fraught with problems which originate in the need to control costs at the expense of the needs of 
seniors. Funding and contract arrangements, fee structures and quality of care are additional problems for them. Moreover, they indicate that the local system lacks a venue through which care providers can raise and discuss issues with Capital Health in an effective and constructive manner. They also describe how they must exercise caution in their relations with bureaucrats and government representatives because, in addition to control, there is a climate of fear and intimidation. This is now described.

\subsubsection{Edmonton's Charities Exercise Caution}

Capital Health is not alone in the need to exercise of caution due to the political climate of modern day Alberta. Care providers also deal with control and intimidation in their day-to-day home and continuing care work. Several research participants expressed 'fear' and/or viewed government as a monolithic entity, unresponsive to their demands. Government was described as the 'sleeping elephant' that must not be upset. One agency representative said, "my cliché is ..., it's ... like sleeping with the elephant; ... things are really direct and hard" (6:42).

Overall, the atmosphere described by the research participants was one where caution and restraint permeated all relationships-those between government representatives and citizens, between government representatives and care givers/providers, and within the bureaucracy, itself. One individual explains the atmosphere in the province in terms of "unwritten rules that should be followed and if you don't follow them then you will be punished. ... So, I personally think that's the biggest constraint" (16:45). Other individuals reflect similar sentiments when saying, "I guess, I would certainly see, you've got to be so sensitive about what you say" (24:141), 
and "large operator [s] in a small pond must be careful [about] what is said" (17:1).

Another individual said,

in terms of our funding relationship with Capital Health, ... I think, at one time, when we were really badly funded and we had a lot less to lose. ... People in the sector were much more vocal, had an ability to be critical of government or policy in ways that I don't think we are able to do now. ... I don't know if this is true across Canada but, certainly in Alberta, ... almost anybody could give you ... examples of ... harsh cause and effect for people who speak out $(6: 32)$.

The punitive working environment is very challenging for charitable agencies working under contract with Capital Health. The skills of diplomacy are necessary and central to the public policy work of community agencies because while agencies are attempting to shape home care policies, they must also take care to not "bite the hand that feeds you". In the words of the previous executive director,

We have to be careful in our approach because the nature of our organization is that [we], in essence, contract with regional health authority to provide services and in doing so, can't be seen as being you know the contraries in the system. [Capital Health would simply ask,] 'Why [would] we want to give you more work and more money if you are going to criticize us? (12:12).

Another agency representative said, "Money is a major issue. ... It very much influences the degree to which we are prepared to be outspoken because we recognize that we might be biting the hand that feeds us" (23:57).

One of the consequences of working in small pond Alberta, according to the research participants, is that the long memory of government could negatively impact one's future career prospects. One individual describes such a risk when saying,

I can operate here and be ... very frank [about] the way ... I think things are going for [Alberta. But,] well, there's a price to be paid. [If] I decide to 
leave ... [my agency,] tomorrow, and get a job, I'm not going to get hired by the government. But, there's lots of opportunities in town. But, when you are in small town Alberta, you're more limited. ... I think that's actually the biggest externality in Alberta (16:44).

Being subservient and/or vulnerable means that the ability for community agencies to shape the home and continuing care policy agenda becomes quite constrained, regardless of the issue. Notwithstanding the constraints, agencies do try to raise issues such as financing and care quality with Capital Health. However, their success rate with making improvements seem minimal.

While providers must adopt a cautious approach when dealing with Capital Health, it seems that citizens, on the other hand, may benefit by being open and less cautious with their complaints. Being up front with complaints is effective, particularly, when combined with threats to air them in the media. One agency representative said,

if you are not getting the service that you want, you phone the highest level of Capital Health you can get your hands on, and tell them that ... it's not acceptable care and that you are going to go to the press. ... Then you will start getting the care that you require. So it is ... one of the ways that they[, Capital Health staff,] deal with the pressures. Is that they hope that the majority of people are quiet and apathetic, and they oil the noisy ones $(23: 103)$.

These words communicate both frustration with the current system, expressed by agencies, as well as the vulnerability and subservience of Capital Health with respect to MHW. The above may also be suggestive of low standards of care, of limited transparency, and of the adoption of a crisis model towards governing, administering and delivering home and continuing care programs.

As a result of the current political climate and service constraints, much of the 
policy and advocacy work performed by community charities exists, firstly, as policy implementation in terms of existing policies, funding allocations and programs, i.e., the status quo. Working with the status quo, however, puts at risk the policy work undertaken by charities to target the unmet needs and/or new and emerging needs of clients. One research participant said,

Well there used to be, for us, a far more active agenda of home care issues... Our organization is a patron of the Canadian Home Care Association. ... When we had our own home care service here, as part of our organization, we used to be concerned about all kinds of things. ... We ... still should be. ... On occasion, we remember that we ought to be $(17: 25)$.

In addition to being cautious, community agencies have other constraints which negatively impact their public policy work. These include low budgets which preclude recruiting policy analysts or researchers, the lack of a formal venue for advocacy groups to meet, and the government's budgetary commitments. These are briefly introduced.

\subsubsection{Providing Services While Dealing with Additional Constraints}

One agency representative described how staffing, i.e., not having a policy analyst or researcher on staff, and financing constraints limit their ability to shape public policy. The representative said,

Certainly, one of the constraints that we have, we have a number of times floated the idea that wouldn't it be wonderful to have a researcher, or policy writer, that could assist us. Not just in influencing public policy, but actually influencing the community's perception of seniors.... We have tried to get funding a couple of times, and have not been that successful yet. ... So it's, so it's back to the money ... issue. It's always an issue, isn't it (23:56)?

Other representatives describe other constraints, such as "the lack of a formal venue for 
advocacy groups in Edmonton to get together" (23:69), or the lack of "visibility or credibility or voice that [is needed] need to influence policy" (23:95). Alternatively, according to one individual, being a charity which can fundraise is a constraint, particularly when the region downloads its responsibilities.

Our government is engaged in minimizing [its] commitment to ongoing programs in case the price of oil turns down. ... So, they believe that if the charitable sector should go find its funding from ... charity. ... We should be out there fundraising and getting corporate donations... And [now] government isn't responsible for providing those services. ... That has made it difficult (23:73).

According to the research participants, the current system is so challenging, and requires such huge inputs of energy, commitment and determination, just to maintain the status quo that it exposes local charities to the risk of policy inertia in regards to their own policy work.

\subsection{Edmonton's Charities Undertake Policy Advocacy}

\subsubsection{For Individuals and the Public}

The research participants describe a health system which is complex, frustrating and under-financed with respect to service providers. Given this state of affairs, it is logical that clients also find the system complex, confusing and difficult to navigate. Regardless of the challenges experienced by local charities, the research participants describe how they manage to both help people negotiate the system and provide outreach. In addition, on behalf of people on fixed incomes and on behalf of informal caregivers, they advocate for affordable housing options and strive to provide accessible transportation options. Helping seniors, other vulnerable citizens and their families 
navigate the system, and improving services and service options are important and valuable tasks that are assumed by charities in the Edmonton area so as to facilitate independence and a good quality of life.

Agency representatives express how doing advocacy is an important part of their identity and their job and is reflected in their missions and the values they communicate to the public. Moreover, they link doing advocacy, providing high quality services and securing positive client outcomes with this identity. One agency representative said,

One thing I have learned is when the senior lives with you, the families expect you to look after them, and to do everything you need to do to look after them. So, they are expecting that you will do the lobbying, you will do the talking, you will do whatever it takes to provide. ... Long-term care is a good example. [We] know [our clients] ... want more care at the bedside. The government said they will start funding that more, [but they ask us to] just give them some time. ... We haven't fired them up ... The home care residents, and ... [their] families ... look to us to be the spokesperson. ... We feel we're representing them ... [because of our identity] and values. ... We ... do an excellent job ... for the residents $(19: 90)$.

Another agency representative said,

You get preoccupied with other things to say, 'Oh the region is doing that, and doing that and, they're doing that... It doesn't matter anyway because they won't listen to us anymore anyhow. And, it... [only leads to the] abdicat[ion of advocacy about] some of those things [and issues]... So [, rather than focussing on what Capital Health is or is not doing], you need to keep pushing $(10: 18)$ ?

This means that agencies articulate their priorities and they provide programs, support groups and other services to seniors. One agency supports, educates and helps new seniors negotiate the system, and advocates on behalf of this group of citizens. Another agency does individual advocacy on behalf of seniors who experience difficulties 
negotiating the health and social care systems. Its representative said, "There's a few practical things that we would do, like have a person tie in with the social service system. [We] look [to ensure that]... they indeed have got themselves plugged into AISH, to different sources of support and, [we] give them assistance from that perspective" (10:14). Yet, another agency strives to alleviate the problems of seniors who are isolated in their homes, or within assisted living institutions. The executive director said, I think probably our most immediate influence is through our outreach department which works with the people who are isolated or confined to the home, or to an assisted living establishment (26:8).

The neighbourhood within which this agency operates is described as follows.

This particular community has the highest percentage of elderly in the whole city. [We] ... recognized that we could really help people if they come into the center. There's people who can't make it in. ... Those are the ones that probably need the most help. So, we're trying to basically carry our mission out into the community for those who can't come to us $(26: 10)$.

The research participants suggest that wait times for long-term care facilities are quite long. As a result, individual advocacy is sometimes necessary to help seniors overcome the long wait lists by accessing long-term care. One individual said,

I know that the biggest issue that we hear here of families actually getting involved in is housing. So if someone needs long-term care and they are on a waiting list. ... We'll try and help them get a place, but ... the waiting lists for certain types of care, especially long-term care ..., the lists are so long ..., unless you are in an emergency situation. ... [Or,] you might be lucky if you end up way across the city and ... then your spouse is trying to get down to visit you until they can find a bed closer (7:28).

Alternatively, the issue of low and/or fixed income and seniors' poverty make it difficult for many seniors to afford housing and other home care services. Research 
participants raised concerns over service or care levels because, notwithstanding that Capital Health provides home care to individuals on very low incomes, the agencies claim that service levels are often inadequate. This means their own budget allocations are inadequate. When these issues are combined, the question of access to services looms large. Needless to say, these issues may also negatively impact caregivers. One agency representative describes the relationship between home care service levels and the caregiving burden.

One of the issues that keeps coming up or continues to grow has to do with again it has to do with caregivers but, it's... providing some more assistance in the home, ... support and companionship ... so that caregiver can have a little bit more free time. ... Capital Health ... [limits the] respite hours. ... We found, ... many of our caregivers [are] seniors. ... A lot of them are saying, 'It's not enough.' ... We really do see, ... quite often, ... the caregivers are so burnt out $(5: 18-20)$.

Another person connects burned out caregivers to elder abuse, but in relation to the finances of seniors. This agency representative said,

I went to the Royal Bank because I was doing a ... presentation about what we do. ... The bankers shared with me what they did on their end, watching seniors accounts. ... You [realize, elder abuse] is such a global thing. It's not just physical and emotional, [it's also] financial. ... The ... [ banks], have in place [protections for seniors].... Normally [we thought] it was the son that was abusive right and we found out that the daughters [are] abusive as well. ... because you, [the family and the senior], have to wait a long time to get [the senior] into long-term care, and you've got people trying to cope at home (25:36).

Since caregivers are so compromised-- physically, emotionally and financially—many community agencies are advocating and talking about their needs. They suggest that if the caregiver isn't cared for, s/he cannot provide care to the family member who needs home care. 
We do have lots of our seniors who are still caring for their spouses at home. ... Our outreach worker has to either help them through various ways whether ... [to] accompan [y] them to ... important ... medical appointments ..., or transportation, or just calling, phone visiting. ... We are starting ... up a group in the new year to ... be ... a support group for caregivers so, they could come. ... They could get some support and talk about you know give each other peer support, and ... the [re] would be some self nurturing sort of... (7:20).

Having examined, briefly, the advocacy work charities undertake on behalf of individuals and their caregivers, the next section examines how they tackle the issue of funding for home and continuing care.

\subsubsection{Charities Protect The 'Contracted' Public Good}

\subsubsection{On Funding}

According to many research participants, funding for home and continuing care services is a serious problem which impacts both access to, and the quality of services. Funding also affects the sustainability of the respective home care programs that are provided by charities. Exacerbating these problems, according to local agencies, is Capital Health's priority to provide acute care. One agency representative said, The ... Association of Alberta ... has been very good at coming together to talk out issues. A big issue that we are talking about is the funding and quality of care, because it is a huge issue in Alberta. We've got all this money and we are building more of those marvellous acute care facilities and [there is] no money left for our seniors, not only seniors, but the people that need long term care (18:17).

In addition to acute care siphoning off funds away from home care, administrative costs also divert funds away from health services. One agency representative said, "I think with regionalization, the admin costs were more than they were with all the small boards across rural Alberta. The bureaucracy is just phenomenal... I can't believe it" (25:61). 
Another agency representative said,

Tell me there's a disconnect, but I think that the bottom line in the last 15 years has been the dollar. There's always a bottom line. So people are not necessarily [getting the care they need].... There's a real philosophy that you are not your brother's keeper, basically. ... [It is] that ... I need to make money and you need to take care of yourself. And if you can't afford to have [, meaning use], a private hospital, gee, that's too bad (25:18).

The net effect of inadequate funding and reduced service is that services become

privatized and clients have to pay for services. One research participant said,

Six months ago, because of budget crunch and deficits in the regions of which Capital Health had a major one. ... They decided that we had been billing in 15 minute increments for the care we provided. They decided that a med assistance and some care could go as low as 5 minutes. ... So, not only did they take away ... [our] 15 minute billing but they started reassessing the entire billing. ... We just saw our approved hours ... plummet to the point where we were in a deficit position, operating (19:18).

Not only are care hours being reduced, but Capital Health planned to introduce user fees for the CHOICE home care program. One executive director said,

Last year, in May, the region decided that they wanted to start charging for this program called CHOICE, which [they] hadn't before. They wanted to charge $\$ 100$ per month for the day care. The drugs were no longer going to be free. ... We sent a lot of signals ... back ... [to Capital Health] that this was going to tip the scales in terms of people [already] staying at home under precarious conditions. ... So [because of local advocacy], they delayed ... and staggered the implementation. ... My assessment is that they delayed and modified ... because they did not want ... the press ... in Edmonton (17:45).

Another agency links its capacity to undertake advocacy and participate in public policy with both its three year funding cycle and its outreach program which is supported by grant funding. If the funding doesn't materialize, their advocacy work is compromised. 
With organizations such as ourselves that rely on grants and funding, those grants and funding cycles are what sort of prompt [our] advocacy, right, because you are trying to get funding for it. So, ... if we identify a gap in service delivery, our social worker will try to find a resolution to that gap, if there is one. ... The outreach program ... is the most one [clearly] tied into public policy because we couldn't exist [without] that program... And, it's [supported by] three year funding. We identified that gap to the funder (27:11).

Since inadequate funding results in privatized services, agencies are committed to tackling this funding issue. One agency representative said,

We make it our business to make consultations whenever there's an issue. So, we have been making it very much our business to have consultations [especially] as we get into the privatization of health care, which I think is coming down the pipes very quickly in Alberta. We had this wonderful majority government again, so we will make it our business (18:20).

As indicated above, there is a close connection with funding and quality of care.

The following section tells how charities tackle the quality of care issue.

\subsubsection{On Quality and Long Term Care}

Several research participants raised the issue of quality of care, e.g., inadequate care hours, in relation to long term care facilities. They expressed the view that due to the lack of regulations pertaining to quality, the competitive environment has a negative impact on clients. Agencies describe how they work to surmount such limitations by recruiting high qualified staff and providing appropriate care hours. Moreover, some unscrupulous operators take advantage of the lack of regulations and oversight at the expense of clients and workers. One individual said,

We don't like privatization at these facilities because, where are the regulations? ... They say there are [standards] ... We asked ..., 'How often do you visit a facility [and monitor it]?' ... [They said,], 'Oh, maybe once a year, maybe, maybe, well. ... They are supposed to be [accredited]. 
So, we have a concern about that and, they are very expensive... The patients still aren't getting the care that they should be because they are cutting corners to make a profit, aren't they?" $(3: 24,27)$.

Another agency representative identifies differences in quality between private for profit and charitable nonprofit providers of long-term care.

Well if you just look at the issue of continuing care funding for instance, the competitive environment is a huge constraint because our partners in the for profit sector are reported to have margins that are very healthy. ... [Whereas], the not for profit ... voluntary sector is almost ... facing deficits trying to meet the basic needs now. ... When you go to government saying there's not enough money, they say well look at those guys. ... It's a very elusive business, the question of quality in long-term care. ... The forprofit organizations for ... [which] we will attribute much less quality, ... don't get people up [out of their beds] (17:42-44).

As a result of the quality conundrum, agencies recommend establishing a seniors' advocate.

The government, for example, gives them [, the facilities], funding every month to help with the, because of the rising costs of utilities. ... Along with that, [seniors] were supposed to be, I believe, given two baths a week, more if required. Well that isn't happening. ... We really believe that there should be an advocacy for seniors (3:35-36).

According to the research participants, Capital Health is ignoring some of its responsibilities, particularly in regards home care which is block funded. One research participant said, "it [, referring to block funded home care,] is one of the only programs they [Capital Health] run where they don't meet with the [block funded] operators. ... There are enough of them out there that they [Capital Health] probably should even have an annual meeting or whatever" (19:49).

The problems of funding and quality of care are sufficiently serious that, at one time, one local charity tried to escalate the debate and turn it into a province-wide issue. 
Unfortunately, the strategy wasn't successful.

We are just about to take an issue to the Capital Region having to do with the level of care in our facilities. ... The] standard funding approach based on a case mix formula ... [has] been slipping. ... There's not enough hours provided for to get quality care. We've been sort of mounting a provincewide, with our colleagues, strategy with the government. We have felt that ... because it ... seemed to be the same across Alberta ... we would approach the government, advocate with the government so that the government would fund the regions to give us [more money]. But, it seems to be that the government is satisfied that they have given the regions enough money to handle these problems. So, we are back to the regions (17:34).

Another research participant describes the challenges facing rural families when a family member lives in a long-term care facility. The large geographic spread of the Capital Health region sometimes makes family visits impossible. This individual said, "in the rural areas where you have limited facilities, somebody living in St. Paul [, for example]... Their wife..., that capital region which is huge, could be 180 miles away. So, that person now is cut off from their family. They can't get there to visit, the husband can't" (3:47).

Notwithstanding the constraints, agencies strive to improve quality through staffing and program but, when doing so, they assume additional risks. One person said,

we, the [home care] program was growing enough ..., was becoming a big enough business for us that we actually decided ..., even though the funding doesn't warrant it ..., that we hired a registered nurse with home care background to oversee all our home care programs. ... What we found is that it was actually a good thing for us to do because I think the staff have been more appreciative. The residents have been, but we certainly are not funded for it. ... We've found efficiencies in other areas that more than compensate in the difference of salary.... That's something we did on our own (19:48).

Although research participants speak about working to improve quality of care, 
they said little about successful policy outcomes in this regard. I now explain the policy work of charities in regards to preventive home care services.

\subsubsection{About Preventive Home Care}

Altogether, the research participants said very little about preventive home care, meaning home support services. One agency representative said,

The CHOICE program presents a kind of slightly altered picture of home care ... because unlike the regular program which, by the way, has seen the preventive part of home care fall off the table... This is [all] acute care substitution now (17:34).

This suggests that preventive home care in the form of home support services are not

available to seniors in the Edmonton region. Later on, this individual said,

We are probably going to see how effective, or not, [the] home care program is. ... In our view, ... the two issues are still there, which [are] the continuity of staff because they are poorly paid, and [that] basically the [region has] ... evacuat [ed] out of the preventive home support business. ... I think [Capital Health,] were short sighted and long minded to get out of that $(17: 52)$.

According to this person, the region was 'long minded' because it was more economical to abdicate out of home support services and to support the creation of a private system, meaning individuals pay for their home support services. Another research participant said,

The health promotion [side of home care] gets almost none.... Prevention and home care isn't getting what it requires. ... And, the other thing, ... home care ... used to be meeting the needs of the individual [who] came first, and the dollars came second. ... From my contacts with my colleagues ..., it's look at the budget first. 'What can you afford?' 'What's the minimum that you can do? 'Who's the family member that you can bring in to avoid us having to spend this money?' It's a budget driven service (23:106-107). 
I now examine how agencies address staff needs in the home and continuing care sector.

\subsubsection{For Employees}

Employee benefits, e.g., unions, wage rates and benefit packages, and working conditions are all affected by funding. As well, each one affects quality of care; all are interconnected. As one agency representative said,

I say, ... if [the continuing care sector] was funded properly, there [would be] benefits all over the place.... If the dollars were the same, funding wise, you could actually move in and still care for people in the home care program, right! ... But the salary drop and benefits is huge. ... Or, you could train people in home care to move into continuing care but there's such a big discrepancy [in wages] that ... people are not going to do it (19: $68)$.

Later, this individual continued,

The funding is so low in home care that you financially cannot make it go at unionized rates period. ... So we have a six month clause in our block funded home care that we can bow out. ... I have said, ... honestly to the employees, unionized is fine. We'll negotiate that; just remember if it's more money than I've got coming in, I will give the contract to the region [, meaning the program will be terminated]. ... And it's as simple as that. And that's why I'm saying the same thing in long-term care. I can tell you, at this facility, I have the best nurses in the city.... I respect each and every one of them. They are with the United Nurses of Alberta. All I can tell you is it cost me $\$ 41.50$ an hour for every nurses' hour. ... The region funds me at $\$ 37$. Do the math (19:79).

Eventually, the employees at this agency did unionize, but the problems continue.

When we unionized here, the nurses just unionized here three years ago, we went right to arbitration. We didn't even negotiate. ... Basically, the arbitrator ... said, 'You're just like ... the public hospitals. So don't even bring Extendicare or Central Park Lodge into this [conversation]. ... So, we ... are losing a quarter of a million dollars a year. ... The judgment ... [is] negotiated with the unions. ... Their latest demand is going to arbitration or mediation, is [for a] 10 [percent increase]. So like where do you get it? The residents pay $\$ 1,425$ per month and the health care funding is fixed $(19: 81,82,83,85)$. 
Another agency representative said, "We attended the equivalent of owner-operator meetings with the home care people where we raise these issues, in particular the issue of compensation for staff, and advocated for some change in it" (17:25). Agencies are aware of the problems for workers and advocate for change. The current environment which is characterized by jurisdictional complexity, competition, capped budgets, and a mix of providers and sectors preclude easy solutions. It also means that wages are decreasing. Another agency locates the labour problem in the sectoral mix of providers-nonprofit and for profit. Each sector addresses the wage and benefits package for its employees differently. The workers who work in unionized settings have higher salaries, benefits and better working conditions. Unfortunately, these compensation packages do not extend to employees working in the for profit sector, a non-unionized sector. According to this agency's executive director,

That [the] ... [non] profit [providers] ... gave the [ir] contract up here because they couldn't meet the needs. But, if you look, ... WeCare, ParaMed, Bayshore, those are all for-profit, ... [which] are out there trying to [provide] the services. ... We advocate, in partnership with the agencies that we work with, [for wages and benefits]. ... You look at, typically, the type of people that these [for-profit] people employ, [you see that they] are females, who may not speak English, who have very little education. They get a low paying salary with no benefits. So, you just keep them [there].... [Their] people don't stay in those jobs long because [they] ... have no opportunity to provide properly for their family. ... [They] have no health benefits, no sick time, and [they] ... are paid a dollar more, an hour, than minimum wage. [The companies say they] ... are expecting the [staff] to go out and be endearing, to be professional ... [but, when they actually provide service,] in a clients' home [they] ... just ... get in and get out... [This is a problem of] retention $(25: 16)$.

Unlike current practice, prior to the introduction of the regional model, the home care workers of some agencies were unionized. One agency representative said, 
We were... [a] unionized [home care provider]. We were unionized by CUPE and we kept losing money. We couldn't afford to continue ... In our negotiations [with CUPE], we gave them a proposal that would see us continue but, they turned us down. So, we had to shut it down (17:9).

Current home care funding levels in combination with the competitive model preclude the provision of union wages.

According to the previous research participant, these issues-wages, unions, privatization and competition within home and health care ultimately negatively impact home care clients. This individual said,

I'll raise two problems with home care. One was, in our view, the single most deleterious problem with home care ...; the staff are paid way less than their counterparts in continuous care [, a sector which is unionized], and, it compels them to work extraordinary hours or to move on to another job. ... We had turnover in our home care program that at one time was 120 percent in one year (17:25).

Such turnover rates mean, though, that care recipients secure care from a variety of care

givers and this impacts their health. This individual continued,

It's not very good for seniors to get a parade of people coming through their homes. It affects quality of care. So, that was our number one issue. But [it was] very hard to do anything ..., because you know the 15 agencies and the region feeling that they can't ... give a bigger price because there was no reason to $(17: 25)$.

The representative of another agency said,

And we actually present them [, staff issues], to funders as well. ... We're saying, ... 'You want to fund our program. You are a very big business and you, only, you are giving me this amount of money.' And, I am saying, 'I need this because I want to give my employees benefits.' And, '[You, the sponsor], you're saying no!' But, 'Would you think of not paying your employees' benefits?' 'Not a chance! Of course you would give them benefits.' And so, we need to change their thought process and say, you know we need to fund them so those employees can do a good job, and stay in the community $(25: 18)$. 
Among all factors, budget caps and the competitive model seem to be the worse contributors to the downward wage spiral. Nonetheless, according to one research participant, competition is not mandatory. Regions seem to have a choice as to whether or not they embrace a competitive model.

The Regional Health Authority in Calgary and Edmonton operate very differently [from] their rural counterparts. [They] like that competition. ... They like it because it keeps the price down. So, none of the other organizations were unionized. We were unionized. ... I think it's like McDonalds... [where they] they will hire [someone but], they don't pay ... $\$ 15$ an hour. ... They understand that kids [who work there] are going to come and go through there [as through a revolving door]. The private [home and continuing care] sector is that way, as well. They understand. ... That's their business. People [, staff], are not going to stay; some will. But, typically, they would have low, low wages. I think the for profit sector maximizes the wage, in fact maximizes the wage at the expense of benefits. So, there would be no benefits. ... But, there might be a better wage. We had as good a wage and all the benefits on top of that (17:25).

The above describes an environment which offers a few benefits, regardless of who the beneficiaries are - seniors, employees, or agencies. Give such constraints, it is logical to expect agencies would use a variety of mechanisms when attempting to shape public policy. When conditions are difficult, agencies collaborate and work collectively with a variety of partners. Collaboration is examined next.

\subsubsection{Edmonton's Charities Collaborate}

According to the research participants, the local environment requires collaborative work which takes place vertically with various levels of government, Capital Health, and umbrella associations, and horizontal collaboration with other charities and, sometimes, with informal groups of citizens. For them, gaining a stronger voice is one important benefit which arises from collaborating. However, collaborating is 
not always easy, particularly when agencies disagree about priorities. Alternatively, when sectors mix—nonprofit and for profit agencies—under a common association, collaboration becomes even more difficult. Some of these issues are presented in the following quotations from the research participants.

One agency representative describes the agency's vertical and horizontal collaboration with umbrella associations and varied government ministries as follows.

We do a lot of our lobbying and our advocacy through the Alberta Long Term Care Association (ALTCA) ... [of which] we're a member. ... We will ... and have used them, particularly in the last couple of years, as they've been more active to lobby the government and to advocate for seniors care. ... We have a common concern,... about the sources of revenue, the amounts of revenue that we get ... [and] the [funding and accountability] formula. ... So, ... we [say we] need more flexibility about care hours... The rules, the regulations are so historical... We will advocate as a member of ALTCA. We have been ... [involved in preparing] documents ... [for] ... the Minister of Seniors to the Minister of Alberta Health and Wellness... We advocate for ourselves ... and for the other faith-based organizations ... with the region (10:11).

Later, this individual listed other associations with which the agency collaborates.

The... Association of Canada and the national... Association, the Christian Association, the Alberta Long-Term Care association, and... accreditation organizations and seniors center groups. In..., for example, we sit on the President's... Council... How could you be a neighbour in the community if you don't participate on some of those key committees and key groups $(10: 29)$ ?

Another agency describes its working links with a federal government

representative, a local community college, and local agencies.

We worked with Anne McClellan's special assistant. We were hoping to put in place a center for healthy living which is basically a one stop shop. [We have been] working in collaboration with various community centers, [and] Grant MacEwan College. We work... so that anybody who has any kind of needs, in terms of activity or wellness, they could phone here and 
we could tell them what programs everybody has and send them to it $(26: 17)$.

Another agency representative describes the various collaborative venues according to the streams of care that are provided under Alberta's continuing care umbrella. This individual said, "Alberta Seniors Citizens Homes Association represents a lot of the supportive housing people. Alberta Long-Term Care Association represents a lot of ... long-term care operators... We're part of both of those and we find they are very influential with government" (19:61). Unfortunately, according to this person, home care lacks a venue for collaboration which means that agencies are essentially on their own when it comes to addressing the needs of seniors who use and/or require this service. This also impacts the employees who provide the care.

Home care ... really do [esn't] have an avenue to present our issues. ... We just do what we've got to do for the staff and the residents. ... Rather than lobbying or advocating, we just do what we've got to do. And, if you've got to fire off a letter or yell at the region we do. ... We know we have to pay the employees more. We know we have to give quality care. ... We adapt our program (19:61-63).

Later, this individual said, "I think you're getting on to something [about home care] that may be one of our big problems. We just don't have that same type of advocacy group.... So I guess if we had something structured and regular it might be a good thing" (19:7677).

When describing how one agency advocates vertically with politicians and horizontally with local agencies, its representative frames collaboration as their guiding principle.

[A] guiding principle that we have ... is to work in collaboration rather 
than just to be a lone ranger, just doing our own stuff. Working together with other agencies, lobby groups, we will always take the position, 'Don't embarrass the politicians', because ... they... will get very defensive ... instead of ... listening to what the issues are, ... and we are not going to accomplish anything (11:6).

Another agency includes Capital Health in its collaborative work.

We advocate for ourselves... and for the other faith-based organizations by the lobbying... that we do with the region itself. ... Having said that, we have sent letters to ministers from our board. So, when we do find an issue for example, it could be around long-term care funding [or some issue], ... board ... advocacy committee ... [will] raise awareness ... to the region. We [may still] ... go and talk to someone [, e.g., a politician or minister], or do something. ... [However, first, we approach the regional authorities] because ... we want to ... be supportive of the region, not to be against or not to be opposing them $(10: 11)$.

One agency representative describes the importance of informal collaboration to communicate issues and problems to various government representatives.

Well, the best thing that has happened is you know we have a group called the Seniors Housing Society of Alberta that meets quarterly. It's mostly [comprised of people from] Edmonton. ... The reason, I think it's Edmonton people, is because the group started out with two issues, issues with home care and issues with this property tax. ... [The group started] about 7 or 8 years ago.... It is in no way is it a formal group. ... It's just an opportunity to get together four times a year [and] ... that's worked the best to tell the region that we've had a, you know this is an issue of home care and we've had enough (19:42).

Another agency representative tells how the agency provides space for informal groups of seniors' advocates who are trying to shape public policy related to seniors' issues. This individual said,

We provide them with free space, and a little bit of clerical support, and filing, and that sort of thing. ... That's another way in which we exercise policy influence by supporting that group and they [review and speak] ... on health issues. ... We don't always have to be the one speaking on health policy issues. ... We give [names the group] ... free space and they 
take a more... direct approach. ... That's a gentle world, I was [also] going to say antagonistic, but it's not necessarily antagonistic. But [their perspective is] ... very direct ... and promot [es] an alternative view (23:4749).

Agencies work collaboratively to identify new and emerging issues, to address

funding and other existing problems, and to provide support to individual citizens. One agency representative said,

So we have done reports like this where we worked with other groups to identify issues that have an impact on the ability to receive care, we do advocacy where we will take a government position and analyze it and send in our response. We have at times taken up individual issues and said that we need to be heard on this and so writing to [about] the... [issues] housing ... [and] we perceive a problem in assisted living [, i.e., ] ... affordable housing for seniors (23:16).

Collaboration, according to the research participants is invaluable. It strengthens the voices of agencies, and it has led to the establishment of an agency which will provide greater support to local agencies in the future. Specifically, inter-agency collaboration helped establish the Edmonton Seniors Coordinating Council, an organization which many hope will help resolve a number of local problems for both agencies and citizens. According to one agency representative, collaboration in the Edmonton area is tremendous. Not just from a networking perspective but, getting to meet people. ... Also working together on projects. ... When five of us, five of our heads can come together and we can all offer something to the table, we can achieve incredible results or move things quite a ways. ... The Seniors Coordinating Council is the perfect example because it came from nowhere. It came from 5 individuals representing organizations bringing it together and moving it forward. ... And, then it kind of grew out of there (5:52).

Several agencies spoke of the newly formed Council and how it came into being.

Another executive director said, 
In the last few years, the seniors' organizations formed a network, ... called the Network of Seniors Service Organization. And, they identified that we needed more collaboration because that's the kind of thing, instead of just reacting, when we are asked. ... This [whole initiative] was a voluntary thing, so we either had a couple people or not that many. ... The Seniors Coordinating Council... is ... a structured organization now, and ... it will have staff. Its job will be to focus on ... advocacy, resource sharing, ... that kind of stuff. Their job is ... to come ... and get that information and put it forth to the network $(27: 11)$.

Another agency describes the benefits of collaboration in terms of service improvements for seniors. Its representative said, "Basically, it's better service provision for seniors throughout Edmonton, [and] sort of better, enhanced capacity for the organizations themselves" (26:30).

In spite of the benefits, doing collaboration is not always easy. Securing agreement about priorities is not always easy. One agency representative said,

I guess an interesting one would be coming to an agreement with other service providers on what it is that we agree on [and] that ought to be put forward as proposals. ... There is a high level of independent thought on the part of community organizations like ours on what would be a good solution or outcome. ... But, that [, priorities and so forth,] might not fit [everywhere].... We, as service providers, don't always have our ducks in a row, in terms of agreeing with each other. Our own internal diversity can be a barrier to promoting good public policy.... That's an issue (21:37).

Alternatively, when sectors mix under a joint umbrella association, collaboration may not take place because trust is required; trust may not come easy when motivations and sectors differ. According to one individual,

We have had some apprehension, in the past, for some group, like ALTCA [about the manner in which they represented the nonprofit sector]. For a while there, ... it tended to get a little private-oriented. ... A lot of private players, in the business, [were] coming to the association events and meetings, and ... were becoming quite dominant... It felt like things were shifting too much, but something has turned around. It could be as matter 
of who is Executive Director today (10:29).

The above suggests that, in addition to having a stronger voice which may improve conditions, collaboration allows agencies to identify new and emerging needs of seniors and to work towards addressing them. This is their environmental scanning work which is examined and described in the following section.

\subsection{Edmonton's Charities and Their Environmental Scanning Work}

\subsubsection{Environmental Scanning in Alberta}

Environmental scanning is about identifying unmet needs and/or new and emerging problems. Although charities have been doing this work for years, it is often not recognized. The problems of adults with special needs, ageism and, and more recently, the needs of baby boomers are the types of issues that are being addressed by charities through their environmental scanning work. Sometimes, charities are so successful that their programs are taken over by a government authority. Home care is a good example of policy success which had been spearheaded by local charities. According to one agency representative, "We were advocating to get funding to start this [home care] program before regionalization took over. So, we were trying to get funding from government. ... When regionalization started, we then started addressing our request to the Regional Health Authority" (17:9).

Nonetheless, when the province began to restructure the health care system, some community agencies became concerned that the success of their home care programs would jeopardize their long term survival. One agency actually lost its home care program. This individual said, 
Seniors don't have a lot of advocacy, and even to find out, just to tap into where the resources are, that they can get. ... We have worked with the provincial government and looking at [how the current system affects seniors]. ... We ... set up a program. ... Once [the program became] successful, ... [it was] taken over. ... People [ in small agencies] don't want to do that, start up the process and everything [only to have them taken away]. ... Our home program went in 1986 . We had a very successful home care program (25:14).

According to this agency representative, when they lost their home care program, seniors lost an advocate.

When the health regions were established a large number of church-based agencies collaborated so as to ensure that their institutions would not be subsumed within Capital Health. Their work led to the development of a protection they call the master agreement. One agency representative said,

There ha [ve] been all kinds of opportunities to respond... The big thing that came out of the Capital Region... [was the] development of the master agreement that allowed the facilities to operate. ... It gave the right to the ... [church-based] voluntary facilities to continue. ... That was key, and of course that was a lot of hard work on behalf of a whole lot of people. ... Relating to the principles of continuing ownership-operation of voluntary health facilities in the regional health care system (18:27).

A more recent initiative being addressed by one agency concerns the unmet needs of seniors and adults with special needs. The agency representative said,

Individuals who [were being cared for by family members] could not necessarily participate in mainstream recreation. ... They needed some place to be able to go. They couldn't go to, lets say, a YMCA because they needed structured support. ... They have special needs. ... Over the years, we ... [have been] quite involved in sort of promoti [ng the] ... need [s of adults with special needs], individuals [who] were pretty well lost or forgotten $(5: 10)$.

Ageism and aging is another big issue which is being addressed by a number of 
agencies. Ageism arises in relation to the finances of seniors, or it may take the simple form of denial about seniors and their needs. Societal-wide ageism ultimately reinforces the provision of low funding for seniors' programs. As research participant said,

The area of seniors, we're not sexy. ... NO one wants to give money to us! They give money to help children, or to teens on the streets. ... It is a huge issue ..., until your mother becomes ill, or until your father is in a situation where you can't leave him alone during the day time. Yet, you have children to care for, and you still go to work. Until you are in that kind of a position, you don't necessarily see the need for our program or ... the impact of that sandwich generation (5:37).

Another agency representative identifies the large numbers of aging baby boomers as a potential problem which, given the above statement, could be problematic for future seniors. This agency is working to address the needs of new seniors and to change its current focus. The agency's representative said,

We have a new generation coming up and that generation is looking after mom and dad who are either at home or in a nursing home. They are entering the senior area themselves and plus they are still dealing with children or grandchildren... They are doing all this and it's those... [who] are in the middle, the baby boomers [who] are coming up.... We have to expand our horizons, change our focuses ... so that we can get people to come to us with those concerns $(7: 47)$.

Given that agencies are constantly addressing a variety of new needs and given the local political constraints, environmental scanning must be done well and carefully. A fundamental aspect of doing good work is collecting sound data and satisfying the concerns of potential sponsors and funders.

\subsubsection{The Burden of Proof and Data Collection}

Agencies are aware that solving old and new problems must be done systematically using accurate data, pilot tests and thorough evaluation of outcomes. Since 
issues are new, data are often lacking and require, therefore, that agencies work to define, measure and test solutions in a variety of ways. The measures include building upon the knowledge and skills of boards and staff members, collaborating with others on research, doing surveys and soliciting data from newsletters, holding focus groups, researching on internet, and using the media. As well, data are generated from outside sources, like speakers, who represent other sectors and interests. One agency representative said, So, ... we have what we call a liaison committee, where all ... the board ... [members] come together. And, that's where we find out what the needs are from their various perspectives. So, that helps us. So then, ... we determine where to fit ourselves in to how we can help with the need in a broader perspective $(18: 24)$.

Another agency representative uses a more analytic approach, based on experience and logic to identify how to resolve the service needs of seniors, while another may begin by identifying needs. One agency representative said,

We have staff who do intake, and they hear all the troubles that people are facing and attempt to find resources. We have the social worker. We have the informal contact with our volunteers and so forth. And, that's where our ear to the ground is. It's with the people that we serve who are coming to us with their individual troubles and identifying when they do it, individual advocacy on behalf of those individuals, to get the system to adapt and meet their needs. ... Or, we may bring that up as a policy issue that comes through the policy committee $(23: 75)$.

One agency undertook a strategic planning exercise to identify and satisfy the social and recreational needs of its clients. The agency's representative said,

[The idea for the caregiver program arose from a] strategic planning ... [process undertaken by] the organization ... with, not only some of our volunteers but, some of the existing caregivers. ... The need was identified and then it was my role to start that program up. So, now that has been running for approximately five years $(5: 15)$. 
Sometimes, agencies undertake broader needs assessments and/or surveys when defining and measuring problems, and identifying solutions. For example, a group of agencies banded together and undertook a city-wide needs assessment on seniors's needs. One of the original coordinators of this exercise said,
About 6 years ago, ... [I] and a number of other agencies all sat around a table and started that whole process [of identifying services gaps for seniors]. ... We applied to levels of government for funding to do some research. ... We ... applied to different levels of government to have position papers written and have that disseminated into the community. ... We worked to the next stage and we have just been successful. ... [This work helped establish] the Edmonton... Seniors Coordinating Council ... which is now going to be an umbrella organization for all services for seniors in Edmonton (5:24).

In a similar manner, because of the dearth of information on the local needs of seniors with respect to services and programs, one agency spearheaded a significant collaborative research endeavor which is described in the following.

We .. met with a number of other executive directors and said should we be doing some research together so that we all work from the common understanding... So, we got some funding from the city and others to do some needs assessment and collaborative research. [The results] came back, nice and statistical. [The question was,] 'How many agencies were actually going to use that for that for adapting their programs?' ... We looked for common themes and got some money to write some extra papers on the seven topics. ... [The] most common... [themes were] transportation, caregiver support, community living, volunteerism, ... social and recreational, ... community services and recreation. It wasn't housing (23:78).

Sometimes, agencies work alone on their surveys. When describing how one agency performed its own survey, its representative claimed that it was "doing the job of government." This individual said,

We did a survey last fall and, we had a tremendous response... We asked 
questions like, 'Have your utilities increased, if so by how much? ... Do you have support system, family, friends, that could take you places and whatever? ... Can you get to the seniors drop in centres or the seniors centres for activities? ... Do you have loved ones in long-term care facilities? ... We compiled all of that information and then we presented it. ... We ... gave [the results] to the government [and said], here's what seniors are telling you (3:46).

Agencies use the media-newspapers and television, and supplement the information gathered from these sources with informal data gathered from clients. As well, the internet becomes a data source which may then be supplemented with other data, perhaps generated collaboratively with other agencies, or through focus group meetings. Another agency solicits data through its quarterly newsletter. Lastly, ideas, data and solutions sometimes come from outside sources, e.g., representatives from other sectors and agencies. One individual said,

[The idea] came from the advocacy committee with discussions ... with ... the Alberta Consumer Association. ... They had done a report on the very same thing: lack of affordable housing and assisted living, non-subsidized. ... So, we got involved ... and none of us new anything about the housing situation. ... We got permission from the board, or endorsement, ... to pursue that as a major project. ... ... The group is now at the point of saying we've done the research. We know the information. [The current questions are,] 'How are we going to disseminate it? How are we going to use it to influence public policy?' (23:24).

The previous individual also describes how the agency went about and did a realistic cost estimate of what it means to live in assisted living. The agency representative said,

To get a handle on the costs, even though we immersed ourselves in it for a year, [wa]s very ... difficult... So, what we did was ..., I [and others] visited two facilities. Each of us visited two or three. And, we made up a case where somebody is in a assisted living facility, ... [someone] who doesn't need any extra help. They're healthy... [A] second case [was developed in terms of] ... somebody who took a short term episodic problem, like a sprained ankle. And, their ... [problem will last] for just 
say two or three weeks. Maybe they can't walk down to the dining room, and they need to be pushed in the wheel chair. Some help at $\$ 17.50 / \mathrm{hr}$ to get a push in the wheel chair. And so, we costed that out. So, we have a comparison of a non-complicated and a minor [case].... We didn't get into [, meaning develop,] a case study on anything that was chronic or long term at all. And so, we compared the costs. [The results were] absolutely mind boggling; 60 percent more a month rent if you sprain your ankle and need a little bit of help (23:28).

One individual describes how the agency which is contracted by Capital Health to provide home care services was prohibited by Capital Health from undertaking their own satisfaction surveys.

We're not, ... [allowed to do client satisfaction surveys] because... [the clients are] not seen as our clients. ... We did our own surveys of satisfaction, but the region wants to do surveys of satisfaction because [they claim] those are the region's clients. And so, if the clients are not satisfied, it's not up to us. We're merely a contractor (17:45).

Unfortunately, such surveys would be useful mechanisms to discern needs, quality, service levels and so forth. Even in this small area, the regional administration is controlling the agenda.

\subsubsection{New Programming Initiatives}

\subsubsection{Successful Public Policy Initiatives}

One of the key successes that has emerged from the collaborative efforts of community agencies, (described above), is the establishment of the Edmonton Seniors Coordinating Council. According to the representative of one of the agencies involved in this initiative,

This [Council emerged from] an action oriented process. ... We were going to make a difference. ... We were going to bring something about. ... That's a fundamental principle that underlines the establishment of the coordinating council. So, when we pull a committee together, it won't be 
a committee of us critiquing them, [government]. It will be them and us together, identifying a problem and finding common ground for a solution, even if its not the best ultimate solution.... [We will try to find] the minimum that we can agree to here. And, let's make that change at the very least and then beginning to make incremental change based on that (23:81-83).

In addition to the establishment of the Edmonton Seniors Coordinating Council, other successful policy initiatives that were described by the research participants include adult day programs, social and peer supports for seniors, programs addressing elder abuse, caregiver programs, and the lowering of health care premiums for seniors in Alberta. These are described in the following.

One agency representative said,

We were one of the first day programs in the Edmonton community providing a social model of support. And so, Capital Health actually came to us and said 'We want to do a pilot study and see whether or not day programs actually do keep people in the community longer. Are they a viable option to institutions?' So, our organization, with a few others, were involved in sort of a pilot. ... It was determined that we were actually keeping people out of institutions. And, that's how we developed our funding relationship with Capital Health (5:12).

Another agency began a peer support group for seniors as a result of data collected from an evaluation. The agency's executive director said, "That [program idea] came through, basically through the service evaluations and talking to members or non-members. They [seniors] indicated they would like this, this was something they could do with" (26:13). Another agency helped establish social work services for seniors. The agency representative said,

We identified that there was a gap within the broader community in terms of social work services for ... seniors who were not plugged into home care, [or] ... into a disease based organization. ... They were having trouble 
coping with family [and] ... societal systems or [just] coping. ... So, we put into a proposal to a funder to expand our well being program to include a social work position and outline some of the outcomes that we expected to achieve. ... They granted the funding (23:35).

The previous agency representative also describes the agency's difficulty in establishing program targeted to elder abuse.

We have a program, that has been up and running for a number of years now, providing ... to abused seniors. ... We are having a devil of a job getting full funding for it. Now there's no way that ... Is something that the marketplace is going to pay for. And, these are pretty much financially disadvantaged people. ... So, while the department of seniors is fantastic, ... hav [ing] given us free accommodation of a floor, ... finding the funding for staff and services has been much more difficult. ... Government ... resists funding ongoing programs. They will do capital, ... special projects, [and] ... one time ... grants. But funding ongoing programs is something that is $\mathrm{xxxx}$ to them and they will resist it (23:74).

Several agencies have successfully filled a service gap for caregivers by

establishing caregiver support programs. One agency representative said

I made application to a number of foundations. ... Capital Health has never funded that caregiver support program. ... The Edmonton Community Foundation ... [shut] the door ... in my face. ... [One] foundations ... [said], 'We can't help you but, we know ... an anonymous donor group that might be able to help you.' ... The anonymous donor actually gave us enough funding for two full years to start the project... We just set it up as a demonstration project. ... [Then] I ... started to apply to Family and Community Services to the city of Edmonton. ... [They have] ... pick [ed] up a big chunk of it. ... We don't charge anybody for attending our support groups, ... [or] information sessions. We do charge our clients who attend our day programs a $\$ 15 /$ day fee. ... We also ... open ... up [our support group] to the community, as well. So, it's not just exclusive to our individuals. ... [Any individual] can attend our support groups (5:16).

Another agency representative helps caregivers deal with the emotional toll which results from their caregiving work by establishing a series of support groups. This 
particular program is targeted to adult children who are caring for their aging parents.

This individual said,

It's not an advocacy issue so much as a meeting an unmet need. So, there are a number of educational institutions will provide training on how to be a caregiver, a hands on caregiver. Not many are dealing with the emotional impact of having to change your relationship and have to become that caregiver (32:33).

Another agency representative describes the agency's Healthy Families initiative which has now become fully supported by the province. This individual said, "The province [has] taken over the whole, the funding of that entire program. But, it started from the community up (24:20). Yet, another agency representative describes how the agency is increasing access for seniors to physician services. This individual said, Hmm, good question. We have, we have such a multi-varied relationship with this region. We've just opened... a Seniors Clinic with physicians, nurses and [Capital Health] ha[s] just agreed to put [in] a home care coordinator... because a lot of the home care clients are orphaned and don't have a physician. [Through] that clinic [seniors] can get in to see them. We've built the clinic around an alternative payment system for the physician so they have more time to spend and do a better job of assessment... It's an alternative primary care [site] targeted for seniors $(17: 51)$.

Another agency representative describes how the agency lobbied to reduce and/or eliminate health care premiums for seniors who, the agency found, were struggling with costs. The agency almost lost its charitable status as a result of its advocacy work. This individual said,

One of the things that we were successful in doing was eliminating the Alberta health care premium... It was $\$ 280$ something a month so, it was quite high. ... I think that was an individual..., about that figure. But,... [about] 63 percent of all seniors in Alberta were already not paying Alberta Health Care because their income was so low. So they [, the government,] 
said, well let's just scrap the whole thing" (3:9).

Some programs developed by community agencies through their advocacy work were, at the time of data collection, either works-in-progress or were about to begin. These are described next.

\subsubsection{Works-in-Progress to Address New and Unmet Needs}

Several of the programs being developed and/or proposed by community agencies involve ongoing education, training and awareness raising about the needs of seniors.

The goals of all initiatives are to increase independence and the quality of life for seniors and their informal caregivers. One individual describes the agency's work as facilitating the needs of seniors through education and awareness raising initiatives targeted to colleges, businesses, and even Girl Guides. This individual said,

We're facilitators. ... As a matter of fact, we're just going to be starting a project called Caregivers. ... Our plan for this coming year is ... to get into the colleges and teach them teach the LPNs, for example, how to deal with seniors and their issues, how to communicate with them. ... We have a senior friendly program. ... We're across Canada. Senior-Friendly was developed to bring awareness to the general public about some of the things that seniors are faced with on a day to day basis.... We have something called Linking the Generations ... [which works, for example, with] the Girl Guides. ... We provide them with a kit and some activities and ... books. ... They meet with seniors in centres, long-term care facilities, and ...then they get a little badge (3:17-19).

Another agency works to educate local government about improving local transportation services for seniors. This individual said,

When we talk about seniors and transportation, transportation is a huge issue; [unfortunately,] it's for the disabled population period. [The program being referenced is DATS]. So, the City of Edmonton ... decide they are going to reclassify everybody.... I have some 75 and 80 year old ladies in my program, I would never ever put them on a regular ETS 
[Edmonton Transportation Service] bus, I would never do that to them. ... We have tried to do to educate them (5:43).

One caregiver issue which is being targeted by one local agency is seniors' guardianship from a variety of perspectives-legal, emotional, administrative. The agency representative said,

We also have a guardianship program where we assist people to apply for legal guardianship, often ... of a parent. ... We've just started running support groups for helping people ... deal with that role of guardianship, [and the day-to-day responsibilities] ... [We] talk about the role.... [We help with] the paperwork, and get[ting] it over to the courthouse. And, ... the next step, ... What does this mean [in terms of] the moral and ethical issues... So, that's the area that we have moved into and again nobody else was offering (23:39-40).

One agency plans to tackle the issue related to the lack of standards related to

assisted living facilities. Another agency representative said its agency was planning to do more work on elder abuse. Another agency is advocating for home supports because the low profit margins associated with these services precludes sufficient service levels.

We have to, like we offer that service, we find people that do that ... because the seniors don't have money. Those people can't. Like, we have to be the ones who advertise them and all that too, because they couldn't. There is such a little profit margin, so that's the thing. In this sector there's not a real margin for profit so the only disadvantage (27:42).

According to one research participant, the socio-political-service environment related to seniors is so complex that a senior's ombudsman position is required. This person's agency will promote the institution of such a position to protect seniors.

I heard this from somewhere that there were something like one hundred and eighty five different organizations who deal with seniors, and of course that could be public [groups]. But, in this SALT, Seniors Action Liaison Team, $[\mathrm{Mr} . X]$... is chairing it. He's trying to get together with ... a circle of Alberta's Seniors Advocacy Group chairperson.'... But, ... he's 
proposing, for a province of Alberta, [the establishment of an] independent seniors advocate and that this ... [would be ombudsman position].... Seven or eight or nine ... different Alberta government departments ... deal with seniors... It's [a] very fragmented [policy environment].... The board will look it over, consider, ... and decide whether or not to go forward with it (23:64-65).

Another agency is promoting computer use among seniors so that seniors can undertake self-advocacy to make government more accountable to them. This idea emerged from a survey targeted to seniors.

\subsection{Promoting Values in Society Through Advocacy-constituted Roles}

\subsubsection{The Tools of Policy Work}

The research participants describe a number of tools that they and their agencies use when doing public policy work. They include: writing reports, position papers and policy papers; busting myths by disseminating accurate information through newsletters; staff and volunteer training; mobilizing seniors to self-advocate; writing letters, letter campaigns, or simply forwarding letters written by the public to government; holding meetings with government and the public; testing pilot projects; speaking at open meetings; posting information on the internet; and fundraising and grant proposal writing. All of these tools and/or processes constitute public education and awareness raising.

The boards of charities are important vehicles for public education on broader policy issues that relate to the needs of seniors and their home care services. Boards liaise with various levels of government and politicians. They send letters. They lobby other powerful groups which may be more effective in moving issues forward. One agency representative said, 
So we have letters [sent] from our board, or letters from board committees. We've ... sat down with ministers and with deputy ministers, ... [and] with the Edmonton MLA caucus. We've sent letters to places like the Alberta Medical Association raising concern about primary care physicians which also affects continuing care. ... So, we will use those opportunities to directly ... participate with the region, ... the... chair of their board and the chair of our board, or ... [making some] speech or ... presentation. ... We're visible (10:13).

Volunteer board committees are often central to public education because agencies lack the paid staff who would otherwise do this work. If agency boards lack the required skills, or are not politically astute, agencies simply address such shortcomings through board recruitment. As one agency representative said,

[We] actively went and recruited, recently, a retired Assistant Deputy Minister. So, ... we have a couple of academics who have a good understanding of that side of policy development, and we now have somebody who actively understands the political process and that sort of thing. So we are building that knowledge and expertise (23:53).

Agencies also use their volunteer boards to avoid problems with the Canada Revenue Agency. One agency representative describes how the agency does its advocacy using its volunteer advocacy committee. The agency representative describes the advocacy committee as a

volunteer committee. We're being very conscious of the Revenue Canada's limitations on advocacy and so attempt to minimize our expenditures on [advocacy].... The ten percent rule. So, I don't attend the advocacy committee meetings unless specifically invited to address a particular topic. ... It's just really to make sure that this is truly a volunteer effort and that we are not moving into that murky water (23:44-45).

As well, agencies strengthen advocacy and program skills by performing internal reviews of their operations using outside consultants.

Doing public awareness means targeting politicians, the general public or business 
leaders. One individual said,

We participate in different ways to promote or to sensitize the community, especially the politicians, about the needs of the community. ... One thing that our founder taught us well is when we do advocacy; first of all it has to be solution-focused. ... The second thing is we don't want to embarrass the politicians. We have to influence them. ... Very often we ... influence them ... in private meetings (11:6).

When describing how the agency educates business leaders and the general public,

another individual said,

Part of our training program is... [to] put gloves on the... prospective trainers... We put stir sticks in them, and say, 'OK, open up this little purse here and take out the money.' We have glasses that simulate glaucoma or generation innocular generation and, we put... [the trainers] in the shoes of seniors (3:37).

While one agency trains the public, another agency trains seniors as volunteers to

support other seniors. This agency representative said,

We're trying to set up a buddy system where we would match some of our more active seniors with clients, outreach clients. ... We'll train our volunteers with home care staff [from the regional authority who] would understand the issues that people face when you go into someone's home... We would provide you know, the ongoing support and the measuring like the statistical... [and Capital Health would provide the training services for the volunteers] because in their minds, if they can get other people sort of helping out, it's... (7:32).

Yet, another agency trains its staff while also improving quality of care. The agency's representative said, "the residents know who... [our staff] are. We train them; we orientate them; the care is good" $(19: 16)$.

Agencies also train seniors to undertake self-advocacy. This was described by one research participant who said, "We provided some instruction to our clients on responding to the questionnaires, our board spent some time developing a position on this 
and we submitted that, and we applied to make a representation at public hearings" (21:18). Another agency might try to mobilize seniors so that they will become more proactive advocates about the larger problems and needs of seniors. This occurs through outreach and support to the groups representing seniors. One individual said, "We bring in guest speakers and try to get seniors fired up. And you know, in watching the news, there are some groups that are able to pull seniors together and get them going" (7:24). Motivating seniors is challenging work because, according to this individual, "Really, they [, the seniors,] come here to enjoy themselves. They have done their bit in society ... [and are in their] golden years... I wish more of them would take... an interest in what was going on" (7:27). Similarly, another agency representative said,

We ... have [here] a residence council, and a family and community advisory council, and we support them. We help them have their meetings. We help them run their meetings, make minutes for them. ... We have helped those councils advocate to the government because, what we are saying is, we have difficulty doing that as ... because of the region. And, [these] people can do things we can't do. And so, we've had them write letters to Health and Wellness, to the Seniors Minister. ... So that way we get our lobbying done and yet we get to do it in a safe way through somebody else (10:15).

Writing and/or reviewing policy, position papers and reports are other tools used by community agencies in their advocacy work. One agency representative said, We ... develop policy papers that will impact the actual proclamation of policy. With the actual proclamation [being] done, as you know through government, and the government getting their input directly from Regional Health Authority. So, we have to find ways to influence (18:12).

Another works by preparing reports on home care. The agency representative said, Home care ... [is] not just for seniors. We believe it's for handicapped and people who need it. And, I think the budget in Alberta was something like 
two percent of the health care budget and you know, of course, we don't endorse that. ... We've [prepared] very short report' on the issues (23:32).

Myth busting which corrects faulty information is also central to changing public policy and public attitudes and perceptions about seniors. One agency representative said, for example, "There are so many myths out there about seniors. ... They are inactive and, they are not contributing... They just sit at home and they just complain... Volunteer Canada [demonstrates that], statistically, seniors do the most volunteering of anybody... They are contributing people..." (3:38). One agency representative said the agency used "1200 volunteers, and we serve about 5000 people" (17:4).

Another agency representative describes how, in a recent election, the agency framed a number of health related issues according to the needs of seniors and disseminated this information to the public.

We ... try to frame policy issues because there are so many issues out there... Making health care sustainable ... is definitely a policy issue. And, we put that out in about June of this year. ... We had it ready for the federal election, and ... the provincial election (18:7).

Another individual describes the importance of 'greasing the wheels' with respect to the agency's relationships with politicians, so as to build personal relationships which support and facilitate advocacy. One agency representative said, "I found the best way [to lobby or advocate] was through the MLAs and through the [city] Councillors. To get to the bureaucrats, going through the bureaucrats without any political pressure got me nowhere" (27:21).

Charities also write letters to government on any set of issues but, because caution must be exercised when doing individual or public advocacy, often agencies simply 
forward letters they have received from the public about various issues they may be working on back to government. For another agency, letter writing is safer than using the media.

Because we are funded by the provincial government, we have taken a more of a balanced approach saying, 'You [government] have a problem because people feel this way.' We can help you with some perspective on that. ... So, we do letter writing and meetings. We don't do media stuff and we leave that to the other groups to do it. ... In fact, [to] the two more radical groups. ... We do get media, but it's not in a cricitcal sense. Like, we won't come out against the government policy in the media, if we can possibly avoid it (23:50-51).

Later on, this individual said, "We did do a little bit of letter writing on ... issue $[X X X]$ to support our common beliefs around this particular issue. So, ... that's another way where we can work with the minister who supports the idea but maybe doesn't have the support of cabinet" (23:77). For another agency representative, letters simply keep issues alive and promote their agency's visibility. Sometimes, as well, visibility is enhanced simply by posting information on agency web-sites.

Other tools, like pilot projects, test the new ideas that have been developed by charitable agencies and which may have been supported through public education and awareness building. Thus, grant proposal writing and fundraising become important venues for public education and advocacy. One agency targets service clubs and local companies as part of its grant proposal processes and, in doing so, raises awareness. Another agency fundraises by placing private sector advertisements on their sponsor's vehicles. 


\subsubsection{Through Broader Engagement and By Speaking Out}

A number of charities have participated in national- and province-wide consultation exercises. One agency representative describes the agency's participation in both national- and province-wide consultations on health care as follows. "We have taken specific actions ourselves, again based on our values, in terms of submissions to things like the Romanow Report, responses to the Kirby Senate Report and... the Mazankowski Report" (12:9). Another agency representative said,

Responding to the reports was what we did specifically, but there was a lot going on in Alberta about discussions about health and which services were being delisted, there was a lot of interest so we were busy primarily I think our responses to the Romanow and the Mazankowski, ... Alberta Commission $(23: 15)$.

While a number of agency representatives said their agencies participated in these highlevel activities, many simply describe local initiatives where they and/or their agencies speak out and collaborate on issues related to home care.

Faith-based agencies, for example, often target their churches as part of their public advocacy work. Alternatively, some agencies may keep issues alive by speaking out at local public meetings. One agency representative said,

We keep talking about affordable housing. That is a huge issue... I went to one of the forums [for the city elections], and I got up [, identified myself,] and I asked..., 'How are you going to provide affordable housing for seniors?'... One of the candidates said, 'Oh well..., there are lots of private companies that will build.' And I said, 'No, no, no...! Don't talk to me about private companies. ... I am talking about affordable housing for seniors, based on their income $(3: 48-49)$.

Other agencies go the collaboration route. According to one agency representative, "We've taken it upon ourselves to represent other like organizations like 
us since we have an ear now. But, that's just because we have such a high social conscience here. I have a lot of retired nurses [who volunteer], and stuff like that" (27:47). However, public advocacy must be done cautiously and discretely! One agency almost lost its charitable status because of its public comments and other public advocacy work. The agency representative said,

Like, we cannot do that in order to maintain our non-profit and our charitable status. It can only be 10 percent advocacy... Our lawyer still has to come here and do a report... to make sure we are following, that we're not doing too much of that. And, so we advocate for seniors but we do it by working with the government instead of running them down. You know what I mean... So when I get letters to the editor, slamming the government, I print them but, then that's not me. Do you know what I mean? It's not us $(3: 9,12,14-15)$.

While many of the above appear to be low-key activities, in total, they represent significant energy, time and commitment towards improving the conditions for seniors.

\subsection{Chapter Summary}

I summarize by introducing the views of the research participants in regard to the assets their agencies bring to the public policy table. Agency representatives describe their agencies as being credible and respected. Their reputation becomes both a tool and an asset for doing policy work. One individual said,

I don't think that there is a lack of community support, in Edmonton. ... We are recognized as being a credible and influential voice for seniors so I think, ... that works in our favour. I don't know that there are external constraints. ... [When,] we want to meet with a government official, we find a way. And, they will meet with us because of the credibility of the organization (23:61).

They also identify their volunteers, their closeness to clients and the community as assets which promote public policy change. In many respects these assets enable charities to 
become community leaders on home care. Their assets are one with their identity and their advocacy-constituted roles.

In the above, the research participants describe constraints which are similar to those experienced in Ottawa. To this list of constraints can be added a new one identified by the individuals in Edmonton, namely fear. However, the constraint which has the greatest impact on the policy work of charities in Edmonton is government's funding restraint agenda which translates into low funding for continuing care services. Multiple lines of authority, complex service delivery mechanisms, the regional model and competition are additional constraints which make for a challenging working environment. The combination of factors mean that Edmonton's charities exercise caution when they work with government and when they do advocacy. In addition to their impact on local charities, the varied constraints mean minimal home care services, acute home care replacing home supports, and a compromised quality of life for the elderly.

Albeit these significant impediments, the research participants describe their efforts to do advocacy throughout their various roles. In regards to public home care, they advocate on behalf of individual clients and their informal caregivers for more services and to improve access to services. They advocate in relation to funding, on quality of care in long-term care facilities, for preventive services, and for employees. Due to the 'fear-factor', they collaborate with other organizations, both formal and informal. Politicians, local government, the regional authority, individuals, and the general public are their advocacy targets. 
Through environmental scanning, Edmonton's charities research on unmet needs, and probe about the realistic costs associated with living in the 'privatized' continuing care settings. Their most successful policy initiatives include the recent establishment of the Edmonton Seniors Coordinating Council which will facilitate collaboration and policy advocacy at the local level and the 'master agreement' through which the identity of church-based institutions has been maintained throughout the province despite the introduction of the regional framework which tends to centralize control. Both are important because they ensure that a balance of views and opinions can inform and shape home care policy beyond what occurs under a narrow restraint-focussed framework. Other successful policy initiatives include social work services for seniors, peer supports and respite. Works-in-progress address ageism, establishing a seniors' ombudsperson, guardianship programs and other programs. Finally, agencies use a variety of tools in their advocacy work, a noteworthy one being the use of informal groups so as to protect their own position within the province. 


\section{CHAPTER 9 - DISCUSSION AND CONCLUSION}

This dissertation uses a qualitative, double case study design to examine the policy work of charities in home care for the communities of Ottawa, Ontario and Edmonton, Alberta. The argument of this research is that nonprofit charities do not simply provide services 'in partnership' with government, rather they perform a variety of roles. I call these the advocacy-constituted roles of charities. The roles are one with the identity and missions of charities, which manifest the values of compassion and caring, and they are reflected in the policies, programs and day-to-day operations of these agencies. The research also identifies the risk, associated with the policy constraints imposed upon local agencies by government, that the policy work of charities becomes less and less visible. This risk requires charities to improvise in ways which contradict their identity, mission and roles and this, in turn, reinforces the risk that their contributions become minimized.

Several conceptual contributions are made by this research to the growing body of positive nonprofit theory which explains the sector according to its own strengths, contributions and weaknesses rather than conceptualizing it derivatively according to another sector like government or for-profit. As well, the research provides empirical explanation about the manner in which charities in Ottawa and Edmonton have participated in policy developing in home care, over time. These contributions are now explained through the interweaving of empirical contributions in home care with the conceptual contributions that relate to nonprofit literature.

Empirical literature which largely explains charities according to a partnership role with government through services' delivery was one of the starting points for this 
research. This common conception of public-serving nonprofit organizations as partners led me to examine charities according to a broader static set of roles which nonprofit literature identifies as being performed by undifferentiated nonprofit organizations. By taking charities out of the sector and examining them according to the static roles, this research demonstrates that public-serving nonprofits, i.e., charities, do more than simply provide services with government funds, on behalf of government. Specifically, it demonstrates that charities perform a wider set of roles or functions, which supplement government's allocations, and provide a wider set of public benefits to individuals, other agencies, donors, the wider public and government. Furthermore, it illustrates the dependence of charities on labour and financial donations in regard to wider benefits. In terms of home care, it is important to first acknowledge that public home care services are provided by charities using the small allocations of government. In this sense, charities facilitate the redistribution of tax dollars to citizens. The research demonstrates that, in addition to services, charities in both Ottawa and Edmonton promote values in society in a variety ways which include volunteer boards, public education campaigns, participating in provincial-national consultation exercises and working with informal groups. The use of informal groups has been particularly important to charities in Edmonton which seem to operate under more stringent policy constraints. As well, the research highlights that charities promote societal values and democracy, and societal stability by countering / enhancing the perspective of government through pilot projects; maintaining a shadow-agenda on home care; fostering debate about home care and the needs of seniors and other vulnerable / invisible populations; 
promoting and/or challenging government to be more accountable to its citizens; using the media to communicate to the public; fostering self-advocacy by seniors; working with informal groups and/or provincial and national associations; encouraging the public to become engaged as volunteers or advocates; educating the public; working with donors; and providing employment - paid and unpaid - to significant numbers of people. This research also explores the environmental scanning work of charities on new and unmet needs. It expands our conceptualization of public-serving nonprofits by highlighting how, aside from providing public services, these agencies perform a variety of roles and, in doing so, supplement public services using financial and labour donations.

Specifically, donor funding supports activities such as pilot projects, education campaigns and strategic planning. Agencies collaborate with donors-individuals and larger-foundational. Volunteers whether or not as board members are also generally considered to be important resources in support of these activities. The staff of charities earn wages which are generally less than the average wages of their counterparts in institutional settings; these comprise an additional set of labour donations which, the research demonstrates, are not always well received by staff. As well, the nonprofit trait of charities generally means reinvesting into services targeted to the public, rather than into private profits, although in-depth analysis would be required to test such claims made by the agency representatives. Alternatively, visual data relating to the poor physical plant of many of the participating agencies support the statements made by the research participants about low budgets and salaries, and that all monies are targeted to services. These represent the ways in which charities redistribute societal resources. Cumulatively, 
they represent the types of efficiencies that charities bring to home care.

The research explores the environmental scanning work of nonprofit charities in Ottawa and Edmonton which continues to address a multitude of new and unmet needs which arise for clients and their families, and which relate to services, the needs of female paid labour, the needs of other charities, and the needs of the public. Over time, charities have generated a number of positive outcomes which include: strategies to address service quality; the development of new services for clients; improved and/or protected local home care budgets; and improved working conditions for employees. Ottawa agencies have been forerunners in the development of geriatric assessment programs, educational and training programs for both geriatricians and personal support workers, and adult day and respite programs. They are partly responsible for the Elinor Caplan procurement review related to the delivery of home care services across the province which occurs under competitive arrangements and capped budgets. They keep alive the funding issue, which means the wait times issue. Agencies in Alberta and Edmonton now have a stronger voice which can shape public discourse on home and continuing care because they have been successful in securing a master agreement which protects their independence and survival. In addition, a number of charities have worked together to establish Edmonton's Seniors Coordinating Council which will strengthen the views and support the work performed by local charities as they struggle to provide care to vulnerable Edmontonians under conditions of competition and budget caps. Nonprofit charities in both locations are tackling issues of ageism and elder abuse. These appear, for example, as inter-generational programs with high schools, 4-H Clubs, Brownies, or 
as documentaries released to local schools. They also appear as support programs for adults caring for their elderly parents. Seniors' addictions-alcohol, gambling and other drugs-are also being addressed by charities. Technology which supports the independence of frail seniors in their own homes is being developed by charities working in collaboration with universities. Respite and adult day services, recreational and palliative care are other successful programs that have been spearheaded by the policy work of nonprofit charities. Many of the successful policy contributions of charities, e.g., training and geriatric assessment, respite and adult day services, are now nation- and province-wide in their scope.

Works-in-progress which arise from environmental scanning work, and which also depend upon financial and labour donations appear as latent policy outcomes related to both locations. Numbered among them are programs for the homeless, e.g., palliative care services for the homeless, and guardianship programs for the family members of seniors. The scope of influence of works-in-progress is generally at the local level.

This research also demonstrates that the above static conception of the five roles-environmental scanning, redistribution, services provision, promoting values and enhancing societal stability—ought to be expanded to include a sixth role, advocacy, which is being undertaken by charities in home care in both locations. This research explores the advocacy work which occurs on behalf of individual clients and their informal caregivers; to improve the quality and levels of services being delivered publicly; on behalf of the peers of charities working in home care; support the needs of a broader public in relation to home care; and to support the work of government and 
donors; the latter may be construed as another form of advocacy. However, given that advocacy underscores each of the five static roles, I consider it to be an integral part of them, rather than conceptualizing it as a sixth role. It is for this reason that I refer to the five static roles as the advocacy-constituted roles of charities. This conceptualization of the work being performed by charities as advocacy work becomes an important contribution made by this research to nonprofit literature which struggles to articulate the roles performed by the sector's organizations. Public-serving nonprofit organizations do indeed perform roles in addition to the provision of services; such understanding may be useful to and support the work of policy practitioners.

The terms partner and partnership are often used to describe the relationship between charities and government, and suggest a positive relationship between the two sectors. As this research demonstrates, while charities are dependent upon government funds and must take care not to offend government, the philosophies of the two sectors and their respective responsibilities differ. The philosophy promoted by charities, armed with mission statements which reflect community values, is based upon the rights of citizens to public goods, like home care, which can be provided by the welfare state. Government and its bureaucrats, on the other hand, see home care as one of a competing set of more important services, programs and promises to be funded and delivered. This research demonstrates how home and health care services are framed by government as problems which require budget cuts and reduced funding allocations. For charities, state policies represent powerful structures which impact their daily operations on behalf of a vulnerable public. Policies do so by shaping the kinds of home care services that are 
publicly available, namely acute care rather than home supports; they shape the manner in which services are delivered, meaning competition; and they determine access to home care services according to low budgets and wait times. This research demonstrates how policies require charities to constantly improvise and innovate if they wish to continue working in home care. It seems that partnership with government may be unequal.

Chapters 2, 5 and 6 explain how federal and provincial government policies have led to a minimal definition and allocation of home care services within Alberta and Ontario. Competition is being used in both provinces so as to lower the costs associated with the delivery of services and, although governments' claims are that good quality services are being provided, it is questionable that this occurs given that quality indicators for home care are lacking, particularly in relation to clients outcomes. Quality measures related to home care are nascent and weak. The health reform processes of both provinces in regard to home care have arisen from the belief that competition between home care providers - charities, public and for-profit - will lead to efficiency, even though problems exist with the measurement of quality. In both provinces, health reform began with major commissions and/or studies which identified the need for, and the strategies to be used in reforming health systems; reform has been kick-started by new legislation in both locations. Alberta seems to have communicated, more explicitly, through its legislation, commission and reports messages about the need for increased self-reliance, self-care and less public services. As well, Alberta seems to rely more on research and reports, and seems to use information as a replacement for health and home care services. These types of issues were noticeably missing during my interviews with 
the research participants in Ottawa. Both provinces sought public support for reform, in part, by framing their fiscal problems in the health sector as expenditure problems, and have relied on market terminology and slogans in their communications to the public when claiming that health care is not affordable. Alberta, more than Ontario, seems to frame the aging process as a crisis and to incorporate this additional crisis into its messages when making its claims about its fiscal crisis.

Although Alberta has adopted a decentralized or regional structure for the administration of health and home care services, the research demonstrates that control and decision-making is centralized with the health Ministry. At the time of data collection, central control of Ontario's health system rested with the MOHLTC. Thus, while both provinces exercised central control over health services, this research demonstrates how centralized control is more problematic for charities in Edmonton and produces significant negative reactions for these stakeholders. In both provinces, cuts to institutional health expenditures were made possible, for example, by using acute home care as a substitute for institutional acute services. Both provinces have closed publicly funded chronic care facilities and have privatized long-term care services through the increased use of for-profit companies in continuing care, and by reinforcing requirements for user fees; the latter did not apply in the former public chronic care facilities. Alberta has also move quickly to develop supportive housing and assisted living models of continuing care which demonstrate a strong for-profit presence. While home care is provided in these housing forms, in essence they represent new forms of institutional care because individuals are required to exit their traditional homes so as to access home care 
within these settings. Both provinces have introduced competition related to the delivery of local home care services whereby charities compete with other charities and with forprofit companies for service contracts. A palpable difference between the two provinces relates to the degree to which charities are able to access government. This research demonstrates how charities in Edmonton appear to be more constrained, in this regard. Charities in Ottawa did not communicate problems with access to government.

The Alberta government has been more clear and up front, than the government of Ontario, about its objectives to privatize home care services. Its use of the regional model, its dilution of responsibilities for senior care among many stakeholders, its market-like messages and slogans with respect to senior care, its promotion of choice when there is less public-choice available are all clear and evident. Although less explicitly stated by policy makers, a similar trend is evident in Ontario. Another constraint has been identified by this research, in relation to Alberta, namely the 'environment of fear'. It appears to impact both nonprofit charities and Capital Health, the latter of which allocates home care funds on behalf of government. Thus, despite the blurring of boundaries between sectors, the 'interactive' state is clearly powerful.

This research has framed the above set of policies as structures which impact both home care and continuing care services, hence clients, and the work of nonprofit charities in Ottawa and Edmonton. What follows from them in both provinces is a narrow definition of the public home care good, one framed according to efficiency requirements. Home supports are less evident and are, largely, being replaced by acute home care services because the latter support efficiency goals in regard to the institutional sector. 
The budgets for home care are also capped and are low in both locations, although Alberta's budgets have traditionally been lower, and still are. Furthermore, the population of seniors is growing faster than the rate of public funding for home care, hospital and continuing care services in both locations. These trends produce tension and frustration, and they challenge the ability of charities to both provide services, in line with governments' mandate, and to perform their other advocacy-constituted roles.

This research also highlights how policies and structures in both provinces negatively impact poor seniors, particularly women and lone seniors. For these seniors, government policies may mean reduced and possibly no access to home care services, particularly in regard to services that promote independence in home settings. As a result, family / informal caregivers who tend to be female and senior are conscripted into providing care.

Within this environment, charities struggle to provide services under a framework defined by competition, the business model, capped budgets, and a clear preference for acute home care. According to the research participants, in addition to their impact on poor seniors, the constraints put at risk the missions and survival of charitable nonprofits, hence the nonprofit form. They also impact female staff and volunteers. Staff wages are being reduced and many women may be required to hold several jobs in order to make a decent wage. Volunteers suffer burn-out and their numbers are also at risk. Although the purpose of a large part of the work of nonprofit charities is to counterbalance government's perspectives on solving social-health-economic problems, the legal and regulatory constraints imposed upon these agencies may impede their ability to do so. 
Hence, legal and regulatory controls may limit the potential for charities to perform their advocacy-constituted roles.

Yet, against this pessimistic view, Taylor (2003) describes how community groups create or generate power for themselves so as to participate in public policy development. This leads to an important conceptual contribution in relation to nonprofit literature. This research demonstrates how despite the constraints, charities manifest tenacity, resilience, adaptability and improvisation skills which enable them to respond to the policy requirements which are imposed upon them and to perform their advocacyconstituted roles. Charity representatives describe how they had to learn, quickly, to adapt and function in the new policy environment created by the 'interactive state.' They describe how through collaboration, public education and awareness raising they were able to generate their own power so that they could continue existing and contributing to home care through their varied roles. They describe a number of additional tools and assets which may be used for their own power generation processes. These include: their missions and philosophies which are, for example, citizen or care-centered; values like compassion; their support of public health care and advocacy on behalf of the public; their ability to mobilize volunteers; their dedicated and committed staff who may receive lower salaries as compared to people in other sectors; their reputation and credibility; their work on service quality, accreditation and standards; and being accountable and transparent in regards to the public. The flexibility of charities to try new programs and/or pilot projects are additional assets and tools. Furthermore, each one is advantageous to governments which are responsible for the social-health policy and 
which must respond to societal needs; the information provided by charities is important to government, in this regard.

This research demonstrates how the policy work of charities begins with individual initiatives which may grow into larger, local initiatives, and perhaps expand into province- and nation-wide policies for the broader public. All the same, agencies must collaborate and support one another to solve local problems and to change policy at a wider level. Local nonprofit charities are better positioned to learn about the needs of citizens and the local community simply because of their day-to-day work within the community. They are in constant communication with staff, practitioners and professionals on local needs. They hear, see and puzzle through the problems in a collaborative manner, and they advocate and seek solutions. They educate and sensitize the public about social conditions and problems so as to seek solutions and their ultimate targets are government, civic and business leaders. This research demonstrates that charities are aware they must become politicized if they wish to 'get things done.' While they may not be constrained by the need to make profits when doing so, this research illustrates how they are constrained by their lack of knowhow and capacity about policy processes. This is an area for which charities will be required to become more engaged. This research demonstrates that charities improvise by circumventing legal barriers and regulatory constraints through, for example, their work with what I call thirdparty organizations. Examples include local Chambers of Voluntary Organizations and the Edmonton Seniors Coordinating Council (see Chapter 8). As well, they work through informal lobby groups while, at the same time, providing support to these groups in the 
form of subsidies, space and rooms, photo-copying and administrative support, and so forth. Informal associations and/or groups can lobby, monitor, respond, and so forth on public issues in a manner that nonprofit charities, constrained by law and regulation, cannot. In addition, nonprofit charities sometimes circumvent the barriers imposed upon them by one level of government by seeking the ear of another level of government. The key benefit of these types of collaboration is the creation of a voice for charities which would, otherwise, not exist on issues they consider important.

This research illustrates that collaboration also includes policy sharing of internal programs and procedures. It may involve assisting other organizations develop similar programs. Or, it may involve organizations working together to secure government funding for needed services target to a larger public. Successful outcomes, in this regard, include programs for the homeless and disabled, and prostitutes in addition to programs for seniors. The kinds of care provided to these groups include early detection for TB, HIV/AIDS care, well-baby clinics and education to mothers, and enhanced home supports for seniors, all of which may be provided at no cost, or on sliding fee scales.

This research highlights that collaboration is important because, ultimately, it put issues and problems in the public domain. Problems are highlighted and measured, solutions are tested and disseminated, and programs are established by charities when they advocate through improvisation. According to the research participants, the goal is to promote public debate so that home care services are improved and enhanced, budgets are increased, client outcome measures are developed, employment policies for the sector are developed, and seniors have expanded choice of services. 
Despite the improvisation and advocacy, this research demonstrates that charities in Edmonton and Ottawa seem to have generated only some minimal level of power in relation to some home care issues, particularly in relation to funding. The positive-sum games required for increased home care budgets are clearly lacking. On the other hand, their knowledge about the needs of seniors and of the local environment, their technical advice and expertise, the information they disseminate to the public have all become material assets which have been and continue to be shared and traded throughout the home care network in both locations; these resources underscore the positive achievements of charities which have been made and which are articulated above. According to the research participants, previous successes do compel the respective agencies to move forward and to continue performing their home care work in the challenging policy environments, but the policy work is difficult and agencies must work collaboratively with one another if they are to have any degree of success. On the other hand, the research participants also maintain that agency-to-agency collaboration is not always easy or successful. Securing consensus may be a challenge for a number of factors which include: the complexity of an issue; limited analytical skills among some of the players; lack of vision and/or leadership; competition or turf wars; inability to hear, perceive and listen; lack of awareness of an agency's limitations; and desire for organizational autonomy. Yet, given the options, it is perhaps better that charities collaborate.

Charities also prefer to work collaboratively with government to develop services according to a joint vision of needs, even though government's solutions are often less 
than ideal and that trust may be lacking. A number of organizations have indicated they are very careful to not antagonize government for fear of being punished through loss of funding. While charities struggle to work collaboratively with government, it doesn't necessarily mean that such shared work is devoid of conflict and tension.

Government is constrained by history, the electoral process, public opinion, the median voter, poor media coverage, the complexity of public policy and so forth. The 'interactive' state focuses on cost reduction, budget caps and services according to a more minimalist welfare state where everyone gets to share equally in a lesser funded service. Charities, by comparison, prefer that all citizens receive more from an expanded welfare state. They know that some people have greater need for service and care; government priorities and targets may be insufficient. Charities endorse a social justice form of equality. Government and nonprofit organizations appear, therefore, at opposite ends of a value spectrum and this is problematic, particularly for charities working in a sector like home care with its budget caps and requirements for competition.

This research demonstrates the impacts of a minimalist, 'interactive', welfare state on poor seniors and informal-family caregivers. Chapters 7 and 8 describe the problems, particularly for charities, and their female staff and volunteers. Overall, this research highlights the risks for charities which arise when governments develop policies which impose a 'one size fits all' approach in regard to its policy stakeholders. Specifically, policies which have been imposed upon charities, which require them to behave as business operators in a manner which contradicts their identity, missions and roles subjects them to the risk that their purpose, identity and value become mis-aligned. This 


\section{Figure 9.1: Impact of Government Policies on the Advocacy-constituted Roles of Nonprofit Charities}

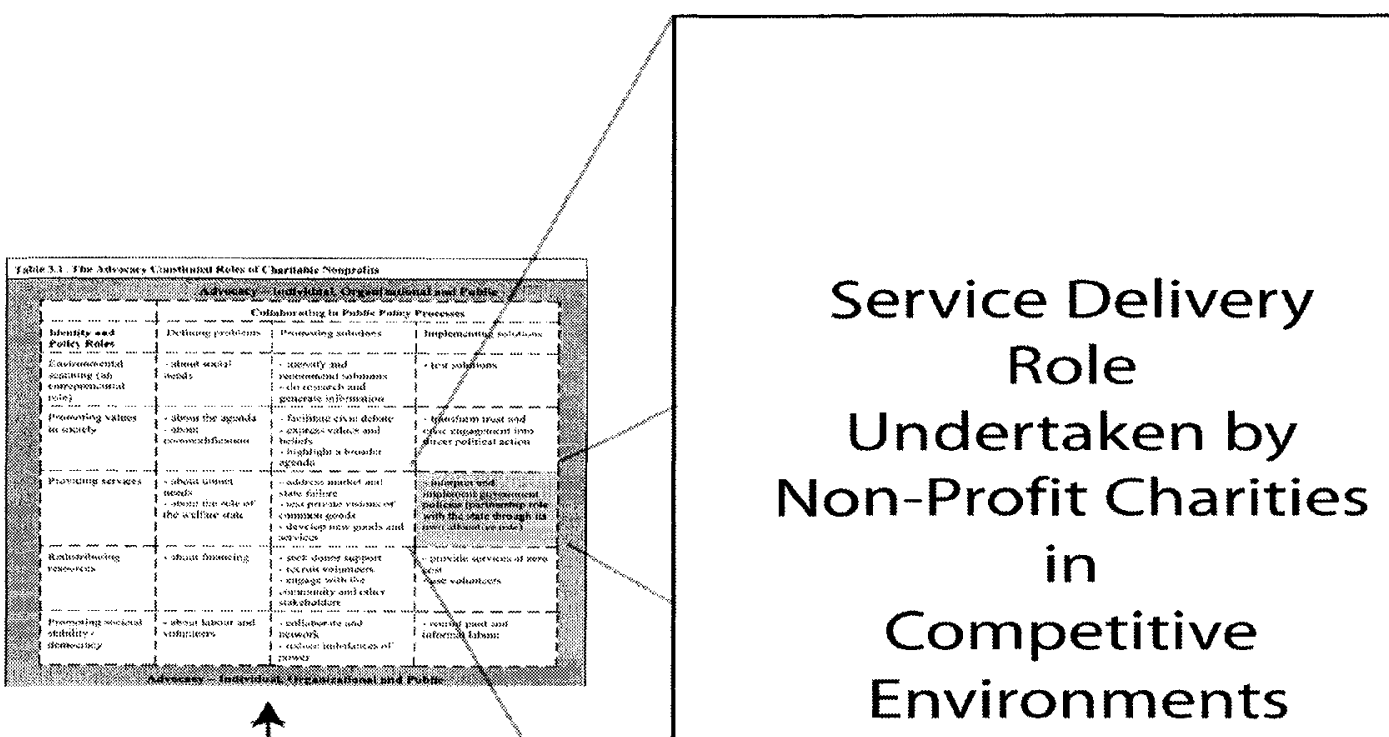

Other Policy - Advocacy Roles

Performed by Non-Profit Charities

- Environmental Scanning

- Promoting Values in Society

- Redistributing Resources

- Promoting Societal Stability

\section{Service Delivery Role Non-Profit Charities} Competitive
Environments

risk is depicted in Figure 9.1, Impact of Government Policies on the AdvocacyConstituted Roles of Nonprofit Charities. The misalignment is worsened by policies which focus on restraint. Governments' misrepresentation of charities, in this manner, may lead to the following problems: shifts in the missions of individual agencies; and the transfer of labour-paid and volunteer—resources away from roles like environmental scanning, social redistribution, values and stability promoting. It compromises the ability of charities to work collaboratively with peers, donors and other stakeholders. It contributes to volunteer burn-out, fewer supplementary services and less problem solving 
on new issues. Moreover, all of the above risk the long-term survival of charities. Although charities struggle to improvise, to generate their own power so they may provide additional public benefits, this research demonstrates how such work is clearly impacted and constrained by the policies of government.

The restraint policies of the 'interactive' state which have been imposed upon charities automatically shifts attention to the efficient use of resources when public home and health care services are being delivered. As a result, all participants are required to focus on the same priorities and processes of government, including nonprofit charities. This means the goals, objectives, administrative arrangements, resources and so forth of home care providers end up mirroring the business priorities of government. This research illustrates how for many charities, particularly the smaller ones with flat organizational structures and which rely significantly on volunteers, satisfying government's policy objectives related to services provision overshadow all their other activities. Thus, the benefits which may be provided by, and the advantages which may emanate from working with nonprofit charities are at risk. Ultimately, all supplementary roles performed by charities which provide other forms of efficiencies in addition to public benefits become invisible and/or are presumed to be deficient when compared to the for-profit sector. Such issues reinforce a narrow focus on the service delivery role of charities, as reflected in empirical research, and contribute to the development of government policies which focus on narrow goals and objectives. A minimalist conception about the roles and contributions of charities is erroneous and leads to significant societal and economic losses. Minimally, such views risk the ability of 
charities to counterbalance public perceptions with knowledge and information about local needs and conditions, and to engage meaningfully in discussions on social and economic issues. It risks their connections with communities and the flexibility by which they are able to respond to new problems and issues.

In light of these risks, this research suggests more attention is needed in regard to the impact of government policies on charities. It is important that nonprofit theory reflects the risks to charities and to society when government policies focus on a narrow definition of these agencies. Theory needs to explain how restrictions imposed upon charities by the state may minimize the realization of a more complete set of public benefits and the positive impacts that may be available to society and the economy through the work of charities. These issues explain my argument that nonprofit charities ought to be considered in their totality, meaning according to their varied advocacy roles rather than merely being viewed as service providers which are contracted to provide home care along side other contenders. All functions performed by these organizations are interrelated, and if and when they are not considered in their totality, public benefits and the agencies, themselves, become at risk of dissolution. These could lead to significant potential losses to society.

Another contribution of this research relates to the specific benefits provided by charitable agencies in regard to modern-day home care. The general tendency to focus on the service delivery role of nonprofit charities in theory and empirical studies has made invisible the other important contributions that may be provided by public-serving nonprofit organizations, particularly in home care. This research explains how, despite 
the constraints imposed upon charities by governments' structures and policies, agencies in Ottawa and Edmonton have shaped, albeit at a modest level, home care public policy. It is important that these contributions be acknowledged and explained in theory, and disseminated to government and policy makers.

Several additional research steps could be taken which would advance this research on the advocacy-constituted roles of nonprofit charities, particularly in relation to the 'interactive' state. It would be useful to undertake a broader examination of the policy work of nonprofit charities using a larger sample of agencies in a wider geographic setting. It would be useful to examine the policy advocacy work of other types of nonprofit organizations, e.g., organizations based on membership and voluntary associations, and to compare research findings. It would also be useful to examine the policy roles of charities in Ottawa as they respond to the new regional, LHIN structure which has recently been adopted by government. Such initiatives would not only test the research outcomes as identified here, but would also contribute to the ongoing development of nonprofit theory, particularly in relation to the changing welfare state. 


\section{APPENDIX 'A' - ETHICS APPLICATION}

\section{A. 1. Main Application}

\section{A.1.1. Lay summary:}

This dissertation will explore the public policy functions of nonprofit charities ${ }^{38}$ organizations that supplement policy implementation but, which may be disregarded due to social-political differences. For such organizations operating in home care, I ask:

a. How might the policy functions of nonprofit charities be considered?

b. Is their public policy function mainly that as state partner, implementing the state's public policies? Or, do they undertake a wider range of public policy functions which may be aligned with a more complete set of public policy processes?

c. What determines whether or not nonprofit charities undertake other policy functions?

\section{A.1.2. Methodology and procedures:}

Three propositions are examined:

a. Nonprofit charities actively exercise a range of policy functions.

b. The varied policy functions undertaken by Nonprofit charities are evident in their operations within their policy communities, e.g., home care, and in the policies that are being developed.

c. Public policies that emphasize and/or focus on the policy implementing functions of nonprofit charities in a manner inconsistent with their other policy functions, may have the effect of changing the purpose and mission of these organizations or risk undermining their long-term prospects for survival.

These will be examined using qualitative case study methodology (Yin 1989) in two cases, or home care policy communities: Ottawa, Ontario and in Edmonton, Alberta.

Quantitative data will be used where appropriate. Data will be collected from a number of sources including key informant, semi structured interviews and from government and other documents, e.g., historical accounts and Hansard records, newspaper articles, policy draft papers and pertinent correspondence. I will investigate events in home care which emerged, beginning mainly in the 1990s.

38

These nonprofit organizations motivated by a concern for social output rather than with income. Their beneficiaries are external to the organization and are considered to be the public. Control of these organizations by their beneficiaries is absent or minimal (Gassler 1986, pp. 42, 52). 
For each home care policy community, my primary goal is to collect and analyse data on the policy functions of nonprofit charities. Data will also be collected on the public policy activities of other interests in the home care policy community such as government, professionals such as medicine and nursing and, for profit interests. My purpose is to learn and understand how these other groups affect the policy functions of these charities. Data will be analysed to determine themes and patterns that emerge within the home care policy community. For each policy community, I will first analyse the public policy functions of nonprofit charities. I will then examine their policy functions in terms of the similar functions of government and other interests. Lastly, I will compare outcomes for the two policy communities.

Key informants will include representatives from nonprofit charities, government bureaucrats (local, provincial and federal), politicians, medical and nursing professionals and corporate interests. They will be identified through preliminary data sources, i.e., investigative contacts, review of pertinent correspondence, historical accounts and Hansard records, policy draft papers, newspaper articles, and legislative records. Both government and non-governmental documentary evidence will inform about the context of the two cases.

Four design tests (Yin 1989, p. 41) will apply to this research. Construct validity will be met through triangulation, using multiple sources of evidence to verify factual information and claims. I will attempt to explain the differences that arise, as appropriate. Moreover, I will take care to note and isolate my own impressions about the public policy and policy functions of nonprofit charities and the public policy processes that I uncover within the home care policy community. Key informants will have the opportunity to review the outcomes of their interviews.

\section{A.1.3. Description of the participants:}

The research participants for Ottawa will be recruited using the Directory of Ottawa Community Services (Ottawa 2001), and for Edmonton using the 2004 Directory of Community Services (Network 2004). I will also interview government officials-local, provincial and federal-and senior officials of for-profit home care organizations.

\section{A.1.4 Recruitment process:}

The recruitment process will be initiated by means of a letter addressed to the organizations' Executive Director or other senior executive. The letter describes the doctoral research and invites the recipient to participate in a semi-structured interview process. Each letter will be followed up by a telephone call to set up the respective appointments. All interviews will be undertaken by myself and audio recorded; each participant will choose the option of having the interview audio recorded. Audio recorded interviews will be transcribed and securely stored at my home (see below). No 
compensation will be provided to the participants. I will recruit a trusted individual, with whom I have previously worked, to transcribe the recorded interviews. This individual will not begin transcription work until she signs a secrecy agreement.

\section{A.1.5 Risks:}

Every effort will be made to minimize and/or eliminate any/all risks to the participants. Given that I will be interviewing the most senior individual within the respective organizations (or their delegated representative) and that participation is voluntary, I do not envision any physical, emotional, psychological, social and economic risk to them. As well, the questions are not of a personal nature, rather they are neutral and pertain to the operations of their organizations. That said, all participants and their organizations will be offered the choice of remaining fully anonymous at all stages of the research, including all follow-up use of the data. The researcher has previously undertaken similar interviews and has had no difficulty in maintaining full anonymity of research participants.

\section{A.1.6 Benefits:}

Given that my research outcomes mainly address theoretical needs, I do not identify any immediate benefits to the participants of this research. However, over time, I anticipate that my research outcomes will support, more fully, the public policy functions undertaken by nonprofit charities and may support the general operations among all interests involved in policy fields where nonprofit organizations are involved. I hope that, particularly for nonprofit charities, my research will improve access to, and communication with government officials, improve participation on task forces or working groups, improve consultation exercises undertaken by government and improve overall service delivery for beneficiaries.

I envision several benefits to academics and government public policy makers. First, my research will contribute to knowledge about the policy-making process in several research domains beginning with the relatively new one surrounding nonprofit organizations. It will inform about policy making for those interested in a) the role of societal organizations like social movement organizations and b) policy applications from the perspective of policy communities and networks. As well, it will inform about the public policy process as it affects several other disciplines-public policy, political science, sociology, economics, medicine, nursing and social work. In particular, it will provide new knowledge about the functions of a subset of nonprofit organizations operating within, for example, the health sector. Each is explained in the following.

Given the paucity and nascency of political-economic theory relating to nonprofit organizations, this research will begin to fill the gap surrounding the specific role undertaken by nonprofit charities in collective action. It expands their functions to a 
broader range of policy processes. It identifies the constraints that affect these functions. This will be useful to all researchers of public policy. Hopefully, it will contribute to the generation of more nuanced theory on the role of nonprofit organizations in public policyand decision-making.

Theorists are struggling with many aspects of nonprofit organizations, namely how to define them, their role, and so forth. Many write about them as belonging to a 'sector' (Salamon and Anheier 1996; Rekart 1993; Hall 2000; McCamus 1996). All organizations are lumped together under the nonprofit status, presuming this trait to be a unifying factor for theory generation. I hope that my focus on nonprofit charities, a sub-set of nonprofit organizations, will be useful to those theorists who undertake the frustrating work of mapping out the sector. Overtime, I would expect to see differences about the different types of nonprofit organizations reflected in theory.

Social movement theorists note the progression of movement activity towards the establishment of social movement organizations (SMO). They have yet to define the public policy functions of these organizations which supposedly continue the advancement of issues or problems that propelled the development of the movement, in the first place. This research may yield useful information on the role of SMOs in the ongoing evolution and dynamics of social movements (Ibid., p. 729).

One of the weaknesses of policy community and policy networks literature is its inability to explain mechanisms of policy innovation and change, an issue of interest to this research. It ignores the social and political dimensions that are associated with the use of power in policy making. By examining the activities, behaviours and functions of nonprofit charities operating within the home care policy community, I hope to provide some insight on the ability of societal groups to influence policy-making according to the process of 'normal' politics. Haddow (1999, p. 508) acknowledges this need.

Since the 1990s, governments have used 'partnership' terminology with respect to their relationships with nonprofit organizations (Canada 1999 c., p. 15; Phillips and Graham 2000, p. 156; Rekart 1993, Preface). I also note the use of similar terminology with respect to governments' relationships with for profit partners. The term obviously has many meanings. I hope to determine what government means by partnership and how it affects the functions of nonprofit charities.

Lastly, I hope that this research will have some relevance to policy practitioners. For example, it could have applications in the development of policies that affect the activities of nonprofit charities, or that relate to governments' monitoring activities. One key goal is to clarify knowledge about nonprofit charitiesand their functions so as to forestall the development of policy that places these organizations at risk to dissolution. We must heed the ideas presented to us by political philosophers and political theorists about the importance of civil society, like nonprofit charities, within modern liberal- 
democratic society. Any policy that puts civil society organizations at risk, puts liberaldemocratic society at risk. The policy processes within all policy communities require the clear, strong and equal input from all sectors-state, market and private nonprofit. This point is particularly relevant to current trends to embrace new public management (Aucoin 1995)

\section{A.1.7. Anonymity of participants:}

The participants will be offered and guaranteed full anonymity. This will be addressed by means of an informed consent form, see below. The questionnaires from participants wishing to remain anonymous will be clearly stamped 'anonymous'. For those individuals and their organizations requiring anonymity, their names and/or their organizations will not be quoted in any of the research findings and research products. If quotes are used, they will be sourced as anonymous. Descriptors of the respective organizations will also be eliminated so as to maintain full and complete anonymity.

\section{A.1.8. Security of data:}

The data will be stored at my home office, for my exclusive use. Hard copies will be securely filed. As well, copies will exist on my computer's hard drive and on a cd-rom where only I have access. I have previous experience with confidential data derived from interviews with international nonprofit organizations. As well, I have worked with documents of the Federal Government of Canada classified as secret as I have 'secretlevel' security clearance. The knowledge I have, related to the importance of confidentiality and how to maintain it, will be transferred to the task of maintaining anonymity for the participants of my research.

Since the data will be used for other academic purposes such as published articles, conferences, classroom presentations, and so forth, it will not be destroyed but will be securely stored for an indefinite period of time. The participants will be made aware if this fact. When the data has outlived its usefulness, hard copies will be shredded, cd-rom copies and tapes will be destroyed and the copies on the computer's hard drive computer will be deleted.

\section{A.1.9. Research Instrument:}

As appropriate for qualitative research, a semi-structured format will be used in the interviews which will constitute a conversation, see below. Different groups of key informant participants are being targeted and will include the executive directors or similar official from Nonprofit charities, professional associations, public serving / disease-focussed associations, for-profit private sector partners and provincial-federallocal government officials. The interview questions and format have been tailored to fit the role and position of the interviewees. The interviews will be approximately one to 
two hours long. All interviews will be taped and transcribed. They will be reviewed by myself and, as much as possible, by the interviewees to ensure that data has not been distorted.

\section{A.1.10. Dissemination:}

Following completion and defence of the dissertation, articles on the research findings will be published in peer review journals, presentations will be made at academic conferences, classroom presentations will be made and so forth.

\section{A.2. Supplementary Documents}

\section{A.2.1 Letter of Invitation:}

Date

Name of Individual

Title

Name of Organization

Address of Organization

Dear Sir or Madam:

\section{Subject: Invitation to participate in doctoral research on the public policy functions of nonprofit organizations}

I am writing to invite you to participate in my doctoral research at Carleton University, School of Public Administration, Ottawa. The title of my dissertation is: Public Policy Functions of Nonprofit Organizations: Applied Theory in Two Cases on Home Care Since the 1990s. My supervisor is Professor Hugh Armstrong, School of Social Work, Carleton University.

My main purpose is to strengthen theoretical understanding for academics, public policy makers and government officials of the important range of functions performed by nonprofit organizations in the development of public policy. Current awareness and understanding of their policy functions largely pertains to their role as policy implementors. Notwithstanding this important policy role, recent academic literature suggests that other equally important public policy functions are performed by nonprofit organizations but, very little is known about them. Unfortunately, because knowledge is limited, these other policy functions are often ignored, made invisible or disregarded as being irrelevant. I note this in mainstream academic literature, in the media, in government documents and in relations with the constituents of nonprofit organizations. 
The home care policy community is the domain through which I hope to garner more nuanced knowledge about the policy functions of nonprofit organizations, including their policy relations with partners, counterparts and government.

Much of the primary data for my research will be collected through informal interviews with key informants, such as yourself, using open ended questions. The interviews will be one to two hours long and will be taped, transcribed and analysed for patterns and themes. You have the option to decline responding to any question(s) and to decline having the interview audio-recorded. A follow-up focus group meeting with your peers may be scheduled and you have the option to participate, or not. Although there are no obvious and immediate benefits to yourself and/or your organization from participating in this research, I anticipate that in time it will support the public policy functions undertaken by nonprofit organizations and will support the general operations for all interests working in policy fields where nonprofit organizations operate. Given that I am interviewing senior executives and that participation is voluntary, I do not associate or envision any risks for participation.

Once your interview has been transcribed, you will have the opportunity to review it to ensure accuracy. It will be stored at my home, for my exclusive use. Hard copies will be securely filed. As well, copies will exist on my computer's hard drive, on tape and on a cd-rom, where access will be limited to myself. I have experience using and storing confidential data from other nonprofit organizations, private sector organizations and government bureaucrats. I have also worked with Federal Government documents marked 'secret', as I have 'secret-level' security clearance. Given these factors, I am fully aware of the importance of anonymity and how to maintain it. Furthermore, since the data will be used for academic purposes in addition to my dissertation, such as published articles, conferences, classroom presentations, and so forth, it will not be destroyed but will be securely stored at my home for an indefinite period of time. When it has outlived its usefulness, all copies will be destroyed, shredded, and/or deleted.

You may withdraw from participating in this research at any time during the study and have your data withdrawn without reprisal. As well, you will have the choice to remain fully anonymous; please refer to the attached consent form for additional details.

Ultimately, my research findings will be available to you and your organization at the National Library and possibly in articles published in peer reviewed journals.

This project has been reviewed and has received ethics clearance through the Carleton University Research Ethics Committee. If you have any concerns or questions about your involvement in this study, you may contact the ethics committee and/or my supervisor (see below). I look forward to your participation and will be contacting you shortly to set up an appointment for your interview. Thank you for considering to participate in this important study. Yours truly... 


\section{A.2.2. Informed Consent}

\section{Title of Study: Public Policy Functions of Nonprofit Organizations: Applied Theory in Two Cases on Home Care Since the 1990s Researcher: Theresa White Lobsinger (tel.: 237-6961;}

Academic literature demonstrates that nonprofit organizations assume a delicate, yet dual role in society: they provide services for government and they operate under autonomous organizational mandates. This duality is offered as a clue and a fact about the important role and public policy functions undertaken by nonprofit organizations in any policy field. However, much of the published literature is descriptive, only providing clues to suggest that nonprofit organizations actively undertake a range of policy functions, in addition to policy implementation. My aim in this research is to move beyond inference, to specifically examine and demonstrate the public policy functions of a subset of service oriented nonprofit organizations working in the area of home care.

My objective is not to de-emphasize government's role in policy development. Rather it is to strengthen the conceptual lens on and about the functions of nonprofit organizations in the development of public policy. I maintain that theory on nonprofit organizations must identify these organizations as legitimate and key public policy actors which respond to societal issues, independently of government and through a variety of functions. Nonprofit organizations must be identified as institutions, in their own right, rather than as derivative ones which partner with government.

1. I have read and understand the invitation letter and have received satisfactory answers to any questions raised by it or, more generally, by this research project.

2. I agree to participating in a 1 to 2 hour long interview with the researcher, Terri White Lobsinger, where I will be asked to respond to a set of open ended questions. I understand that I may decline to answer any question(s) and that I will be given the choice of having my interview taped for later transcription and analysis. As well, I understand that transcription will be undertaken by a trusted third party individual who has signed a confidentiality and secrecy agreement.

3. I understand that although the benefits to myself or to my organization may be nonexistent or may not be immediately realized, it is anticipated that over time the research outcomes may support any current and/or future public policy functions that I and my organization undertake.

4. I understand that the risks to myself and/or my organization are minimal or nonexistent.

5. I understand that I will be contacted so that I may have the opportunity to verify the transcript of my interview. I understand the mechanisms employed by the researcher to ensure/guarantee anonymity, should I decide that this is a requirement. 
6. I understand that a focus group interview may be scheduled, for peers. In the event that one is scheduled, I may be provided with an opportunity to participate in it.

7. I understand that I may withdraw my participation at any time during the study and have my data withdrawn without reprisal. I will contact Ms. White Lobsinger to notify her of my decision using her telephone number and/or email address, listed above.

8. I understand that the research findings from this research will ultimately be available to myself and to my organization at the National Library and possibly in articles published in peer reviewed journals.

9. I understand that this project has been reviewed and received ethics clearance through the Carleton University Ethics Committee and that if I have any concerns or questions about my involvement in this study, I may contact the ethics committee.

10. I understand that although this research, firstly, fulfills the educational requirements of Ms. White Lobsinger with respect to her Ph.D. in Public Policy at Carleton University, the research findings may also be used in published articles, conferences, and classroom presentations at a later time.

11. I understand that due to the above, the data will be stored indefinitely at the home office of Ms. White Lobsinger in paper files, on tape, on cd-rom files and on her computer. I understand that when the data has outlived its usefulness, hard copies will be shredded, tapes and cd-rom copies will be destroyed and computer copies will be deleted.

Please check any that apply:

a. With my signature, I agree to participate in this research and waive anonymity requirements. I may be quoted in the research findings.

b. With my signature, I agree to participate in this research and require anonymity; quotes from my interview may be cited but I and my organization will be kept anonymous:

c. I would be willing to participate in a follow-up focus group meeting with my peers, if one is held.

NAME: (please print)

Date: (signature) (signature)

Date: 


\title{
A.2.3. Research Assistant Contract
}

\section{Subject: Doctoral Dissertation Entitled: Public Policy Functions of Nonprofit Organizations: Applied Theory in Two Cases on Home Care Since the 1990s}

\author{
Researcher: $\quad$ Theresa White Lobsinger (tel.: 237-6961; \\ PhD Supervisor: Professor Hugh Armstrong
}

Further to our discussions, I am pleased to offer you short-term research assistance work related to the transcription of data to be collected for my doctoral research.

As you know, much of the primary data for my research will be collected through approximately 60 informal interviews with key informants, using open ended questions. The interviews will be one to two hours long and will be taped and transcribed. Followup focus group meetings may also be scheduled; these meetings will also be taped and transcribed. All participants of this research will be given the opportunity to review the transcriptions of their meetings with me so as to ensure accuracy. This project has been reviewed and has received ethics clearance through the Carleton University Research Ethics Committee (see below). All participants are being offered and assured complete anonymity. As well, I will be assuring all participants that there are no risks to them and/or their organizations associated with participating in my research.

Your role is to transcribe the data from the tapes to written form. When the task of transcribing is completed, all data-tapes, floppy disks, CD-rom versions, paper copies-will be handed over to me where it will be securely stored at my home, for my exclusive use, i.e., my dissertation, published articles, conferences, classroom presentations, and so forth. At that time, you will delete and destroy any copies of data that may remain in your possession. In this regard, your assurance of maintaining the anonymity and full confidentiality with respect to research data is very important and will be maintained.

As part of the consideration required of you under this work, you agree that neither you nor any of your relatives, agents, representatives or employees, will, at any time during the time of this agreement or thereafter, divulge by publication, speech or prepared statements, broadcast or any method whatsoever to any person, firm, organization, journal or publisher or any other entity, any information received or generated during the course of your work to transcribe participant interviews gathered for my doctoral research. All material and information generated by or in association with you during this work assignment is the exclusive property of myself, Theresa White Lobsinger, and is not to be used for any purpose whatsoever. Upon termination of this work, you will promptly return or deliver all information pertaining to this work. This paragraph shall survive the termination of this agreement for whatever cause and shall continue to bind you 
thereafter.

Kindly return to me a copy of this letter duly signed by you, below, indicating your acceptance to the work, and the terms and conditions outlined above. I look forward to having your research support.

Yours sincerely ...

I have read and understand this offer of research assistance employment. I agree to maintain complete confidentiality of all material related to this work of transcription.

$N A M E$ :

(please print)

Date:

(signature)

RESEARCHER:

(signature)

Date: 


\section{APPENDIX 'B' - INTERVIEW TOOL USED WITH NONPROFIT CHARITIES AND OTHER NONPROFIT ORGANIZATIONS}

The following five groups of questions have been asked of key informants on their public policy activities in home care.

1. Organization's basic information:

a. What is the mission or purpose of your organization?

b. How would you describe the historical consistency of this mission?

c. Please describe the practices relating to the appointment of your organization's Board.

i. Are BOD members dues paying individuals?

d. How is your organization registered with the Canada Revenue Agency?

2. Organization's knowledge, involvement, and capacity to shape home care public policy, including its views on policy:

a. How would you describe the main function(s) of your organization in the area of home care and home care public policy, for the period since 1990? i. Does it have other objectives, targets or priorities for home care?

b. These questions address your organization's influence on home care public policy and opinion.

i. Specifically: who in your organization is responsible for public policy development?

(1) What resources are devoted to public policy development?

(2) What actually does the organization do here?

c. Optional questions depending upon previous answers.

i. How does your organization define public policy?

(1) How would it describe the phases of public policy development?

(2) Would it consider service provision as public policy?

(3) What is the role of civil society in public policy?

d. Please describe how internal constraints affect your organization's participation in any aspect of public policy on home care.

e. Please describe how external constraints affect your organization's 
participation in any aspect of public policy on home care.

f. How would you describe your organization's relationships with the provincial Ministry of Health, and/or any other level of government on the issue of home care?

i. Have you had consultations-on problem definition, on solutions, or both, or none-with government?

ii. Have consultations been regular through the policy development process?

iii. Have you received feedback?

g. How would you describe the match between your organization's priorities and those of government for/on home care?

h. How would you describe the match between your organization's priorities and those of your home care community - for your city (for national or provincial organization - for other Canadians)?

i. How do you discern the priorities for the residents of this community (for national or provincial organization - for other Canadians)?

i. What are your organization's best assets in working on or advocating on/about home care?

j. How has your organization responded to changes in home care policy since 1990 ?

3. Organization's collaboration with other interests (peers) sharing a home care associational system:

a. Is your organization a member of an umbrella association on the issue of home care?

i. If not, the following questions would relate to your operations of your peer organizations working in the area of home care.

b. How would you describe the mission capacity and/or operations of an umbrella or key association (or peers) in shaping home care public policy?

c. What processes does this organization use to shape public opinion about home care?

i. Does it consult-on problem definition, on solutions, or both, or none-with government?

ii. Are consultations regular through the policy development process? 
d. How well does this umbrella organization represent your organization on/about home care public policy?

i. How close is the match between its views and the views of your organization on home care?

e. Does the umbrella association enjoy a strong membership, good communication and relations with other peer organizations on home care?

f. Is there a membership fee to being a member of the umbrella association?

g. What are the incentives for participating/aligning with the umbrella association?

h. How might external supports, e.g., legislative, professional regulatory, etc., facilitate the role of the umbrella association in any phase of home care public policy?

i. How would you describe the impediments facing the umbrella or key association on policy-making on home care?

\section{Assessment of other interests in the home care policy community:}

Begin by describing who the other interests in the policy community might be: private for-profit interests; nursing or medical-professional, government. The questions here are quite broad.

a. Please describe, if possible, the activities of other competing interests in shaping home care public policy (from problem definition, to recommending solutions or to providing services).

b. What is your relationship with these other groups?

c. How closely do the views, priorities and approaches of these other groups match those of your organization on/about home care?

d. How might supports, like Acts, professional regulations, etc., enhance the role of these other groups in any phase of home care public policy?

e. How would you describe the impediments facing these other groups on policy-making on home care? 


\section{Assessment of the home care policy community:}

Define policy community: "A policy community includes all of the societal interests and government bureaucracies active within a policy sector... The [policy community's] sub-government includes the ... members that are most important; ... 'mak[ing] policy in the given field'... The attentive public includes less powerful groups and bureaucracies, as well as interested media representatives, academics, etc. It 'attempts to influence policy, but does not participate in policy-making on a regular basis" (Haddow 1999, p. 506).

a. How would you describe the effectiveness of the home care "policy community" to develop-shape public policy on home care?

i. What might enhance its effectiveness?

ii. How closely does the policy community work with citizens?

iii. How effective are the working relations, including communication, within and among the policy community members?

iv. How effective is the policy community in shaping individual / societal preferences for home care services?

v. Do any groups appear to be more effective? Please explain.

vi. Please describe any factor(s) that may possibly limit the degree of influence. 


\section{APPENDIX 'C' - INTERVIEW TOOL USED WITH PROVINCIAL-FEDERAL GOVERNMENT OFFICIALS}

\section{The Ministry's Role in Home Care}

a. How would you describe the Ministry's role in the delivery of home care services? (Is the role clear?)

b. Is this role consistent with and supportive of its overall health mandate?

i. How does it fit with the Ministry's overall mandate?

c. How does it balance / address issues of quality, equity and access?

d. What are the Ministries priorities for home care?

\section{Information, issue framing and consultation:}

a. How does the Ministry generate information - technical or otherwise - in satisfying its mandate on home care?

i. Where (level) does the responsibility for information gathering reside?

(1) What type of information is gathered?

ii. Does the Ministry have in-house capacity to evaluate and use information?

b. Does it consult regularly throughout the public policy process?

i. How does it select who it consults with?

(1) Is there a relation between the group(s) met and the particular phase of public policy that is being worked on?

(2) Does it include outsiders regarding jurisdiction?

ii. What consultative tools would be used?

iii. How does long term policy planning occur and who would most likely participate?

iv. Would participation to planning occur for groups in terms of their knowledge-authority on home care?

c. How might institutional structures enhance the consultative process for some groups (providing them with more opportunities to frame issues and access resources)?

d. How does the Ministry consult with other jurisdictions - levels of government; Ministries - over home care.

i. Which ones?

ii. How would you describe the working relationship between the Ministry and these other jurisdictions on home care?

iii. How might decisions vary by jurisdiction? 
e. How does feedback occur with respect to the consultation process and societal groups?

\section{Assessing public needs for home care:}

a. How does the Ministry discern the needs, wants and opinions of the public for home care?

b. What has been the Ministry's main focus regarding home care since the early 1990 s?

c. During consultations or ad hoc communications with the public, what have emerged as the key issues/priorities?

d. How does the Ministry respond to these communications?

4. Concentration of decision-making and Degree of state autonomy:

a. Which officials are the ultimate (or local) policy- and decision-makers on home care (please describe the level and numbers of officials)?

b. Are you able to describe the involvement of the political executive in home care policy- and decision-making?

c. Are you able to describe the relationships between the political executive and public servants over home care?

d. How closely aligned is the Ministry's functional mandate on home care with the mandate of others in society like home care providers and researchers?

e. How does the Ministry balance/juggle the needs of home care with the needs of providers, researchers, and broader society?

i. How does juggling occur with respect to other health needs, e.g., acute care?

f. How much negotiation does the Ministry accept (engage in) in the interpretation and implementation of home care at other levels?

i. Are rules, laws and regulations which define government's policies for home care consistently applied across communities and groups?

g. How might the Ministry define the narrow public interest for home care? i. The broader public interest? 


\section{APPENDIX 'D' - INTERVIEW TOOL USED WITH LOCAL GOVERNMENT OFFICIALS}

1. Information, issue framing and consultation:

a. How does local government generate its own information, technical or otherwise, required for the pursuit of its mandate on home support and acute home care?

i. Where does the responsibility for information gathering reside?

ii. How does it gather information?

iii. What type of information is gathered?

iv. Does it have in-house capacity to evaluate and use information?

2. Assessing public needs for home care:

a. How does local government discern local needs, wants and opinions on/about home care?

b. How does it describe the home care issue since the early 1990 s?

c. Which local groups are consulted?

i. How are groups selected?

d. How does it consult with other jurisdictions?

i. Which ones?

ii. How would you describe the working relationship between local government and other jurisdictions on home care?

iii. How might decisions vary by jurisdiction?

iv. How does feedback occur with respect to the consultation process?

e. Is critical information dispersed among a large group of officials and/or associations within the sector? If yes,

i. Which groups liaise with government on informational and policy issues?

f. How might institutional structures enhance the consultative process for some groups?

\section{Concentration of decision-making:}

a. Who are the local policy- and decision-makers on home care?

b. How have task forces, coordinating committees, or work liaison groups 
been used to examine home care as a local issue?

i. How does long-term planning take place?

ii. Who participates?

(1) How are groups chosen?

\section{Degree of local autonomy:}

a. Does local government have a clear notion of its role on home care?

b. Is there strong local-political support for local government's role here?

c. How do bureaucrats and elected representatives cooperate?

d. How would you describe the professional approach of the bureaucrats of local government?

e. How closely aligned is local government's functional mandate on home care with that of others in society like home care providers and researchers?

f. How does this government balance/juggle the needs of home care, with the needs articulated by providers, researchers and the broader public?

g. How much negotiation is there in the interpretation and implementation of home care at this level of government?

i. How are rules, laws and regulations interpreted and applied? 


\section{APPENDIX 'E' - INTERVIEW TOOL USED WITH PRIVATE FOR-PROFIT GROUPS}

\section{Organization's basic information:}

a. What is the mission or purpose of your organization?

b. How would you describe the historical consistency of this mission?

c. Please describe the practices relating to the appointment of your organization's Board.

i. Do members receive an honorarium or salary?

d. How is your organization registered with the Canada Revenue Agency?

2. Organization's knowledge, involvement, and capacity to shape home care public policy, including its views on policy:

a. How would you describe the main function(s) of your organization in the area of home care and home care public policy, for the period since 1990 ?

i. Does it have other objectives, targets or priorities for home care?

b. Your organization's influence on home care public policy and opinion:

i. Specifically: who in your organization is responsible for public policy development?

ii. What resources are devoted to public policy development?

iii. What actually does the organization do?

Here: Optional questions depending upon previous answers

c. How does your organization define public policy?

$i$. How would it describe the phases of public policy development?

ii. $\quad$ Would it consider service provision as public policy?

iii. What is the role of civil society in public policy?

d. Please describe how internal constraints affect your organization's participation in any aspect of public policy on home care.

e. Please describe how external constraints affect your organization's participation in any aspect of public policy on home care.

f. How would you describe your organization's relationships with the provincial Ministry of Health, and/or any other level of government on the 
issue of home care?

i. Have you had consultations-on problem definition, on solutions, or both, or none-with government?

ii. Have consultations been regular through the policy development process?

iii. Have you received feedback?

g. How would you describe the match between your organization's priorities and those of government for/on home care?

h. How would you describe the match between your organization's priorities and those of your home care community - e.g., for your city or province?

i. How do you discern the priorities for the residents of this community?

i. What are your organization's best assets in working on or advocating on/about home care?

j. How has your organization responded to changes in home care policy since 1990 ?

3. Organization's collaboration with other interests (peers) sharing a home care associational system:

a. Is your organization a member of an umbrella association on the issue of home care?

b. How would you describe the mission capacity and/or operations of this umbrella association in shaping home care public policy?

c. What processes does this organization use to shape public opinion about home care?

i. Does it consult-on problem definition, on solutions, or both, or none-with government?

ii. Are consultations regular through the policy development process?

d. How well does this umbrella organization represent your organization on/about home care public policy?

i. How close is the match between its views and the views of your organization on home care?

e. Does the umbrella association enjoy a strong membership, good communication and relations with other peer organizations on home care? 
f. Is there a membership fee to being a member of the umbrella association?

g. What are the incentives for participating/aligning with the umbrella association?

h. How might external supports, e.g., legislative, professional regulatory, etc., facilitate the role of the umbrella association in any phase of home care public policy?

i. How would you describe the impediments facing the umbrella or key association on policy-making on home care?

4. Assessment of other interests in the home care policy community:

Begin by describing who the other interests in the policy community might be: non-profit interests; nursing or medical-professional, government. The questions here are quite broad.

a. Please describe, if possible, the activities of other competing interests in shaping home care public policy (from problem definition, to recommending solutions or to providing services).

b. What is your relationship with these other groups?

c. How closely do the views, priorities and approaches of these other groups match those of your organization on/about home care?

d. How might supports, like Acts, professional regulations, etc., enhance the role of these other groups in any phase of home care public policy?

e. How would you describe the impediments facing these other groups on policy-making on home care?

5. Assessment of the home care policy community:

Define policy community: "A policy community includes all of the societal interests and government bureaucracies active within a policy sector... The [policy community's] sub-government includes the ... members that are most important; ... 'mak[ing] policy in the given field'... The attentive public includes less powerful groups and bureaucracies, as well as interested media representatives, academics, etc. It 'attempts to influence policy, but does not 
participate in policy-making on a regular basis"" (Haddow 1999, p. 506).

a. How would you describe the effectiveness of the home care "policy community" to develop-shape public policy on home care?

i. What might enhance its effectiveness?

ii. How closely does the policy community work with citizens?

iii. How effective are the working relations, including communication, within and among the policy community members?

b. How effective is the policy community in shaping individual / societal preferences for home care services?

i. Do any groups appear to be more effective? Please explain.

c. Please describe any factor(s) that may possibly limit the degree of influence with government and the public by any member of the policy community? 


\section{BIBLIOGRAPHY}

Abelson, Julia, Sara Tedford Gold, Christel Woodward, Denise O'Connor, Brian Hutchison. 2004. "Managing under managed community care: the experiences of clients, providers and managers in Ontario's competitive home care sector." Health Policy 68, no. 3: 359-372.

Agency, Canada Revenue. 2007 a. Income Tax Guide to the Non-Profit Organization (NPO) Information Return. Government of Canada. http://www.craarc.gc.ca/E/pub/tg/t4117/t4117-e.html\#P65_1095. [cited March 2, 2007].

Agency, Canada Revenue. 2007 b. Charities Directorate. Government of Canada. http://www.cra-arc.gc.ca/tax/charities/menu-e.html. [cited March 2, 2007].

Agency, Canada Revenue. 2006. Guidelines for Registering a Charity: Meeting the Public Benefit Test. Government of Canada. http://www.craarc.gc.ca/tax/charities/policy/cps/cps-024-e.html. [cited May 9, 2006] .

Agency, Canada Revenue. 2005. Registered Charities Newsletter, No. 22, Spring 2005. Government of Canada.

http://www.cra-arc.gc.ca/E/pub/tg/charitiesnews-22/charitiesnews-22-e.html\#P13 0 5377. [cited March 8, 2005].

Agency, Canada Revenue. 2003. Policy Statement: Political Activities. Government of Canada. http://www.cra-arc.gc.ca/tax/charities/policy/cps/cps-022-e.html. [cited May 92006$]$.

Alberta, Government of Alberta. 2003. "Public Health Act: Coordinated Home Care Program Regulation.” Alberta Regulation 296/2003. Edmonton: Alberta Queen's Printer.

Alberta, Government of Alberta. 1994. Regional Health Authorities Act. CR-9.07 s29. (Assented to June 24, 1994. Amendments January 1, 1995, March 31, 1995, April 5, 1995, March 31, 1996) Alberta Legislature. http://www.gov.ab.ca/qp/ascii/Acts/WPD/R09P07.TXT. [cited May 17 2001].

Alberta, Provincial Health Authority of. 2000 a. "Health Care Employers Key Contacts and Information for Human Resource Practitioners", ed. Janice Kuzyk. Edmonton: Provincial Health Authority of Alberta, pp. 46.

Alberta, Government of Alberta. 2001. "Public Health Act: Application in Respect of Regional Health Authorities Regulation." Alberta Regulation 164/1995. Edmonton: Alberta Queen's Printer.

Anderson, Malcolm, Janice Keefe, Karen Parent and Patricia Conrad. "Technical Report 2: The Public-Private Split in Continuing Care - Case Studies of Nova Scotia and Alberta." Federal-Provincial-Territorial Advisory Committee on Health Services (ACHS) Working Group on Continuing Care, pp. 54.

Angus, Douglas E., Ludwig Auer, J. Eden Cloutier and Terry Albert. 1995. Sustainable Health Care For Canada. Ottawa: Queen's-University of Ottawa Economic Projects, pp. 146.

Appleton, Barry. 1999. "International agreements and National Health Plans: NAFTA." In ed., Daniel Drache and Terry Sullivan, Health Reform: Public Success, Private Failure. New York: Routledge, 1999, pp. 87-104. 
Armstrong, Hugh. 2001. "Social Cohesion and Privatization in Canadian Health Care." Canadian Journal of Law and Society 16, no. No. 2: 65-81.

Armstrong, Hugh and Pat Armstrong. 1996. Wasting Away. Toronto: Oxford University Press, pp. 245.

Armstrong, Pat, Hugh Armstrong, Colleen Fuller and Canadian Health Coalition. 2000. "Heatlh Care, Limited: The Privatization of Medicare." Ottawa: Canadian Centre for Policy Alternatives, pp. 43.

Armstrong, Pat. 2002 a. "A Women's Guide to Health Care Debates." The Canadian Women's Health Network, pp. 3 of 11.

Arnstein, Sherry. 1969. "A Ladder of Citizen Participation." American Institute of Planners Journal 35, no. July: 216-224.

Aronson, Jane, Margaret Denton and Isik Zeytinoglu. 2004. "Market-Modelled Home Care in Ontario: Deteriorating Working Conditions and Dwindling Community Capacity." Canadian Public Policy 30, no. No. 1: 111-125.

Association, Canadian Home Care. 2003. "Portraits of Home Care: A Picture of Progress and Innovation." Ottawa: Canadian Home Care Association, pp. 10.

Atkinson, Michael and William D. Coleman. 1996. "Policy Networks, Policy Communities and the Problems of Governance." In ed. Michael Howlett Laurent Dobuzinskis, David Laycock, Policy Studies in Canada: The State of the Art. Toronto: University of Toronto Press, pp. 193-218.

Aucoin, Peter. 1995. the/ new public management: CANADA in Comparative Perspective. Montreal: Institute for Research on Public Policy (IRPP), pp. 274.

Auditor General of Ontario, Provincial. 2004. 2004 Annual Report of the Office of the Provincial Auditor of Ontario. http://www.auditor.on.ca/en/home_act_en.htm. [cited February 20 2007].

Auditor General of Ontario, Provincial. 1998. Long-Term Care Community Based Services Activity. http://www.auditor.on.ca/en/reports_health_en.htm. [cited June 19 2006].

Auer, Ludwig, Douglas E. Angus, J. Eden Cloutier and Janet Comis. 1995. "CostEffectiveness of Canadian Health Care." Queen's-University of Ottawa Economic Projects, 290. Ottawa: University of Ottawa, pp. 290.

Bachrach, Peter and Morton S. Baratz. 1962. "Two Faces of Power." American Political Science Review LVI, December: 947-952.

Ballinger, Geoff, Jingbo Zhang and Vern Hicks. 2001. "Home Care Estimates in National Health Expenditures." Ottawa: Canadian Institute for Health Information, pp. 26, plus appendices.

Baranek, P., Raisa Deber and A. Paul Williams. 1999 a. "Long-Term Care Diversity within the Care Continuum." Canadian Public Administration 42 (1 Spring): 6992.

Baranek, P., Raisa Deber and A. Paul Williams. 1999 b. "Policy trade-offs in "home care': the Ontario example." Canadian Public Administration 42(No. 1 Spring): 69-92.

Baranek, Patricia, Raisa Deber and A. Paul Williams. 2004. "Chapters 6 through 8." In Almost Home: Reforming Home and Community Care in Ontario. Toronto: University of Toronto Press, pp. 148-300. 
Barber, Katherine Ed. 1998. The Canadian Oxford Dictionary. Toronto: Oxford University Press.

Barer, Morris, Robert G. Evans and Clyde Hertzman. 1995. "Avalanche or Glacier?: Health Care and the Demographic Rhetoric." Canadian Journal on Aging 14, no. 2: 193-224.

Berger, Peter L. and Richard J. Neuhaus. 2001. "To Empower People: The Role of Mediating Structures in Public Policy." In ed. J. Steven Ott, The Nature of the Non Profit Sector. Boulder, Col.: Westview press, pp. 241-250.

Berta, Whitney, Audrey Laporte and Vivian Vaidmanis. 2005. "Observations on Institutional Long-Term Care in Ontario: 1996-2002." Canadian Journal on Aging 24, no. 1: 71-84.

Black, Charlyn, Noralou P. Roos, Betty Havens and Leonard MacWilliam. 1995. "Rising Use of Physician Services by the Elderly: The Contribution of Morbidity." Canadian Journal on Aging 14, no. 2: 225-244.

Blair, Carol. 1999. "Summary of Consultations With Public." KPMG Report. Edmonton: Alberta Health and Wellness, pp. 38.

Boase, Joan Price. 1996. "Institutions, Institutionalized Networks and Policy Choices: Health Policy in the US and Canada." Governance: An International Journal of Policy and Administration 9, no. 3, July: 287-310.

Boase, Joan Price. 1994. Shifting Sands. In ed. Iain Glow and Paul Pross, Canadian Public Administration Series. Montreal \& Kingston: Mc-Gill-Queen's University Press.

Boyne, George A. 1998. "Competitive Tendering in Local Government: A Review of Theory and Evidence." Public Administration 76, no. Winter: 695-712.

Broda, Dave and Alberta Health and Wellness. 1999 a. Healthy Aging: New Directions for Care. Part One: Overview. Edmonton: Government of Alberta.

Broda, Dave and Alberta Health and Wellness. 1999 b. Healthy Aging: New Directions for Care. Part Two: Listening \& Learning. Edmonton: Government of Alberta.

Broda, Dave and Alberta Health and Wellness. 1999 c. Healthy Aging: New Directions for Care. Part Three: Implementing New Directions. Edmonton: Government of Alberta.

Brooks, Arthur C. 2002. "Does Civil Society Stop the Downward Spiral of Bad Government or Speed It Up?." Nonprofit and Voluntary Sector Quarterly 31, No. 1, no. March: 140-144.

Browdie, Richard and Adrian Turwoski. 1986. "The Problems of Providing Services to the Elderly in Their Own Homes." In ed. Anabel O. Pelham and William F. Clark, Managing Home Care for the Elderly. New York: Managing Home Care for the Elderly, pp. 15.

Brown, David L. and Archana Kalegaonkar. 2002. "Support Organizations and the Evolution of the NGO Sector." Nonprofit and Voluntary Sector Quarterly 31, No. 2, no. June: 231-258.

Burawoy, Michael. 1998. "The Extended Case Method." Sociological Theory 16, no. No. 1, March: pp. 4-33. 
Canada, Health Canada. 2003 b. 2003 First Ministers' Accord on Health Care Renewal. Ottawa: Health Canada. http://www.hc-sc.gc.ca/hcs-sss/deliveryprestation/fptcollab/2003accord/index_e.html. [cited April 3, 2006].

Canada, Health Canada. 2002. Canada Health and Social Transfer. Government of Canada. http://www.hc-sc.gc.ca/ahc-asc/media/nr-cp/2002/2002_caresoinsbk5_e.html. [cited April 3, 2006].

Canada, Health Canada. 2004 a. Pan-Canadian Health Human Resource Strategy Government of Canada. http://www.hc-sc.gc.ca/hsc-sss/hhr-rhs/strateg/ar-ra2005/comp-act_e.html. [cited April 29, 2007].

Canada, Health Canada. 2004 b. First Minister's Meeting on the Future of Health Care 2004 Government of Canada. http://www.hc-sc.gc.ca/hcs-sss/deliveryprestation/fptcollab/2004-fmm-rpm/index_e.html. [cited April 29, 2007].

Canada, Health Canada. 1999 a. Home Care in Canada 1999: An Overview. Health Canada. http://www.hc-sc.gc.ca/homecare/english/profil.html. [cited January 20, 2003].

Canada, Health Canada. 1999 b. "Provincial and Territorial Home Care Programs: A Synthesis for Canada." Ottawa: Public Works and Government Services Canada, pp. 88.

Canada, Health Canada. 1999 c. "Report on the National Roundtable on Home and Community Care." Ottawa: Public Works and Government Services Canada, pp. 47. http://www.hc-sc.gc.ca/homecare/english/rt1.html.

Canada, Health Canada. 1998. "Public Home Care Expenditures in Canada 1975-76 to 1997-98." Ottawa: Government of Canada, pp. 4.

Canada, Statistics Canada. 2005. Annual Demographic Statistics 2005, catalogue 91$213 X P B C D-R o m$.

Canada, Statistics Canada. 2001 a. Census of Canada. Government of Canada. http://www12.statcan.ca/english/Profil01/CP01/Details/Page.cfm?Lang=E\&Geol $=$ CMA... [cited September 26 2006].

Canada, Statistics Canada. 2007. Portrait of the Canadian Population in 2006, by Age and Sex, 2006 Census. Catalogue no. 97-551-XIE. Ottawa: Ministry of Industry. Canada, Statistics Canada. 1976. "Census of Canada." Ottawa: Government of Canada.

Caplan, Elinor. 2005. "Realizing the Potential of Home Care." Toronto: CCAC Procurement Review, pp. 90.

Carnwath, Lianne. 2004. "Operational Review of the Ottawa Community Care Access Centre (OCCAC)". Ottawa: Ministry of Health and Long Term Care, pp. 126.

Carson, Emmett D. 2002. "Public Expectations and Nonprofit Sector Realities: A Growing Divide With Disastrous Consequences." Nonprofit and Voluntary Sector Quarterly 31, No. 3, no. September: 429-436.

CHCA, Canadian Health Care Association. 1999. "Funding Canada's Healthcare System". Ottawa: Canadian Health Care Association, pp. 63.

CHSRF, Canadian Health Services Research Foundation. 2002. "Homecare in Canada." Ottawa: Commission on the Future of Health Care in Canada, pp. 13.

CIHI, Canadian Institute for Health Information. 2005. National Health Expenditure Trends 1975-2005. Ottawa, Ontario: Canadian Institute for Health Information. 
Clark, William and Anabel O. Pelham. 1986. "Social Policy Implications of the Community-Based Long-Term Care Experience." In ed. Anabel O. Pelham and William F. Clark, Managing Home Care for the Elderly. New York: Springer Publishing Company, pp. 159-189.

Clarke, Egerton. 2001. Aging and Caregiving in Canada. Queenston: The Edwin Mellen Press, pp. 340.

Clement, Wallace. 1997. "Introduction: Whither the New Canadian Political Economy." In ed. Wallace Clement, Understanding Canada: Building on the New Canadian Political Economy. Montreal \& Kingston: McGill-Queen's University Press, pp. 3-18.

Cloutier-Fisher, D., \& A.E. Joseph. 2000. "Long-term care restructuring in rural Ontario: Retrieving community service user and provider narratives." Social Science and Medicine 50: 1037-1045.

Cloutier-Fisher, Denise and Mark W. Skinner. 2006. "Levelling the playing field? Exploring the implications of managed competition for voluntary sector providers of long-term care in small town Ontario." Health \& Place 12: 97-109.

Coalition, Ontario Health. 2004. A CLOSER LOOK Homecare Ontario Health Coalition. http://www.ontariohealthcoalition.ca. [cited 2005].

Coalition, Ottawa Community Support. "Help for Seniors Living at Home". Ottawa: Ottawa Community Support Coalition, Undated.

Commission, Health Services Restructuring. 1999. "Implementing Integrated Health Systems In Ontario: A Review of Legislative / Regulatory Implications." Ottawa: Health Services Restructuring Commission, pp. 34.

Commission, Health Services Restructuring. 2000. "Looking Back, Looking Forward: A Legacy Report." Ottawa: Canadian Health Services Research Foundation, pp. 208.

Communications, Director of. 1999. Major Reorganization Positions Government for the 21st Century. Government of Alberta. http://www.gov.ab.ca/acn/199905/7709.html. [cited September 1 2006].

Connects, Alberta. 2006. Email message to author, August 30.

Consulting, PWC. 2002. "Ottawa Community Care Access Centre: Baseline Assessment." Ottawa: Ottawa Community Care Access Centre, pp. 74.

Council, Champlain District Health. 2003. "Annual District Service Plan For LongTerm Care Community Support Services (2002)." Ottawa: Champlain District Health Council, pp. 413.

Council on Aging, Council on Aging of Ottawa. 2004. Fact Book on Aging. Ottawa: The Council on Aging of Ottawa.

Dawson, Anne and Mark Kennedy. 2004. "PM, premiers reach health deal." Ottawa Citizen, Thursday, September 16, pp. A1, A4.

Deber, Raisa B., A. Paul Williams. 1995. "Policy, Payment, and Participation: LongTerm Care Reform in Ontario." Canadian Journal on Aging 14, no. No. 2: 294318.

Deber, Raisa and Bill Swan. 1999. "Canadian health expenditures: Where do we really stand internationally?" Journal of the Canadian Medical Association 160, no. 12, June 15: 1730-1734. 
Denton, Frank T. and Byron G. Spencer. 1995. "Demographic Change and the Cost of Publicly Funded Health Care." Canadian Journal on Aging 14, no. 2: 174-192.

Denton, Margaret, Isik Urla Zeytinoglu, Sharon Webb and Jason Lian. 1999. "Occupational Health Issues Among Employees of Home Care Agencies." Canadian Journal on Aging 18, no. No. 2: 154-181.

Di Matteo, Livio and Rosanna Di Matteo. 2001. "Public Homecare Expenditures in Canada." Canadian Public Policy 17, no. 3: 313-333.

Doern, Bruce G. and Richard W. Phidd. 1992. "Process 1: The General Policy Process." In Canadian Public Policy: Ideas, Structure, Process, 82-94. Scarborough, Ontario: Nelson Canada.

Donaldson, Cam and Karen Gerard. 1993. Economics of Health Care Financing: The Visible Hand. First ed. New York: St. Martin's Press.

Doran, D., Jennie Pickard, Janet Harris, Peter C. Coyte, Andrew MacRae, Heather Laschinger, Gerarda Darlington, Jennifer Carryer. 2002. "Competitive Bidding for Community-Based Nursing Services: Report of Phase 1, Community Nursing Services Study." Toronto: University of Toronto, pp. 29.

Douglas, James. 1987. "Political Theories of Nonprofit Organization." In ed. Walter W. Powell, The Nonprofit Sector: A Research Handbook. New Haven, Ma.: Yale University Press, pp. 43-54.

Douglas, James. 2001. "Political Theories of Nonprofit Organization." In ed. J. Steven Ott, The Nature of the Non Profit Sector. Boulder, Col.: Westview Press, pp. $205-$ 216.

Dunn, Fred J., Auditor General. 2005. "Report of the Auditor General on Seniors Care and Programs." Edmonton: Auditor General Alberta, pp. 97.

Edmonton Seniors Coordinating Council. "Meet ESCC - Our Vision \& Our Mission." Http://www.seniorscouncil.net/content.php?id=16.

Eisenberg, Pablo. 2000. "The Nonprofit Sector in a Changing World." Nonprofit and Voluntary Sector Quarterly 29, No. 2, no. June: 325-330.

Employees, National Union of Public and General. 2004. Corrupt, cozy review scheduled for Ottawa CCAC: Voices of home care users and caregivers will not be heard National Union of Public and General Employees, April 16. http://www.nupge.ca/news_2004/n16ap04b.htm. [cited August 23 2005].

Employees, National Union of Public and General. 2005. Ontario's competitive bidding process is a mess National Union of Public and General Employees, April 1. http://www.nupge.ca/news_2004/n16ap04b.htm. [cited August 23 2005].

Evans, Robert. 1997. "Going for the Gold: The Redistributive Agenda behind MarketBased Health Care Reform." Journal of Health Politics, Policy and Law 22, no. No. 2, April: 427-465.

Evans, Robert. 1993. "Health Care Reform: "The Issue from Hell'." Policy Options July-August: $35-41$.

Evans, Robert. 1984. Strained Mercy. Vancouver: Butterworth \& Co.

Evans, Robert G., Morris L. Barer, Steven Lewis, Michael Rachlis and Greg L. Stoddart. 2000. "Private Highway, One-Way Street: The Deklein and Fall of Canadian Medicare?" Vancouver: University of British Columbia. 
Evans, Robert G. and Gregory L. Stoddart. 1990. "Pruducing Health, Consuming Health Care." Social Science and Medicine 31, no. No., 12: 1347-1363.

Evans, Robert G. and Maureen M. Law. 1995. "The Canadian Health Care System: Where Are We and How Did We Get Here?" In ed. David W. Dunlop and Jo. M. Martins, An International Assessment of Health Care Financing, Lessons for Developing Countries. Washington: The World Bank, pp. 79-113.

Fast, Janet, Norah Keating, Pam Otfinowski, and Linda Derksen. 2004. "Characteristics of Family/Friend Care Networks of Frail Seniors." Canadian Journal on Aging 23, no. 1: 5-19.

Finance, Ministry of. 1999. 1999 Ontario Budget: Paper B: Ontario's Fiscal Plan. Government of Ontario. http://www.fin.gov.on.ca/english/index.html. [cited November 11].

Finlayson, Marcia, Lisa Lix, Gregory Finlayson and Terry Fong. 2005. "Trends in the Utilization of Specific Health Care Services among Older Manitobans: 1985 to 2000." Canadian Journal on Aging 24, no. Supplement 1: 15-27.

Fooks, Cathy and Steven Lewis. 2002. "Romanow and Beyond: A Primer on Health Reform Issues in Canada." Ottawa: Canadian Policy Research Networks, pp. 25.

Forbes, William F., Jennifer A. Jackson and Arthur S. Kraus. 1987. Institutionalization of the Elderly In Canada. Toronto: Butterworths, A division of Reed Inc., pp. 148.

Force, Health System Integration Task. 2004. Ontario Health Providers Establish Task Force to Support System Integration and Provide Better Care. Toronto: Ministry of Health and Long-Term Care. http://www.oha.com/Client/OHA/OHA_LP4W_LND_WebStation.nsf/CD0BBBE 7B8237E... [cited November 2 2004].

Frank, Richard G., and David S. Salkever. 1994. "Nonprofit organizations in the health sector." Journal of Economic Perspectives 8, no. 4: 129-145.

Frankish, C. James, Brenda Kwan, Pamela A. Ratner, Joan Wharf Higgins and Craig Larsen. 2002. "Challenges of citizen participation in regional health authorities." Social Science and Medicine 54: 1471-1480.

Frumkin, Peter. 2002. On Being Nonprofit: A Conceptual Policy Primer. Cambridge, Ma.: Harvard University Press, pp. 213.

Garber, Ralph. 1991. "Epilogue." In ed. Lilian M. Wells, An Aging Population: The Challenge for Community Action. Toronto: Governing Council, University of Toronto.

Garland, Robert. 1979. "The Politics of Aging." In ed. Dermot Stewart, The Aged in Society. Saint John: Keystone Printing \& Lithographing Ltd., pp. 25-37.

Gassler, Robert Scott. 1986. The Economics of Nonprofit Enterprise: A Study in Applied Economic Theory. Lanham, MD: University Press of America, Inc.

Gassler, Robert Scott. 2003. "A Framework for Heterodox Economics." Paper presented at the Economics for the Future, Cambridge (UK), September 17-19.

Getty, Don. 1991. "Partners in Health: The Government of Alberta's Response to the Premier's Commission on Future Health Care For Albertans". Edmonton: Government of Alberta, pp. 76. 
Gramsci, Antonio. 1973. "The Study of Philosophy." In ed. Quinton Hoare and Geoffrey Nowell Smith, Selections from the Prison Notebooks of Antonio Gramsci. London: Unwin Brothers Limited, pp. 321-343.

Greaves, Lorraine, Olena Hankivsky, Georgia Livadiotakis and Renee Cormier. 2002. "Final Payments: Socioeconomic Costs of Palliative Home Caregiving." Centres of Excellence for Women's Health Research Bulletin, Spring, pp. 4-5.

Grønbjerg, Kirsten A. 2001. "Markets, Politics, and Charity: Nonprofits in the Political Economy." In ed. J. Steven Ott, The Nature of the Non Profit Sector. Boulder, Col.: Westview Press, pp. 217-231.

Gross, John and Cope W. Schwenger. 1981. Health Care Costs for the Elderly in Ontario: 1976-2026. Toronto: Ontario Economic Council.

Gruending, Dennis. 1985. Emmett Hall, Establishment Radical, Toronto: Macmillan of Canada, pp. 80-102, 209-221.

Haddow, Rodney. 1999. "Interest Representation and the Canadian State." In ed. Alain G. Gagnon, Canadian Politics. Peterborough: Broadview Press, pp. 501-522.

Hall, Michael and Keith G. Banting. 2000. "The Nonprofit Sector in Canada: An Introduction." In ed. Keith G. Banting, The Nonprofit Sector In Canada: Roles and Relationships. Kingston: Queen's University, School of Policy Studies, pp. 128.

Hansard, Ontario. 2002. Long-Term Care. Parliamentary Debates, Government of Ontario. http://hansardindex.ontla.on.ca/hansardetitle/37-3/1056a-11.html. [cited November 29 2005].

Hansard, Ontario. 1998. Long-Tern Care. Parliamentary Debates, Government of Ontario. http://hansardindex.ontla.on.ca/hansardetitle/36-2/1004a-41.html. [cited November 29 2005].

Hansmann, Henry. 1987. "Economic Theories of Nonprofit Organization." In Walter W. Powell, The Non Profit Sector. New Haven and London: Yale University Press, pp. 27-42.

Hansmann, Henry. 1980. "The Role of Nonprofit Enterprise." The Yale Law Journal 89, no. 5: 835-901.

Havens, Betty. 1986. "Boundary Crossing: An Organizational Challenge for Community-Based Long-Term Care Service Agencies." In eds. Anabel O. Pelham and William F. Clark, Managing Home Care for the Elderly. New York: Springer Publishing Company, pp. 77-98.

Havens, Betty. 1995. "Long-Term Care Diversity within the Care Continuum." Canadian Journal on Aging 14, no. No. 2: 245-262.

Health, Alberta. 1992. "Home Care in Alberta: New Directions in Community Support." Edmonton: Government of Alberta, pp. 36.

Health, Capital. 2004. "Annual Report 2003-2004." Edmonton: Capital Health, pp. 170. Health, Capital. 2007 a. Email message to author, March 6.

Health, National Forum on. 1997. An Overview of Women's Health National Forum on Health. http://www.hc-sc.gc.ca/hcs-sss/pubs/care-soins/1997-nfoh-fnssv2/legacy_heritage8_e.html. [cited April 21 2007]. 
Healthy Aging, Subgroup. 2002. "Alberta's Healthy Aging and Seniors Wellness Stratetic Framework 2002-2012". Edmonton: Alberta Health and Wellness, pp. 53.

Hébert, Réjan. 2002. "Research on Aging: Providing Evidence for Rescuing the Canadian Health Care System." Canadian Journal on Aging 21, no. 3: 343-347.

Hébert, Réjan, Nicole Dubuc, Martin Buteau, Johanne Desrosiers, Gina Bravo, Lise Trottier, Carole St-Hilaire and Chantale Roy. 2001. "Resources and Costs Associated with Disabilities of Elderly People Living at Home and in Institutions." Canadian Journal on Aging 20, no. 1: 1-21.

Hébert, Réjean. 2003. "Yes to Home Care, but Don't Forget Older Canadians." Canadian Journal on Aging 22, no. 1: 9-10.

Henderson, Karen. 2006. "Long term care planning: It's not just the old." The Caregiver. Caregiver Network Inc., pp. 1-2.

Herd, Pamela. 2005. "Universalism Without the Targeting: Privatizing the Old-Age Welfare State." The Gerontologist 45, no. 3: 292-298.

Hicks, Vern, Geoff Ballinger and Terry Campbell. 2000. "The Impact of Regionalization on National Health Expenditures". Ottawa: Canadian Institute for Health Information, pp. 14.

Hirst, Paul. 1994. Associative Democracy. Amherst: The University of Massachusetts Press.

Hollander, Marcus. 1994. "The Costs, and Cost-Effectiveness, of Continuing-Care Services in Canada". Ottawa: University of Ottawa, pp. 113.

Hollander, Marcus. 1999. "The Costs, and Cost-Effectiveness, of Continuing-Care Services in Canada." Ottawa: Health Transition Fund, Health Canada, pp. 67.

Hollander, Marcus. 2004. "Unfinished Business: The Case for Chronic Home Care Services, A Policy Paper." Victoria: Hollander Analytic Services Ltd., pp. 11.

Hossli, Walter J. 2000. Competition in the Voluntary Sector: The Case of CommunityBased Trainers in Alberta. Calgary: The Muttart Foundation.

Hudson, Alan. 2002. "Advocacy by UK-Based Development NGOs." Nonprofit and Voluntary Sector Quarterly 31, NO. 3, no. September: 402-418.

Hurley, Jeremiah, Jonathan Lomas and Vandna Bhatia. 1994. "When tinkering is not enough: provincial reform to manage health care resources." Canadian Public Administration 37, no. No. 3 (Fall): 490-514.

Hyndman, Lou. 1989 a. The Rainbow Report: Our Vision for Health. 3 vols. Vol. Volume 1. Edmonton: Premiers Commission on Future Health Care for Albertans.

Hyndman, Lou. 1989 b. The Rainbow Report: Our Vision for Health. 3 vols. Vol. Volume 2. Edmonton: Premiers Commission on Future Health Care for Albertans.

Hyndman, Lou. 1989 c. The Rainbow Report: Our Vision for Health. 3 vols. Vol. Volume 3. Edmonton: Premiers Commission on Future Health Care for Albertans.

Imagine Canada. 2006 a. "Recruitment and Retention of Paid Staff." National Survey of 
Nonprofit and Voluntary Organizations. Imagine Canada.

$\mathrm{http}: / / \mathrm{www}$. imaginecanada.ca/files/en/nsnvo/m_recruiting_retaining_staff_factshe et.pdf. [cited 2006].

Imagine Canada. 2006 b. "The Nonprofit and Voluntary Sector in Canada." National Survey of Nonprofit and Voluntary Organizations. Imagine Canada. http://www.imaginecanada.ca/files/en/nsnvo/sector_in_canada_factsheet.pdf. [cited 2006].

Jenkins, J. Craig. 1987. "Nonprofit Organizations and Policy Advocacy." In ed. Walter W. Powell, The Nonprofit Sector: A Research Handbook. New Haven, Ma.: Yale University Press, pp. 296-318.

Jessop, Bob. 1993. "Towards a Schumpeterian Workfare State" Preliminary Remarks on Post-Fordist Political Economy." Studies in Political Economy 40, Spring: 7-39.

Justice, Department of. 1984. Canada Health Act. Government of Canada. http://laws.justice.gc.ca/en/ShowFullDoc/cs/C-6///en. [cited January 20, 2003].

Keigher, Sharon M. 1999. "Feminist Lessons from the Gray Market in Personal Care for the Elderly; So What If You Have to Spend Your Own Money?" In ed. Sheila M. Neysmith, Critical Issues: for Future Social Work With Practice with Aging Persons. New York: Columbia University Press, pp. 155-186.

Laghi, Brian, Campbell Clark and Drew Fagan. 2004. "PM pulls out a deal." Globe and Mail, Thursday, September 16, pp. A1, A10.

Lalond, Marc. 1974. "A New Perspective on the Health of Canadians." Ottawa: Department of National Health and Welfare, pp. 76.

Langton, Stuart. 1987. "Envoi: Developing Nonprofit Theory". In eds. Susan A. Ostrander and Stuart Langton, Shifting the Debate: Public/Private Sector Relations in the Modern Welfare State. New Brunswick: Transaction Books, pp. 134-148.

Lesemann, Frédérick and Daphne Nahmiash. 1992 a. "Home-Based Care in Canada and Quebec: Informal and Formal Services." In eds. Frédérick Lesemann and Claude Martin, Home-Based Care, The Elderly, The Family, and the Welfare State: An International Comparison. Ottawa: University of Ottawa Press, pp. 81-99.

Lesemann, Frédérick and Claude Martin. 1992 b. "Problems and Limitations in International Comparisons." In eds. Frédérick Lesemann and Claude Martin, Home-Based Care, The Elderly, The Family, and the Welfare State: An International Comparison. Ottawa: University of Ottawa Press, pp. 252-271.

Lewis, S., William Blundell, Richard Cashin, Andre-Pierre Contandriopoulos, Robert Evans, Tom Noseworthu and Mrcel Saulnier. 1997. Canada Health Action: Building on the Legacy, National Forum on Health. http://www.hc-sc.gc.ca/hcssss/pubs/renewal-renouv/1997-nfoh-fnss-v2/legacy_heritage3... [cited June 20, 2007].

Lohmann, Roger A. 2001. "And Lettuce Is Nonanimal: Toward a Positive Economics of Voluntary Action." In ed. J. Steven Ott, The Nature of the Non Profit Sector. Boulder, Col.: Westview Press, pp. 197-204.

Lomas, Jonathan. 1999. "The evolution of devolution. What does the community want?." In eds. Daniel Drache and Terry Sullivan, Health Reform: Public Success, Private Failure. New York: Routledge, pp. 166-185. 
Lowry, Jean Ann. 2002. Why Having a National Home Care Program is a Women's Issue. The Canadian Women's Health Network Magazine, Spring/Summer. [cited 23/08/05].

Lukes, Steven. 1986. Power. New York: New York University Press.

MacNabb, Larry. 2002. "Do you know who your peers are? Health Region Peer Groups-Technical Document." Kingston, Ontario: Statistics Canada, pp. 14.

Madore, Odette. 2004. "The CANADA HEALTH ACT: Overview and Options." Ottawa: Parliamentary Research Branch, pp. 23.

Markle-Reid, Maureen, Robin Weir, Gina Browne, Sandra Henderson, Jacqueline Roberts and Amiram Gafni. 2003. "Frail Elderly Homecare Clients: The Costs and Effects of Adding Nursing Health Promotion and Preventive Care to Personal Support Services." Ottawa: Canadian Health Services Research Foundation, pp. 29.

Marzouk, M.S. 1991. "Aging, Age-Specific Health Care Costs and the Future Health Care Burden in Canada." Canadian Public Policy 17, no. 4: 490-506.

Maslove, A. M. 1995. National Goals and the Federal Role in Health Care. Ottawa, National Forum on Health, pp. 51.

Mason, Jennifer. 2000. Qualitative Researching. London: Sage Publications Ltd.

Maurier, Wendy and Herbert C. Northcott. 2000. Aging in Ontario: Diversity in the new Millenium. Calgary: Detselig Enterprises Ltd.

McAdam, Doug, John D. McCarthy and Mayer N. Zald. 1988. "Social Movements." In ed. Neil J. Smelser, Handbook of Sociology. Newbury Park, Ca.: Sage Publications, pp. 695-737.

McCamus, John D., Commission Chair. 1996. "Report on the Law of Charities." Toronto: Ontario Law Reform Commission, pp. 383.

McMaster, Geoff. 2005. Critics wary of health care recommendations Express News. http://www.expressnews.ualberta.ca/print.cfm?id=1681. [cited April 22 2005].

McQuaig. 1995. Shooting the HIPPO, Death by Deficit and Other Canadian Myths. Toronto: Viking.

Melucci, Alberto. 1985. "The Symbolic Challenge of Contemporary Movements." Social Research 52, no. No. 4, Winter: 789-816.

Mhatre, Sharmila and Raisa B. Deber. 1992. "From Equal Access to Health Care to Equitable Access to Health: A Review of Canadian Provincial Health Commissions and Reports." International Journal of Health Services 22, no. No. 4: 645-668.

Miles, Matthew B. and A. Michael Huberman. 1994. Qualitative Data Analysis. Thousand Oaks, Ca.: Sage Publications Inc., pp. 338.

Mimoto, H. and P. Cross. 1991. "The Growth of the Federal Debt." In Canadian Economic Observer. Ottawa: Statistics Canada, pp. 3.1 - 3.18.

Mirosh, Dianne and Lyle Oberg. 1993. "Starting Points: Recommendations for Creating A More Accountable and Affordable Health System." Edmonton: Alberta Health Planning Secretariat, pp. 53.

Mitchell, Lori, Noralou Roos and Evelyn Shapiro. 2005. "Patterns in Home Care Use in Manitoba." Canadian Journal on Aging 24, no. Supplement 1: 59-68.

Montigny, Edgar-André. 1997. Foisted upon the Government? State Responsibilities, 
Family Obligations, and the Care of the Dependent Aged in Late NineteenthCentury Ontario. Kingston: McGill-Queen's University Press, pp. 220.

Muhr, Thomas. 1997. ATLAS ti: The Knowledge Workbench. Short User's Manual. Berlin: Scientific Software Developments.

Musgrave, Richard A. 1959. "Chapter 1 A multiple theory of the public household." In The Theory of Public Finance. Toronto: McGraw-Hill, pp. 3-27.

Nahmiash, Daphne and Myrna Reis. 1992. "An Exploratory Study of Private Home Care Services in Canada." Ottawa: Health and Welfare Canada, pp. 63.

National Health and Welfare, Ministry of. 1977. "Review of the Literature on Home Care." Ottawa: Government of Canada, pp. 93.

Naylor, C. David. 1986. Private Practice, Public Payment. Kingston \& Montreal: McGill-Queen's University Press.

NCGHCRW, National Coordinating Group on Health Care Reform and Women. 2002. "Women and Home Care", pp. 16.

Network, The Support. 2004. Directory of Community Services: Edmonton and area's most comprehensive human services directory. Edmonton: The Support Network.

Neysmith, Sheila M., and Lilian Wells. 1991. "Home Care: Who Defines the Priorities." In ed. Lilian M. Wells, An Aging Population: The Challenge for Community Action. Toronto: Governing Council, University of Toronto, pp. 96-107.

Neysmith, Sheila M. 1997. "Towards a Woman-Friendly Long-Term Care Policy." In eds. Patricia M. Evans and Gerda R. Wekerle, Women and the Canadian Welfare State. Toronto: University of Toronto Press, pp. 222-245.

Neysmith, Sheila and Margaret Macadam. 1999. "Controversial Concepts." In ed. Sheila M. Neysmith, Critical Issues: for Future Social Work With Practice with Aging Persons. New York: Columbia University Press, pp. 1-26.

Nodice. 2004. Alberta Provincial Election 2004. http://www.nodice.ca/elections/alberta/results.php. [cited April 12 2005].

Nordlinger, Eric A. 1981. On the Autonomy of the Democratic State. London: Harvard University Press.

Northcott, Herbert C. 1997. Aging in Alberta. Calgary: Detselig Enterprises Ltd.

Northcott, Herbert C. 1990. "Aging in Alberta: Rhetorics and Realities." Edmonton: Alberta Health, pp. 7.

O'Brien, Kathy. 2002. Government Increases its Control Over CCACs. http://www.casselsbrock.com/publicationdetail.asp?aid=510\&pid=16. [cited August 23 2005].

O'Connor, Deborah. 1999. "Constructing Community Care." In Critical Issues: for Future Social Work With Practice with Aging Persons. New York: Columbia University Press, pp. 71-96.

Ontario, Government of Ontario. 2006 a. Local Health Integration Networks: Building a True System. Toronto: Ministry of Health and Long-Term Care. http://www.health.gov.on.ca/english/public/legislation/lhins/hu_lhins.html. [cited April 13 2007].

Ontario, Government of Ontario. 2006 b. Choosing quality, rewarding excellence: Ontario's response to the Caplan report on home care. Toronto: Ministry of Health and Long-Term Care. http://www.health.gov.on.ca/english/public/pub/ 
ministry_reports/caplanresp06/caplanres... [cited May 4 2006].

Ontario, Legislative Assembly of Ontario. 2006 c. Legislative Assembly of Ontario. http://www.ontla.on.ca/web/home.do. [cited June 14 2006].

Ontario, Government of Ontario. 2004. McGuinty Government Announces New Chair of Ottawa Community Care Access Centre. Toronto: Ministry of Health and LongTerm Care. Ontario Queen's Printer. http://ogov.newswire.ca/ontario/GPOE/ 2004/09/03/c6510.html?lmatch=\&lang=_e.html. [cited November 2 2004].

Ontario, Government of Ontario. 2003. McGuinty government makes a record investment in home care services. Toronto. Ministry of Health and Long-Term Care. Queen's Printer for Ontario, July 5.

http://ogov.newswire.ca/ontario/GPOE/2004/07/05

/c0412.html?lmatch=\&lang=_e.html. [cited November 2 2004].

Ontario, Legislative Assembly of Ontario. 1996. Government Process Simplification Act. Ontario Legislature.

http://www.ontla.on.ca/documents/bills/36_parliament/session1/G96067e.htm. [cited June 20 2006].

Ontario, Legislative Assembly of Ontario. 2001. An Act Respecting Community Care Access Corporations. Ontario Legislature, December 14. http://www.elaws.gov.on.ca/DBLaws/Source/Statutes/English/2001/S01033_e.htm. [cited August 5 2005].

OPSEU, Ontario Public Services Employees Union. 2004 a. Loss of VON dramatically affects care OPSEU online, July 13. http://www.opseu.org/campaign/von/ vonindex.htm. [cited August 23 2005].

OPSEU, Ontario Public Services Employees Union. 2004 b. Niagara home care patients face uncertainty during transition to new providers OPSEU online, August 27. http://www.opseu.org/news/Press2004/aug272004.htm. [cited August 23 2005].

OPSEU, Ontario Public Services Employees Union. 2004 c. Niagara CCAC acted in bad faith in awarding of contract OPSEU online, August 30. http://www.opseu.org/ news/Press2004/aug302004.htm. [cited August 23 2005].

Ott, J. Steven. 2001. "The Nonprofit Sector's Distinctive Values and Contributions to Society." In ed. J. Steven Ott, The Nature of the Nonprofit Sector. Boulder: Westview Press, pp. 47-56.

Ottawa, Community Information Centre of. 2001. Directory of Ottawa Community Services. Ottawa: Community Information Centre of Ottawa.

Pal, Leslie A. 1987. Public Policy Analysis: An Introduction. Toronto: Methuen Publications.

Paquet, Bernard. 2002. "Low Income Cutoffs from 1992 to 2001 and Low Income Measures from 1991 to 2000." Ottawa: Statistics Canada, pp. 55.

Payne, Barbara J., Karen R. Grant, Cheryl Christian. 2002. "Blurring the Boundaries: Women's Caring Work and Manitoba Health Care Reform." Centres of Excellence for Women's Health Research Bulletin, Spring:11-13.

Philippon, Donald and Sheila A. Wasylyshyn. 1996. "Health-care reform in Alberta." Canadian Public Administration 39, no. No. 1 (Spring): 70-84. 
Phillips, Susan D. and Katherine A. Graham. 2000. "Hand-in-Hand: When Accountability Meets Collaboration in the Voluntary SEctor." In ed. Keith G. Banting, The Nonprofit Sector in Canada: Roles and Relationships. Kingston: Queen's University, School of Policy Studies, pp. 149-190.

Pierson, Paul. 1995. "Fragmented Welfare States: Federal Instutions and the Development of Social Policy." Governance 8, no. No. 4, October: 449-478.

Progressive Conservative Party, of Ontario. 1994. The Common Sense Revolution Progressive Party of Ontario. http://www.ontariopc.com/feature/csr_text.htm. [cited December 5 2005].

Puscas, D. and Tony Clarke. 2002. "Waiting in the Wings! How for-profit health corporations are planning to cash-in on the privatization of Medicare in Canada" Ottawa: Polaris Institute.

Rachlis, Michael, Robert G. Evans, Patrick Lewis and Morris L. Barer. 2001. "Revitalizing Medicare: Shared Problems, Public Solutions." Vancouver: Tommy Douglas Research Institute, pp. 51.

Rekart, Josephine. 1993. Public Funds, Private Provision: The Role of the Voluntary Sector. Vancouver: UBC Press, pp. 194.

Rice, James and Michael Prince. 2000. Changing Politics of Canadian Social Policy. Toronto: University of Toronto Press, pp. 309.

Ridler, Neil B. 1979. "Will Canada be Able to Support its Elderly?" In ed. Dermot Stewart, The Aged in Society. Saint John: Keystone Printing \& Lithographing Ltd., pp. 6-16.

Romanow, Roy J., Q.C. 2002. "Building on Values, The Future of Health Care in Canada." Saskatoon: Government of Canada, pp. 356.

Ross-Kerr, Janet. 1998. Prepared to Care, Nurses and Nursing in Alberta. Edmonton: The University of Alberta Press.

Salamon, Lester M. 1987. "Of Market Failure, Voluntary Failure, and Third-Party Government: Toward a Theory of Government-Nonprofit Relations in the Modern Welfare State." In eds. Susan A. Ostrander and Stuart Langton, Shifting the Debate: Public/Private Sector Relations in the Modern Welfare State. New Brunswick: Transaction Books, pp. 29-49.

Salamon, Lester M. 2001 a. "Scope and Structure: The Anatomy of America's Nonprofit Sector." In ed. J. Steven Ott, The Nature of the Nonprofit Sector. Boulder: Westview Press, pp. 23-39.

Salamon, Lester M. 2003. "Voluntary Failure Theory Correctly Viewed." In eds. Helmut Anheier and Avner Ben-Ner, The Study of The Nonprofit Enterprise: Theories and Approaches. New York: Kluwer Academic / Plenum Publishers, pp. 183-186.

Salamon, Lester M. and Helmut K. Anheier. 1996. The Emerging Nonprofit Sector. Manchester: Manchester University Press.

Saunders, L. Duncan, Arif Alibhai, David B. Hogan, Colleen J. Maxwell, Hude Quan and Devid Johnson. 2001. "Trends in the Utilization of Health Services by Seniors in Alberta." Canadian Journal on Aging 20, no. No. 4: 493-516.

Shapiro, Evelyn. 1997. "The Cost of Privatization: A Case Study of Home Care in Manitoba." Winnipeg: Canadian Centre for Policy Alternatives, pp. 14. 
Shapiro, Evelyn. 2002. "Home Care." Ottawa: Health Canada, pp. 22.

Shapiro, Evelyn. 1991. "Home Care: Where is it and where should it be going?." In ed. Lilian M. Wells, An Aging Population: The Challenge for Community Action. Toronto: Governing Council, University of Toronto, pp. 18-42.

Shapiro, Evelyn. 2003. "The Romanow Commission Report and Home Care." Canadian Journal on Aging 22, no. 1: 13-17.

Shields, John and B. Mitchell Evans. 1998. Shrinking the State: Globalization and Public Administration "Reform". Halifax: Fernwood Publishing.

Smith, Steven R. and Michael Lipsky. 1993. Nonprofits for Hire, The Welfare State in the Age of Contracting. Cambridge, Ma.: Harvard University Press, pp. 292.

Statistics, Canada. 2005. Table 111-0034 Seniors' characteristics, by family type, age of oldest individual and source of income, annual (dollars unless otherwise noted. for 2005). Government of Canada, May 2007. [cited July 24 2007].

Steinberg, Richard. 2003. "Economic Theories of Nonprofit Organizations: An Evaluation." In ed. Helmut Anheier and Avner Ben-Ner, The Study of Nonprofit Enterprise. New York: Kluwer Academic / Plenum Publishers, pp. 277-310.

Stewart, Dermot. 1979. "Preface." In ed. Dermot Stewart, The Aged in Society. Saint John: Keystone Printing \& Lithographing Ltd., pp. i-iii.

Stone, Deborah. 2002. Policy Paradox: The Art of Political Decision Making. Revised edition ed. New York: Norton, pp. 428.

Sullivan, Helen and Chris Skelcher. 2002. Working Across Boundaries: Collaboration in Public Services. New York: Palgrave MacMillan.

Supports, Ministry of Seniors and Community. 2002. Ministry Overview. Government of Alberta. http://www.seniors.gov.ab.ca/about_ministry/ministry_overview/ index.asp. [cited January 2007].

Taft, Kevin and Gillian Steward. 2000. Clear Answers: The Economics and Politics of For-Profit Medicine. Edmonton: Parkland Institute, pp. 124.

Tanner, Frances. 1999. "Community Service Centres of Ottawa-Carleton: A History." Ottawa, pp. 73.

Taylor, Marilyn. 2003. Public Policy in the Community. New York: Palgrave Macmillan.

Taylor, Malcolm G. 1987. Health Insurance and Canadian Public Policy: The Seven Decisions that Created the Canadian Health Insurance System and Their Outcomes. Kingston: McGill-Queen's University Press, pp. 563.

Te'eni, Dov and Dennis R. Young. 2003. "The Changing Role of Nonprofits in the Network Economy." Nonprofit and Voluntary Sector Quarterly 32, No. 3, no. September: 397-414.

Thayer Scott, Jacqueline. 2001. "Voluntary Sector." In ed. J. Steven Ott, The Nature of the Nonprofit Sector. Boulder, Colorado: Westview Press, pp. 40-45.

Tindale, Joseph A. 1991. "Developing a Comprehensive Health and Social Service System with and for the Elderly." In ed. Lilian M. Wells, An Aging Population: The Challenge for Community Action. Toronto: Governing Council, University of Toronto, pp. 70-83.

Tuohy, Carolyn and Patricia O'Reilly. 1992. "Professionalism in the Welfare State." Journal of Canadian Studies, July: 73-92. 
Tuohy, Carolyn Hughes. 1999. Accidental Logics, The Dynamics of Change in the Health Care Arena in the United States, Britain, and Canada. New York: Oxford University Press.

Turcotte, Martin and Grant Schellenberg. A Portrait of Seniors in Canada. Ottawa: Statistics Canada, 2007.

Urry, John. 2000. "Sociology of Time and Space." In ed. Bryan S. Turner, The Blackwell Companion to Social Theory. Malden, Ma.: Blackwell Publishers Inc., pp. 416-443.

Vogel, Donna, Michael Rachlis \& Nancy Pollak. 2000. Without Foundation: How Medicare is Undermined by Gaps and Privatization in Community and Continuing Care. Vancouver: Canadian Centre for Policy Alternatives.

VSI, Joint Accord Table of the Voluntary Sector Initiative. 2002. "A Code of Good Practice on Policy Dialogue." Ottawa, October, pp. 16. http://www.craarc.gc.ca/tax/charities/policy/cps/cps-022-e.html. [cited May 9, 2006].

Webb, Kernaghan. 2000. Cinderella's Slippers? The Role of Charitable Tax Status in Financing Canadian Interest Groups. Vancouver: SFU_UBC Centre for the Study of Government and Business.

Weisbrod, Burton A. 1988. The Nonprofit Economy. Cambridge, Ma.: Harvard University Press.

Weisbrod, Burton A. 1977. "Not-for-Profit Organizations." In ed. Burton A. Weisbrod, The Voluntary Nonprofit Sector: An Economic Analysis. Lexington, Ma.: Lexington Books, pp. 1-10.

Welfare, National Council of. 2006. "Poverty Profile, 2002 and 2003." Ottawa: National Council of Welfare, pp. 157.

Wellness, Alberta Health and. 2000 a. "Strategic Directions and Future Actions: Healthy Aging and Continuing Care in Alberta." Edmonton: Alberta Health and Wellness, April, pp. 11.

Wellness, Alberta Health and. 2000 b. "Healthy Aging: New Directions for Care." Edmonton: Alberta Health and Wellness, April, pp. 135.

Wellness, Alberta Health and. 2006. Vision, principles and mission statement Government of Alberta, April 7. http://www.health.gov.ab.ca/about/ Minister_vision.html. [cited January 2007].

Williams, Allison. 2002. "Labour Process Change: Women's Paid Home Care Work in Saskatoon." Centres of Excellence for Women's Health Research Bulletin, Spring:13-15.

Williams, Allison. 1996. "The Development of Ontario's Health Care Policy: A Critical Geographic Analysis." Social Science and Medicine 42, no. 6: 937-948.

Williams, Paul A., Jan Barnsley, Sandra Leggat, Raisa Deber, and Pat Baranek. 1999. "Long-Term Care Goes to Market: Managed Competition and Ontario's Reform of Community-Based Services." Canadian Journal on Aging 18, no. No. 2: 125153.

Woodward, Christel A., Julia Abelson and Brian Hutchison. 2001. "My home is not my home anymore': Improving Continuity of Care in Homecare." Ottawa: Canadian Health Services Research Foundation, pp. 26. 
Yin, Robert K. 1989. "Case Study Research: Design and Methods". In eds. Leonard Bickman and Debra Rog, 2nd edition ed. 19 vols. Vol. 5, Applied Social Research Methods Series. Newbury Park, Ca.: Sage Publications Inc.

Young, Dennis R. 2000. "Alternative Models of Government-Nonprofit Sector Relations: Theoretical and International Perspectives." Nonprofit and Voluntary Sector Quarterly 29, No. 1, no. March: 149-172.

Young, Dennis R. 2001 a. "Contract Failure Theory." In ed. J. Steven Ott, The Nature of the Non Profit Sector. Boulder, Col.: Westview Press, pp. 193-196.

Young, Dennis R. 2001 b. "Government Failure Theory." In ed. J. Steven Ott, The Nature of the Non Profit Sector. Boulder, Col.: Westview Press, pp. 190-192. 